\title{
TARGETING CELL INVASION SIGNALING TO IMPEDE BREAST CANCER METASTASIS
}

\author{
Dissertation \\ for the award of the degree \\ "Doctor Rerum Naturalium" \\ of the Georg-August-Universität Göttingen \\ within the doctoral program Molecular Medicine \\ of the Georg-August University School of Science (GAUSS)
}

submitted by

Johanna W. Hellinger

from Jena

Göttingen 2019 


\section{Members of the Thesis Committee}

Prof. Dr. Hubertus Jarry, Department of Clinical and Experimental Endocrinology; University Medical Center Göttingen (UMG)

Prof. Dr. Heidi Hahn, Department of Human Genetics, University Medical Center Göttingen (UMG)

Prof. Dr. Dieter Kube, Department of Hematology and Oncology, University Medical Center Göttingen (UMG)

\section{Members of the Examination Board}

Reviewer: Prof. Dr. Hubertus Jarry, Department of Clinical and Experimental Endocrinology; University Medical Center Göttingen (UMG)

Second Reviewer: Prof. Dr. Heidi Hahn, Department of Human Genetics, University Medical Center Göttingen (UMG)

Prof. Dr. Dieter Kube, Department of Hematology and Oncology, University Medical Center Göttingen (UMG)

\section{Further members of the Examination Board}

Prof. Dr. mult. Thomas Meyer, Department of Psychosomatic Medicine and Psychotherapy, University Medical Center Göttingen (UMG); and German Centre for Cardiovascular Research, University of Göttingen

Prof. Dr. Ralf Dressel, Institute of Cellular and Molecular Immunology, University Medical Center Göttingen (UMG)

Prof. Dr. Peter Burfeind, Institute of Human Genetics, University Medical Center Göttingen (UMG)

Date of the oral examination: 30.01 .2020 


\section{AFFIDATIV}

Here I declare that my doctoral thesis entitled "Targeting cell invasion signaling to impede breast cancer metastasis" has been written independently with no other sources and aids than quoted.

Göttingen, December 2019

Johanna W. Hellinger 


\section{TABLE OF CONTENT}

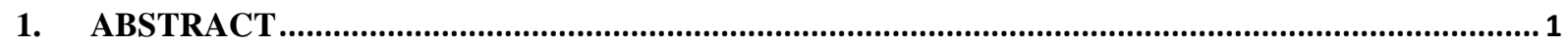

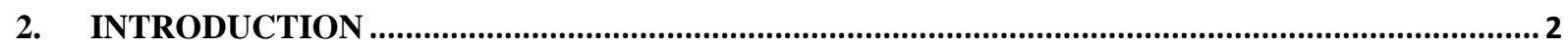

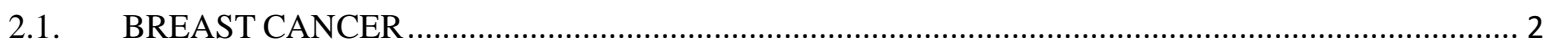

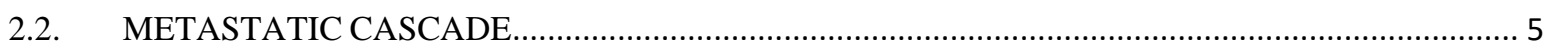

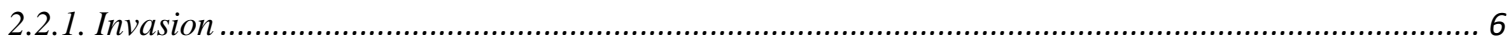

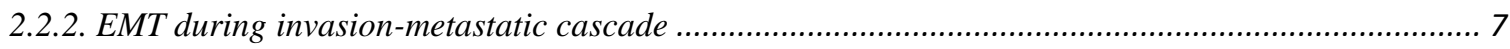

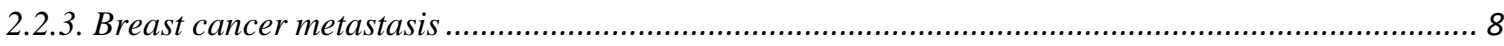

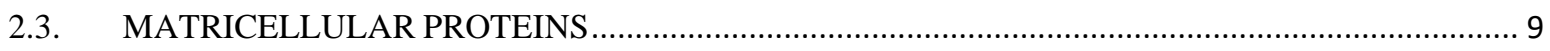

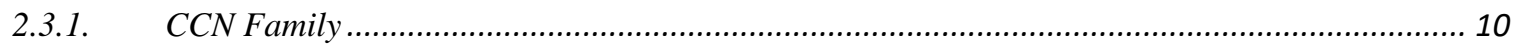

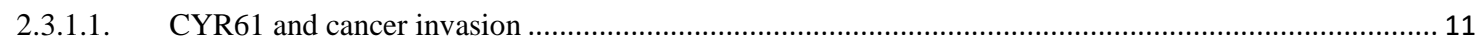

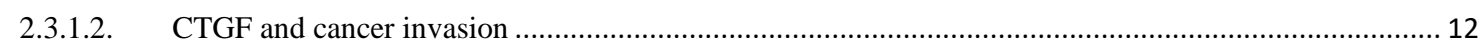

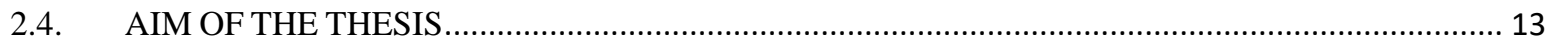

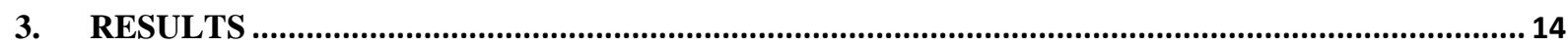

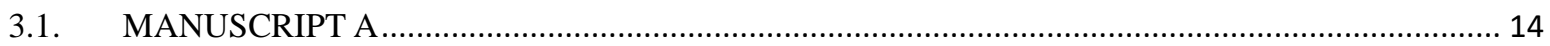

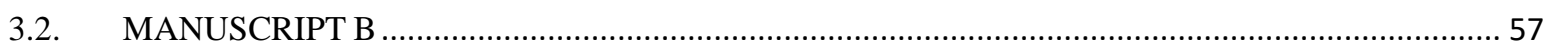

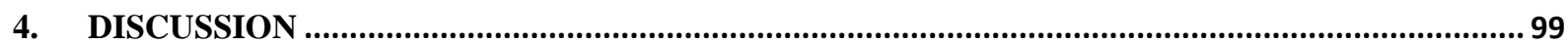

4.1. IDENTIFICATION OF MOLECULAR MECHANISMS UNDERLYING REDUCED BREAST

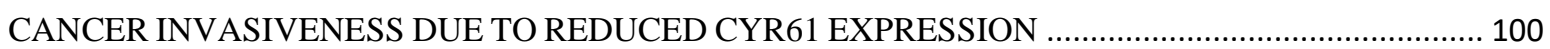

4.2. IDENTIFICATION OF EXTRACELLULAR DRIVERS OF INVASION ......................................... 102

4.3. IDENTIFICATION OF MOLECULAR MECHANISM UNDERLYING REDRUCED BREAST

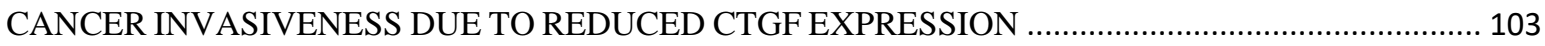

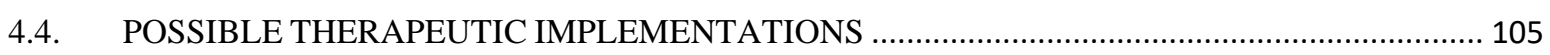

4.4.1. Treatment with GnRH agonist may help prevent EMT induction and invasiveness of breast cancer

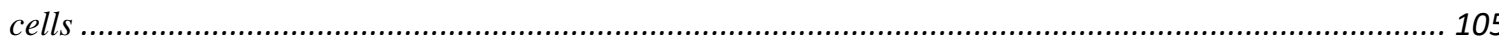

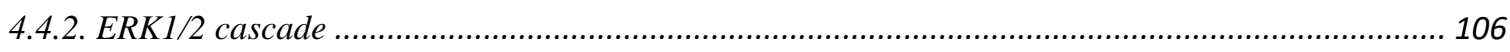

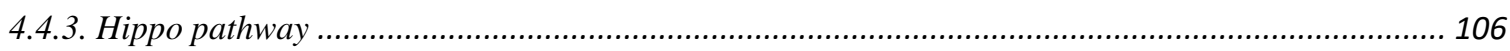

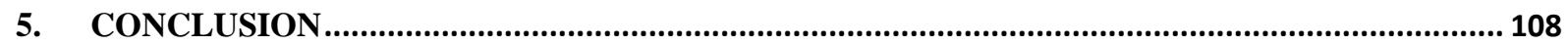

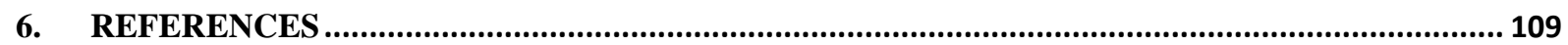

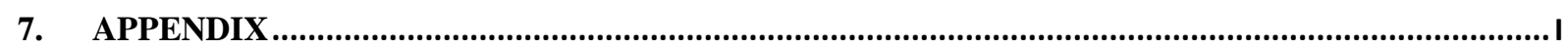

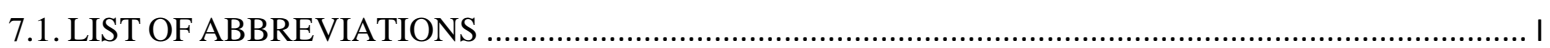

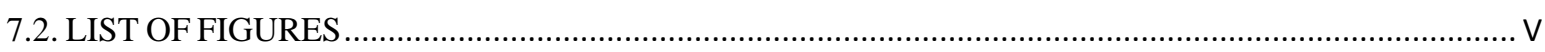

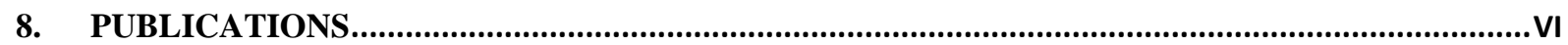

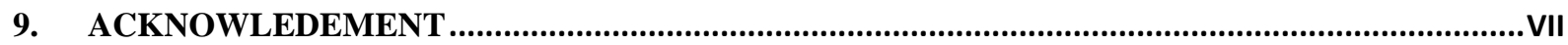




\section{ABSTRACT}

Breast cancer cell invasion is the initial step of the invasion-metastatic cascade, and approximately $90 \%$ of all cancer-related deaths are due to currently incurable cancer metastasis (1). Unique features of tumor microenvironment such as growth factors, cytokines, and extracellular matrix (ECM) composition modify tumor behavior and drive tumor progression (2). Matricellular protein, e.g. Cysteine- Rich Angiogenic Inducer 61 (CYR61), Connective Tissue Growth Factor (CTGF), exert their function by altering cell-ECM interactions, extracellular signaling, and were reported to facilitate angiogenesis, tumor initiation, invasion and progression (3-7).

The tumor microenvironment (TME) is crucial for tumor progression, drug delivery, therapy outcome, and drug efficacy. Identifying drivers that modify TME thereby supporting tumor initiation, invasion and progression would be of benefit to design new treatment options for metastatic breast cancer.

We aimed to identify molecular mechanisms underlying reduced breast cancer invasiveness due to reduced CYR61 expression. Using 2D transwell invasion and 3D spheroid invasion assays to evaluate the effect of CYR61 and downstream targets on the invasiveness of breast cancer cell. Furthermore, we wanted to shed light on the unique interaction between breast cancer cells and osteosarcoma cells. Combining this co-culture model with mass spectrometry-based secretome analysis, we identified potential extracellular secreted drivers of breast cancer invasion. Additionally, we wanted to identify molecular mechanisms underlying reduced breast cancer invasiveness due to reduced CTGF expression by assessing cell-ECM adhesion and proteolytic activity of breast cancer cells and identifying possible treatment options targeting CTGF.

Reduced CYR61 expression led to dephosphorylated ERK1/2 and lower S100A4 expression, thereby decreasing 3D spheroid invaded area growth. These results suggest that CYR61 and S100A4 are predictive markers and therapeutic targets for advanced breast cancer. Targeting CTGF, one potential driver of breast cancer bone-directed invasion, led to reduced proteolytic activity, decreased 2D transwell invasion and 3D spheroid invaded area growth, and increased cell-ECM invasion. Our results demonstrated a RhoA dependent- CTGF regulation, which can be impaired by GnRH agonist treatment. 


\section{INTRODUCTION}

\subsection{BREAST CANCER}

Breast cancer is the most prominent cancer found in women. In 2018, every 18 seconds a patient was diagnosed with breast cancer. Breast cancer accounts for 626,679 death per year worldwide with a predicted annual increase of $3.1 \%$ (1). Due to advances in multimodal therapy, early-stage breast cancer, defined as cancer that is contained in the breast or has only spread to axillary lymph nodes, is curable in $70-80 \%$ of all cases (8). Currently, advanced breast cancer-cancer with distant metastasis - is not curable, but treatment is available to prolong survival and relieve symptoms (8). Treatment strategies differ depending on histological subtypes and molecular alterations of this heterogeneous disease (8). Two histological subtypes can be distinguished according to carcinoma invasiveness. The preinvasive subtype includes ductal carcinoma in situ (DCIS), wherein the tumor spreads through the duct, distorts duct architecture, and can progress to invasive disease; and lobular carcinoma in situ, wherein lobe architecture is not altered (8). Invasive subtype comprises invasive ductal carcinoma (IDC), which develops from DCIS and can metastasize through vascular and lymphatic system, and invasive lobular carcinoma, which is an isolated tumor mass and metastasizes through viscera (8).

Molecular alterations in breast cancer led to classification of different subtypes (Figure 1). Originally, breast cancer molecular subtypes were classified through gene expression studies using isolated RNA from frozen tissue (9). Six intrinsic subtypes were classified through qPCR array (PAM50) using isolated RNA from formalin-fixed and paraffin embedded tissue (Figure 1) (10-12):

- Luminal A. Activation of estrogen receptor 1 (ESR1).

- Luminal B. Mutations in phosphatidylinositol-4, 5-bisphosphate-3 kinase catalytic subunit $\alpha$ (PI3KCA), ESR1, erb-B2 receptor tyrosine kinase 2 (ERBB2/HER2), and erb-B2 receptor tyrosine kinase 3 (ERBB3) genes; amplification of HER2, growth factor receptor bound protein 7 (GRB7), DNA topoisomerase 2 A (TOP2A), and/or MYC proto-oncogene (MYC) and mutations in the PI3KCA gene.

- Basal-like. Mutations in tumor suppressor P53 (TP53) and breast cancer 1 early onset (BRCA) genes.

- Claudine-low. No expression of estrogen receptor (ER) or progesterone receptor (PR) and no overexpression of HER2 (triple-negative breast cancer [TNBC]).

- $\quad$ Normal-like (8). 
In current clinical practice, breast cancer is classified according to surrogated immunohistochemistry (IHC)-based subtypes (Figure 1) (8). Surrogated IHC-based subtype classification contains five subtypes based on the histological and immunohistochemical expression of ER, PR, HER2, and Ki-67 as markers for proliferation:

- TNBC. No expression of ER and PR; no amplification of HER2; high Ki-67 expression; high histology score of special types including metaplastic, adenoid cystic, medullary-like, or secretory. Marked by poor prognosis.

- HER2-enriched (non-luminal). No expression of ER and PR; HER2 amplification; high Ki-67 expression. Marked by intermediate prognosis.

- Luminal A-like. Expression of ER and PR; no amplification of HER2; low Ki-67 expression. Marked by good prognosis (8).

- Luminal B-like. Lower expression of ER and PR than luminal A-like; high Ki-67 expression. May or may not have HER2 amplification. Marked by intermediate prognosis.

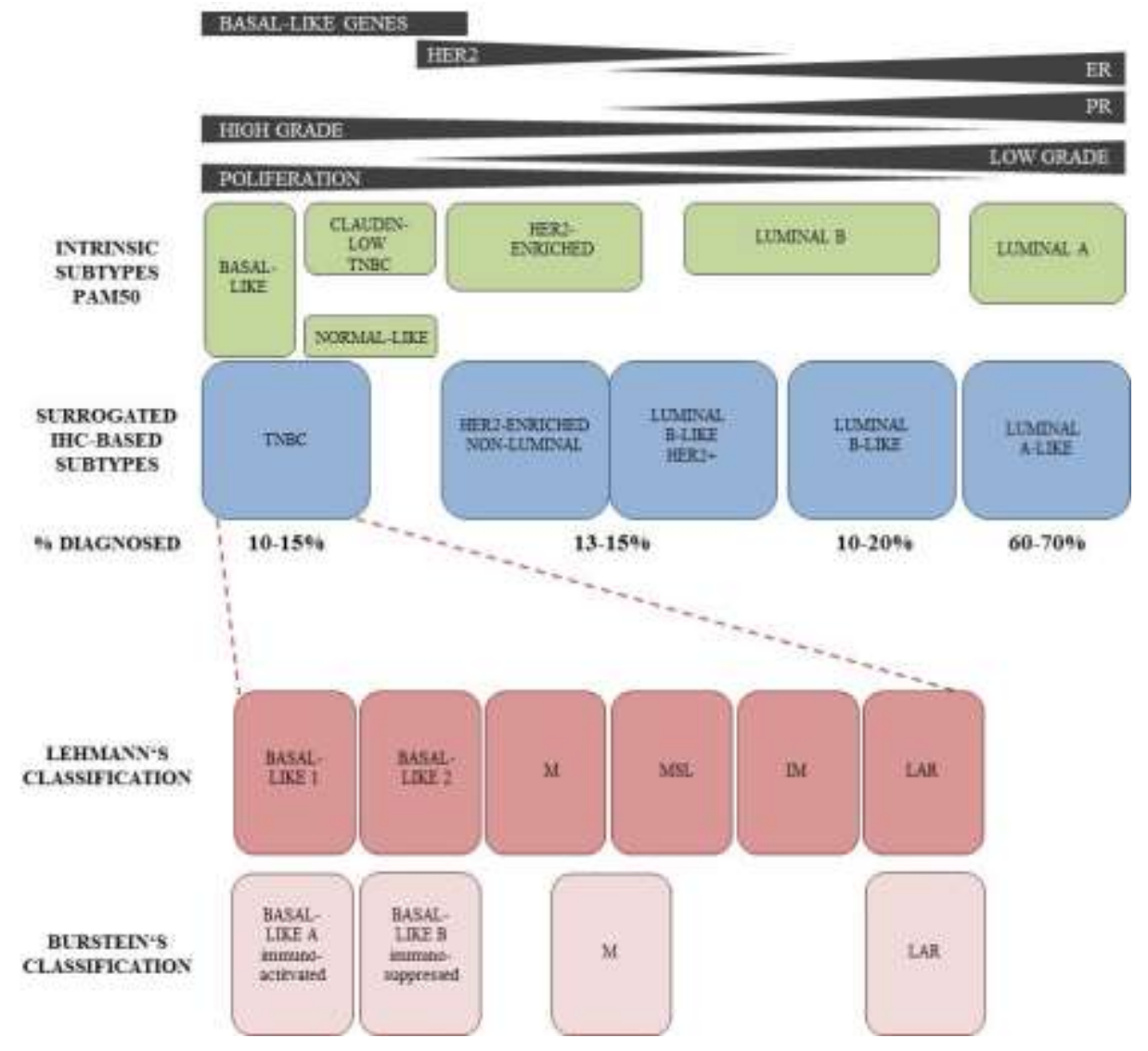

Figure 1 Characteristics and classification of breast cancer subtypes. Breast cancer can be classified according to intrinsic subtypes and PAM50 gene expression signature or surrogated immune-histochemical-based subtypes. Furthermore, TNBC can be classified according to Lehmann's (13) and Burstein's (14). Scheme illustrates proliferation, tumor grading, ER expression, PR expression, HER2 amplification, and expression of basal-like genes. Scheme modified regarding to $(8,15$, 
16). IM immunomodulatory, LAR luminal androgen receptor, M mesenchymal, MSL mesenchymal/ stem-like, TNBC triple negative breast cancer

Prevailing studies have demonstrated discordance of intrinsic subtypes and surrogated IHCbased subtypes, concluding that IHC-based classification could lead to suboptimal treatment discussions and poor outcomes (17). Treatment of heterogeneous TNBC is far behind other subtypes and, thus, is associated with the worst prognosis (8). Two different classifications were proposed for further classification of TNBC. The first classification was proposed by Lehmann et al. with the following six subtypes:

- Basal-like 1. Molecular alterations in cell cycle and DNA repair signaling, such as TP53, BRCA, mitogen-activated protein kinase kinase kinase 1 (MAP3K1/MEKK1), and PIK3CA (16).

- Basal-like 2. Molecular alterations in growth factor and metabolism signaling (13).

- Mesenchymal. Molecular alterations in cell motility, extracellular matrix (ECM) receptor, and cell differentiation signaling (e.g., Rho pathway, TGF $\beta$ signaling) (13).

- Mesenchymal/stem-like (MSL). Low expression of claudins. Molecular alterations are versatile and include, but are not limited to, extracellular signaling-related kinase 1/2 (ERK1/2 or MAPK1), G-protein coupled receptor, and calcium signaling (13).

- Immunomodulatory (IM). Molecular alteration in cellular immune process (13).

- Luminal androgen receptor (LAR). Overexpression of LAR. Molecular alterations in, but not restricted to, androgen/estrogen metabolism signaling (13).

Refinement of this classification led to four subtypes with implications for neoadjuvant therapy response (18). A similar classification was reported by Burstein et al. with RNA and DNA approaches (14). These subtypes are basal-like A (immune-activated), basal-like B (immunosuppressed), mesenchymal (mesenchymal and MSL are merged here), and LAR (14). Currently, no diagnostic test is routinely used in clinical practice (8).

Of all patients diagnosed with breast cancer, those with TNBC account for $10-15 \%$ of all cases. Thus, we want to investigate the drivers of this heterogeneous breast cancer subtype with special focus on mesenchymal molecular alterations. Understanding what drives tumor progression and advanced breast cancer could lead to the development of specific treatments to be able to prolong patient survival, impede metastasis, and cure this specific subtype. 


\subsection{METASTATIC CASCADE}

To date, advanced cancer with distant metastases is not curable and is the cause of approximately $90 \%$ of cancer-related deaths (8). The invasion-metastatic cascade leading to cancer metastasis is a multistep-process (Figure 2) (19-22).

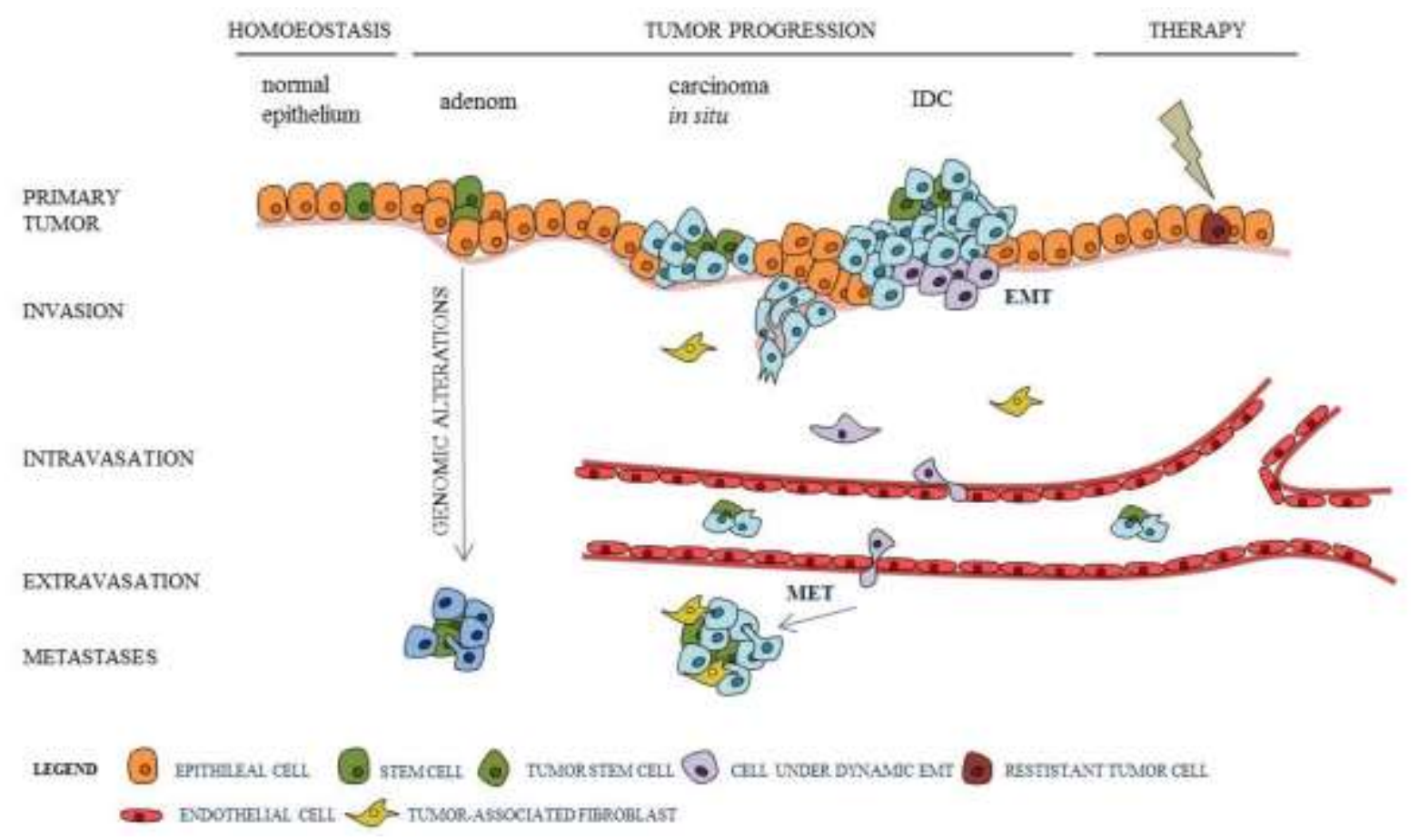

Figure 2 The Invasion-metastatic cascade. Scheme illustrating progress from tissue homoeostasis towards tumor progression and metastasis. Multistage invasion-metastatic cascade comprises dissemination of tumor cell from primary tumor site (invasion), migration through extracellular matrix (ECM), intravasation into vascular system, extravasation into parenchyma of distant site, colonization at metastatic niche. To proceed, metastatic tumor cells might hijack developmental processes like epithelial-mesenchymal transition (EMT) and mesenchymal-epithelial transition (MET). Scheme modified regarding to (23-25).

This process is initiated by local invasion of cancer cells from the primary tumor (carcinoma in situ) into the surrounding tissue (IDC). Due to gained motile and invasive properties, tumor cells move through the extracellular matrix (ECM) and intravasate into the vascular system. However, they need to survive during hematogenous non-adhesive transit. To exit hematogenous transit, tumor cells need adhesive properties to extravasate through the vascular walls into distant site tissue. Having unique microenvironmental features at the distant site, tumor cells need adhesive properties to form micrometastases and induce angiogenesis. Tumor metastasis is an inefficient process and needs special cellular features to proliferate, invade, intravasate, survive, extravasate, and proliferate again in different microenvironments (26). Evaluating which molecular alterations appear during the invasionmetastatic cascade could help to design treatment options to impede this process. 


\subsubsection{Invasion}

Tumor initiation is a complex biological event. It starts with molecular alterations in normal cells, leading to uncontrolled proliferation, resistance to cell death signaling, and hyperplasia $(27,28)$. The tumor mass consists of heterogeneous tumor cells and the tumor microenvironment (TME). The TME comprises cancer-associated fibroblasts, immune and inflammatory cells, lymphatic vascular and blood networks, adipose cells, neuroendocrine cells, and the ECM. This composition has a critical role in malignancy evolution and varies depending on tissue site $(29,30)$. Regarding prognosis of a given tumor, the composition of the ECM is of great importance $(30,31)$. Three-dimensional structure of the ECM contains a reservoir of growth factors, collagens, elastin, fibronectin, hyaluronic acid, proteoglycans, and glycoproteins; it provides hydration and facilitates $\mathrm{pH}$ homeostasis (32-34). Due to continuous proliferation, the TME is constantly remodeled, leading to altered paracrine and autocrine communication between different cell types, increased interstitial fluid pressure, increased ECM stiffness, increased vascular network formation, and tumor progression (27, 35). Identifying the drivers within the TME, specifically the ECM, that alter tumor cell behavior toward invasion could help to design new therapeutic treatments targeting tumor progression and tracking tumor stage (30). Adhesion receptors (e.g., integrins, cadherins) transform stimuli by extracellular ligands from microenvironment into intracellular signals, thereby leading to cellular transformational processes, invasion, proliferation, or survival (36). Likewise, cells use adhesion receptors to sense, adapt, and respond to mechanical or biophysical signals from the ECM. They interact with the ECM through focal adhesions and hemidesmosomes (cell-ECM adhesions) (29). Understanding differences in physiological processes such as wound healing regarding adhesion receptor binding and alterations in cellECM adhesion compared to pathological processes such as fibrosis or tumor cell invasion could help specify targeted therapy to impede tumor cell invasion.

To be able to invade into surrounding tissue, molecular alterations are essential for cancer cells to drive proteolytic degradation of ECM and alter in cell-cell and cell-ECM adhesion (37). Different processes can enable the dissemination of primary tumor cells. Of these, collective invasion has been well described (25). In this process, invading cells keep their epithelial traits (cell-cell junctions) and disseminate as a collective cohesive cohort (Figure 2) $(19,25)$. Additionally, cells can invade by different types of single-cell invasion. First: in a mesenchymal manner, wherein cells are elongated and cell-ECM adhesion remains (25). Second: in an amoeboid manner, wherein cells are in rounded shape and rely on the contractility of cortical actomyosin (38). And third: cells using intermediate behaviors of the 
former mentioned single cell invasion types, which were already reported before (38-41). Another possible invasion process is the epithelial-mesenchymal transition (EMT). In this process, cells invade by gaining mesenchymal traits and losing epithelial traits due to higher cellular plasticity.

\subsubsection{EMT during invasion-metastatic cascade}

The EMT is a group of dynamic biological programs employed under physiological conditions during embryogenesis and wound healing. These programs are dynamic with different intermediated states contributing to cellular plasticity. They are orchestrated through a set of transcription factors (EMT-TFs) $(23,42,43)$ but are triggered by heterotypic signals (19, 23, 42, 43). Tumor cells hijack such physiologic dynamic programs to acquire mesenchymal traits and reduce epithelial traits $(19,44)$. Furthermore, it was suggested that the acquisition of mesenchymal traits led to resistance to common cytotoxic therapies and tumor initiation (19, 45-47). Currently, the contribution of the EMT to cell dissemination and metastasis is highly debated (43). One recent study indicated that acquiring a fully mesenchymal state resulted in cells unable to metastasize $(48,49)$. Cancer cell dissemination and intravasation could also be observed by collective invasion. It remains elusive if cells at the leading edge of invasive cohorts are in an intermediate state of the EMT due to acquired invasive properties (43). Recent studies suggested that cancer-associated fibroblasts or cancer cells at the leading edge under dynamic EMT programs led to collective invasion $(25,50)$. Interestingly, remodeling of the ECM during wound healing due to upregulation of Transforming Growth Factor $\beta$ (TGF $\beta$ ), interleukins, and growth factors results in comparable ECM composition (19). It was demonstrated that non-invasive breast cancer cells under dynamic EMT programs are able to form distant metastases in vivo and are more invasive in a 2D transwell invasion assay in vitro (51). Nevertheless, fundamental issues regarding EMT contribution to tumor invasion and metastasis remain elusive.

Regarding tumor initiation, two models currently exist. First clonal evolution: where cells gain tumorigenic properties due to molecular alterations leading to tumor initiation. Second: the cancer stem cell model, where cancer stem cells are considered as the precursor to initiate tumor growth and progression $(8,52)$. Growing evidence demonstrates that the EMT is able to induce stemness in cancer cells. Additionally, stem cells might evolve from clonal evolution, which could explain the polyclonal appearance of metastatic colonies (53). Further research should aim to reveal intracellular and extracellular signals that can activate, sustain, and reverse EMT. Reversion of EMT is also referred as mesenchymal-epithelial transition. 
Distinguishing between different states could help to track tumor progression. Thus, we want to investigate the effect of EMT on breast cancer invasion by identifying intracellular and extracellular targets leading to altered EMT-TFs expression and acquired invasive traits. Furthermore, we want to target these intracellular and extracellular drivers to impede dynamic EMT programs and investigate whether this leads to reduced invasive capacities.

\subsubsection{Breast cancer metastasis}

Currently, metastatic breast cancer is incurable with a median overall survival of less than three years (54). De novo breast cancer accounts for more than $25 \%$ of all diagnosed metastatic breast cancers $(8,55,56)$. The most common metastatic sites for breast cancer (ranked from highest to lowest percentage) are bone, axillary lymph nodes, liver, lung, and brain (Figure 3) (8).
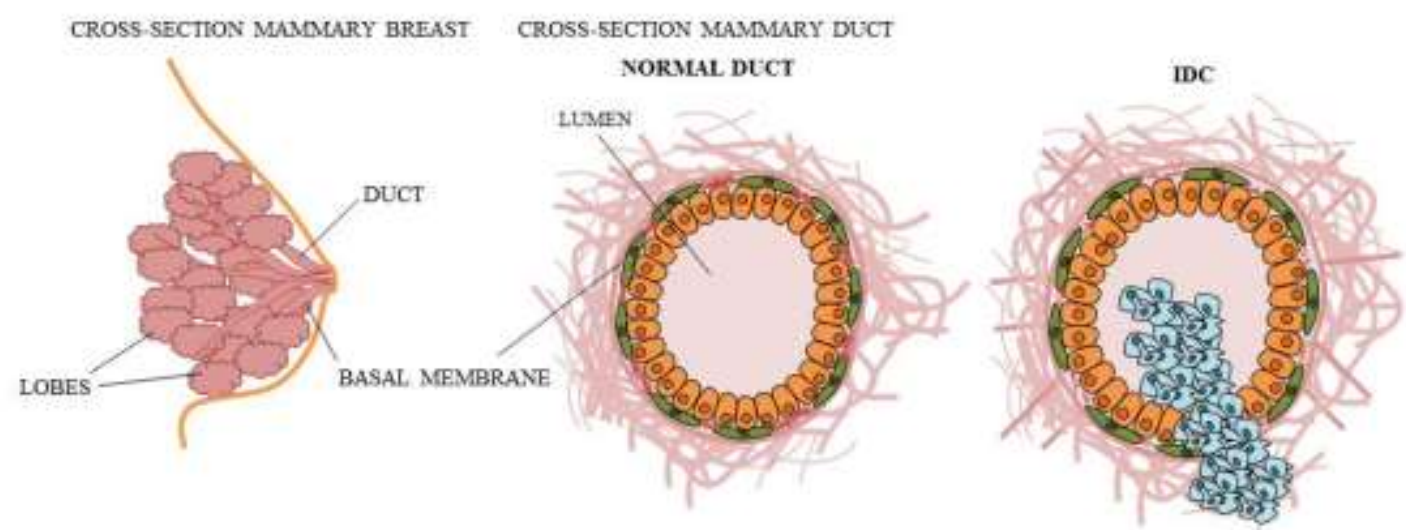

INVASION

DISTANT METASTASES
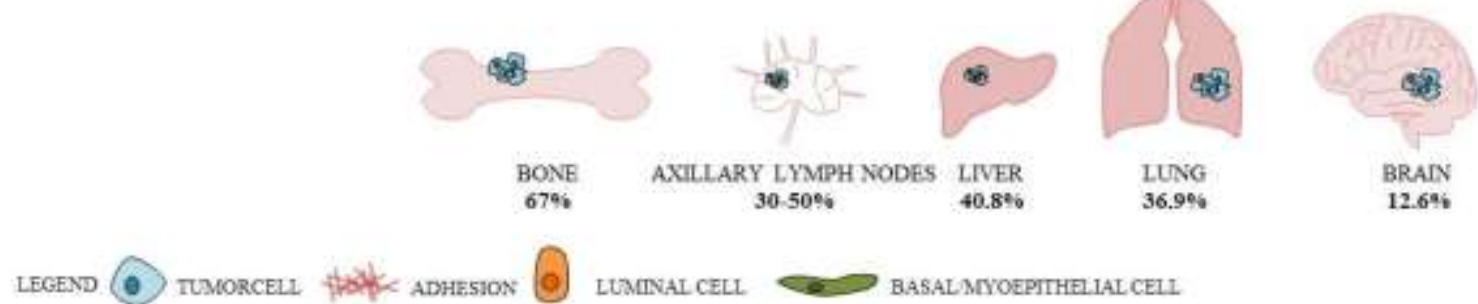

Figure 3 Metastatic sites of breast cancer. Anatomy of mammary duct and lobes in cross-section and cross-section of normal mammary duct vs. invasive ductal carcinoma (IDC). Most prominent site for distant metastases drom breast cancer is bone, counting for $67 \%$ of all breast cancer metastases.

Tropism to specific metastatic sites depend on the intrinsic subtype (8).The intrinsic subtypes luminal A and B (no HER2 amplification) have a tropism for bone and lymph node metastases. TNBC have tropism for lung and brain metastases. Additionally, breast cancers with an amplification of HER2 have tropism for brain metastases (8, 57). Molecular alterations at the primary tumor site driving tumor progression and metastasis are up to $80 \%$ conserved at the metastatic site (8). Subclonal diversity differs by intrinsic subtypes of breast 
cancer when comparing the primary site with the metastatic site. The highest subclonal diversity could be detected at PR-expressing tumors ( $33 \%)$, followed by ER-expressing tumors $(\sim 20 \%)$, and HER2-amplified tumors $(\sim 8 \%)$. Differences between microenvironmental components of the primary site and unique features at the distant metastatic site can lead to discordance $(8,58,59)$. Despite these findings, specific features that lead to metastases remain elusive (8). Bone is the most frequent site for metastases of breast cancer, accounting for $67 \%$ of all breast cancer-derived metastases (Figure 3) (8). Of these, 79\% are classified as luminal B subtype, 60\% as luminal A subtype, and 40\% as HER2amplified basal-like subtype (57). Due to unique physical properties, colonization in bone only appears in $24 \%$ of patients with detected circulating tumor cells (CTC) (60). Even when detected in bone marrow, outgrowth of metastatic tumor is not guaranteed (60-62). Bone is 100,000 times more rigid than soft tissue (58). Previous studies have suggested that rigidity facilitates cell transformational processes, leading to osteolytic gene expression in breast cancer cells and induced TGF $\beta$ signaling (63-66). It remains elusive which specific features of disseminated breast cancer cells are indispensable to colonize at the metastatic site.

Bones are continuously resorbed by osteoclast activity. These multinucleated cells are formed upon receptor activator of nuclear factor- $\kappa \mathrm{B}$ ligand (RANKL) and the activity of macrophage colony-stimulating factor (M-CFS). Due to bone resorption, growth factors are released. Recent studies have reported that tumor cells express receptors to facilitate invasion and chemotaxis in different metastatic niches such as bone, lymph nodes, and the lungs. One of these specific receptors is $\mathrm{C}-\mathrm{X}-\mathrm{C}$ motif chemokine receptor 4 (CXCR4), which is able to bind to mesenchymal stem cells close to bone surface with CXCL12 receptors (67-72). Engineered bone structures with mesenchymal stem cells deficient of expressing CXCL12 are resistant to tumor cell invasion (71). Specific knowledge of bone environmental components and cellular interactions of cells that are specific to that location with disseminating tumor cells could help impede colonization and tumor cell attraction. However, it remains unclear why luminal cancer cells preferentially metastasize to bone and if specific paracrine signals or ECM components have an effect on relapse. Thus, we analyzed breast cancer bone-directed invasion with cell lines that harbor specific characteristics, including expression of CXCR4 or the luminal subtype, that make them preferentially metastasize to bone.

\subsection{MATRICELLULAR PROTEINS}

Unique features of TME such as growth factors, cytokines, chemotactic stimuli, and ECM composition modify tumor behavior and drive tumor progression (2). It remains unclear 
which TME and ECM components alter tumor behavior toward invasion and metastasis. Additionally, it is not clear which interactions can be diminished to impede cell invasion without impeding physiological processes. Regulation of ECM composition is critical during development and fulfills versatile functions, including maintaining tissue homeostasis, regulating proliferation and survival signaling, scaffolding cell-cell-interactions, establishing ECM- growth factor interactions, and associating with proteins $(73,74)$. During physiological processes such as wound healing, stroma is modulated through TGF $\beta$, interleukins, colonystimulating factor 1 (CSF-1), tumor necrosis factor $\alpha(\mathrm{TNF} \alpha)$, and ligands of epithelial growth factor receptor (EGFR) (75). The basal membrane is the boundary between the duct and the adjacent tissue, which can be degraded by proteases (e.g., MMPs) and cause invasive programs to be initiated. The deposition of ECM components (e.g., collagens, fibronectin, matricellular proteins) leads to matrix remodeling and the release of proteases (76). In 1995, Bornstein described for the first time a group of secreted proteins within the ECM that facilitate wound healing and inflammation, naming them as matricellular proteins $(3,77)$. These proteins are non- structural components of the ECM; they exert functions on cell-ECM interaction, regulatory function of the cell, and act highly tissue and context specific (78). More specifically, they form scaffolds by binding to the ECM or cell surface receptors. These scaffolds trigger different extracellular signaling pathways to increase growth factors and inflammatory cytokines (79). Characteristics of matricellular proteins include: secretion by different cell types, counter-adhesiveness, and association with insoluble parts of the ECM (80). Originally defined as modulators of cell-ECM interactions, members of the family of matricellular proteins were secreted protein acidic and rich in cysteine (SPARC), thrombospondine-1 (TSP-1), and tenascin C (TN-C) $(3,4)$. The expanded family includes members of the CCN family, such as Cysteine-Rich Angiogenic Inducer 61 (CYR61) and Connective Tissue Growth Factor (CTGF) (80). Several proteins of this family have been proposed as therapeutic targets or predictive markers for a variety of pathological incidents including cardiovascular diseases, fibrosis, and different cancer entities (81-83).

\subsubsection{CCN Family}

The CCN family contains six homologues proteins, all of which are found in the ECM: CYR61, CTGF, nephroblastoma overexpressed (NOV), Wnt-1 induced secreted protein (WISP) 1, WISP-2, and WISP-3 (84-86). Each protein constitutes four main domains: homologies to insulin-like growth factor binding proteins, Von Willebrand factor type $\mathrm{C}$ (VWC) repeat, TSP-1 repeat, and carboxyl-terminal domain (CT) (84). Members of this 
family are reported to be involved in versatile cellular processes, including regulation of inflammatory regulators (e.g., TGF $\beta$, prostaglandins), angiogenesis, signal modulation of proteins involved in tumor growth, tumor initiation, and tumor progression (e.g., integrins, Wnt) $(5,6,87-91)$.

\subsubsection{CYR61 and cancer invasion}

As a member of the matricellular family, CYR61 is associated with ECM and exerts its functions in matrix signaling by binding to integrin receptors $\left(\alpha_{V} \beta_{3}, \alpha_{V} \beta_{3}, \alpha_{6} \beta_{1}, \alpha_{M} \beta_{2}\right)$, syndecan 4 (SDC4), and heparan sulfate proteoglycans (HSPGs) (77, 80, 92, 93). CYR61 exerts its funtion in cell type and tissue specific manner (94). While it acts as a tumor suppressor in human hepatocellular carcinoma and non-small cell lung cancer (NSCLC) (95, 96), CYR61 also acts as an oncogene in the cancers of the breast, ovaries, stomach, and pancreas, as well as glioblastoma (97-101). In physiological events, CYR61 exerts functions in cardiovascular development during embryogenesis (77). Its binding to integrin $\alpha v \beta_{3}$ facilitates proliferation, survival, and angiogenesis (73, 77, 102). Additionally, it was proposed that CYR61 induces vascular endothelial growth factor A (VEGF-A) and VEGF-C expression, which are known angiogenic factors $(90,91)$. Furthermore, its binding to integrin $\alpha_{6} \beta_{1}$ and HSPGs induces apoptosis and senescence (77). Diverse signaling pathways induced transcriptional activation of CYR61 including TGF $\beta$ signaling, growth factors stimulation, cytokine stimulation, estrogen signaling, and tamoxifen signaling, as well as bacterial and viral infections $(77,87,103-106)$. Through the transcriptional activation of yes-associated protein (YAP), CYR61 is part of the Hippo signaling pathway (107). Previous studies have demonstrated that CYR61 can affect estrogen resistance and resistance to chemotherapy, as well as facilitate breast cancer tumor growth, tumor progression, and metastasis, thereby leading to poor prognosis $(97,108-111)$.

Regarding breast cancer, growing evidence demonstrates that increased CYR61 expression led to tumor growth in vivo and poor prognosis (109). Decreased CYR61 expression reduced invasion and transendothelial migration in TNBC cells and reduced lung metastasis (112114). Additionally, it was proposed that breast cancer cells under dynamic EMT programs exhibit increased CYR61 expression, metastasis, and tumor cell invasion (7). Using neutralizing CYR61 antibodies, breast cancer invasion and metastasis could be diminished in vitro and in vivo $(7,115)$. Thus, we investigated breast cancer bone-directed invasion and reveal the underlying mechanism that led to reduced breast cancer cell invasion due to reduced CYR61 expression. Furthermore, we wanted to evaluate whether CYR61 can be used as a prognostic marker and therapeutic target for advanced breast cancer. 


\subsubsection{CTGF and cancer invasion}

Under physiological incident, CTGF is upregulated during embryogenesis and facilitates renal, skeletal, and cardiovascular development (116). CTGF exerts its function context and tissue specific. Previous studies have demonstrated that CTGF acts as a tumor suppressor regarding advanced colon cancer but acts as a oncogene in other tumor entities (116-120). CTGF binding is reported with following receptors: $\alpha_{M} \beta_{2}, \alpha_{v} \beta_{3}, \alpha_{4} \beta_{1}, \alpha_{5} \beta_{1}, \alpha_{5} \beta_{3}$, tropomyosinrelated kinase A, tyrosine kinases, low-density receptor-related proteins (LRPs), and HSPGs (80, 116, 121-126). Additionally, CTGF binds to cytokines and ECM proteins, thereby regulating matrix turnover, cell adhesion, and motility (116). Versatile stimuli lead to transcriptional induction of CTGF (e.g., mechanical stress, cytokines, growth factors, and oxygen deprivation) (127). Furthermore, CTGF is transcriptionally induced by key regulators of the Hippo pathway, which are YAP, transcriptional coactivator with PDZ-binding motif (TAZ), and transcriptional enhancer factor TEF-1 (TEAD) (116). Stimulation of ETS protooncogene 1 (ETS1) leads to the induction of CTGF and was reported to remodel the ECM in cancer cells, fibroblasts, and endothelial cells (116, 128, 129). Regarding breast cancer, CTGF induced motility by binding to integrin $\alpha_{5} \beta_{3}$ and ERK1/2 phosphorylation; it also correlates with poor prognosis and facilitates osteolytic metastasis (116, 129, 130). Likewise, CTGF upregulation led to invasion, migration, and mammosphere formation through the EMT (111). It was proposed that CTGF regulation and regulation of other $\mathrm{CCN}$ protein or TME components result in synergistic effects (131).

Both CYR61 and CTGF have the ability to interact with different cell types and the ECM, making them valuable targets for localized drug delivery (81). Thus, we investigated the molecular mechanisms of CYR61 and CTGF with regards to TNBC, cells with high cellular plasticity, and breast cancer bone-directed invasion. Identifying prognostic markers and therapeutic targets could help to improve the treatment of currently incurable metastatic breast cancer. 


\subsection{AIM OF THE THESIS}

The aim of this thesis was to elucidate the mechanism of breast cancer cell invasion to impede metastasis. To achieve this aim, the following three tasks were implemented:

1. Identification of molecular mechanisms underlying reduced breast cancer invasiveness due to reduced CYR61 expression. The task was to evaluate whether CYR61 could be of value as a prognostic marker and therapeutic target for advanced breast cancer. It was demonstrated that CYR61 is upregulated in mesenchymaltransformed breast cancer cells and that reducing extracellular CYR61 led to reduced 2D transwell invasion in a co-culture model with osteosarcoma cells (7). In this study, transient RNA silencing was used to reduce CYR61 expression and reveal the effects on cell signaling.

2. Identification of the extracellular drivers of invasion to better understand the unique interaction between breast cancer cells and osteosarcoma cells. Von Alten et al. demonstrated that co-culturing non-invasive breast cancer cells with primary osteoblast and osteosarcoma cells led to increased 2D transwell invasion (132). In this study, we combined this co-culture model with mass spectrometry based secretome analysis to identify potential extracellular secreted drivers of breast cancer invasion.

3. Identification of molecular mechanisms underlying reduced breast cancer invasiveness due to reduced CTGF expression. CTGF expression is induced when breast cancer cells are mesenchymal transformed, facilitating invasiveness and metastasis (51). In this study, transient RNA silencing was used to reduce CTGF expression thereby assessing the effect on invasion by 3D spheroid invasion assay. Additionally, cell-ECM adhesion and proteolytic activity of breast cancer cells were assessed. Furthermore, possible treatment options targeting CTGF were identified. 


\section{RESULTS}

\subsection{MANUSCRIPT A}

Inhibition of CYR61-S100A4 Axis Limits Breast Cancer Invasion

\section{Citation}

Hellinger, J. W., Hüchel, S., Goetz, L., Bauerschmitz, G., Emons, G., \& Gründker, C. (2019). Inhibition of CYR61-S100A4 Axis Limits Breast Cancer Invasion. Front Oncol, 9(1074). doi: 10.3389/fonc. 2019.01074

Own contribution: Conducted experiments and analyzed data for figures 1- 6 and supplemental material. Shared contribution for experiments presented in figures $1 \mathrm{C}, 2 \mathrm{C}$, and 4 C-E. Contribution to: method design, figure arrangement, manuscript writing, and manuscript revision. 


\section{OPEN ACCESS}

Edited by:

Mohit Kumar Joly

Indien institute of Science MSOLl inchis

Reviewed by:

Seurav Kumar

indian Institute of Sciance MScl inche

Doniele Vergers

University of Salenta Hay

Bisrat G. Debeb

University of Texas MD Andersan

Cancer Conter, United States

Correspondence:

Cansten Griniches

grundhenumed unf-goettinger. de

Specially section:

This articio was submitted to Molecular and Celedier. Oncoibay

a soction of the joume

Frontiers in Oncology

Received: 22 Juy 2019 Accopted: 30 Soptombor 2019 Published: 23 October 2018

Citation

Helloger JW, Hücne' S, Goetz L

Bawerscturtitz $G$, Emons $G$ and

Grinaler C (2019) hivibition of

CYR61-S1C044 Axis Limits Breast Cincer hivesion

Front. Oncol, 9:1074

do: $103389 /$ tonc 201901074

\section{Inhibition of CYR61-S100A4 Axis Limits Breast Cancer Invasion}

\author{
Johanna W. Hellinger, Silke Hûchel, Lena Goetz, Gerd Bauerschmitz, Günter Emons and \\ Carsten Gründker* \\ Department of $G$ necology and Obstotrics, Unworsity Modiane Göttingen, Götingen, Gormany
}

Background and Objective: Matricellular proteins modulate the micro environment of tumors and are recognized to contribute to tumor cell invasion and dissemination. The cysteine-rich angiogenic inducer 61 (CYR61) is upregulated in mesenchymal transformed and invasive breast cancer cells. CYR61 correlates with poor prognosis of breast cancer patients. The signaling mechanism that causes invasive properties of cancer cells regarding to epithelial-mesenchymal transition (EMT) needs further research. In this study, we investigated the signaling mechanism, which is responsible for reduced cell invasion after suppression of CYR61 in mesenchymal transformed breast cancer cells and in triple negative breast cancer cells.

Methods: We addressed this issue by generating a mesenchymal transformed breast cancer cell line using prolonged mammosphere cultivation. Western blotting and quantitative PCR were used to analyze gene expression alterations. Transient gene silencing was conducted using RNA interference. Proliferation was assessed using AlamarBlue assay. Invasiveness was analyzed using 2D and $3 \mathrm{D}$ invasion assays. Immune-histochemical analysis of patient tissue samples was performed to examine the prognostic value of CYR61 expression.

Results: In this study, we investigated whether CYR61 could be used as therapeutic target and prognostic marker for invasive breast cancer. We discovered an interaction of CYR61 with metastasis-associated protein S100A4. Suppression of CYR61 by RNA interference reduced the expression of S100A4 dependent on ERK1/2 activity regulation. Non-invasive breast cancer cells became invasive due to extracellular CYR61 supplement. Immune-histochemical analysis of 239 patient tissue samples revealed a correlation of higher CYR61 and S100A4 expression with invasive breast cancer and metastasis.

Conclusion: Our data suggest that suppression of CYR61 impedes the formation of an invasive cancer cell phenotype by reducing ERK $1 / 2$ phosphorylation thereby suppressing S100A4. These findings identify mechanisms by which CYR61 suppresses cell invasion and suggest it to be a potential therapeutic target and prognostic marker for invasive breast cancer and metastasis.

Keywords: breast cancer, CYR61, invasion, EMT, triple negative breast cancer 


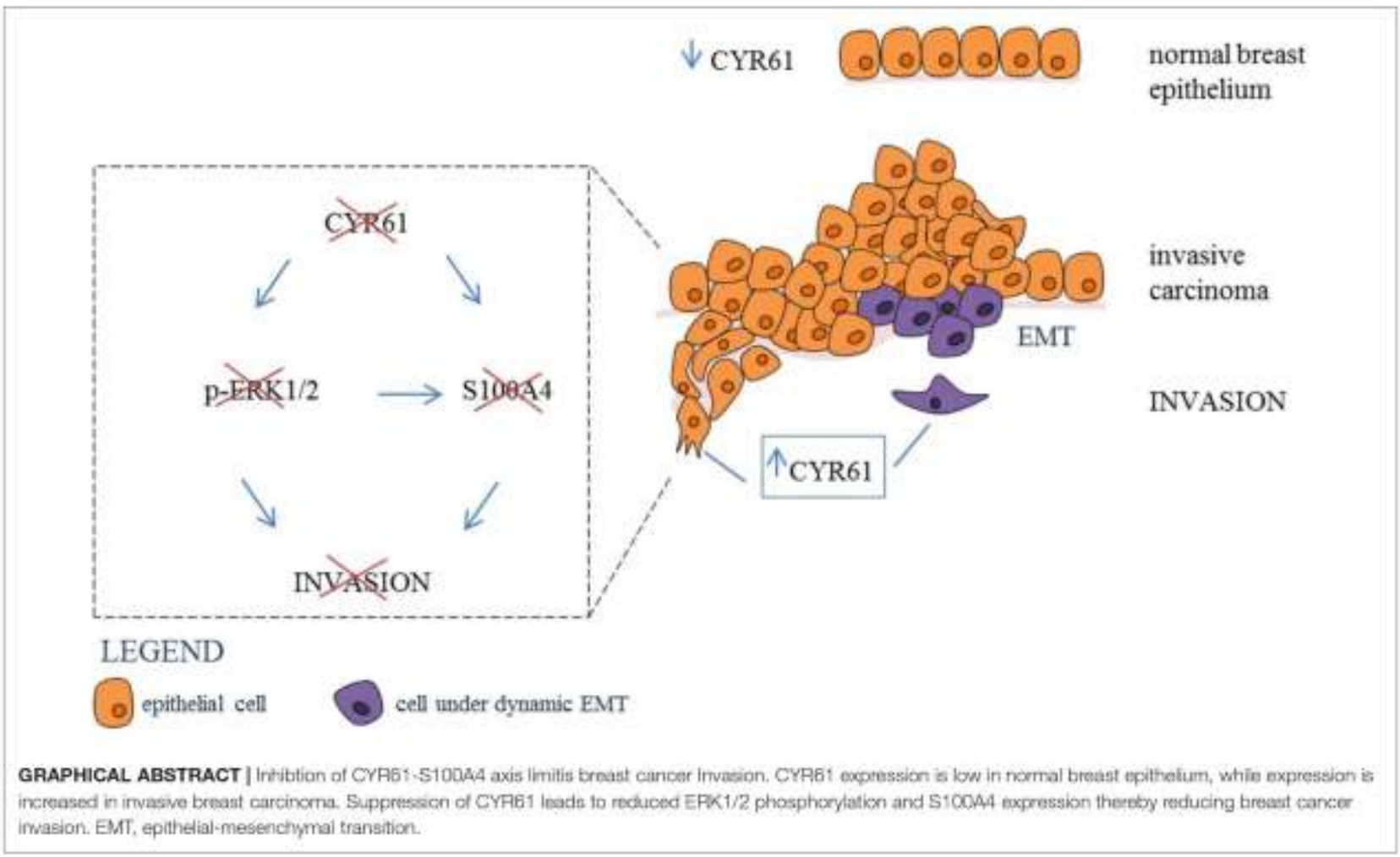

\section{INTRODUCTION}

In 2019, approximately 271270 woman and men in the United States will be diagnosed with breast cancer. Due to improved early detection techniques and treatment options 5 year-survival rates for local and regional breast cancer are $84-99 \%$. However, only 27 of patients diagnosed with distant metastasis survive a period of 5 years (1). Consequently it is necessary to identify prognostic markers for the early detection of breast cancer metastasis and new treatment options for this indications which accounts for more than $90 \%$ of cancer related death (2).

The first key event in the multi-step process of metastasis is the separation of tumor cells from the primary tumor and the dissemination into the surrounding tissue. Cells gain the ability to migrate and invade by altering their cytoskeletal organization, cell-cell-contacts, contacts with the extracellular matrix (ECM) and surrounding stroma (3). Epithelial-mesenchymal transition (EMT) is a transient dynamic program induced by different transcription factors (TFs). EMT-TFs orchestrate tumor-promoting micro environmental changes, cancer cell stemness, and chemo resistance $(4,5)$. The contribution of EMT programs to the metastatic cascade regarding breast cancer is supported by several publications (68). However, it is still under debate if an involvement of EMT programs is indispensable for creating an invasive phenotype (4).
Therefore it is necessary to study cancer cell invasion with regards to EMT complexity $(9,10)$.

The cysteine rich angiogenic inducer (CYR61) belongs to the CCN family (CYR61, CTGF /CCN12, NOV/CCN3, WISP-1/CCN4, WISP-2/CCN5, WISP-3/CCN6) of matricellular proteins and is localized on cell surface, cytoplasm and as a secreted protein in the extracellular matrix. The functions of CYR61 are cell type and context-dependent (11). They are transmitted through binding to integrin and heparin sulfate proteoglycans (HSPGs), CYR61 was shown to be involved in facilitating EMT programs in different cancer entities (12-14). It is known that elevated CYR61 expression promotes tumor progression, proliferation, migration and invasion of breast cancer $(15,16)$, whereas the role of CYR61 in breast cancer EMT programs remains elusive. Otherwise, CYR61 can act as a tumor suppressor in non-small cell lung cancer (17) and in fibroblasts by inducing apoptosis and senescence during wound healing $(18,19)$. The role of CYR61 signaling in cancer invasion and EMT programs regarding to a potential use as therapeutic target and prognostic marker needs further evaluation.

We hypothesize that CYR61 is a key regulator of breast cancer invasion. We want to identify the mechanisms by which CYR61 facilitates an invasive phenotype. Furthermore, we want to investigate the value of CYR61 as a therapeutic target and prognostic marker for invasive and metastatic breast cancer. 


\section{MATERIALS AND METHODS Cell Lines and Cell Culture}

Human breast cancer cell lines MCF-7, T47D, MDA-MB-231. and HCC1806 were obtained from American Type Cell Collection (ATCC; Manassas, VA, USA) and cultured in minimum essential medium (MEM; biowest, Nuaillé, France) supplemented with $10 \%$ fetal bovine serum (FBS; biochrom, Berlin, Germany), $1 \%$ Penicillin/Streptomycin (P/S; Gibco, Carlsbad, CA, USA), 0,1\% Transferrin (Sigma, St. Louis, USA) and 26 IU Insulin (Sanofi, Frankfurt, Germany). Human osteosarcoma cell line MG-63 was purchased from ATCC and cultured Dulbecco's modified eagle medium (DMEM; Gibco) supplemented with $10 \%$ FBS (biochrom) and $1 \%$ Penicillin/Streptomycin (Gibco). To retain identity of cell lines, purchased cells were expanded and aliquots were frozen in liquid nitrogen. A new frozen stock was used every half year and Mycoplasma testing of cultured cell lines was performed routinely using PCR Mycoplasma Test Kit I/C (PromoCell GmbH, Heidelberg, Germany). All cells were cultured in a humidified atmosphere with $5 \% \mathrm{CO}_{2}$ at $37^{\circ} \mathrm{C}$.

\section{Generation of Mesenchymal Transformed MCF-7 Cells}

Mesenchymal transformed MCF-7 breast cancer cells (MCF-7. EMT) were generated as described earlier (20). Briefly, $4 \times$ $10^{4} \mathrm{cells} / \mathrm{ml}$ were cultured in prolonged mammosphere culture (5-6 weeks) in ultralow adherence six well plates (Corning, Lowell, MA, USA) in DMEM/F12 (Gibco) supplemented with $10 \%$ charcoal-stripped fetal calf serum (cs-FCS;PAN-biotech, Aiden Bach, Germany), 2\% B27 supplement (Invitrogen, Darmstadt, Germany), $1 \%$ penicillin/streptomycin, $0.5 \mathrm{mg} / \mathrm{ml}$ hydrocortisone (Sigma, St, Louis, MO, USA), $5 \mu \mathrm{g} / \mathrm{ml}$ insulin, $20 \mathrm{ng} / \mathrm{ml}$ epidermal growth factor (EGF; Sigma, St. Louis, MO, USA).

\section{Treatment With rhCYR61 and U0126}

Human breast cancer cells were seeded at $5 \times 10^{5}$ cells $\mathrm{ml}$ in MEM supplemented with $10 \% \mathrm{FB}, 1 \% \mathrm{P} / \mathrm{S}, 0,1 \%$ Transferrin 26 IU Insulin. Cells treated with $1 \mu \mathrm{g} / \mathrm{ml}$ rhCYR61 (recombinant human CYR61: C-63398; PromoKine; Heidelberg; Germany) were serum-deprived $24 \mathrm{~h}$ prior to treatment and lysed $24 \mathrm{~h}$ after treatment. Cells treated with $10 \mu \mathrm{M} \mathrm{U0126}$ ("thrl-u0126; InvivoGen; San Diego: USA) were lysed $24 \mathrm{~h}$ after treatment.

\section{Transwell Invasion Assay}

Using co-culture transwell assay as described earlier (21), $1 \times$ $10^{4}$ breast cancer cells were seeded in DMEM w/o phenol red (Gibco), supplemented with $10 \%$ cs-FCS into a cell cultural insert (upper well) with a polycarbonate membrane $(8 \mu \mathrm{m}$ pore diameter, Merck Millipore, Cork, Ireland) coated with $30 \mu \mathrm{L}$ of a Matrigel (BD Bioscience, Bedford, MA, USA) solution (1:2 in serum-free DMEM). The osteosarcoma cells were seeded $\left(2.5 \times 10^{4}\right)$ in DMEM supplemented with $10 \% \mathrm{cs}$-FCS into the lower well (24-well-plate). After $24 \mathrm{~h}$ cells were co-cultured for $48 \mathrm{~h}$ or $96 \mathrm{~h}$. Stably transfected cells (overexpressing CYR61 or $\$ 100 \mathrm{~A} 4$ ) were seeded at a density of $1 \times 10^{4}$ per well in DMEM w/o phenol red cell cultural insert (upper well, Matrigel-coated with a polycarbonate membrane), with the lower well containing DMEM w/o phenol red supplemented with $10 \%$ cs-FBS and cultured for $96 \mathrm{~h}$. Invaded cells on the lower side of the insert were stained with hematoxylin and the number of cells in four randomly selected fields of each insert was counted.

\section{D Spheroid Assay}

Assessment of $3 \mathrm{D}$ cell invasion was pursued as describes earlier with minor changes (22). Briefly $1 \times 10^{3}$ breast cancer cells were seeded in $100 \mu \mathrm{L}$ in a well of an ultra-low-adherence 96-well plate (UL.A; Nexcelom, Cenibra GmbH, Bramsche, Germany). After $48 \mathrm{~h}$ spheroid formation was visually confirmed and $50 \mu \mathrm{L}$ of media was removed. Thereafter $50 \mu \mathrm{L}$. Matrigel were added to the spheroid wells. Central position of the spheroids was checked visually and Matrigel was allowed to solidify for $1 \mathrm{~h}$ at $37^{\circ} \mathrm{C}$ and $5 \% \mathrm{CO}_{2}$. Afterwards $50 \mu \mathrm{L}$ media were added to each well and a picture was taken marking time point 0 (toh). When indicated $1 \mu \mathrm{g} / \mathrm{ml}$ rhCYR61 or $10 \mu \mathrm{M}$ U0126 were added. Spheroid growth area was analyzed using Imagel polygonal selection and measurement. Mean values were calculated and compared to respective control.

\section{Small Interfering RNA Transfection}

Breast cancer cell lines MCF-7-EMT $\left(5 \times 10^{5}\right.$ cells $\left./ \mathrm{ml}\right)$ and MDA-MB-231 $\left(2.5 \times 10^{5}\right.$ cells $\left./ \mathrm{ml}\right)$ were seeded in $2 \mathrm{ml}$ of MEM with $10 \%$ FBS $(-\mathrm{P} / \mathrm{S})$ in $25 \mathrm{~cm}^{2}$ cell culture flask. The cells were transiently transfected with siRNA specific to S100A4 (sc-106781 pool of three S100A4-specific siRNAs; Santa Cruz. Biotechnology, Dallas, USA), CYR61 (sc-39331 pool of three CYR61-specific siRNAs; Santa Cruz Biotechnology) or YAP1 (sc38637 pool of three YAP1 specific siRNAs; Santa Cruz Biotechnologies) in OPTI-MEM 1 medium (Gibco, Carlsbad, CA, USA) with siRNA transfection reagent (sc-29528; Santa Cruz. Biotechnology, Dallas, USA). A non-targeting siRNA was used as control (sc-37007 control-A; Santa Cruz Biotechnology, Dallas, TX, USA). After an incubation period of $6 \mathrm{~h}, \mathrm{MEM}$ supplemented with $20 \% \mathrm{FBS}$ and $20 \%$ penicillin/streptomycin was added.

\section{Immune-Histochemical Staining}

Immune-histochemical staining of human tissue array slides (T087a; BR20837; BR248a; US Biomax, Derwood, MD, USA) was performed as described earlier (23). Sample sections were deparaffinized and rehydrated. Then antigens were retrieved by slide incubation in $0.01 \mathrm{M}$ citrate buffer $(\mathrm{pH} 6.0$ ) in microwave $(700 \mathrm{~W})$ for $5 \mathrm{~min}$. Using $3 \%$ hydrogen peroxidase solution for $6 \mathrm{~min}$ the endogenous peroxidase activity was quenched. Sample sections were incubated over night with primary labeled antibodies against S100A4 (NBP2-54580AF488; Alexa Fluor 488 labeled; $5 \mu \mathrm{g} / \mathrm{ml}$; Novus Biologicals, Centennial, $\mathrm{CO}$, USA) and CYR61 (NB100-356R; DyLight labeled; $5 \mu \mathrm{g} / \mathrm{ml}$; Novus Biologicals) at $4^{\circ} \mathrm{C}$. Staining was visualized using a Zeiss Scope Al Axio microscope (ZEISS, Oberkochen, Germany) with an oil EC PLAN-NEOFLUAR 100x (ZEISS, Oberkochen, Germany) objective and the ZEN software (ZEISS, Oberkochen, Germany).

\section{Real-Time Quantitative PCR Analysis}

Total RNA was extracted using an RNeasy mini kit (Qiagen, Hilden, Germany) and $2 \mu \mathrm{g}$ were reverse transcribed with 
high capacity cDNA reverse transcription kit (Qiagen, Hilden, Germany). Real- time qQPCR was performed using SYBR green PCR master mix kit (Qiagen, Hilden, Germany). Primer were, for S100A4 5' - GTACTCGGGCAAAGAGGGTG-3' (forward) 5' - TTGTCCCTGTTGCTGTCCAA-3' (reverse), for CYR61 5 '. CTCCCTGTTTTTGGAATGGA-3' (forward) 5' - TGGTCTTG CTGCATTTCTTG - 3' (reverse), for YAP1 5'- TCCCAGATG AACGTCACAGC $-3^{\prime}$ (forward) 5 ' - TCATGGCAAAACGAGG GTCA-3' (reverse), E-cadherin 5'-CCTCCTGAAAAGAGAG TGGA $-3^{\prime}$ (forward) 5'-GTGTCCGGATTAATCTCCAG $-3^{\prime}$ (reverse), Vimentin 5'-GCTGCTAACTACCAAGACAC-3' (forward) 5'-TCAGGTTCAGGGAGGAAAAG-3' (reverse), Zeb1 $5^{\prime}$-AAGACAAACTGCATATTGTGGAAG - $3^{\prime}$ (forward) $5^{\prime}$-CTGCTTCATCTGCCTGAGCTT-3' (reverse), SNAII 5'-GCCAAACTACAGCGAACTGG-3' (forward) 5'- GAGA GAGGCCATTGGGTAGC- $3^{\prime}$ (reverse), SNAI2 $5^{\prime}$ - AAGATGCA CATCCGAAGCCA-3' (forward) 5'- CATTCGGGAGAAGGTC CGAG - 3' (reverse) and GAPDH 5'. GAAGGTCGGAGTCAAC GGAT $-3^{\prime}$ (forward) 5' - TGGAATTTGCCATGGGTGGA - $3^{\prime}$ (reverse). PCR conditions were: denaturing once at $95^{\circ} \mathrm{C}(2 \mathrm{~min})$, $95^{\circ} \mathrm{C}(5 \mathrm{~s})$, and $60^{\circ} \mathrm{C}(15 \mathrm{~s})$ for 40 cycles.

\section{Western Blot Analysis}

Cells were lysed in cell lytic M buffer (Sigma, St. Louis, USA) supplemented with $0.1 \%$ phosphatase-inhibitor (Sigma, St. Louis, MO, USA) and $0.1 \%$ protease-inhibitor (Sigma, St. Louis, MO, USA). Isolated proteins $(40 \mu \mathrm{g})$ were fractioned using $12 \%$ SDS gels and electro-transferred to a polyvinylidene difluoride membrane (Merck Millipore, Cork, Ireland). Primary antibodies against S100A4 1:250 (HPA007973; Sigma, St. Louis, USA), CYR61 1:250 (HPA029853; Sigma, St. Louis, MO, USA), YAP 1:250 (sc-398182; Santa Cruz Biotechnology, Dallas, TX, USA), ERK1/2 1:1000 (4695S;Cell Signaling Technologies Inc, Danvers, MA, USA), Phospho-ERK1/2(Thr202/Tyr204) 1:1000 (9101S; Cell Signaling Technologies Inc.), and GAPDH 1:2000 (5174; Cell Signaling Technologies Inc) were used. The membrane was washed and incubated in horseradish peroxidase-conjugated secondary antibodies (GE Healthcare, Buckinghamshire, UK). Antibody-bond protein bands were assayed using a chemiluminescent luminol enhancer solution (Cyanagen, Bologna, Italy).

\section{ECM Degradation}

Wells of a 96-well plate were coated at room temperature for $20 \mathrm{~min}$ with $0.05 \mathrm{mg} / \mathrm{ml}$ Poly-L-tysine in DPBS (Sigma) and $15 \mathrm{~min}$ with glutaraldehyde $0.5 \%$ in DPBS. Gelatin (2 $\mathrm{mg} / \mathrm{ml}$; G9391; Sigma) was FITC conjugated as recommend by manufacture (\#343210; EMD Millipore Corp.. Billeria, MA, USA). Wells were coated with $60 \mu \mathrm{L}$ FITC-conjugated gelatin (2 $\mathrm{mg} / \mathrm{ml}$; Invitrogen, Milpitas, CA, USA) diluted 1:5 with unlabeled gelatin (Sigma) and incubated for $10 \mathrm{~min}$ at RT. Solution was discarded and wells were incubated for $30 \mathrm{~min}$ in $70 \%$ ethanol and afterwards free aldehydes were quenched with culture media for $30 \mathrm{~min}$ at room temperature before cells were seeded. Cells were seeded $\left(4.4 \times 10^{3}\right.$ cells per Well $)$ and treated with rhCTGF $(1 \mu \mathrm{g} / \mathrm{ml} ; \mathrm{R} \& \mathrm{D}$ systems). After $24 \mathrm{~h}$ proteolytic activity was detected by measuring fluorescence (extinction 490 $\mathrm{nm} / \mathrm{emission} 520 \mathrm{~nm}$ ) using Synergy (BioTek Instruments, Bad
Friedrichshall, Germany). Each experiment was performed in duplicates for at least three times. Mean values were compared to the respective control

\section{AlamarBlue Assay}

3D spheroids were grown as described above and $48 \mathrm{~h}$ after adding Matrigel AlamarBlue (BioRad, Hercules, USA) was added and incubated for $4 \mathrm{~h}$ at $37^{\circ} \mathrm{C} 5 \% \mathrm{CO}_{2}$. The colorimetric change of resazurin to resorufin upon cellular metabolic reduction was measured by absorbance reading at $540 \mathrm{~nm}$ and $630 \mathrm{~nm}$, using Synergy (BioTek Instruments). Relative AlamarBlue Reduction was calculated as indicated by manufacturer.

\section{KM Plotter Analysis}

The database of the Kaplan-Meier plotter (www.kmplot. com) downloads information of gene expression and overall survival from Gene Expression Omnibus (GEO; only Affymetrix microarrays), the European Genome-Phenome Archive (EGA) and The Cancer Genome Atlas (TCGA). To be able to analyze the prognostic value (overall survival) of CYR61 in 1,402 patient samples, the samples were split into two cohorts according to the expression of quantiles of CYR61 where all possible cutoff values between the lower and the upper quantiles are computed and the best performing threshold is used as a cutoff. These groups are compared by a Kaplan-Meier survival plot and the hazard ratio with $95 \%$ confidence intervals. Redundant samples were removed, biased arrays excluded and the proportional hazard assumption was set to zero (24).

\section{Statistical Analysis}

All experiments were performed at least in three biological and technical replicates. Data were analyzed by GraphPad Prism (GraphPad software Inc., v+ 7.03, La Jolla, Ca, USA) using unpaired, two-tailed, parametric t-test comparing two groups (treatment to respective control) by assuming both populations have the same standard derivation. $P<0.05$ was considered statistically significant.

\section{RESULTS}

\section{CYR61 Expression Correlates With Altered Breast Cancer Cell Invasion}

Mesenchymal transformed breast cancer cells show a TGF $\beta$. dependent increased invasive and metastatic potential (20). Despite, it is still under debate; if EMT programs are indispensable for cell invasion (4) and which key players are crucial for pathological EMT programs. We investigated whether within dynamic EMT programs or triple-negative breast cancer ( $T N B C_{i}$ no expression of estrogen or progesterone and no overexpression of Her2neu) cells show changes in CYR61 expression. It was shown before that non-invasive breast cancer cells gain invasiveness when co-cultured with primary osteoblasts or osteosarcoma cells (21). Gründker et al. suggested that mesenchymal transformed non-invasive MCF-7 cells (MCF-7 EMT) show an increased invasiveness and elevated CYR61 expression (23). Increased invasiveness could be suppressed by reducing extracellular CYR61 using blocking antibodies. Despite, it remains elusive, if targeting intracellular CYR61 
alters cell invasiveness in $2 \mathrm{D}$ transwell co-culture invasion assay. Two non-invasive estrogen positive cell lines (MCF-7, T47D) were mesenchymal transformed (MCF-7-EMT; T47DEMT) and altered expression of EMT-Transcriptionfactors (EMT-TFs) was assessed. Mesenchymal transformation using prolonged mammosphere culture leads to a decreased E-cadherin expression (Figure 1, Figure S1B) in two different estrogen positive breast cancer cells lines. Transforming growth factor induced (TGFBI), Zinc Finger E-Box Binding Homeobox 1 (Zeb1) and Snail Family Transcriptional Repressor 2 (Snai2) expression was increased after mesenchymal transformation (Figure 1, Figures S1A,D-F), while vimentin expression was upregulated in MCF-7-EMT breast cancer cells (Figure 1, Figure S1C) and Snail Family Transcriptional Repressor 1 (Snail) was upregulated in T47D-EMT cells. In addition CYR61 expression is upregulated in mesenchymal transformed breast cancer cells (Figure 1A; MCF-7-EMT: $2.18 \pm 0.2$ SEM relative expression compared to MCF-7; $n=5$; T47D-EMT: $3.04 \pm 0.62$ SEM relative expression compared to T47D) and in TNBC cells (Figure 1A; MDA-MB-231: 68.67 \pm 11.27 SEM relative expression compared to MCF-7; $n=4$; HCC1806: $1.3 \pm 0.09$ SEM relative expression compared to MCF-7;n=3). Moreover, mesenchymal transformed and TNBC cell lines show increased invasiveness in a 2D transwell co-culture invasion assay (Figure 1B; MCF7-EMT: $683.9 \pm 53.25$ SEM invaded cells in \% to MCF7; $n=36 ; P<0.0001$; T47D-EMT: $11881 \pm 155.8$ SEM invaded cells in $\%$ to T47D: $n=36 ; P=0.0022 ; \mathrm{MDA}$ MB-231: $466.7 \pm 58.52$ SEM invaded cells in $\%$ to MCF-7; $n=24 ; P<0.0001 ;$ HCC1806: $2277 \pm 237.4$ SEM invaded cells in $\%$ to MCF-7; $n=54 ; P<0.0001$ ). To determine whether intracellular suppressed CYR61 regulates breast cancer cell invasion, we transiently reduced CYR61 (see verification of CYR61 suppression Figure 1, Figure $\mathbf{S 2 A}$ ) in different invasive breast cancer cell lines and analyzed invasiveness using 2D invasion co-culture assay, Reducing CYR61 results in decreases cell invasion (Figure 1C; MCF-7-EMT CYR61-' $59.01 \pm 4.34$ SEM invaded cells in \% to MCF-7-EMT control: $n=36 ; P<$ 0.0001: T47D-EMT CYR61 $\div 50.73 \pm 8.71$ SFM invaded cells in $\%$ to T47D-EMT control; $n=36 ; P=0.002 ;$ MDA-MB-231

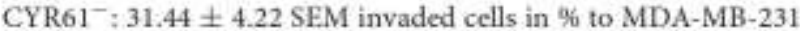
control: $n=18 ; P<0.0001 ; \mathrm{HCC} 1806 \mathrm{CYR}^{-} 1^{-}: 18.51 \pm 2.96 ; n$ $=18 ; P<0.0001)$. To confirm the impact of CYR61 suppression on breast cancer cell invasion, we assessed whether CYR61 suppression leads to a reduced $3 \mathrm{D}$ spheroid invasion growth. Reducing CYR61 results in a decreased 3D spheroid invasion area (Figure ID; MCF-7-EMT CYR61 ${ }^{-}: 87.93 \pm 2.54$ SEM invaded area in \% to MCF-7-EMT control; $n=5 ; P=0.0014$; T47DEMT CYR61 $1^{-}: 61.56 \pm 4.3$ SEM invaded area in $\%$ to T47DEMT control; $n=6 ; P<0.0001 ; \mathrm{MDA}-\mathrm{MB}-231 \mathrm{CYR}^{-} 1^{-}=50.37$ $\pm 13.29 ; n=5 ; P=0.006 ; \mathrm{HCC} 1806 \mathrm{CYR}^{-} 1^{-}: 82.24 \pm 4.81$ SEM invaded area in $\%$ to HCC1806 control; $n=6 ; P=0.004$ ). To determine whether decreased 3D spheroid invaded area is due to altered proliferation AlamarBlue Assay was conducted. Transient reduces CYR61 does not alter proliferation in 3D breast cancer cell spheroids after $96 \mathrm{~h}$ (Figure 1, Figure S2B). Furthermore, increased extracellular CYR61 expression increases 3D spheroid invaded area of non-invasive estrogen positive breast cancer cells
(Figure 1E; MCF-7 rhCYR61: $119.7 \pm 2.93$ SEM invaded area in $4 \%$ to MCF-7 control; $n=5 ; P=0.001 ;$ T47D rhCYR61 $128.6 \pm 4.38$ SEM invaded area in \% to T47D control; $n=4 ; P$ $=0.0006$ ). The underlying mechanism of cell invasion into the surrounding tissue evolve different processes including altered cell-cell adhesion, cell-ECM adhesion and ECM degradation (3). Proteolytic activity of estrogen positive breast cancer cells treated with extracellular CYR61 was increased (Figure 1F; MCF 7 rhCYR61: $110.8 \pm 2.65$ SEM relative proteolytic activity in 96 compared to MCP-7 control; $n=3 ; P=0.015$; T47D rhCYR61: 106.2 \pm 1.806 SEM relative proteolytic activity compared to T47D control; $n=3 ; P=0.026$ ), while proliferation was not altered (Figure 1, Figure S2C). Collectively, these data indicate that suppression CYR61 decreases invasivenes: in mesenchymal transformed and TNBC cells. Furthermore increased extracellular CYR61 expression increases invasiveness of non-invasive estrogen positive breast cancer cells.

\section{Suppression of CYR61 Reduces S100A4 Expression}

Identically to CYR61, S100A4 is upregulated during EMT programs in breast cancer and correlates with bone metastasis $(23,25)$. Blocking extracellular signaling of $5100 \mathrm{~A} 4$ reduced invasiveness of breast cancer cells in a $2 \mathrm{D}$ transwell invasion assay (23). Both CYR61 and S100A4 alter breast cancer invasivenes: but the underlying molecular mechanisms remain elusive. Chen et al. suggested that CTGF regulates \$100A4 through regulation of extracellular regulated kinases ERK1 and ERK2 (26). CYR61 and CTGF both bind to integrin $\alpha \mathrm{V}(12,26,27)$ We wanted to elucidate, whether suppression of CYR61 decreases S100A4 expression (Figure 2A). S100A4 was upregulated in mesenchymal transformed and TNBC cells (Figure 2B; MCF7-EMT: $1.84 \pm 0.27$ SEM relative expression compared to MCF-7:n $=5 ; P=0.014 ;$ T47D-EMT: $1.47 \pm 0.16$ SEM relative expression compared to $\mathrm{T} 47 \mathrm{D} ; n=5 ; P=0.0185$ HCCI806: $1.89 \pm 0.38$ relative expression compared to MCF$7 ; n=6 ; P=0.0403 ;$ MDA-MB-231: $90.31 \pm 13.3$ SEM relative expression compared to $\mathrm{MCF}-7 ; n=4 ; P=0.0005$ ) To elucidate the impact of CYR61 expression on S100A4 relative $5100 \mathrm{~A} 4$ expression was assessed after transient CYR61 suppression. Decreased CYR61 expression resulted in decreased \$100A4 expression (Figure 2C; MCF-7-EMT CYR61-0.64 \pm 0.05 SEM relative $\$ 100 \mathrm{~A} 4$ expression compared to MCF-7. EMT control; $n=4 ; P=0.0002$; T47D-EMT CYR61 ${ }^{-}: 0.79$ \pm 0.04 SEM relative S100A4 expression compared to T47DEMT control; $n=3 ; P=0.0078 ;$ MDA-MB-231 CYR61 $\div 0.78$ \pm 0.08 SEM relative $\$ 100 \mathrm{~A} 4$ expression compared to MDA. MB-231 control; $n=4 ; \quad P=0.0297 ;$ HCC1806 CYR61-: $0.63 \pm 0.07 \mathrm{SEM}$ relative $\$ 100 \mathrm{~A} 4$ expression compared to HCC1806 control; $n=3 ; P=0.0066$ ), while suppresses S100A4 had no impact on CYR61 expression (Figure 2, Figure S3D). We investigated whether decreased $5100 \mathrm{~A} 4$ suppresses cel invasion in a $2 \mathrm{D}$ transwell co-culture assay. Decreased $\mathrm{S100A4}$ expression (verification Figure 2, Figures \$1-S3) suppressed the invasiveness of mesenchymal transformed und TNBC cells (Figure 2D; MCF-7-EMT S100A4-; $83.81 \pm 4.9$ SEM invaded 


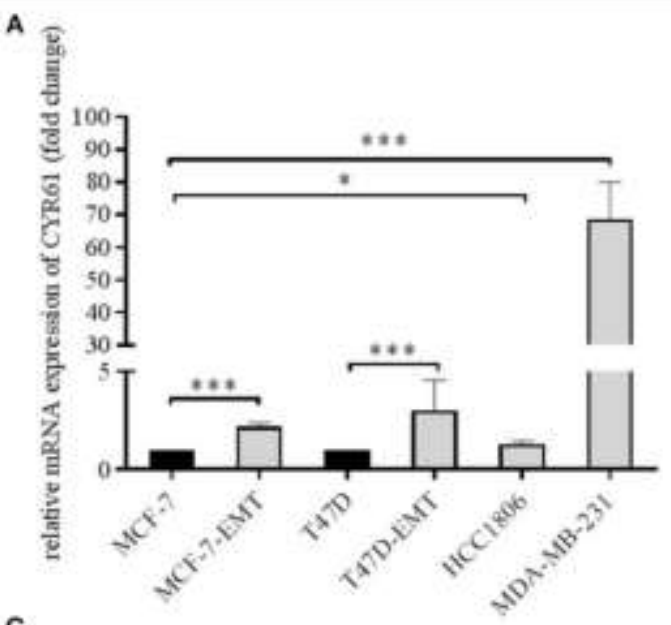

B

C
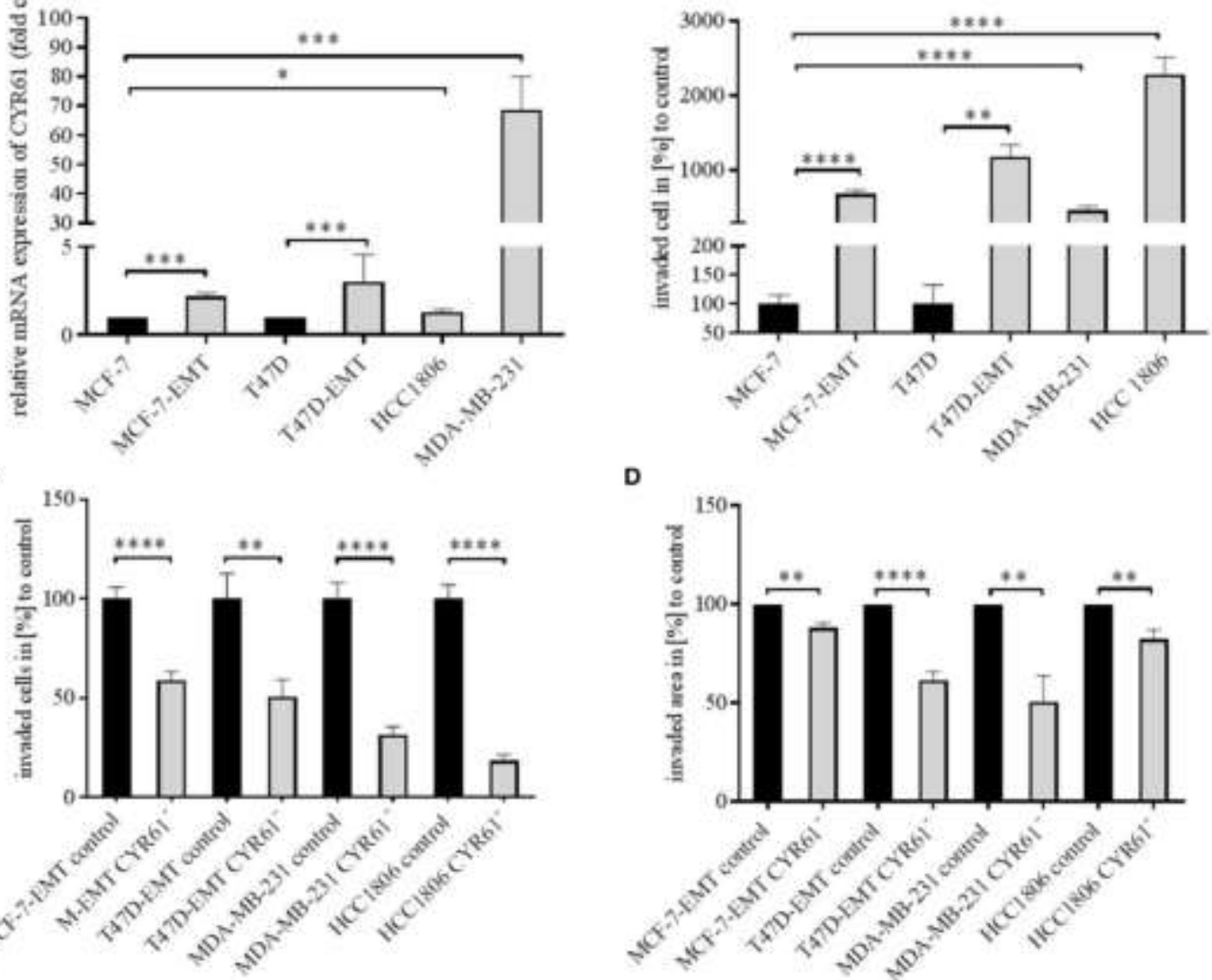

E
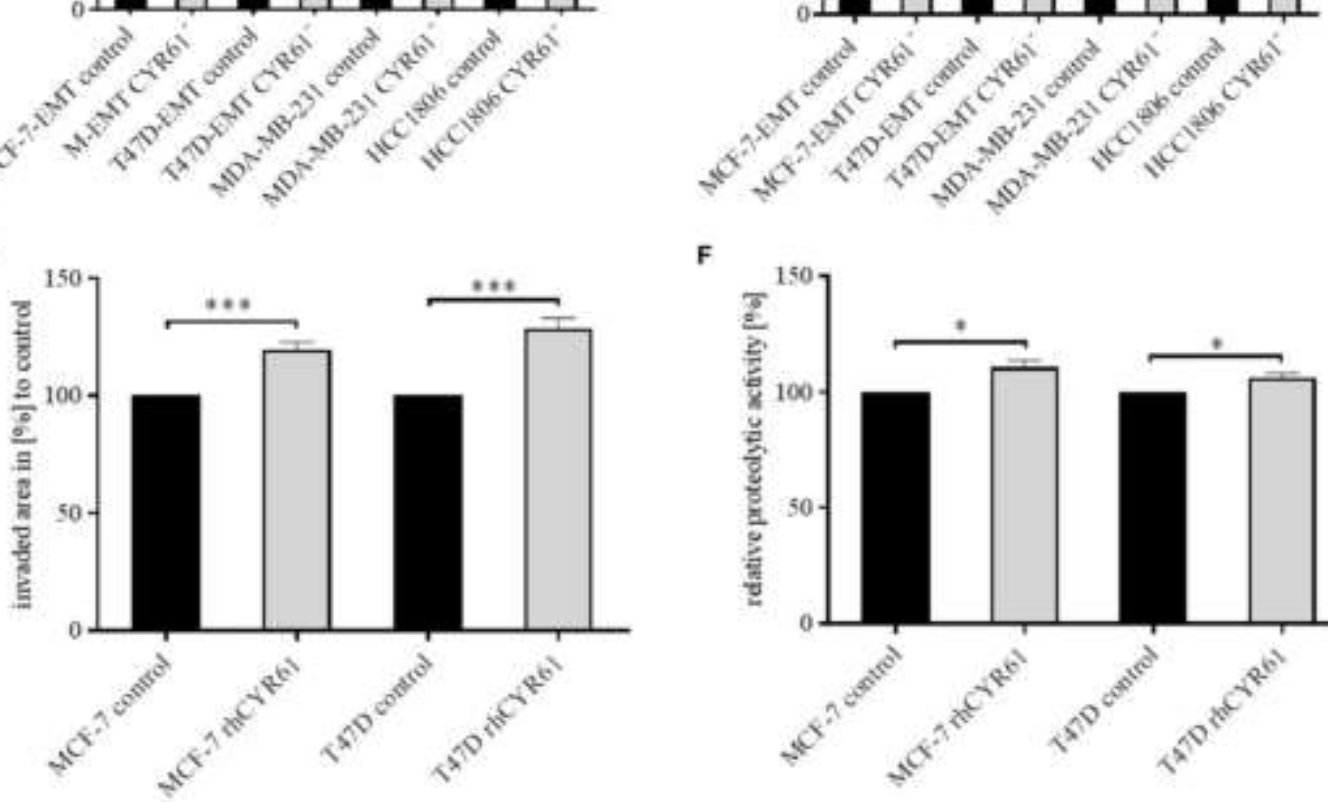

F

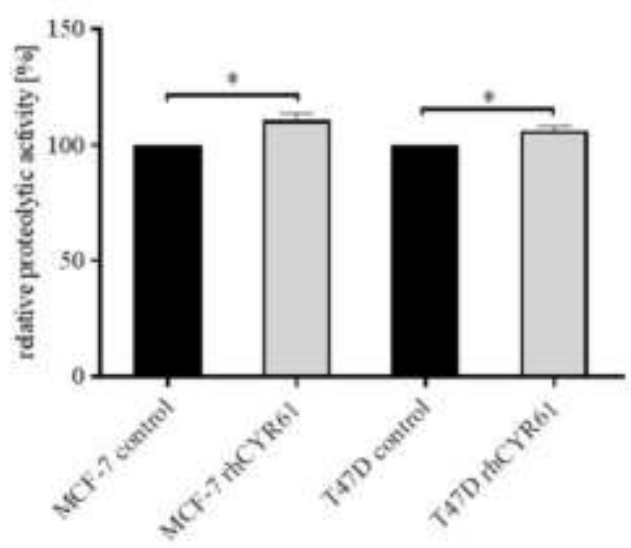

FIQUAE 1 | CYA61 expression correlates with breast cencer celt irwsiveness. (A) Felative CYA61 expression of invasive breast cancer cell ines compared to non-nvasive controls. Data represent mean \pm SEM. Using unpared, two-taled t-1est ansisis. MCF-7-EMT $n=5 ;$ T47D-EMT $n=6$; MDA-MB-23t $n=4 ;$ HCC1808 $n=3 ; \cdot P<0.05 ; \cdots P<0.005$ (B) 20 invasion anatysis of co-cutured (MG-63, osteosanooma cells) breast cencer cells for $96 \mathrm{~h}$. Percentege of cell invasion compered

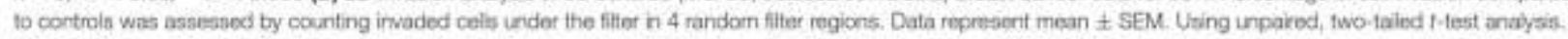

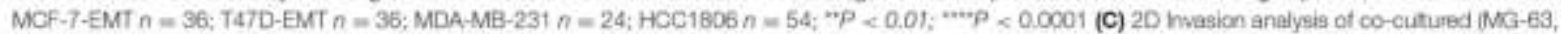

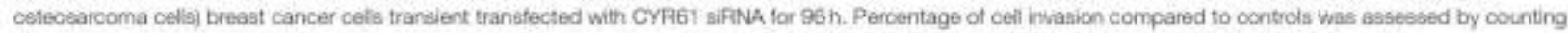
invaded cels under the filter in 4 random fiter regions. Data represent mean \pm SEM. MCF-7-EMT $n=36$; T47D-EMT $n=18 ;$ MCA-MB-231 $n=18$;

Continuedj 
FIGURE 1 | HCC1BD6 $n=36$; $" P<0.01 ; \cdots+P<0.0001$ (D) 30 invasion analysis of breast cancer spiteroids seeded after transient sifNA transfection. Spheroid area was assessed $48 \mathrm{~h}$ after adding Matrigel ueng polygonal selection and compared to spheroid area at time point 0 fadding of Matrigali. Aree growth was

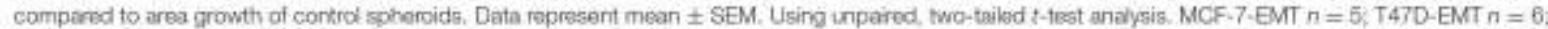

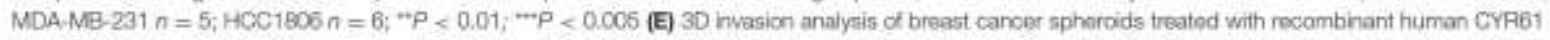
(thCYF81). Spheroid area was assessed $48 \mathrm{~h}$ after adding Matrigel and riCYFist using polygonal selection and compared to spheroid area st time point 0 (adding of

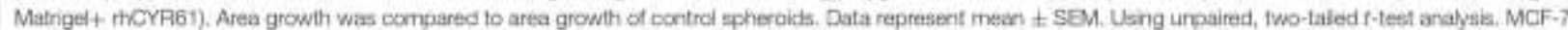
$n=3 ; . T 470 n=3 ; \cdots P<0.006$ (F) Proteotytic activity of non-imasive breast cancer cells traeted with thCYRi61 was asses by measurement of flucrescence 24 h after seeding cels on wels coated with FIC-labeled gelatin. Feiative protechytic activity of hCYAB1 treated cells was compered to proteclytic activity af control cels. Data represent mean $\pm S E M$. Uaing urpained, two-teled $\mathrm{t}$-test analyas. MCF-7 $n=3$; T47D $n=3{ }^{*} \mathrm{P}<0.05$

cell in $\%$ compared to MCF-7-EMT control; $n=36 ; P=$ 0.0321 ; T47D-EMT $\$ 100 \mathrm{~A}^{-} ; 66.29 \pm 8.52$ SEM invaded cells in $\%$ to T47D-EMT control: $n=36 ; P=0.0303 ;$ MDA-MB-231 S100 A4 ${ }^{-}: 65.02 \pm 5.58$ SEM invaded cells in \% to MDA-MB231 control; $n=24 ; P=0.0003 ;$ HCC1806 S100A4 ${ }^{-}: 51.84$ \pm 4.62 invaded cells in $\%$ to HCC1806 control; $n=36 ; P$ $<0.0001)$. Furthermore, decreased $\$ 100 \mathrm{~A} 4$ expression reduces 3D spheroid invasion area of mesenchymal transformed and TNBC cells (Figure 2E; MCF-7-EMT S100A4 ${ }^{-}: 82.77 \pm 2.82$ SEM invaded area in $\%$ compared to MCF-7-EMT control; $n=$ 6; $P=0.0001$; T47D-EMT S100A4 ${ }^{-}: 78.24 \pm 4.17$ SEM invaded area in $\%$ to T47D-EMT control; $n=6 ; P=0.0004$; MDA-MB$231 \mathrm{~S}^{2} 00 \mathrm{~A}^{-} ; 47,93 \pm 7,95 \mathrm{SEM}$ invaded area in $\%$ to MDA-MB231 control; $n=12 ; P<0.0001 ; \mathrm{HCC} 1806$ S100A4- $: 67.97 \pm$ 5.46 invaded area in $\%$ to $\mathrm{HCCl} 806$ control; $n=6 ; P=0.0002$ ), while proliferation was not altered (Figure 2, Figure S3E). To assess whether extracellular CYR61 can counteract the S100A4 suppressive effect on 3D spheroid invaded area, spheroids with suppressed S100A4 were treated with rhCYR61. Decreased S100A4 expression and additional increased extracellular CYR61 expression lead to an increased spheroid invaded area (Figure $2 \mathrm{~F}$; MCF-7-EMT S100A4 ${ }^{-}+$rhCYR61: $112.8 \pm 4.97$ SEM invaded area in $\%$ compared to MCF-7-EMT S100A4 ${ }^{-} ; n=4 ; P=0.0415$; T47D-EMT S100A $4^{-}+$rhCYR61: $118.9 \pm 4.36$ SEM invaded area in $\%$ compared to T47D-EMT S100A4- $n=6 ; P=0.0015$; MDA-MB-231 S100A4- +rhCYR61: $174.2 \pm 33.83$ invaded area in \% compared to MDA-MB-231 $100 \mathrm{~A}^{-} ; n=5 ; P=0.0596$; HCC1806 S100A4 ${ }^{-}+$rhCYR61: $116.3 \pm 6.85$ invaded area in $\%$ compared to HCC1806 $\$ 1004^{-} ; n=6 ; P=0.0383$ ). These data indicate a close correlation between CYR61 and \$100A4 expression and the invasiveness of mesenchymal transformed and TNBC cells in vitro.

\section{ERK1/2 Activity Is Transducer of CYR61 Mediated S100A4 Regulation}

We found that decreased CYR61 resulted in a decreased $\$ 100 \mathrm{~A} 4$ expression. Despite it remains elusive how CYR61 regulates S100A4 expression. To elucidate underlying intracellular mechanism we tested, whether decreased CYR61 expression reduces the phosphorylation of ERK1/2 thereby regulating S100A4 expression (Figure 3A). Mesenchymal transformed and TNBC cells shows a decreased ERKI/2 expression, while ERK1/2 phosphorylation was increased compared to noninvasive estrogen positive breast cancer cells (Figure 3B). Reducing CYR61 expression led to a decreased ERK1/2 phosphorylation (Figure 3C), MEK1 and MEK2 are upstream regulators of ERK1/2 activity (28) By using U0126 inhibitor, ERK phosphorylation can be diminished (29). Blocking ERK1/2 phosphorylation due to an MEK1 and MEK2 specific inhibitor U0126 (verification of U0126 induced blocking of ERK1/2 phosphorylation Figure 3, Figure $\mathrm{S} 4 \mathrm{~A}$ ) resulted in a decreased S100A4 expression (Figure 3D; MCF-7-EMT U0126: $0.89 \pm$ 0.02 SEM relative S100A4 expression compared to MCF-7-EMT DMSO; $n=3 ; P=0.0114 ;$ T47D-EMT U0126; $0.38 \pm 0.07$ SEM relative $\$ 100 \mathrm{~A} 4$ expression compared to T47D-EMT DMSO control; $n=3 ; P=0.0009 ;$ MDA-MB-231 U0126: $0.85 \pm 0.02$ SEM relative S100A4 expression compared to MDA-MB-231 DMSO; $n=3 ; P=0.0026$; HCC1806 U0126: $0.71 \pm 0.06$ SEM relative S100A4 expression compared to HCC1806 DMSO; $n=3 ; P=0.0076)$. Furthermore, U0126 treatment reduced 3 D spheroid invaded area (Figure 3E; MCF-7-EMR U0126: $47.52 \pm 5.77$ SEM invaded area in \% compared to MCF-7-EMT DMSO; $n=6 ; P<0.0001 ;$ T47D-EMT U0126: $71.51 \pm 2.61$ SEM invaded area in \% compared to T47D-EMT DMSO; $n$ $=5 ; P<0.0001 ; \mathrm{MDA}-\mathrm{MB}-231$ U0126: $35.31 \pm 10.91$ SEM invaded area in \% compared to MDA-MB-231 DMSO; $n=$ 6; $P=0.0002 ;$ HCC1806 U0126: $85.01 \pm 4.05$ SEM invaded area in $\%$ compared to HCC1806 DMSO; $n=5 ; P=0.006$ ). Treatment with U0126 reduced proliferation in 3D spheroids (Figure 3F; MCF-7-EMT U0126: $86.57 \pm 2.11$ SEM relative AlamarBlue reduction in $\%$ compared to MCF-7-EMT DMSO; $n$ $=3 ; P=0.0031 ;$ T 47D-EMT U0126: $67.53 \pm 8.61$ SEM relative AlamarBlue reduction compared to T47D-EMT DMSO; $n=4$; $P=0.0093 ;$ MDA-MB-231 U0126:52.23 \pm 13.32 SEM relative AlamarBlue reduction in \% compared to MDA-MB-231 DMSO; $n=3 ; P=0.023 ;$ HCC1806 U0126: $70.37 \pm 9.29$ SEM relative AlamarBlue reduction in $\%$ compared to $\mathrm{HCCl} 806 \mathrm{DMSO} ; n=$ 3; $P=0.0332)$. Moreover, treating non-invasive estrogen positive breast cancer cell spheroids with rhCYR61 lead to increased ERK1/2 phosphorylation (Figure 3, Figure S4B). These results suggest that decreased ERK1/2 phosphorylation suppresses S100A4 expression. Moreover, ERK1/2 phosphorylation is reduced by decreased CYR61 expression.

\section{Suppression of YAP1 Reduces Invasiveness Through Altering CYR61-S100A4-pERK1/2 Signaling}

Yes-associated protein (YAP) is a known upstream target of CYR61 in breast cancer (30). Validating that the observed results can be reproduced by altering YAP expression (Figure 4A), YAP was transiently decreased (verification Figure 4, Figure S5A). Decreased YAP expression reduced invaded area of $3 \mathrm{D}$ spheroids 


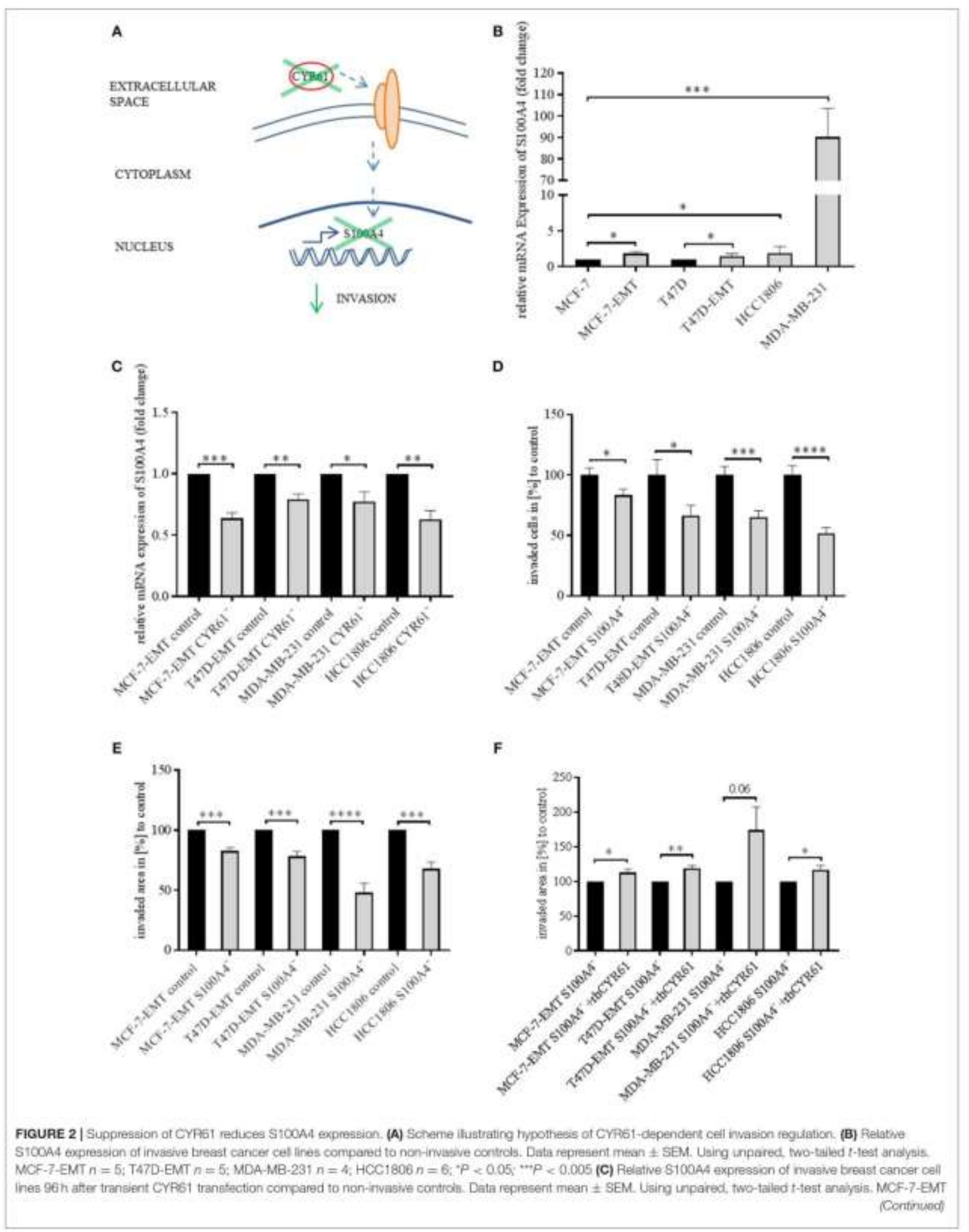




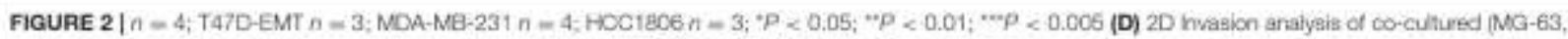
cetecsarcoma celis) breast cancer cels transient transfected with $8100 A 4$ s i ANA for. $96 \mathrm{~h}$. Percentage of cel invesion compared to controls was assessed by counting invaded cels under the filter in 4 random Elter regioes. Data reoresent mean \pm SEM. MCF. 7 -EMT $n=36 ;$ T47D-EMT $n=36 ;$ MDA-MB-231 $n=24$ :

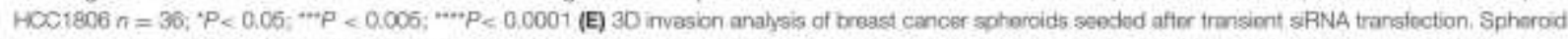
area was assessed $48 \mathrm{~h}$ after adding Matrigei using polygona selection and compared to sphercid area at time point 0 (adding of Matrigel). Area growth wiss

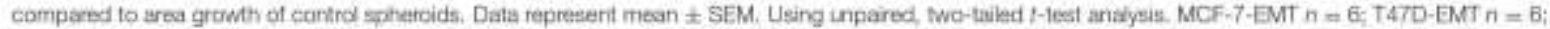

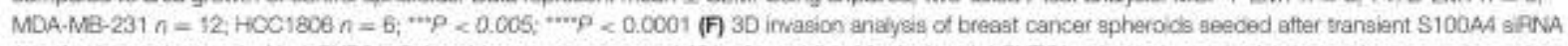
transfection and treated with thCYA61. Spheroid area was assessed $48 \mathrm{~h}$ after ading Matrigel and HCYABt using polygonal seiection and compared to sphercid area at time point 0 (edding of Matrigel + ihCYR61). Area growth was compared to ares growth of S100A4-spharcids. Data represent mean \pm SEM. Using unpared two triled f-test aralysis. MCF-7 EMT $n=4 ;$ T47D-EMT $n=4 ;$ MDA-MB-23t $n=5 ;$ HCC1806 $n=8 ; * P<0,05 ; * P<0,001$

(Figure 4B; MCF-7-EMT YAP $: 87.48 \pm 3.84$ SEM invaded area in \% compared to MCF-7-EMT control; $n=4 ; P=0.0172 ;$ T47DEMT YAP- $: 76.23 \pm 5.1$ SEM invaded area in $\%$ compared to T47D-EMT control, $n=5 ; P=0.0016$; MDA-MB-231 YAP$47 \pm 12,39$ SEM invaded area in \% compared to MDA-MB231 control; $n=12 ; P=0.0003 ;$ HCC1806 $\mathrm{YAP}^{-}=60.67 \pm 7.38$ SEM invaded area in \% compared to HCC1806 control), while proliferation was not altered (Figure 4, Figure S5B). Decreased YAP expression reduces CYR61 expression (Figure 4C: MCF7-EMT YAP $=0.79 \pm 0.05$ SEM relative CYR61 expression compared to MCF-7-EMT control; $n=3 ; P=0.01$; T47DEMT YAP ${ }^{-}: 0.82 \pm 0.05$ SEM relative CYR61 expression compared to T47D-EMT control: $n=3 ; P=0.0269$; MDAMB-231 YAP $* 0.74 \pm 0.03$ SEM relative CYR61 expression compared to MDA-MB-231 control; $n=3 ; P=0.0008 ;$ HCC1806 YAP $^{-}: 0.54 \pm 0.12$ SEM relative CYR61 expression compared to HCC1806 control; $n=3 ; P=0.0198$ ) and S100A4 expression (Figure 4D; MCF-7-EMT YAP-: $0.86 \pm 0.04$ SEM relative S100A4 expression compared to MCF-7-EMT control; $n=$ 3; $P=0.0362 ;$ T47D-EMT YAP $: 0.72 \pm 0.08$ SEM relative S100A4 expression compared to T47D-EMT control; $n=3$; $P=0.0289 ;$ MDA-MB-231 YAP $: 0.88 \pm 0.03$ SEM relative S100A4 expression compared to MDA-MB-231 control; $n=$ 3; $P=0.0179 ;$ HCC1806 $\mathrm{YAP}^{-}: 0.78 \pm 0.04 \mathrm{SEM}^{-}$relative \$100A4 expression compared to $\mathrm{HCCl} 806$ control; $n=3$; $P=0.0067$ ). Furthermore, decreased YAP expression reduces ERK1/2 phosphorylation (Figure 4E). Transient decreased YAP expression in mesenchymal transformed and TNBC cells treated with rhCYR61 show no impact on spheroid invaded area (Figure 4F). Collectively, these data suggest that decreased YAP expression leads to a CYR61, pERK1/2 and S100A4 suppression. The effect of decreased YAP expression on spheroid invaded area can be restored be supplemented extracellular CYR61.

\section{CYR61 and S100A4 as Prognostic Markers for Invasive and Metastatic Breast Cancer}

To assess the value of CYR61 and $\$ 100 \mathrm{~A} 4$ as prognostic marker meta-analysis were conducted. Reduced CYR61 expression increases the probability of distant-metastasis free survival (DMFS) of breast cancer patients with a lymph node positive status (Figure 5A; dataset 213226_at; $n=382$; FDR $1 \% ; P=$ $2.8 \mathrm{e}^{-07}$ ). Reduced $5100 \mathrm{~A} 4$ expression increases the probability of DMFS of breast cancer patients with a lymph node positive status but shows a higher FDR (Figure 5B; dataset 203186_s_at; $n=382 ;$ FDR $>50 \% ; P=0.024$, cut-off values see Figure 5,
Figure S6). Analyzing the effects of decreases CYR61 or \$100A4 expression with regards to the relapse free survival (RFS) shows comparable results (Figures 5C,D; CYR61: dataset 213226_at; $n$ $=1133 ;$ FDR $1 \% ; P=6.8 \mathrm{e}^{-09} ;$ S100A4: dataset $203186 \_$_at; FDR $>50 \% ; P=0.0012$, cut-off values see Figure 5, Figure S6). These data demonstrate that CYR61 could act as a prognostic marker in breast cancer.

\section{CYR61 and S100A4 as Therapeutic Target for Invasive and Metastatic Breast Cancer}

CYR61 and \$100A4 are drivers for breast cancer cell invasion in vitro. Consequently, we examined the value of CYR61 and/or $\$ 100 \mathrm{~A} 4$ as a potential therapeutic target for advanced breast cancer. Analyzing the expression in 239 paraffin-fixed patient breast tissue sections (104 invasive breast cancer sections with corresponding metastatic lymph node section and progesterone receptor-, estrogen receptor- and Her2neu expression, BR20837; 17 invasive ductal,1 medullary carcinoma and 6 normal breast tissue sections, $\mathrm{BR} 248 \mathrm{Ba} ; 2$ invasive ductal carcinomas, 1 invasive lobular carcinoma and 2 normal breast tissue section, T087a). Analyzing if expression was detected (immunofluorescence signal for CYR61 and/or S100A4 1.5 spots $+; 5.10$ spots ++ ; $>10$ spots +++$)$ or not $(-)$, we find the following pattern: $90.2 \%$ of invasive ductal carcinomas were positive for CYR61 expression, $82 \%$ were positive for $\mathrm{S} 100 \mathrm{~A} 4$ expression and $78 \%$ showed both CYR61 and S100A4 expression (Figure 6A and Figure S7). Corresponding metastatic lymph node sections were in $96 \%$ positive for CYR61, in $75 \%$ positive for $5100 \mathrm{~A} 4$ and in $74 \%$ for both CYR61 and S100A4. TNBC tissue sections were in $97 \%$ positive for CYR61, in $75.8 \%$ positive for $5100 \mathrm{~A} 4$, and in $75.8 \%$ expressing both CYR61 and S100A4. Interestingly, CYR61 expression was only detected in $12.5 \%$ of normal breast tissue samples and $\$ 100 \mathrm{~A} 4$ expression in none (Figure 6D, detailed list Figure S7). Visual expression of CYR61 and S100A4 in blood vessels (Figure 6D) could be found throughout all tissue sections. We find that the CYR61 and $\$ 100 \mathrm{~A} 4$ expression appeared in very close localization to each other (Figure 6, white arrows) or even co-localized (Figure 6, white stars). These studies demonstrate that CYR61 and $\$ 100 \mathrm{~A} 4$ could be valuable therapeutic targets and prognostic marker for invasive breast cancer and metastasis,

\section{DISCUSSION}

CYR61 is best recognized as regulator of inflammation and wound healing $(31,32)$. Several studies indicate that CYR61 can facilitate invasion and is crucial for EMT programs regarding 
A
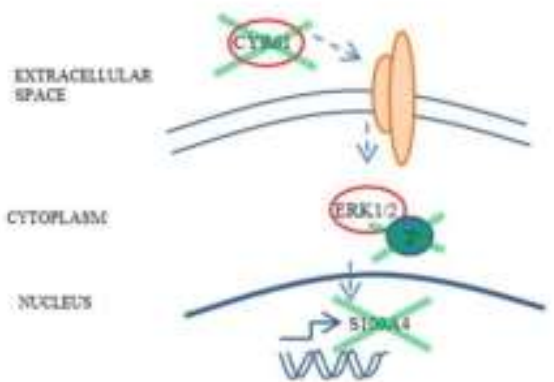

C

MCF-7.EMT T47D-EMT MDA-MB-231 HCC1806

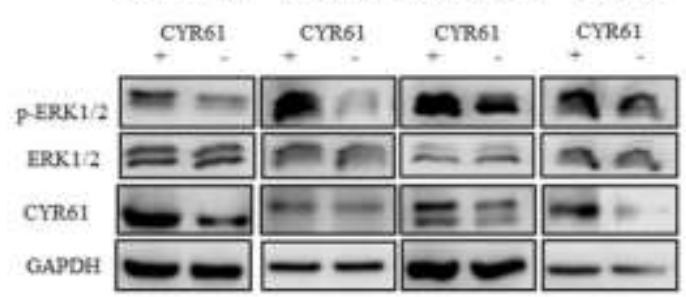

E
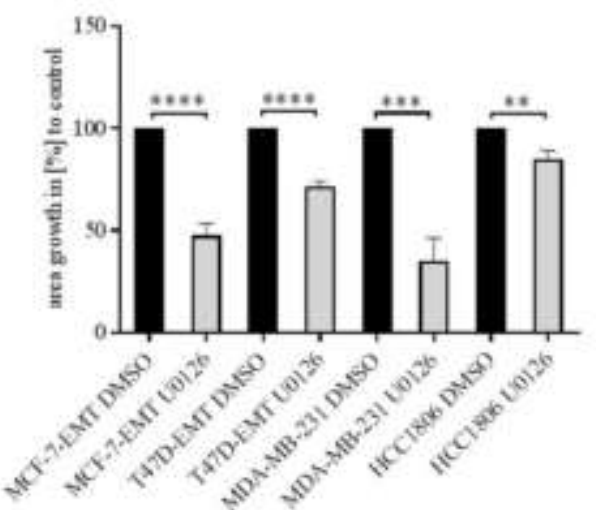

B

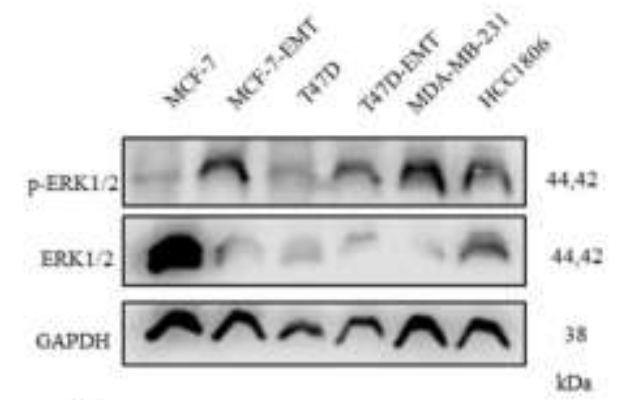

D

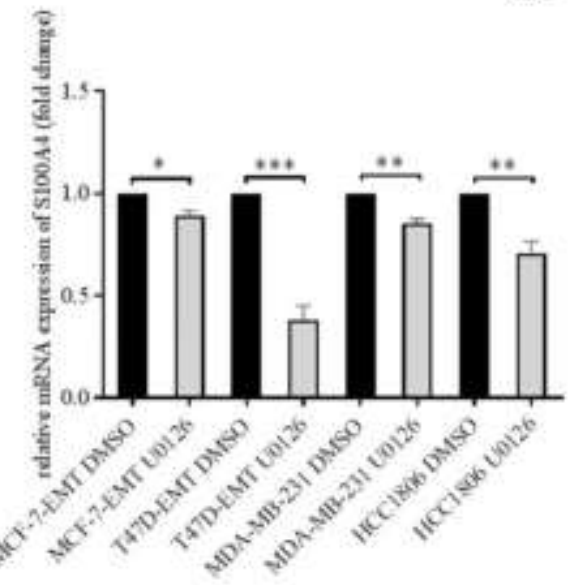

$\mathbf{F}$

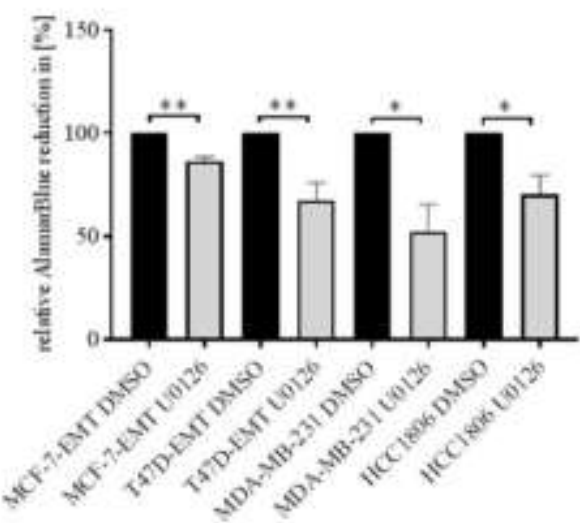

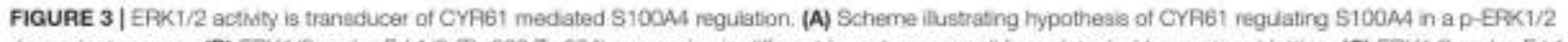
dependent manrer. (B) ERK 1/2 and p-Erk1/2 (Thr202/Tyr204) expression in different brasat cancer cell ines detected by western blotting. (C) EAK1/2 and p-Erk1/2 (Thr20e/Tyr204) and CYR61 excression in different breast cencer cell Ines after transiant CYA61 transfection detected by westem blotting. (D) Relative StOOA4 expression of invasive breast cancer cel lines treated with 10 pM U0126 compared to DMSO controis, Data represent mean \pm SEM, Using unpaired, fwo-taled t-test

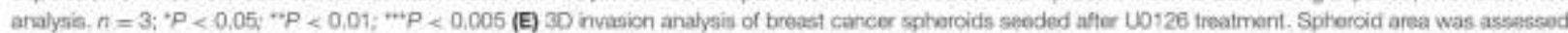
$48 \mathrm{~h}$ after adding Matrigei ising polygonal selecton and cornpared to sphercid atea at time point 0 (adding of Matrigai $+10 \mu \mathrm{M}$ U0126). Area growh was cornpared to area growth of control sphercids. Data represent mean \pm SEEM. Using unpaired, two-taied t-tent aratysis. MCF-7-EMT $n=6$; T47D-EMT $n=5 ;$ MDA-MB-23t $n=$

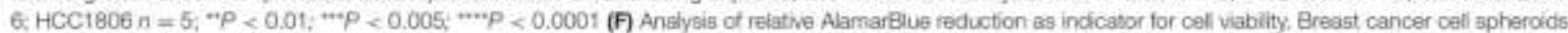

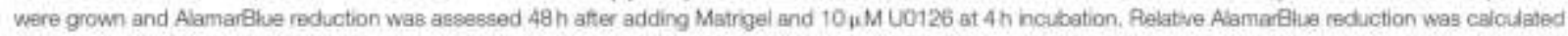
compared to DMSO control sphercids. Data represent mean \pm SEM. MCF-7-EMT $n=3 ;$ T47D-EMT $n=4 ;$ MDA-MB-231 $n=3 ;$ HCC1806 $n=3 ; \cdot P<0.05 ; " P$ $<0.01$.

cancer progression $(12,15,16,23)$. The question remains how CYR61 facilitates invasion in breast cancer and which role it possesses regarding EMT complexity (4). Since CYR61 has known oncogenic functions in serval tumor entities (12, 13 ), including breast cancer $(15,16)$, the question appeared if CYR61 might be a valuable therapeutic target in aggressive breast cancer 
A

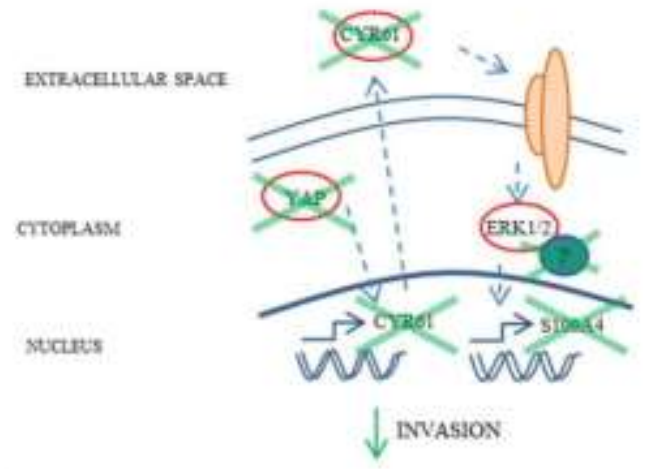

C

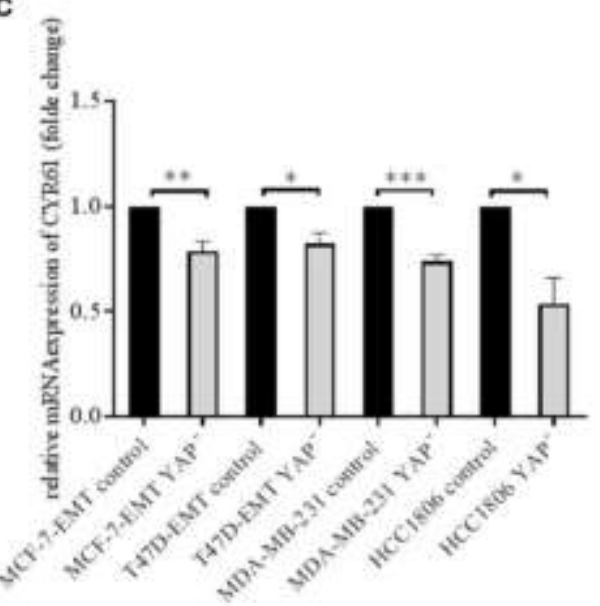

E

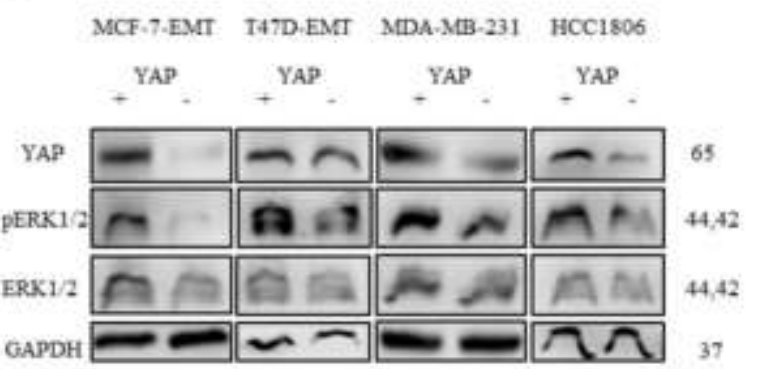

B

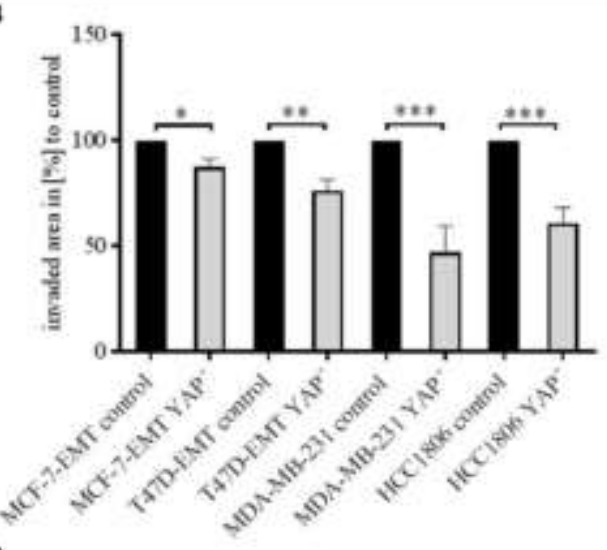

D

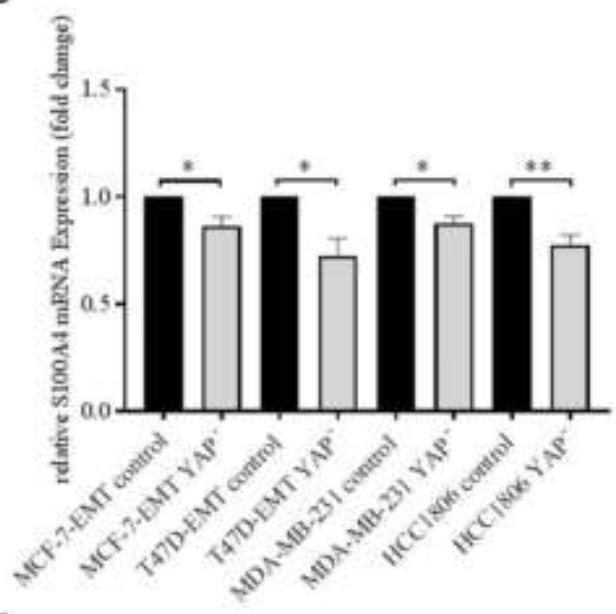

F

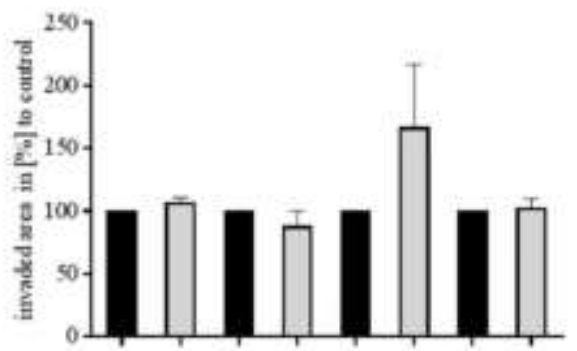

.

FIGURE 4 | Suppression of YAP reduces ivissiveness through blocking CYP61-S100A4-pEAK1/2 signaing. (A) Scherne illustrating hypothesis of YAP regulating S100A4 in a CYA61 - p-EFK1/2 dependent marner. (B) 3D invasion analysis of breast cancer spheroids seeded after transiemt YAP sPNA transtection. Spheroid area was assessed $48 \mathrm{~h}$ after adding Matrigut using polygonal solection and compared to spheroid area at time point 0 tadding of Matrigel), Ares growth was compared to

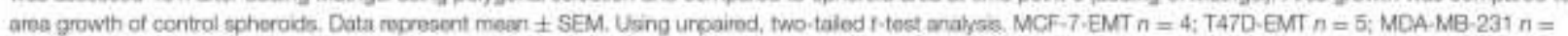

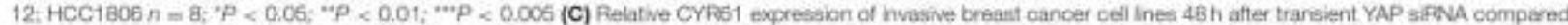

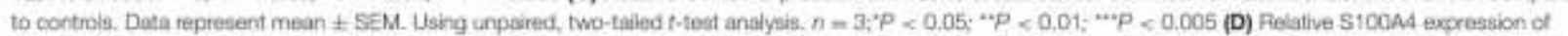
imasive breast cancer cel ines 48 h atter transient YAP sPNA compared to controla. Data represent mean \pm SEM. Using unpaired, two-taled t-test analysis.

(Continued) 


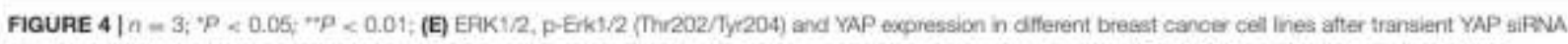
transfection datected by westem blotting. (F) $3 D$ invesion analysis of breast cancer spheroids seeded after transient YAP siFNA transtection and treated with HCYA61. Spheroid area was assessed 43h atter adding Matrigel and ticYR61 vaing polygonal seloction and compared to spheroid area at time point 0 (edding of Matrigel + inCYA61). Arca growth was companod to area growth of YAP- npheroids, Chata mopnesent meon \pm SEM. Uaing unpained, two-taied $t$-test analysia. MCF-7.EMT $n=6$; T47D-EMT $n=6$; MDA-ME-23i $n=4 ;$ HCC 1800 $n=6$.

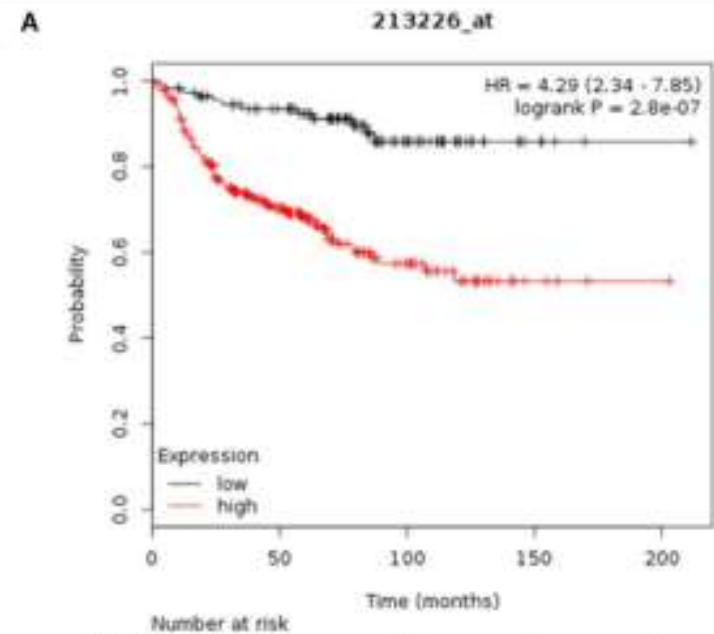

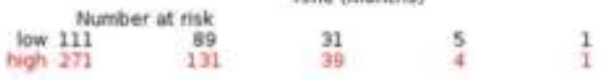

C

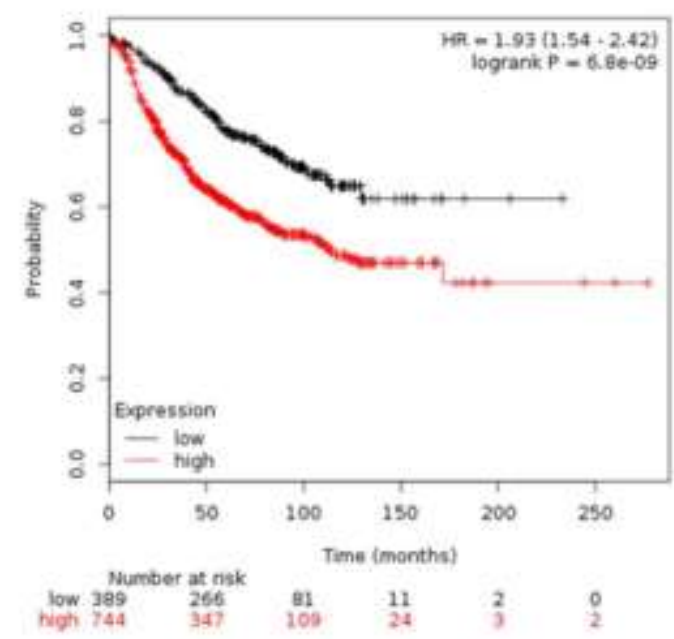

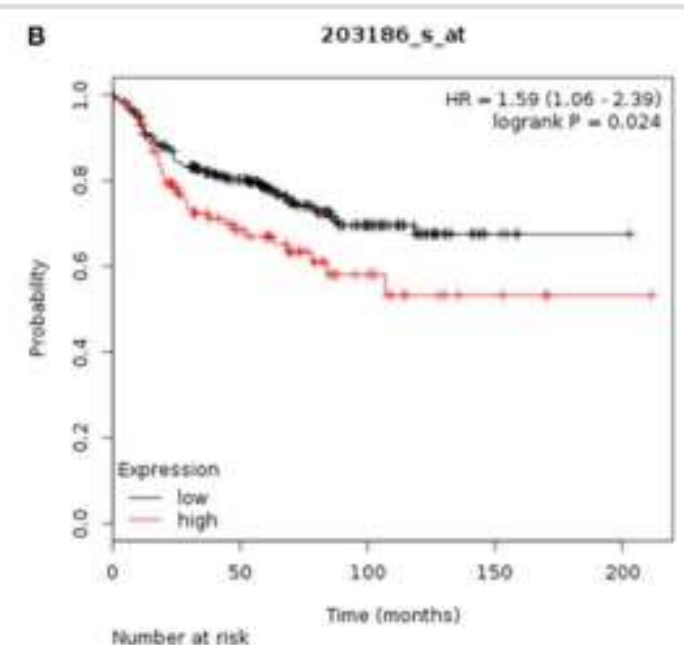

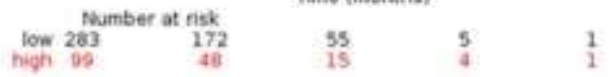

D

203186_s_at

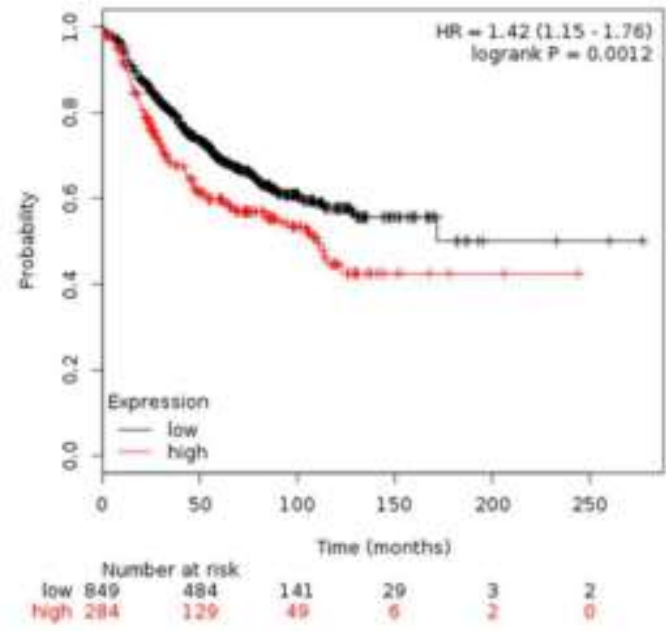

FiGURE 5 | CYR61 and $5100 A 4$ as progncstic marker for breast cancer progression. (A) Probabilty of dstant metastasis tree survial (DMFS) n 382 brasst cancer

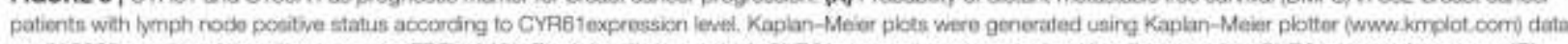

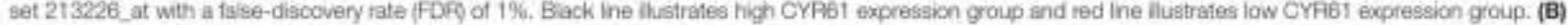
Probability of DNFS in 382 breast cancer patients with lymph node posithe status according to S100A4 expression level. Kaplan-Meier plots were generated using

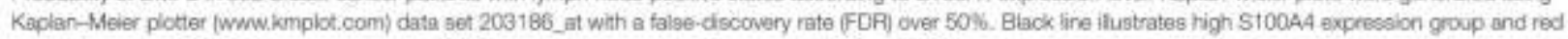
Ine llustrates low $5100 \mathrm{A4}$ expression group. (C) Probebility of fernission frese survival (AFS) in 1133 breast cancer patients with lymph node postive status according

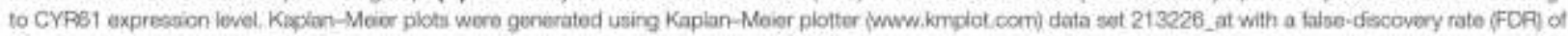
1\%. Block line ilustrates high CYA61 mproseion group and red ine ilustrates iow CYA61 oxpression groip. (D) Probability of RFS in 1133 brosest cancer pationts with

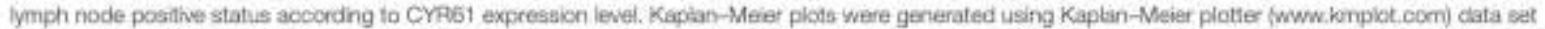

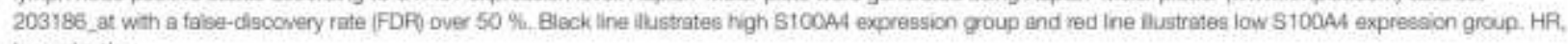
hezard ratio. 


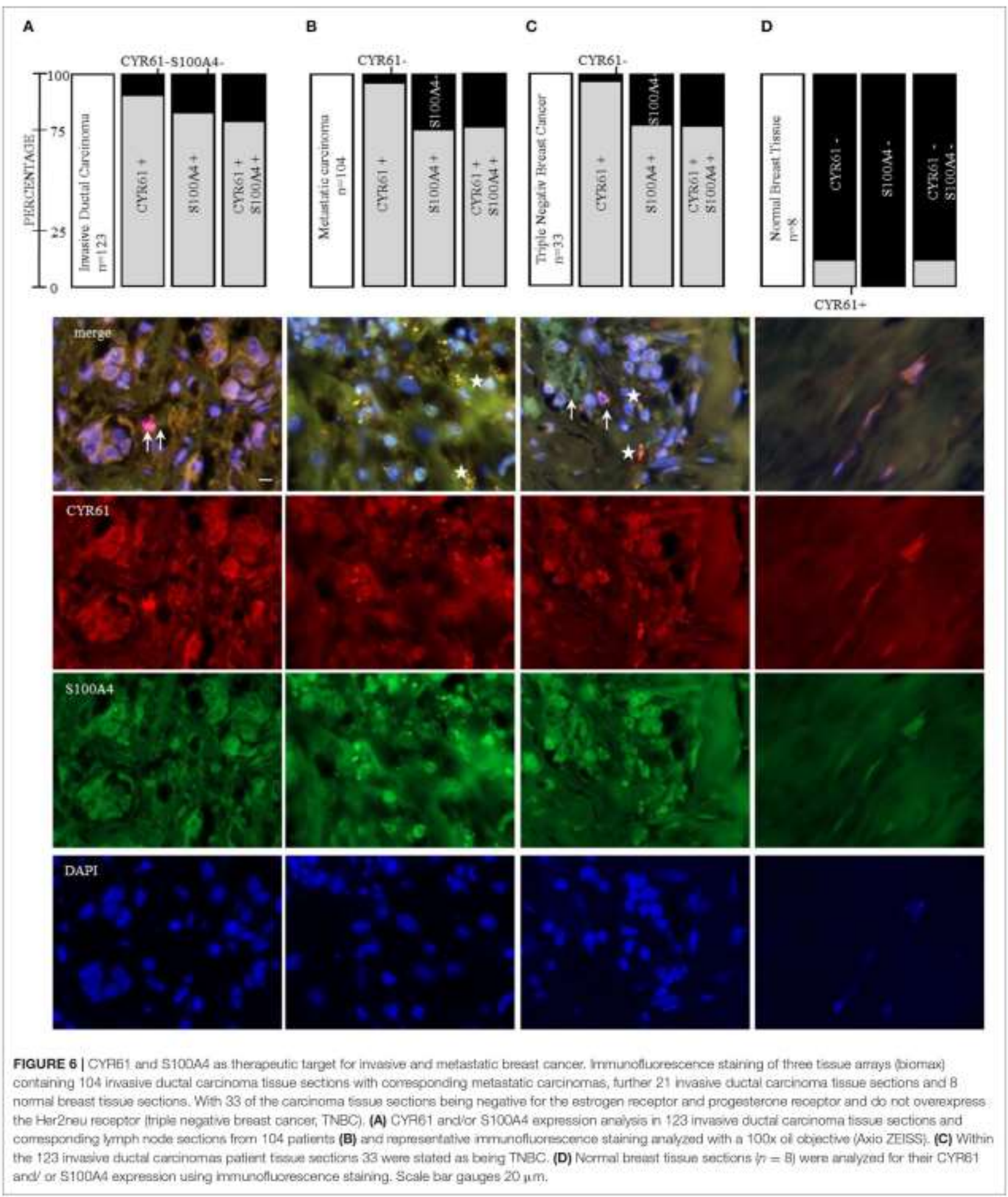

and if it could be a prognostic marker for these indications. We report that a higher CYR61 expression correlates with a poor prognosis of breast cancer patients. Moreover, we found that reducing the CYR61 expression leads to a decreased invasion in $2 \mathrm{D}$ and $3 \mathrm{D}$ invasion analysis setups, showing comparable results. Suggesting that reduced invasion upon CYR61 suppression is 
due to reduces ERK1/2 phosphorylation and SI00A4 expression. CYR61 might be a valuable therapeutic target and prognostic marker for invasive and metastatic breast cancer.

Triple negative breast cancers (TNBC) account for 15-20\% of all breast cancer incidents and there is no specific targeted therapy available (33). There is a need for identifying new targets for future therapy options. Consistent with previous published results we could demonstrate that CYR61 expression is increased in TNBC cell line MDA-MB-231 (34) and further more in the TNBC cell line HCC1806. The contribution of FMT-induced expression changes to the invasion and metastatic cascade regarding cancer progression is highly debated and needs to be interpreted cell and tissue specific $(4,8,35)$. Mesenchymal transformed breast cancer cells show an increased expression of CYR61 and S100A4 (23), which we could reproduce in our setting. It was shown that $\$ 100 \mathrm{~A} 4$ facilitates breast cancer invasion (36). Grùndker et al. demonstrated that suppressing extracellular signaling of CYRó1 and $\mathrm{S} 100 \mathrm{~A} 4$ decreased the ability of breast cancer cell invasion in a co-cultural setting mimicking bone metastasis (23). It was not tested how the intracellular signaling is affected when CYR61 or S100A4 expression is reduced. We report here that transient gene silencing of either CYR61 or $\$ 100 \mathrm{~A} 4$ can reduce invasiveness in mesenchymal transformed and TNBC cells. To further assess the impact of CYR61 on breast cancer cell invasion we increased extracellular CYR61 expression in non-invasive breast cancer cells and could show that this led to an increased invasive behavior. These findings indicate that CYR6 1 could be a regulator of breast cancer cells invasion. We showed that reversing EMTinduced upregulation of CYR61 and S100A4 leads to reduced invasive behavior in breast cancer cells in different invasion setups. This could indicate a role of EMT within this process. Further research is necessary to assess, if modulating CYR61 regulates EMT-TFs and thereby facilitates cellular plasticity. It has been suggested that targeting EMT-TFs could help to overcome chemo resistance and recent findings suggest an involvement of CYR61 in resistance to certain therapies in different tumor entities $(5,37,38)$.

Despite, it was unclear how CYR61 regulates invasiveness of breast cancer cells. We suggest that CYR61 tegulates S100A4 expression in mesenchymal transformed and TNBC cells through regulating ERK1/2 phosphorylation. Reducing S100A4 expression leads to decreased 3 D spheroid invasion and invasiveness of breast cancer cells in co-culture with osteosarcoma cells. Adding extracellular CYR61 to breast cancer spheroids with transient decreased $\$ 100 \mathrm{~A} 4$ expression could restore the effect und led to a slightly increased invaded area. Hou et al suggested that regulating CYR61 in osteosarcoma cells targets the MEK-ERK pathway (12). ERK1/2 signaling is gaining higher interest since the unique ERK1/2 position within cellular signaling. Targeting ERK1/2 could be valuable for therapy-resistant cancer to known clinically used BRAF and MEK inhibitors (39). We could show that inhibition of ERK1/2 phosphorylation led to decreased 3D spheroid invasion and reduced spheroid proliferation. Inhibition of ERK1/2 phosphorylation led to decreased S100A4 expression. But $\$ 100 \mathrm{~A} 4$ decreased expression by itself had no impact on spheroid proliferation, neither had CYR61 or YAP transient suppression.

YAP is regulated negatively through the Hippo-Pathway, which regulates key events of organ size, development and angiogenesis (40-42), Regarding breast cancer YAP is reported to have dual function as oncogene and tumor suppressor (43). Higher YAP expression correlates with increased EMT marker expression (44). We suggest that reduced YAP expression leads to decreased 3D spheroid invasion by suppression of CYR61, pERK1/2 and S100A4. The effect of reduced YAP expression on 3D invasion could be restored by extracellular CYR61 addition.

CYR61 or S100A4 are suggested to be valuable prognostic markers regarding several tumor entities (45-48). Egeland et al. suggested the use of S100A4 as a prognostic marker for earlystage breast cancer (49). We examined whether CYR61 and S100A4 could be valuable prognostic marker for invasive and metastatic breast cancer. CYR61 and \$100A4 are highly expressed in invasive-ductal carcinomas, including TNBC, and both are expressed in metastatic lymph node sections. Of all analyzed tissue sections $82.2 \%$ expressing CYR61 did express S100A4, respectively, which lead to the conclusion, that CYR61 together with $\$ 100 \mathrm{~A} 4$ would be valuable prognostic marker for breast cancer and breast cancer metastasis. Moreover, we found that expression of CYR61 and S100A4 is closely located (Figure 6, indicated by arrow) or even co-localized (Figure 6, indicated by star). Considering that CYR61 regulates cancer invasion and the findings, that it may be a valuable prognostic marker in different cancer entities $(45,46,50,51)$, It was suggested before, that CYR61 regulates $\mathrm{E}$-cadherin, $\mathrm{N}$-cadherin and Twist in osteosarcoma cells (12). Further investigations should clarify if CYR61 suppression regulates EMT-TFs in breast cancer and facilitates invasion by altering ECM degradation and adhesion. Secretome analysis of co-cultured cancer cells could identify secreted proteins, like matricellular proteins, that are drivers for invasion and promote metastasis.

Our findings suggest that CYR61 plays a major role in breast cancer invasion. This impact is facilitated through the regulation of ERK phosphorylation and S100A4 expression. Moreover, targeting YAP, a CYR61 upstream regulator, regulates CYR61, ERK phosphorylation and S100A4. We could identify a close correlation between CYR61 and S100A4 expression and breast cancer invasion and metastasis in breast cancer patients, CYR61 together with $\$ 100 \mathrm{~A} 4$ might be utilized as therapeutic target and prognostic marker for invasive breast cancer and metastasis.

\section{DATA AVAILABILITY STATEMENT}

The datasets used and/or analyzed during the current study are available from the corresponding author on reasonable request.

\section{AUTHOR CONTRIBUTIONS}

Conception and design of the reported work was done by $\mathrm{JH}$ and $\mathrm{CG}, \mathrm{JH}, \mathrm{GB}$, and $\mathrm{CG}$ did the development of methodology used. $\mathrm{JH}$ and $\mathrm{SH}$ performed invasion assays. $\mathrm{JH}$ and LG 
contributed to protein expression analysis. IH contributed to immune histochemical staining, gene expression analysis, proliferation analysis, in silico and network analysis. Analysis and interpretation of data was performed by $\mathrm{JH}, \mathrm{SH}, \mathrm{LG}, \mathrm{GB}, \mathrm{GE}$, and CG. All authors read and approved the final manuscript.

\section{FUNDING}

Research reported in this publication was supported, by the Deutsche Krebshilfe grant 70112534.

\section{ACKNOWLEDGMENTS}

We would like to thank Sonja Blume for her excellent technical assistance. The group of Dr. Florian Wegwitz for fruitful discussions. Moreover, we appreciate the valuable suggestions of the reviewers.

\section{SUPPLEMENTARY MATERIAL}

The Supplementary Material for this article can be found online at: hrtps://www.frontiersin.org/articles/10.3389/fonc. 2019.01074/full\# supplementary-material

Figure S1 | CYA61 expressian correlates with breast carcer coll invasiveness, (A) Figlative transforming growth factor bets induced (TGFE) expression of mesenctiymal transfomed bestst cancer cell lines compared to non-imaske controls was assessed using real-tme quartitative PCA. Data repreeent mean = SEM. Using unpared, two-taied t-1est analysis. MCF-7-EMT $n=3$; T47D-EMT n $=6 ; \cdots p<0.0005 ; \cdots+P<0.0001$ (B) Relative E-condherin oxpression of mesenchinmal trareformed beast cancer cell ines bormoared to non imvasive controks ivas assessed using roal-tme quartitative PCF. Data represent mean = SEM. Using unpared, two-taled t-test malysis. MCF-7-EMT $n=4$ : TA7D-EMT $n$ $=3 ; * P<0.05 ; *+* P<0.0001$ (C) Hesative Vimentin expression of mesenchymal fransformed breast cancer cell ines compared to non-hwasive controls was aseassed using real-tme quantitative PCR. Deta represent mean \pm SEM. Using unpaired, twa-tailed t-t0es analysis. MCF.7.EMT $n=5 ;$ T47D.EMT $n=3 ; * P<$ Q.05 (D) Felative Zeb1 expression of mesenchyms traneformed breast cancer cel lines compared to non-irvasive controls was assessed using real-time quanttative PCR. Data represent mean \pm SEM. Using unpaired, two-tailed $t$-test analygis, MCF-7-EMT $n=4 ;$ T47D-EMT $n=3 ;{ }^{*} P<0.05$ (E) Raiative SNAI1 expression of mesenchymal frarsformad breast canoser onil lnes Dorroared to non-inwasive controls was assessed using real-time cuartitative $\mathrm{PCR}$. Data represent mean = SEM. Using unpared, two-taled $f$-test analysis. MCF-7-EMT $n=4$; TA7D-EMT $=5 ; * P<0.0005$ (F) Pelative SNAR2 expression of mesenchymal transformes breast cancer cell ines compared to non-invasive controls was assessed uaing real-time quartitative PCA. Data represent mean \pm SEM. Using inpared, two-tailed $t$-test analyos. MCF-7-EMT $n=3$ : T47D-EMT $n=4:{ }^{*} P<0.05$.

Figure S2 | CYA61 expression correlates with breast cencer cell irwasivenesg. (A) Pielative CYF31 expression $96 \mathrm{~h}$ affer trunsient CYF31 sFNA transfoction compared to contral was asseesed using real-Ime quantitative PCR. Data tepresent meen \pm SEM. Using uroaired, fwo-taled t-test anakss. MCF- $\gamma$-EMT $n$ $=8 ;$ TA7D-EMT $n=7 ;$ MDA-MB-231 $n=3 ;$ HCC1806 $n=4 ; * P<0.01$;

\section{REFERENCES}

1. Nonne AM, Howlader N, Krapcho M, Meller D, Brest A, Ya M, et al. (eds.). SEER Cancer Statistics Review, 1975-2015. Bethesda, MDE National Cancer Institute. Avaibble online at: hitps//seer.cancer.gov/css/1975_2015/ (accessed September 10, 20:8). $\cdots P<0,0001$ (B) Aralysas of rolative Alaviar Bue reduction as indicator for coll visbilty. Transient transfected bresst cancer cel sphercids were grown anc Alamarblue reduction was assesaed 48 hours after adding Matrigel at $4 \mathrm{~B}$ ncubation. Felative AlsmerBlive reduction wiss calculated compared to contro spheroids, Deta represent mean \pm SEM, $n=3$ (C) Analysis of redative AlarrarBue reduction as indicator for coll viabilty. Brast cancer coll sphervicks ware grown and Alarnarblue reduction was asseeseed $48 \mathrm{~h}$ afler adcing Matrigel and $\mathrm{f} \mu \mathrm{g} / \mathrm{mi}$ theYpst at $4 \mathrm{~h}$ incubation. Redative. Alamartiue reduction was caiculated compared to control sphercide. Deta represent mean \pm SEM. $n=3$.

Figure S3 | Suppression of CYA61 reduces S100A4 expression. (A) Immanobiot

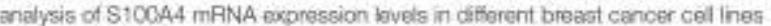
$96 \mathrm{~h}$ after $\$ 10044$ siRNA iransfection was cetected ising westem bioting. Oate represert mean \pm SEM. Using unpsired, two-taliad $t$-test anslysis, MCF-7-EMT $n$ $=4:$ T47D-EMT $n=4$ : MDA-NE-231 $n=3 ;$ HOC1806 $n=3 ; \cdot p<0.05 ; * P<$ $0.01 ; \cdots P<0.005$ (B) Recresentative experiments of S100A4 protein expression quantification corresponding to (A). (C) STO0A4 MPNA expression analysis $96 \mathrm{~h}$ after siFNA transfection ising cuantiativo PCA. Date represant moan \pm SEM. Using unpaired, two-tailad $t$-test anatysis. MCF-7.EMT $n=4$ :T470-EMT $n=4$ :

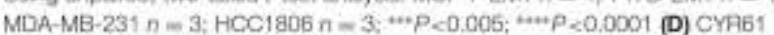
mPNA expression analysis $96 \mathrm{~h}$ after $\$ 100 \mathrm{~A} 4$ siFNA transfection using quantitative PCA. Date represent mean \pm SEM. MCF-7-EMT $n=5$; TA7D-EMT $n=6$; MDA-MB-231 $n=3 ;$ HCC18C6 $n=3$ (E) Analysis of redative Alamarblue reduction as incicator for cel viablity. Breast cancer cell spheroids transient transfected with S100A4 sPNA were gown and Alamarelue reduction was assessed $4 \mathrm{~d} h$ ater edding Matrigel of $4 \mathrm{~h}$ incibation, Pelative Alamarlive reduction was calculated compared to control sphercids, Data represent mean \pm SEM. $n=3$

Figure $\$ 4$ | ERKK1/2 activity is transchucer of CYA61 madiated S100A4 reggulaticn, (A) ERK $1 / 2$ and p-Erk1/2 (Thr202/Tyr204) excoression in different breast oancer Del ines with or without 10 a M Uor26 trestrnent detectod by westem blotting. (B) EFK1/2 and p-Erkt/2 (Thr202/Tyt204) expression in non-irwasive trasst cancer cel ines with or without $1 \mu \mathrm{g} / \mathrm{mi}$ incYhol treatment detected by weetem biotting-

Figure S5 | Suppression of YAP redices invasiveness through blocking CYA61-StCOA4-pERiK1/2 signaling. (A) Relative YAP expression 98 h after transient YAP a FNA transfection compered to control was assessed using real-fime quantitative PCR. Data repcesent mean \pm SEM. Using unpairod, two-talied t-teat ansives's. MCF-7-EMT $n=5$; T47D-EMT $n=3$; MDA-MB-231 $n$ $=3 ;$ HCC1806 $n=3 ; * P<0.05 ; * P<0.01 ; * \cdots P<0.001$ (B) Analysis of relative Alamer Blue reduction as indicator for cel vability. Breast cancer cel spheroids were grown and AlamarBlue reduction wass assessed 48 hours after adding Matrigel at 4 h hcibation, Ralative Alarmerelis reduction was caloulated corrpared to control spharcids. Deta represent mean \pm SEM. $n=3$

Figure S6 I CYF61 and S100A4 as prognostic marker for breast cancer progreseson. Ou-oft values ware downioaded trom kmplotcom ahter targat (dateret 213226_at $=$ CYR61; dataset 203186___at $=$ S100A4) specific anabysis. AFS, redapse free survival; DMFS, distant metastasis tree survival.

Figure \$7 CYA61 and S1OCA4 are highly expressed in invasive and mecastatic B cancer patient tigeve samples. Expression analysis of CYF61 and $\$ 100 \mathrm{AA}$ va fluorescence staining using biomex tissue artyrs (BR 20837,BR 248a, TOB7a) wth paraffin-ambedided patient sarnples. Table shows Artaytyp of anolyzed samples, pationts ago, sex, the crganic tissue site, pathology diagnosis, clasestication of $M$ tumors (TNM), grading, stage, typ, tisse 10 and bor most analyzed tised the xpression of estrogenfEF, progesteran (PF) and Herceptinreceptor2 (Her2). Expression of CYR61 and \$100A4 was assessed as $(-)$ not expressed, $(t)$ low expressior, $1++)$ medium expression, $(+++)$ high expression.
2. Gupta GR, Massague 3. Cancer metsstasis building a framework. Cell (2006) 1276679-95, doi: 10.1016/j_cell.2006.11.001

3. Hanahan D. Weinberg RA. Hallmarks of cancer the next generation. Cell. (2011) 144:646-74. doi: 10.1016/j.cell 2011.02.,113

4. Brabletz T, Kalluri R, Nieto MA, Weinbert RA. Emt in cascer. Nat Rev Cancer. (2018) 18:128-34. doin 10.1038/nrci.2017.118 
5. Van Staalduinen 1. Baker D, Ten Dijke P, Van Dam H. Epithelialmesenchymal-transition-inducing transcription factors new targets for fackling chemoresistance in cancer? Oncogene. (2018) 37.6195-211, doi: 10.103\%/44138t-018-037k-x

6. Fischer KR, Durrans A, Lee S, Sheng J, L F, Wong ST, et al. Epitheliai-tomenenchynal transition is not required for lung metastasis but contributes to chemoresistance, Nature, (2015) 527:472-6, doi: 10.1038/nature 15748

7. Tran HD, Luitel K, Kim M, Zhang K, Longmore GD, Tran DD. Transient inaill expression is necessary for mefastatic competence in breast cancer. Cuncer Res. (2014) 74.6330-41. doit 10.1158/0008-5472.CAN-14-0923

8. Ye X. Brabletz T, Kang Y Longmore GD, Nieto MA. Stanger BZ, et al. Upholding A role for emt in breast cancer metastasis, Nature; (2017) 547:EIF3, doi: 10.1038/nature22816

9. Garg M. Ipithelial, mesenchymal and hybrid epithelial/mesenchymal phenotypes and their clinical relevance in cancer metastasis. Expert Rev Mol Med. (2017) 19:E3. dot 10.1017/erm.2017.6

10. Simeone P. Trerotola M. Franck I. Tristan C. Fournier I. Salzet M, et al The multiverse sature of epithelial to mesenchymal transition. In: Vincent T. editor. Seminars in Cancer Biology. London: Academic Press Ltd-Elsevier Science Ltd (2018).

11. Kim YN, Choe SR, Cho KH, Cho DY, Kang I, Park CG, et al Resveratrol suppresses breast cancer cell invasion by inactivating $\mathrm{A}$ Rhoa/yap signaling axis. Exp Mol Met. (2017) 49.E296. dot: 10.1034/emm.2016.151

12. Hou CH, Lin L.L. Hou SM, Lu LF. Cyr6s promotes epithelialmesenchymal transitionand tumor metastasis of osteosarcoma byraf. 1/Mtek/E.rk/Elk-1/Twist-1 segnaling pathway. Mol Cancer. (2014) 13:13. doi: 10.11 $186 \sqrt{1476-4598-13-236}$

13. Haque I. Mehta S, Majumder $M$, Dhar $K$, De A, Mcgregor D, it al, Cyr61/Cenl signaling is critical for cpithelial-mesenchymal transition and stemness and promotes parscreatic carcinogenesis. Mol Cancer. (2011) 10.8 doi: $10.1186 / 1476-4598-10-8$

14. Huang X, Xiang L, Li Y, Zhoo Y, Zhu H, Xiao Y, et al, Snail/Foxk1/Cyrs signaling axis regulates the epithelial-mesenchymal transition and metastasis in codorectal cancer. Cell Physiol Biochem. (2018) 47:590-603, dot: $10.1159 / 000490015$

15. Tsai M-S, Bogart DF, Castanieda IM, L R. Lupu R. Cyról promotes breast tumorigenesis and cancer progression. Oncogene. (2002) 21:8178. doi: 10.1038/sj.onc.1205682

16. Huang HT, Lan Q, Lorusso G, Duffey N, Rugg C. The matricellutar protein Cyr61 promotes breast cancer lung metastasis by facilitating tumor cell extravasation and suppressing anoikis. Oncolarget. (2017) 8:16, doi: 10.18632/oncotarget. 13677

17. Tong X. Xie D, O'kelly L, Miller CW, Muller-Tidow C, Koefller HP. Cyró1, A member of Cen family, is A furnor suppressar in non-small cell lung cancer.) Bint Chem. (2001) 27647709-14. doi: 10.1024/jbc.M107878200

18. Iun IT, Lau LF. The matricellular protein $\mathrm{Ccnl}$ indaces fibroblast senescence and restricts fibrosis in cutaneous wound healing. Nat Cell Biol. (2010) 12:676-85, dot 10.1038/ncb2070

19. Todorowic V, Chen CC, Hay N, Lau LF. The matrix protein Cant (Cyr61) induces apoptosis in fibroblasts $/$ Cell Biol. (2005) 171.559-6s. doi: 10.1083/jcb.200S44015

20. Ziegler E, Hansen MT, Haase M, Imons. G, Grundker C. Generatian of Mef.7 cells with aggressive metastatic potential in vitro and in vimo. Brast Canct Res Treat f2014) 148:260-77, doi: 10.1007/s10549-014-3159-4

21. Voe Alten f. Fister S, Schulz H, Viereck V, Frosch KH, Emons G, et aL. Girh analog reduce invasiveness of human breast cancer cells. Hraast Cancer Re Treat (2006) 100:13 21, doi: 10.1007/st1549-606-9222-2

22. Vinci $M$, Box $C$, Eccles SA. Three- dimensional (3D) tumor sphervid invasion assay, I Vis Exp. (2015) e52686. doi: 10.3791/52686

23. Grundker $\mathrm{C}$. Baserschmitz G, Schubert A. Emons $G$. Invasion and increased expression of $5100 \mathrm{n} 4$ and Cyr61 in mesenchymal transformed breast cancer cells is downregulated By Ginh. Int J Oncol. (2016) 48:2713-21, doi: $10.3892 /$ ija. 2016.3491

24. Gyorffy B, Lancrky A, Fklund AC, Denkert C, Budezies $1,1 . \mathrm{Q}$, et al. An online survival analysis tool to rapidly assess the effect of 22,277 genes on breas cancer prognosis using microarray data of 1,809 putients. Breast Cancer Res Truat (2010) 123725-31. doit 10.1007/s10549-009-0674-9
25. Chen A. Wang L Li BY, Sherman J, Ryu IE, Hamamura K, et al. Reduction in migratary phenotype in a metastasized hreast cancer cell line vie downregulation of \$100a4 and Grm3. Sd Rep. (2017) 7:3459. dot $10.1038 / 541598-017-03811-9$

26. Chen PS, Wang MY, Wu SN, Su IL, Hong CC, Chuang SE, et al. Ctgf enhances the motility of breast cancer cells via an integrin-r vils-Erkt/2dependent S100a4-upregulated pathway. I Cell Sci. (2007) 120:2053-65. doi $10.1242 / j \mathrm{cs} 03460$

27. Jim Leu S-I, Sung I-S, Huang M-L, Chea M-Y, Tsai T-W. A novel anti-Cenl monostonal antibody suppresses Rac-dependent cytoskeletal reorganizatikn and utigratory activities in breast cancer erlls, Biodiem Biophy Res Commum. (2013) 434:885-91. doi: 10.1016/i,bbre.2013,04.045

28. Shaul YD, Seger R. The Mek/Erk cascader from signaling specificity to diverse functions. Aliochim at Biophys Acfa Mal Cell Res. (2007) 1773:1213-26. doi: $10.1016 /$ j, bbamer. 2006, 10.005

29. Favata MF, Horiuchi KY, Manos ET, Diulerio Al, Stradley DA, Feeser WS, et al. Identification of $A$ novel inhibitor of mitogen-activated protein kinase kinase I Biol Chen. (1998) 273;18623-32, doi: 10.1074/5bc.273.29.18623

30. Shen 1. Cao B, Wang Y, Ma C. Zeng Z Liu L. et al. Hippo component yap promotes focal adtiesion and tumour aggressiveness via transcriptionally activating Thbs $1 /$ fak signalling in breast cancer. I Exp Ciin Cancer Res Cr. (2018) 37:175-175. doi: 10.1186/s130-46-018-0850-8.

31. Emse $Y$, Imhof BA. Matricellular protein Cenl/Cyrol: a newe player in inflammation and leckocyte trafficking Semin ImmunopathoL \{2014) 36:2539. doi: $10.1007 /$ s00281-014-0420-1

32. Bornstein P. Matricellalar proteins: an overview. I Cell Commun Signal. (2009) 3:163-5, doi: 10.1007/s12079-009-0069-2

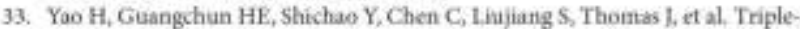
negative breast cancer: is there a treatment an the horizon? Oncafarget. (2016) 8:12, doi: 10.18632/oncotarget. 12284

34. Xie D, Nakachi K. Wang H. Elashoff R, Koefler HP. Elevated lewels of connective tissue growth factor, WISP-1, and CYR61 in primary breast cancers associated with more advanced features, Cancer Res. (2001) 61:8917-23.

35. Nieta MA. Context-specific roles of emt programmes in cancer cell dissemination. Nat Cell Biol, \{2017) 19:416-8. doi: 10.103B/ncb3524

36. Jenkinson SR, Barraclough R, West CR, Rudland PS S100a4 regulates cell motility and invasion in an in vitro model for breaut cancer metastasis. Br I Cancer. (2004) 90:293-62. doi: 10.1038/sj,bjc.6601483

37. Maity G, Ghosh A, Gupta VG, Haque 1, Sarkar S, Das A, et al Cyrot/Ccnl regulates Dok And Ctgf and causes gemcitabine resistant phenotype in pancreatic ductal adenocarcinoma. Mol Ciancer Therapent Molcanther. (2019) 0499:2018, doin 10.1158/1535-7163.MCT-18-0899

38. Long X, Yu X, Perlaky L, Man T-K, Redell MS, Stromal Cyr61 confers resistance to mitoxantrone via spleen tyrosine kinase activation in human acute mycloid leukaemia. Dr I Hatematol. (2015) 170:704-18. doi: $10.1111 /$ bih. 13492

39. Liu $F$, Yang $X$, Geng $M$, Huang $M$. Turgeting Eirk, an achilles' heel of the mapk pathway, in cancer therapy. Acta Pharmaceat $\operatorname{Sin} B$. (2018) 8:552-62. doE 10.1016ij.apsb. 2018.01 .008

40. Boupathy GTK. Hong W. Role of hippo pathway-Yap/Taz signaling in angiogenexis. Front Cell Dev Bjöl (2019) 7:49 doi 10.3389/foell.2019. 00049

41. Haldet G, Johnson RL. Hippo signaling growth control and beyond. Dexiopment. (2011) 138:9-22 doi: 10.1242/dev.0 45,500

42. Pan D. The hippo signaling pathway in developenent and cancer, Dev Cell. (2010) 19:491-505, doi: 10.1016/1.devcel 2010.09.011

43. Cas L, Sun PL, Yao M, Iia M, Gao H. Expression of yes associated protein (Yap) and its clinical significance in breast cancer tissues. Hum Puthol (2017) 68:166-74, doit 10.1016/7.humpath.2017,08.032

44. Warren ISA, Xiao $\mathrm{Y}$, Lamar IM. Yap/Taz activation as a target for treating metastatic cancer, Cancers: (2018) 10:E115, doi: 10,3390/cancersioo 40115

45. Mayer S, Gabriel D, Erbes T, Timme-Bronsert S, Jager M, Rucker G. et al. Cyr61 expression pantern and association with dinicopathological factors in patients with cervical cancer. Anticancer Res. (2017) 37:2451-6. dot 10.21873/anticanres, 11585 
46. Wei L. Yu G. Shao G. Sun A. Chen M. Yang W, et al. Cyre1 (Cen1) is a metastatic hicamarker of gastric cardia adenocarcinoma. Oncotarget. (2016) 7:31067-78. doi: 10.18632/ oncotarget $88-45$

47. Destek S, Gul Vo. Sto0a4 may be a good prognostic marker and a therapeutic target for colion cancer. / Oncol (2018) 2018:1828791. doi: 10.1155/2013/18 28791

48. Ai KX, Lu LY. Huang XY, Chen IV, Zhang HZ Prognostic siqnificance of \$100as and vasculat endothelial growth factor expression in pancreatic cancer. Worfd / Gastroenterol, (2008) 14:1931-5, dois 10.3748/wjg, ! 4,1931

49. Fgeland EV, Boye K. Park D, Synnestvedt M, Sauer T, Oslo Breast Cancer $C$, et al. Prognostic significance of Sto0u4-expression and subcellular localization in early-stage breast cancer. Brast Crncer Res Traat. (2017) 162:127-37, doi: 10,1007/s10549-0164096-1

50. Monnier Y. Farmer P. Bieler G, Imaizumi N, Sengstag T, Alghisi GC, et al. Cyr6i and alphavbetas integrin cooperate to promote invasion and metastasis of tumors growing in preirradiated stroma. Cancer Rex (2008) 68:7323-31. doi: 10.1158/0008-5472.CAN-0s-0841

51. Kassis IN, Virador VM, Guancial EA, Kimm D, Ho AS Mishra M, et al Genomic and phenotypic analysas reveals A key role for Cenl (Cyr61) In bag3-modulated adhesion and invasion. / Pathol. (2009) 218495-504. doi: 10.1002/path.2557

Conflict of Interest: The authors declare that the tesarch was conducted in the absence of any commercial or financial reiationships that could be coastrued as a potential contlict of interest.

Copyright o 2019 Hellinger, Hëchel, Goete, Baaerschnits, Emens and Gründket. This is an open-dccess article distributed under the ferms of the Creative Commons Attribution License (CC BY). The use, distrithution or reproduction in ofher forums is permitted, provided the original author(s) and the copyright owner(s) are credited itent that the ariginal publication in this journal is cited, in acrardance with accepted arademic practice. Na se, distribution ar reproduction is permitted whide does not campily with these terms. 


\section{Supplementary Material}

The Supplementary Material for this article can be found online at: https://www.frontiersin.org/articles/10.3389/fonc.2019.01074/full\#supplementary-material

A

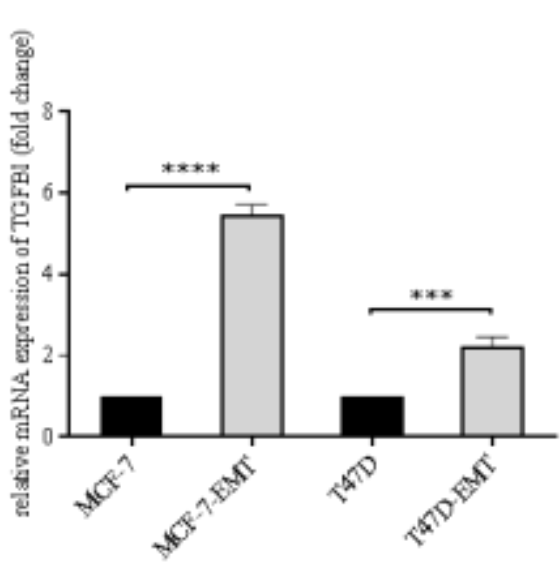

$\mathrm{C}$

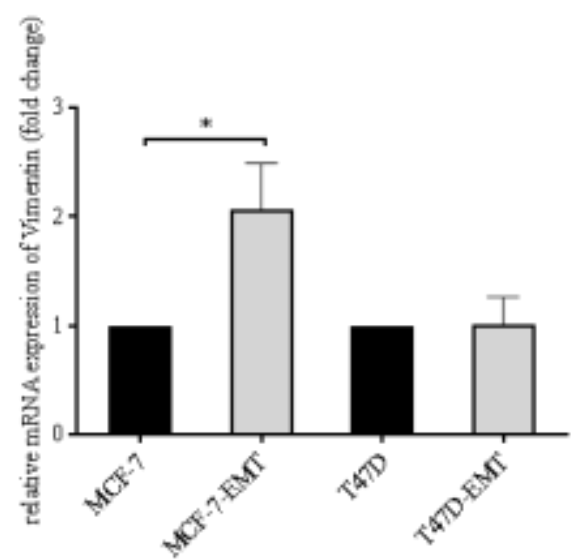

$\mathrm{E}$

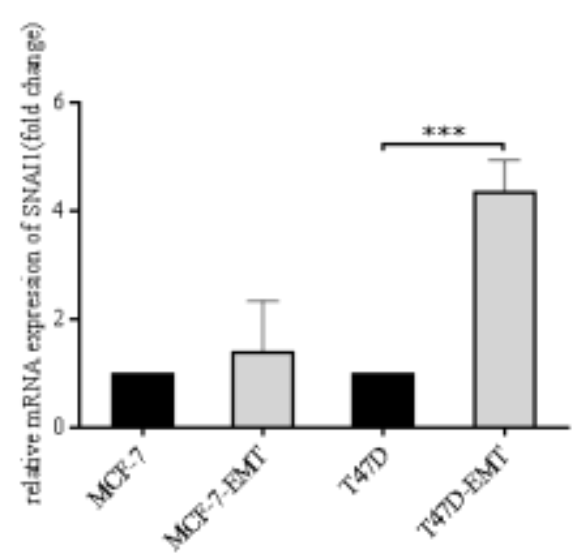

B

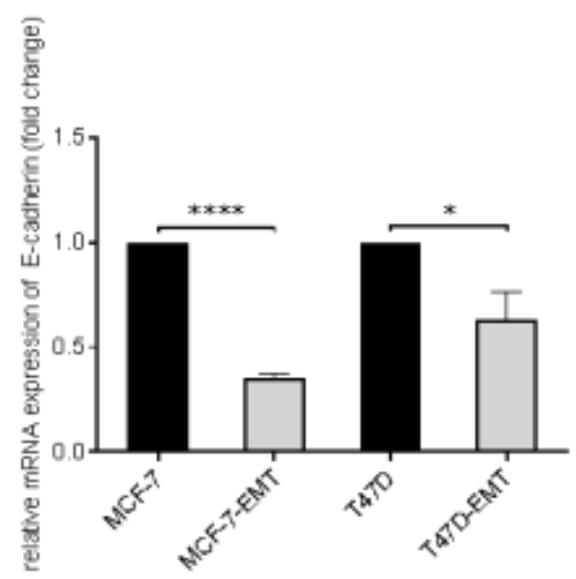

$\mathrm{D}$

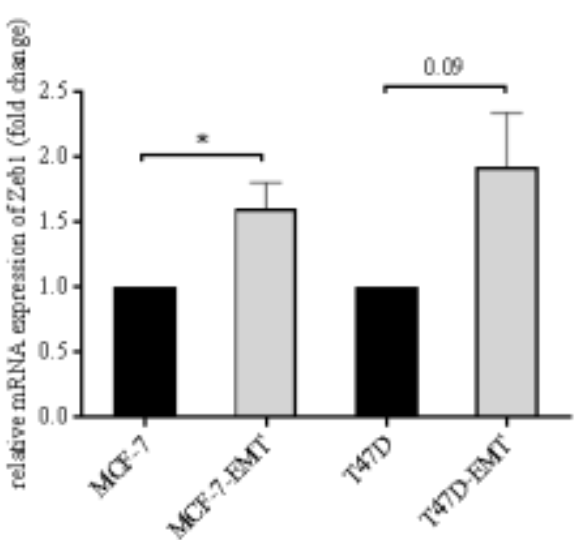

$\mathrm{F}$

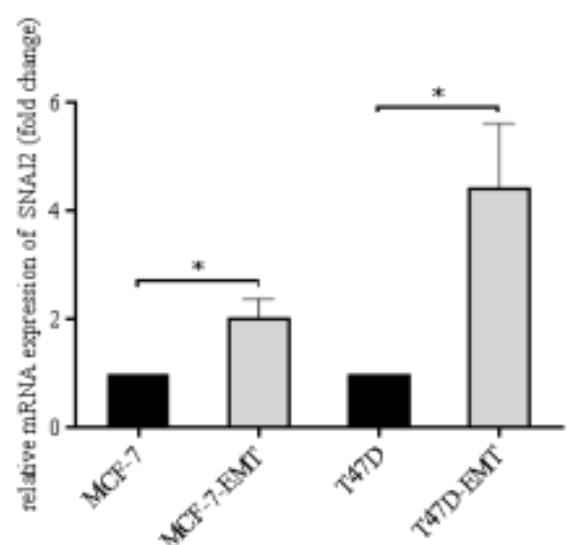

Figure S1. CYR61 expression correlates with breast cancer cell invasiveness. (A) Relative transforming growth factor beta induced (TGFBI) expression of mesenchymal transformed breast cancer cell lines compared to non-invasive controls was assessed using real-time quantitative PCR. Data represent mean \pm SEM. Using unpaired, two-tailed $t$-test analysis. MCF-7-EMT $n=3$; T47D-EMT $n=6 ;{ }^{* * * *} P<0.0005 ;{ }^{* * * * *} P<$ 0.0001 (B) Relative E-cadherin expression of mesenchymal transformed breast cancer cell lines compared to non-invasive controls was assessed using real-time quantitative PCR. Data represent mean \pm SEM. Using unpaired, two-tailed $t$-test analysis. MCF-7-EMT $n=4$; T47D-EMT $n=3$; ${ }^{*} P<0.05$; ${ }^{* * * *} P<0.0001$ (C) Relative Vimentin expression of mesenchymal transformed breast cancer cell lines compared to non-invasive controls was assessed using real-time quantitative PCR. Data represent mean \pm SEM. Using unpaired, two-tailed $t$-test analysis. MCF-7-EMT $n$ $=5$; T47D-EMT $n=3 ;{ }^{*} P<0.05$ (D) Relative Zeb1 expression of mesenchymal transformed breast cancer cell lines compared to non-invasive controls was assessed using real-time quantitative PCR. Data represent mean \pm SEM. Using unpaired, two-tailed $t$-test analysis. MCF-7-EMT $n$ $=4$; T47D-EMT $n=3 ;{ }^{*} P<0.05$ (E) Relative SNAI1 expression of mesenchymal transformed breast cancer cell lines compared to non-invasive 
controls was assessed using real-time quantitative PCR. Data represent mean \pm SEM. Using unpaired, two-tailed $t$-test analysis. MCF-7-EMT $n$ $=4$; T47D-EMT $n=5 ;{ }^{* * *} P<0.0005$ (F) Relative SNAI2 expression of mesenchymal transformed breast cancer cell lines compared to noninvasive controls was assessed using real-time quantitative PCR. Data represent mean \pm SEM. Using unpaired, two-tailed $t$-test analysis. MCF7-EMT $n=3$; T47D-EMT $n=4 ;{ }^{*} P<0.05$.
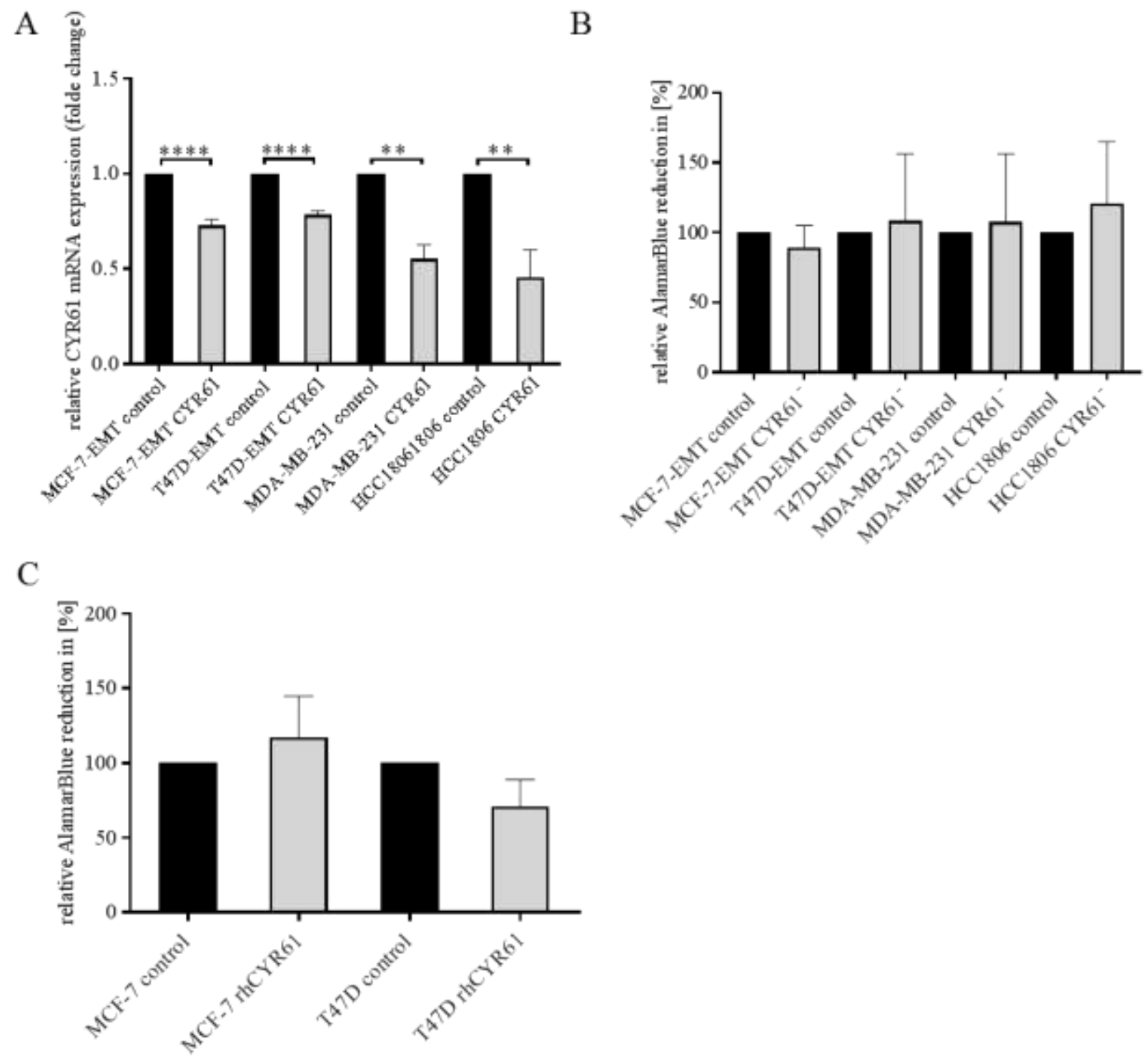

Figure S2. CYR61 expression correlates with breast cancer cell invasiveness. (A) Relative CYR61 expression $96 \mathrm{~h}$ after transient CYR61 siRNA transfection compared to control was assessed using real-time quantitative PCR. Data represent mean \pm SEM. Using unpaired, two-tailed $t$-test analysis. MCF-7-EMT $n=8$; T47D-EMT $n=7$; MDA-MB-231 $n=3$; HCC1806 $n=4 ;{ }^{* * *} P<0.01$; ${ }^{* * *} P<0.0001$ (B) Analysis of relative AlamarBlue reduction as indicator for cell viability. Transient transfected breast cancer cell spheroids were grown and AlamarBlue reduction was assessed 48 hours after adding Matrigel at $4 \mathrm{~h}$ incubation. Relative AlamarBlue reduction was calculated compared to control spheroids. Data represent mean \pm SEM. $n=3$ (C) Analysis of relative AlamarBlue reduction as indicator for cell viability. Breast cancer cell spheroids were grown and AlamarBlue reduction was assessed $48 \mathrm{~h}$ after adding Matrigel and $1 \mu \mathrm{g} / \mathrm{ml} \mathrm{rhCYR61} \mathrm{at} 4 \mathrm{~h}$ incubation. Relative AlamarBlue reduction was calculated compared to control spheroids. Data represent mean \pm SEM. $n=3$. 


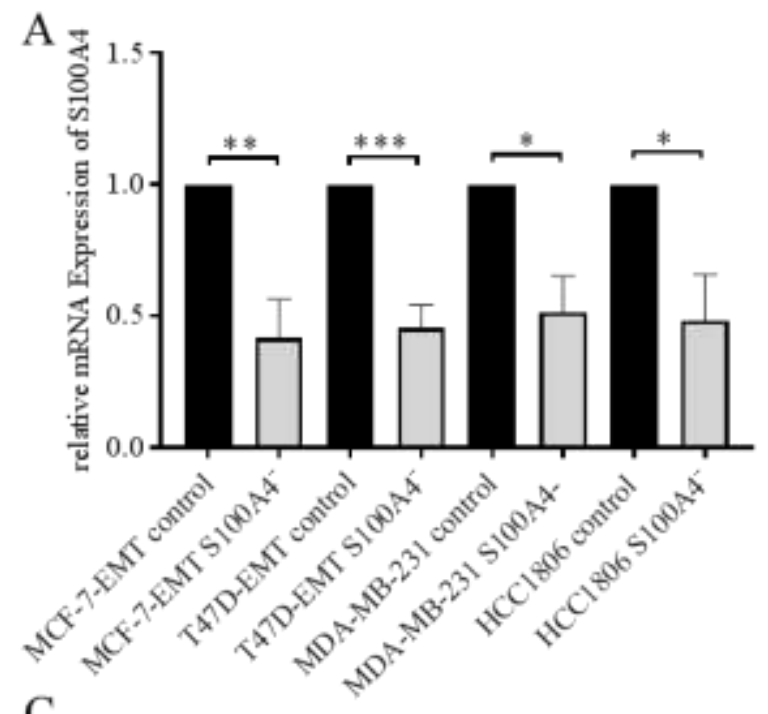

B
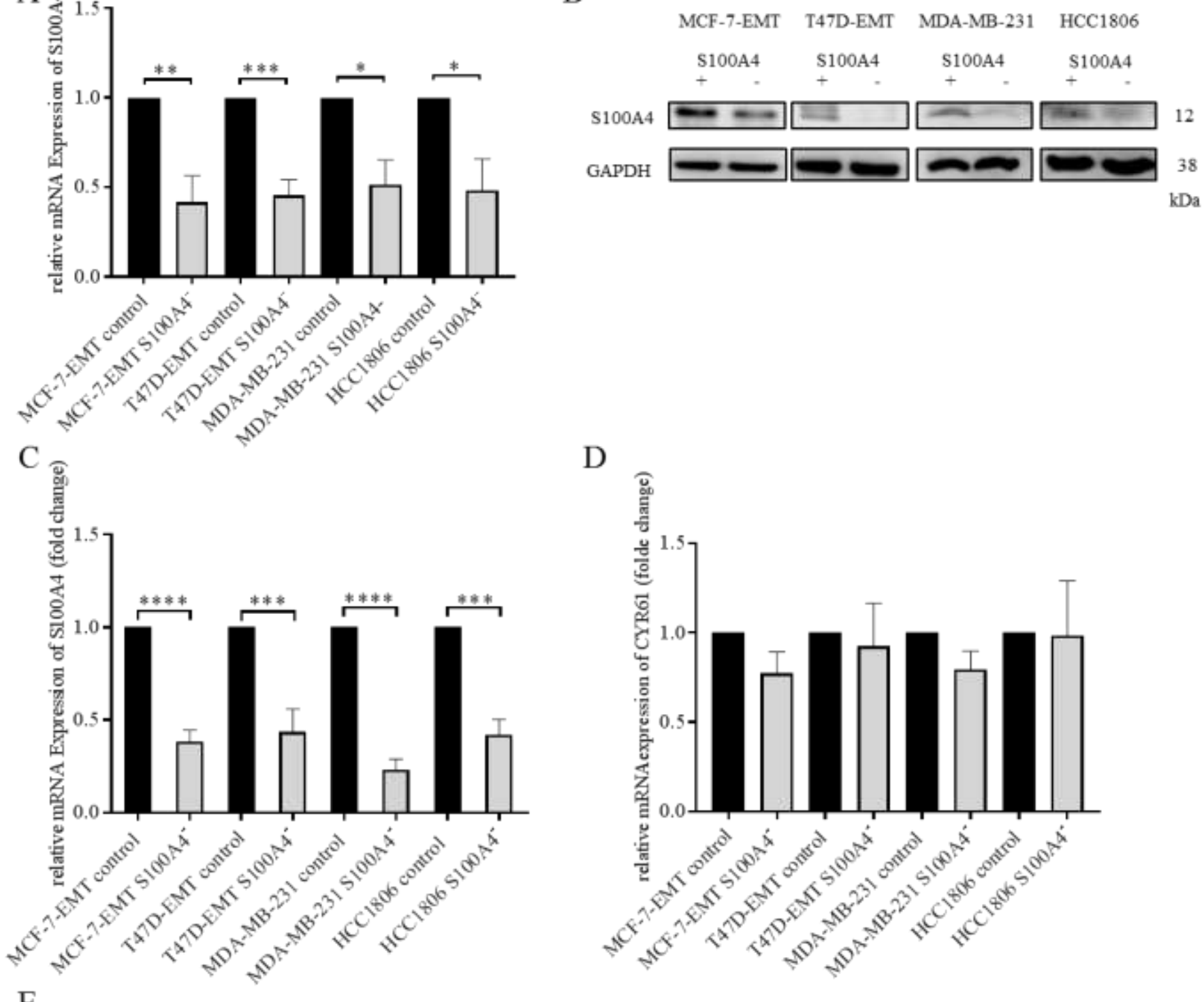

$\mathrm{D}$
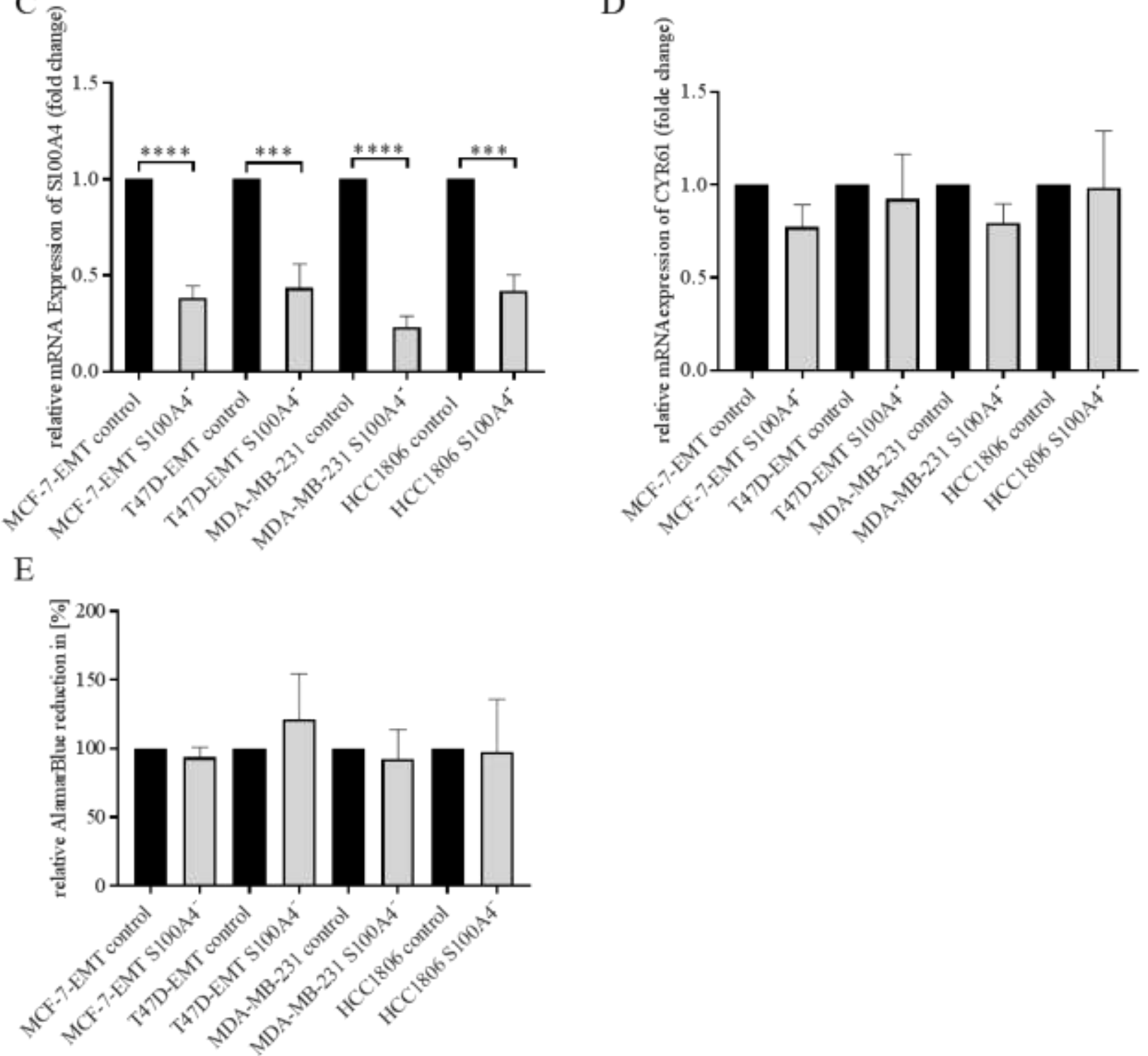

Figure S3. Suppression of CYR61 reduces S100A4 expression. (A) Immunoblot analysis of S100A4 mRNA expression levels in different breast cancer cell lines $96 \mathrm{~h}$ after S100A4 siRNA transfection was detected using western blotting. Date represent mean \pm SEM. Using unpaired, twotailed $t$-test analysis. MCF-7-EMT $n=4$; T47D-EMT $n=4$; MDA-MB-231 $n=3$; HCC1806 $n=3 ;{ }^{*} P<0.05 ;{ }^{* * *} P<0.01$; ${ }^{* * * *} P<0.005(\mathbf{B})$ Representative experiments of S100A4 protein expression quantification corresponding to (A). (C) S100A4 mRNA expression analysis $96 \mathrm{~h}$ after siRNA transfection using quantitative PCR. Date represent mean \pm SEM. Using unpaired, two-tailed $t$-test analysis. MCF-7-EMT $n=4$; T47D-EMT $n=4$; MDA-MB-231 $n=3$; HCC1806 $n=3 ;{ }^{* * *} P<0.005 ;{ }^{* * * *} P<0.0001$ (D) CYR61 mRNA expression analysis $96 \mathrm{~h}$ after 
S100A4 siRNA transfection using quantitative PCR. Date represent mean \pm SEM. MCF-7-EMT $n=5$; T47D-EMT $n=6$; MDA-MB-231 $n=3$; HCC1806 $n=3$ (E) Analysis of relative AlamarBlue reduction as indicator for cell viability. Breast cancer cell spheroids transient transfected with S100A4 siRNA were grown and AlamarBlue reduction was assessed $48 \mathrm{~h}$ after adding Matrigel at $4 \mathrm{~h}$ incubation. Relative AlamarBlue reduction was calculated compared to control spheroids. Data represent mean \pm SEM. $n=3$.
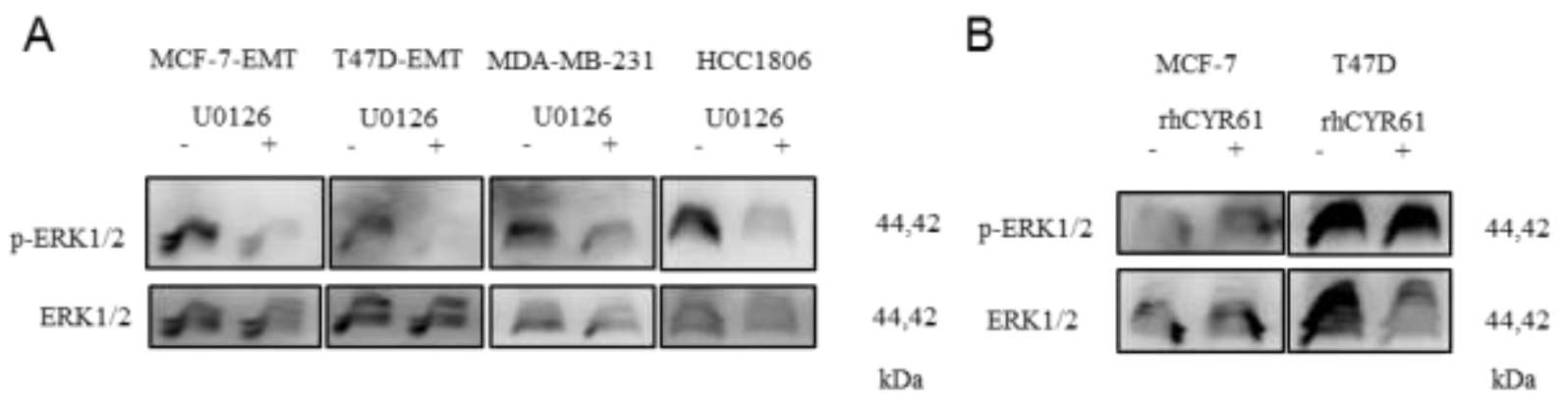

Figure S4. ERK1/2 activity is transducer of CYR61 mediated S100A4 regulation. (A) ERK1/2 and p-Erk1/2 (Thr202/Tyr204) expression in different breast cancer cell lines with or without $10 \mu \mathrm{M}$ U0126 treatment detected by western blotting. (B) ERK1/2 and p-Erk1/2

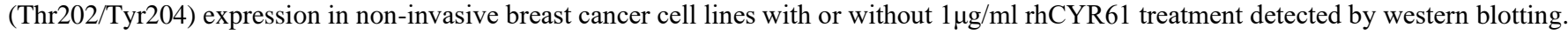
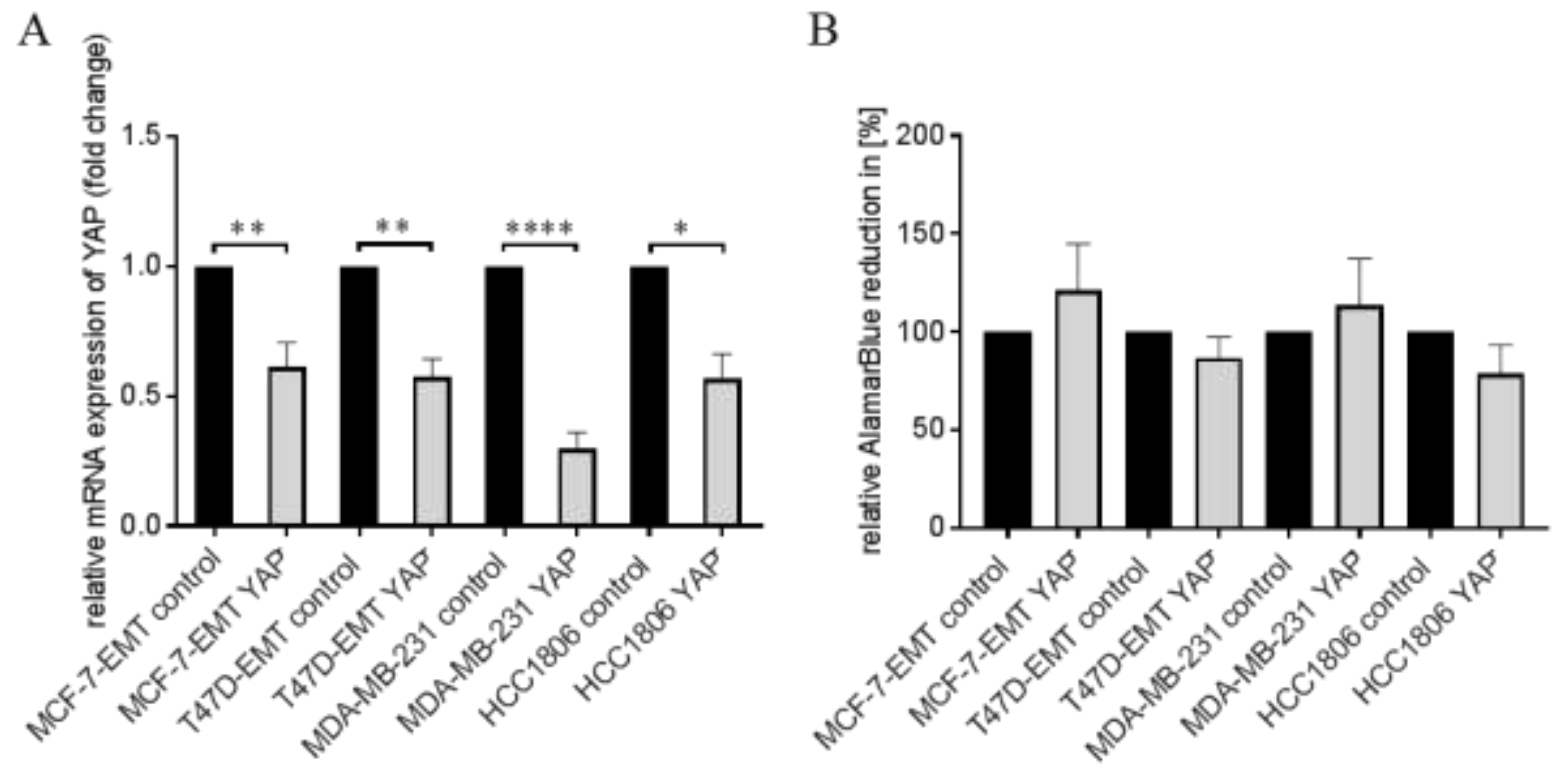

Figure S5. Suppression of YAP reduces invasiveness through blocking CYR61-S100A4-pERK1/2 signaling. (A) Relative YAP expression $96 \mathrm{~h}$ after transient YAP siRNA transfection compared to control was assessed using real-time quantitative PCR. Data represent mean \pm SEM. Using unpaired, two-tailed $t$-test analysis. MCF-7-EMT $n=5$; T47D-EMT $n=3$; MDA-MB-231 $n=3$; HCC1806 $n=3 ;{ }^{*} P<0.05 ;{ }^{* * *} P<0.01$; ${ }^{* * * * *} P<$ 0.001 (B) Analysis of relative AlamarBlue reduction as indicator for cell viability. Breast cancer cell spheroids were grown and AlamarBlue reduction was assessed 48 hours after adding Matrigel at $4 \mathrm{~h}$ incubation. Relative AlamarBlue reduction was calculated compared to control spheroids. Data represent mean \pm SEM. $n=3$.

Table S6. CYR61 and S100A4 as prognostic markers for breast cancer progression. Cut-off values were downloaded from kmplot.com after target (dataset 213226_at = CYR61; dataset 203186_s_at = S100A4) specific analysis. RFS, relapse free survival; DMFS, distant metastasis free survival.

\begin{tabular}{|l|l|l|l|}
\hline RFS, 213226_at & RFS,203186_s_at & DMFS, 213226_at & DMFS,203186_s_at \\
\hline "cutoff value" "p value" & "cutoff value" "p value" & "cutoff value" "p value" & "cutoff value" "p value" \\
\hline $2361.19562075974189 e-05$ & 17240.215266077871679 & $2415.66603372054164 \mathrm{e}-06$ & 17200.0851389129703291 \\
\hline $2379.16064789491244 \mathrm{e}-06$ & 17260.191509442365171 & $2434.29158303050237 \mathrm{e}-06$ & 17300.0762015647592793 \\
\hline $2371.31517158498129 \mathrm{e}-05$ & 17300.215326922690825 & $2443.03409633506391 \mathrm{e}-06$ & 17370.0673434160590155 \\
\hline $2371.03268303958126 \mathrm{e}-05$ & 17330.199535025397062 & $2452.20617246315946 \mathrm{e}-06$ & 17470.0556060355003921 \\
\hline $2371.00797209752201 \mathrm{e}-05$ & 17370.186083604474143 & $2464.43337966471447 \mathrm{e}-06$ & 17480.087933906857383 \\
\hline
\end{tabular}




\begin{tabular}{|c|c|c|c|}
\hline $2381.57871180219704 \mathrm{e}-05$ & 17380.165469954866447 & $2471.00878139384086 \mathrm{e}-05$ & 17560.0752060763965201 \\
\hline $2391.3133087896966 \mathrm{e}-05$ & 17430.196401432280997 & $2497.66093542547974 \mathrm{e}-06$ & 17600.0684295279604519 \\
\hline $2402.04982598729364 \mathrm{e}-05$ & 17440.229162350068697 & $2495.8403632995363 \mathrm{e}-06$ & 17610.058187868026223 \\
\hline $2401.82132154802339 \mathrm{e}-05$ & 17460.271702917719659 & $2504.06173852962599 \mathrm{e}-06$ & 17770.0513550586893096 \\
\hline $2412.92356093257728 \mathrm{e}-05$ & 17470.306719419607372 & $2513.25679224266739 \mathrm{e}-06$ & 17890.0416604122418941 \\
\hline $2412.31493902208557 \mathrm{e}-05$ & 17480.359338656499993 & $2512.44171086549727 \mathrm{e}-06$ & 17900.0363794114545782 \\
\hline $2411.76178184373432 \mathrm{e}-05$ & 17540.33247013388508 & $2511.70432254920083 \mathrm{e}-06$ & 17920.0292419343852079 \\
\hline $2431.33655356101547 \mathrm{e}-05$ & 17560.30867274953045 & $2521.23662871620578 \mathrm{e}-06$ & 17990.0429254824133023 \\
\hline $2431.01074182558003 \mathrm{e}-05$ & 17590.297076013999274 & $2528.20637044318673 \mathrm{e}-07$ & 18110.0366056590849839 \\
\hline $2448.05231597533762 \mathrm{e}-06$ & 17600.282453439032526 & $2575.63565007549727 \mathrm{e}-07$ & 18190.0604947658664786 \\
\hline $2446.40227151926798 \mathrm{e}-06$ & 17600.259763610817575 & $2603.78015050594982 \mathrm{e}-07$ & 18390.0814051076668032 \\
\hline $2458.94217762414939 \mathrm{e}-06$ & 17610.295737208212877 & $2602.78867625880252 \mathrm{e}-07$ & 18400.0725683150354628 \\
\hline $2457.10601420161883 \mathrm{e}-06$ & 17610.276436035709882 & $2626.62580763810539 \mathrm{e}-07$ & 18620.107455633487161 \\
\hline $2455.2466149349506 \mathrm{e}-06$ & 17650.262381467087415 & $2671.43703413579832 \mathrm{e}-06$ & 18870.0977158797816955 \\
\hline $2456.92955615444468 \mathrm{e}-06$ & 17650.23526798320554 & $2681.03511381610577 \mathrm{e}-06$ & 19010.0849816218819209 \\
\hline $2455.35539351897985 e-06$ & 17650.208769914409052 & $2687.34527087598025 \mathrm{e}-07$ & 19120.0758511612442003 \\
\hline $2464.07384862899374 \mathrm{e}-06$ & 17690.236957978028407 & $2691.73399462544133 \mathrm{e}-06$ & 19180.104776762227724 \\
\hline $2463.17352482592792 \mathrm{e}-06$ & 17720.216103513770683 & $2723.7616837191834 \mathrm{e}-06$ & 19210.0939248047300196 \\
\hline $2464.83428874564762 \mathrm{e}-06$ & 17720.198984416826844 & $2729.3088758236215 \mathrm{e}-06$ & 19220.128904150968058 \\
\hline $2466.51540647678139 \mathrm{e}-06$ & 17770.237961479866444 & $2721.98618701841013 \mathrm{e}-05$ & 19420.172333234285498 \\
\hline $2469.60522328286029 \mathrm{e}-06$ & 17770.216140569100701 & $2731.39090123512098 \mathrm{e}-05$ & 19470.147449458900218 \\
\hline $2467.60227337093244 \mathrm{e}-06$ & 17790.196004566051068 & $2732.90651110483875 \mathrm{e}-05$ & 19600.131128731953917 \\
\hline $2486.11384563808937 \mathrm{e}-06$ & 17790.183960951153308 & $2732.1610279594908 \mathrm{e}-05$ & 19700.112497065151357 \\
\hline $2495.52392967401172 \mathrm{e}-06$ & 17850.212511725412508 & $2731.48060434349562 \mathrm{e}-05$ & 19870.0956183630635912 \\
\hline $2494.50373640015211 \mathrm{e}-06$ & 17860.25270823918695 & $2751.21762063713948 \mathrm{e}-05$ & 19920.0794500645492436 \\
\hline $2493.42171236322741 \mathrm{e}-06$ & 17890.23112027846647 & $2758.57026095868463 \mathrm{e}-06$ & 19940.106254306905796 \\
\hline $2502.77973353690619 \mathrm{e}-06$ & 17890.214447470846727 & $2755.99395959210991 \mathrm{e}-06$ & 19990.0901955813852092 \\
\hline $2502.76598099768766 \mathrm{e}-06$ & 17890.194359112734678 & $2771.37382970206712 \mathrm{e}-05$ & 19990.0748279991348035 \\
\hline $2502.02198567778034 \mathrm{e}-06$ & 17900.186889836352773 & $2771.15386745084267 \mathrm{e}-05$ & 20080.0617007183075305 \\
\hline $2501.68050999171943 \mathrm{e}-06$ & 17900.218133359598657 & $2792.5296652380713 \mathrm{e}-05$ & 20110.090045061272588 \\
\hline $2511.40629752065635 \mathrm{e}-06$ & 17990.19392212993269 & $2812.05543480013004 \mathrm{e}-05$ & 20150.0760836642596744 \\
\hline $2511.24119074640383 \mathrm{e}-06$ & 18000.178129139124167 & $2854.86238237439318 \mathrm{e}-05$ & 20150.106782995278059 \\
\hline 251 1.70597296855757e-06 & 18110.199602294170614 & $2854.09335500751729 \mathrm{e}-05$ & 20440.0891305277018941 \\
\hline $2511.31653941659593 \mathrm{e}-06$ & 18110.191793866795494 & $2877.37085799374926 \mathrm{e}-05$ & 20630.0775417186529733 \\
\hline $2521.20379161649975 \mathrm{e}-06$ & 18120.231110558427013 & 2890.000130883380082825 & 20950.0703899398757712 \\
\hline $2521.69670519156728 \mathrm{e}-06$ & 18140.211299491514386 & 2910.00010703511141319 & 21000.066121449983751 \\
\hline $2521.25655580240913 \mathrm{e}-06$ & 18170.188598316049836 & $2929.25938850192543 \mathrm{e}-05$ & 21010.0584410377368827 \\
\hline $2529.79088268016071 \mathrm{e}-07$ & 18190.222863161545062 & $2926.47255128320978 \mathrm{e}-05$ & 21020.0897470557658191 \\
\hline $2521.62115713453481 \mathrm{e}-06$ & 18200.250822080526413 & 2930.000116182583821955 & 21220.0744985900059224 \\
\hline $2532.32017150858521 \mathrm{e}-06$ & 18260.229714663031805 & $2949.54973299709394 \mathrm{e}-05$ & 21230.0626274422039131 \\
\hline $2532.30573700354952 \mathrm{e}-06$ & 18270.208763457277195 & 2950.000208139612756675 & 21280.0523805135143922 \\
\hline $2531.82940585258251 \mathrm{e}-06$ & 18310.189273427256919 & 2950.000174334483184824 & 21280.0475036128885575 \\
\hline $2541.43772194205471 \mathrm{e}-06$ & 18340.171195510768562 & 2960.000360834213675276 & 21570.0386292387616045 \\
\hline $2551.00990012930069 \mathrm{e}-06$ & 18390.163869501705034 & 2980.000343339337023463 & 21700.0610571335943456 \\
\hline $2557.67022996450706 \mathrm{e}-07$ & 18400.15194307716761 & 3030.000280923155394741 & 21760.0868137561902532 \\
\hline $2565.72842213331093 \mathrm{e}-07$ & 18460.180511260025027 & 3080.000579316402860686 & 21810.0719782664801982 \\
\hline $2565.12077636849462 \mathrm{e}-07$ & 18490.166161704496115 & 3080.00108472383027114 & 21850.10865715156357 \\
\hline
\end{tabular}




\begin{tabular}{|c|c|c|c|}
\hline $2564.18382948619289 \mathrm{e}-07$ & 18580.153668285590497 & 3090.000795639197176734 & 21850.14245627598121 \\
\hline $2563.76138022839534 \mathrm{e}-07$ & 18590.171849271687902 & 3150.00118424622265356 & 21860.120210191385983 \\
\hline $2562.71179761202056 \mathrm{e}-07$ & 18620.203201790486923 & 3170.000966155129936141 & 22170.164789660012147 \\
\hline $2572.08668260892608 \mathrm{e}-07$ & 18620.231961198310353 & 3180.000704898666113674 & 22230.143921673503251 \\
\hline $2581.4838685036267 \mathrm{e}-07$ & 18650.221095888409517 & 3190.000647468397959816 & 22300.20275136250539 \\
\hline $2591.40405063353555 \mathrm{e}-07$ & 18650.255831811329815 & 3200.000509583008150516 & 22340.275634979398276 \\
\hline $2591.2914549019083 \mathrm{e}-07$ & 18660.254123071669478 & 3240.0004358655842579 & 22390.345404787345011 \\
\hline $2601.00031872896089 \mathrm{e}-07$ & 18740.237474329558779 & 3240.000370063021993161 & 22490.442542517710701 \\
\hline $2607.91898819851866 \mathrm{e}-08$ & 18750.222836880414222 & 3250.000313584378086373 & 22540.396778781473283 \\
\hline $2601.19628971284591 \mathrm{e}-07$ & 18750.259743649781649 & 3260.000622992311550719 & 22620.366538337268565 \\
\hline $2619.57591369532551 \mathrm{e}-08$ & 18780.23859204708506 & 3260.000457498193164985 & 22640.337220912257099 \\
\hline $2619.49707348318896 \mathrm{e}-08$ & 18820.22478029135448 & 3300.000885063518853757 & 22790.314798263683163 \\
\hline $2617.36233095599559 \mathrm{e}-08$ & 18830.264621565762214 & 3300.000760368780494458 & 22870.284916304363587 \\
\hline $2611.07718611697116 \mathrm{e}-07$ & 18860.236600847775659 & 3310.00140324914659562 & 22960.247357485139009 \\
\hline $2628.11910031428553 e-08$ & 18860.236160079816392 & 3310.00246679287864937 & 23030.230725590598424 \\
\hline $2626.10481789564687 \mathrm{e}-08$ & 18870.275324204482123 & 3310.00188831275111445 & 23100.223438557821734 \\
\hline $2634.12928825577197 \mathrm{e}-08$ & 18880.302749313427006 & 3310.00158440892511735 & 23210.191954709102051 \\
\hline $2636.71643917149467 \mathrm{e}-08$ & 18990.340276754214218 & 3320.00147475979578715 & 23260.255484682851482 \\
\hline $2635.88748279017892 \mathrm{e}-08$ & 19000.306940775781175 & 3360.00123685500726878 & 23330.229125617947425 \\
\hline $2641.04193878636138 \mathrm{e}-07$ & 19010.348872456969976 & 3380.00220124492747253 & 23380.203003645668535 \\
\hline $2641.71846160967881 \mathrm{e}-07$ & 19020.328574041869557 & 3380.00371272359011954 & 23410.185117873391642 \\
\hline $2641.32262361285385 \mathrm{e}-07$ & 19020.376916141761159 & 3390.00314243956006788 & 23440.159245678113497 \\
\hline $2669.98524761763875 \mathrm{e}-08$ & 19040.347784490224784 & 3410.00462758843392508 & 23520.141132228404744 \\
\hline $2667.4513990977465 \mathrm{e}-08$ & 19040.317635339967506 & 3410.00388676501701501 & 23540.13279180502925 \\
\hline $2661.21466082303456 \mathrm{e}-07$ & 19080.299826002515624 & 3440.00337118731305097 & 23550.119638440562708 \\
\hline $2671.88390779531922 \mathrm{e}-07$ & 19160.269408317383367 & 3450.00256075742349082 & 23600.101254839079628 \\
\hline $2671.61634415296597 \mathrm{e}-07$ & 19160.314871422095889 & 3450.00411263470286305 & 23670.0842681749327846 \\
\hline $2671.34563795550768 \mathrm{e}-07$ & 19160.289128432144377 & 3480.00348007049785326 & 23710.0794864608093663 \\
\hline $2681.04411183698971 \mathrm{e}-07$ & 19170.319093473252659 & 3490.00347445429704873 & 23720.116586066077033 \\
\hline $2681.65843934030185 \mathrm{e}-07$ & 19180.297618971055644 & 3490.00553500357650694 & 23780.103477588588751 \\
\hline $2681.65023602893832 \mathrm{e}-07$ & 19190.280250300628833 & 3500.00897944104750537 & 23830.150449947990125 \\
\hline $2691.27184828779825 \mathrm{e}-07$ & 19220.258193523198209 & 3540.00773100382998504 & 23920.137103793667081 \\
\hline $2691.1517759490598 \mathrm{e}-07$ & 19250.28610286180373 & 3560.0124958659493957 & 23950.19055322547557 \\
\hline $2691.67981362486636 \mathrm{e}-07$ & 19350.284500175566847 & 3560.0104990814929842 & 24050.174812188761902 \\
\hline $2691.1919691844664 \mathrm{e}-07$ & 19370.326019134433791 & 3590.0150389947418161 & 24150.15282904391052 \\
\hline $2699.0107305950049 \mathrm{e}-08$ & 19390.379820256832246 & 3600.0119737554915491 & 24360.13654510473774 \\
\hline $2706.67132945553206 \mathrm{e}-08$ & 19420.407659741183885 & 3610.010255961062127 & 24420.125119126299403 \\
\hline $2705.82980838048641 \mathrm{e}-08$ & 19440.370533469916463 & 3680.0088350470522196 & 24660.110025709304274 \\
\hline $2708.88747224703224 \mathrm{e}-08$ & 19470.347634265643376 & 3700.00674829354262729 & 24700.0988178801976953 \\
\hline $2707.16454489069207 \mathrm{e}-08$ & 19480.325119523274265 & 3710.00524697388947692 & 24850.0835739556345095 \\
\hline $2705.6170264661759 \mathrm{e}-08$ & 19500.300132013482624 & 3710.00861791575945847 & 24940.0689423806353213 \\
\hline $2714.26608740555778 \mathrm{e}-08$ & 19530.271680666266674 & 3730.00656273931468387 & 24980.0677467263103555 \\
\hline $2723.23272231206317 \mathrm{e}-08$ & 19540.310860984912757 & 3740.00640647469531253 & 25050.0592582853170343 \\
\hline $2732.27221484960793 \mathrm{e}-08$ & 19550.294206314642646 & 3740.00537889077755083 & 25070.0532352116546972 \\
\hline $2731.81173992475081 \mathrm{e}-08$ & 19640.285472328965033 & 3780.00421284049805404 & 25130.0461494252525911 \\
\hline $2732.87305753632339 \mathrm{e}-08$ & 19650.275800091017399 & 3790.00325155254065601 & 25160.0380401133620312 \\
\hline $2732.29393376516285 \mathrm{e}-08$ & 19700.257589142035339 & 3790.00239805229412238 & 25250.034214588174705 \\
\hline
\end{tabular}




\begin{tabular}{|c|c|c|c|}
\hline $2733.6288547944352 \mathrm{e}-08$ & 19720.235463643431292 & 3800.00430273655416247 & 25270.0545472026566984 \\
\hline $2733.27387702503401 \mathrm{e}-08$ & 19730.272223516723934 & 3850.00374941568100984 & 25450.0447863305895111 \\
\hline $2732.5119030411247 \mathrm{e}-08$ & 19750.250524999762855 & 3870.00314541229009513 & 25520.0393087404175503 \\
\hline $2732.22065582589082 \mathrm{e}-08$ & 19790.285998768656639 & 3870.00235196251809966 & 25530.0571978312041423 \\
\hline $2741.87687883013155 \mathrm{e}-08$ & 19850.321910692963709 & 3880.0042084260996017 & 25550.0534174179934813 \\
\hline $2741.69538635352851 \mathrm{e}-08$ & 19870.371934370143207 & 3900.00338688030159739 & 25820.0761005491107757 \\
\hline $2751.27514775405402 \mathrm{e}-08$ & 19870.427020288476206 & 3900.00264773961984399 & 25890.0649045385775959 \\
\hline $2759.37434208037047 \mathrm{e}-09$ & 19900.390679006151845 & 3910.0019896076297633 & 25970.0587391725181905 \\
\hline $2756.82632494974911 \mathrm{e}-09$ & 19920.420094001485059 & 3930.00163430741441306 & 26010.0518004672962135 \\
\hline $2761.16068509248279 \mathrm{e}-08$ & 19930.453378553118673 & 3930.00280016003421213 & 26090.0462461735235759 \\
\hline $2761.81584434155724 \mathrm{e}-08$ & 19940.419582528326454 & 3930.00456514074505066 & 26170.0699139415927424 \\
\hline $2771.46770273712349 \mathrm{e}-08$ & 19950.387723377817179 & 3980.00698094011181394 & 26240.0698332569322473 \\
\hline $2771.22636260035947 \mathrm{e}-08$ & 19970.443010880839524 & 3990.0057353698952054 & 26400.101246664631641 \\
\hline $2772.04465617770211 \mathrm{e}-08$ & 19990.503988575557351 & 3990.00561091308056894 & 26410.128997252013429 \\
\hline $2781.5458386903866 \mathrm{e}-08$ & 20000.462307852074369 & 4010.00416367708329823 & 26420.182110690382545 \\
\hline $2782.20976346110291 \mathrm{e}-08$ & 20080.492053878562571 & 4030.00345325539946129 & 26440.165447853529337 \\
\hline $2793.35019040287321 \mathrm{e}-08$ & 20110.548027596120278 & 4030.00251829979113749 & 26460.232405307020051 \\
\hline $2792.7753825126986 \mathrm{e}-08$ & 20110.597503604961244 & 4040.0042743888810074 & 26730.200912759040937 \\
\hline $2794.33388500642451 \mathrm{e}-08$ & 20140.554620059815944 & 4050.00627680803791797 & 26750.178629389453745 \\
\hline $2793.07350176420584 \mathrm{e}-08$ & 20150.600402996216928 & 4070.00530522849531012 & 27040.24527543966663 \\
\hline $2804.61425662123816 \mathrm{e}-08$ & 20150.656365576982325 & 4080.00425243634028116 & 27170.213715935925123 \\
\hline $2807.6995421927073 e-08$ & 20210.622168570833772 & 4090.00310478760628996 & 27280.182237125038688 \\
\hline $2801.20988626006735 \mathrm{e}-07$ & 20220.590462571278286 & 4090.0022397738795944 & 27290.165695060835247 \\
\hline $2801.00273684133789 \mathrm{e}-07$ & 20240.636788944501883 & 4110.00159572693627053 & 27550.152624439741069 \\
\hline $2817.39575423125416 \mathrm{e}-08$ & 20240.613033005589626 & 4120.00112224333580269 & 27680.137611575420534 \\
\hline $2816.55825826978429 \mathrm{e}-08$ & 20260.576122889153891 & 4130.000935693375710089 & 27760.124638967108924 \\
\hline $2821.13656968170339 \mathrm{e}-07$ & 20390.540066615992411 & 4130.00189531492152339 & 27790.103671327307853 \\
\hline $2828.70573739764069 \mathrm{e}-08$ & 20410.512767860010821 & 4140.00133560496850971 & 27830.0935876621967305 \\
\hline $2836.86509733505147 \mathrm{e}-08$ & 20440.470971143388139 & 4230.00113160029658199 & 27920.0850157191357667 \\
\hline $2836.22386341353476 \mathrm{e}-08$ & 20490.453977649444532 & 4250.000975109435587762 & 28070.125953733682631 \\
\hline $2861.06038442249101 \mathrm{e}-07$ & 20540.429119949133783 & 4280.00175124837988438 & 28170.111870405951665 \\
\hline $2861.76753272906893 \mathrm{e}-07$ & 20560.467999511097211 & 4310.00142608167910296 & 28360.150267611241634 \\
\hline $2861.25325452904335 \mathrm{e}-07$ & 20560.531966784577156 & 4320.00126054041139456 & 28400.148254781114133 \\
\hline $2871.0584352627685 \mathrm{e}-07$ & 20610.495744072867847 & 4320.00100564457554897 & 28460.132821882521155 \\
\hline $2871.46456968219688 \mathrm{e}-07$ & 20630.45720374724927 & 4330.000991115121332764 & 28460.186734138291301 \\
\hline $2871.98223909175788 \mathrm{e}-07$ & 20640.441357235782128 & 4370.00158321354894209 & 28480.243251896880292 \\
\hline $2871.42623854171298 \mathrm{e}-07$ & 20710.487829301255586 & 4370.00283170716413961 & 28490.309360698619301 \\
\hline $2871.20510533219154 \mathrm{e}-07$ & 20720.456850796266864 & 4370.00207470401516052 & 28690.277674085018493 \\
\hline $2889.07188849597063 \mathrm{e}-08$ & 20730.498638809802843 & 4390.00148052541997956 & 28900.246034185434486 \\
\hline $2887.30139807503249 \mathrm{e}-08$ & 20760.557910858378448 & 4440.00267885790881428 & 29070.212182802812189 \\
\hline $2891.04844137482907 \mathrm{e}-07$ & 20770.543993881598222 & 4470.00433381606036698 & 29100.190903806408577 \\
\hline $2891.56868317113812 \mathrm{e}-07$ & 20860.541175598385868 & 4520.00331472177865177 & 29200.163762639877945 \\
\hline $2891.29013594141192 \mathrm{e}-07$ & 20950.50774505900349 & 4520.00526404147870352 & 29200.143454884186663 \\
\hline $2899.176287052437 \mathrm{e}-08$ & 20950.498181442621935 & 4550.00920380689482192 & 29250.120593543009316 \\
\hline $2897.04673652762722 \mathrm{e}-08$ & 20970.533717647396442 & 4580.0160618210534534 & 29510.101358604870804 \\
\hline $2901.00755291665422 \mathrm{e}-07$ & 20980.515607733546018 & 4600.0119958935819044 & 29520.0875619860742392 \\
\hline $2901.46371683218405 \mathrm{e}-07$ & 21010.473938001168804 & 4650.0202823747237908 & 29670.0776047290755741 \\
\hline
\end{tabular}




\begin{tabular}{|c|c|c|c|}
\hline $2901.35039699977746 \mathrm{e}-07$ & 21140.537245505172286 & 4650.0171370570894152 & 29790.110239215506483 \\
\hline $2912.29879716928671 \mathrm{e}-07$ & 21230.506195550453999 & 4660.0127866434355218 & 30090.0903739953954005 \\
\hline $2912.08308547300362 \mathrm{e}-07$ & 21270.472546686639048 & 4660.00940685821381715 & 30220.0795062886969751 \\
\hline $2911.63744850789627 \mathrm{e}-07$ & 21280.524587096468455 & 4680.014739215951181 & 30340.0716117004809856 \\
\hline $2921.37104937070198 \mathrm{e}-07$ & 21280.50899846632858 & 4710.0224264017550586 & 30450.108641115050008 \\
\hline $2921.05029175023752 \mathrm{e}-07$ & 21290.467704322326176 & 4720.0168089763934393 & 30550.0898641763468526 \\
\hline $2927.53991763469131 \mathrm{e}-08$ & 21430.437418267890435 & 4730.0286855948032703 & 30680.0743141656131258 \\
\hline $2926.30710489391006 \mathrm{e}-08$ & 21440.411224934581717 & 4750.0249866081719786 & 30720.106914612636845 \\
\hline 2938.74374301851333 e-08 & 21470.388109318823133 & 4760.0211654895773197 & 30840.087158828203676 \\
\hline $2937.26779884052675 e-08$ & 21480.365708059157096 & 4770.0181584613585305 & 31070.120696801649496 \\
\hline $2945.13157436543565 \mathrm{e}-08$ & 21510.344251868288328 & 4770.0138343460534508 & 31090.107232571749157 \\
\hline $2948.77429109369388 \mathrm{e}-08$ & 21540.363163607594829 & 4770.0119036337577698 & 31230.106348004865172 \\
\hline $2941.49547734196176 \mathrm{e}-07$ & 21550.401521648128648 & 4810.0201941241871229 & 31230.0958182733410868 \\
\hline $2942.23924790709873 \mathrm{e}-07$ & 21620.454621306627265 & 4820.016901717305413 & 31500.0808487141957904 \\
\hline $2941.5877542047793 e-07$ & 21620.512750594460228 & 4860.0252462582282001 & 31690.0785618145011202 \\
\hline $2952.47502582206849 \mathrm{e}-07$ & 21620.565349790397007 & 4870.041102024890602 & 31760.108964137429538 \\
\hline $2952.11965944796333 \mathrm{e}-07$ & 21630.536892071834426 & 4880.0658712354984232 & 31860.0936881637696263 \\
\hline $2953.5108045004506 \mathrm{e}-07$ & 21650.507559034551738 & 4880.097055966957743 & 32060.125970352907788 \\
\hline $2962.64067238631149 \mathrm{e}-07$ & 21660.549637615819215 & 4920.0870424308456467 & 32070.10290043621273 \\
\hline $2962.55138578597602 \mathrm{e}-07$ & 21690.514645790294705 & 4940.0839581527225681 & 32230.0831360318383928 \\
\hline $2962.09823680097365 \mathrm{e}-07$ & 21750.473288096501925 & 5060.118130218938485 & 32550.127811843937393 \\
\hline $2973.17168378005661 \mathrm{e}-07$ & 21760.441088421928376 & 5110.179776480337608 & 32560.113797112567825 \\
\hline $2974.78409231341459 \mathrm{e}-07$ & 21810.404866351470378 & 5120.161318915894916 & 32760.0961454833849308 \\
\hline $2986.79045897511443 \mathrm{e}-07$ & 21840.462794625768934 & 5160.146335059435057 & 32840.078884458552078 \\
\hline $2985.30389107633589 \mathrm{e}-07$ & 21850.525609394566797 & 5230.201768263133772 & 32980.0641012916527399 \\
\hline $2984.33109593189762 \mathrm{e}-07$ & 21860.483819200848602 & 5240.289142068203547 & 33020.053795670075411 \\
\hline $2983.44355362669191 \mathrm{e}-07$ & 21870.537307022040612 & 5250.243153260512366 & 33110.0502627549129147 \\
\hline $3004.63454157717536 \mathrm{e}-07$ & 21880.502103131252314 & 5250.218640055843596 & 33180.0717846178995084 \\
\hline $3004.384678022884 \mathrm{e}-07$ & 21890.54498907422458 & 5260.180358577027205 & 33240.0601269881928223 \\
\hline $3013.52417529270177 \mathrm{e}-07$ & 21890.606247485777509 & 5260.161634022812842 & 33980.0522202566408647 \\
\hline $3033.47003545231317 \mathrm{e}-07$ & 21920.570175904721589 & 5280.132286250713154 & 33990.0714642218668313 \\
\hline $3032.74958287027616 \mathrm{e}-07$ & 21920.62776154074037 & 5280.112399527702889 & 34070.0574588969108735 \\
\hline $3032.07984688804785 \mathrm{e}-07$ & 21940.590535260697454 & 5300.172129427675998 & 34110.0501003375143075 \\
\hline $3041.57607281892069 \mathrm{e}-07$ & 21960.63963083243406 & 5310.147711879810305 & 34220.0710371837046017 \\
\hline $3041.26565121272293 \mathrm{e}-07$ & 21980.600070296777585 & 5320.196645048097449 & 34410.056344796844109 \\
\hline $3041.25032323161633 \mathrm{e}-07$ & 22020.586404402896709 & 5370.276069411934701 & 34450.0446062286379904 \\
\hline $3058.96853348253401 \mathrm{e}-08$ & 22040.553505186049998 & 5370.384689933780886 & 34480.0677357403108566 \\
\hline $3056.4082170236901 \mathrm{e}-08$ & 22060.533588655143947 & 5460.335092745753487 & 34900.0583655196928524 \\
\hline $3065.02250703249274 \mathrm{e}-08$ & 22080.596051458434985 & 5470.434304481518211 & 35330.0511817881007089 \\
\hline $3064.38862803875395 \mathrm{e}-08$ & 22080.567740770636341 & 5480.518296247814666 & 35750.0401680320256471 \\
\hline $3067.68637227199775 \mathrm{e}-08$ & 22170.601276964383235 & 5530.647690853284132 & 35780.0318241662094364 \\
\hline $3066.32590616556072 \mathrm{e}-08$ & 22220.567187422638689 & 5550.793981065922219 & 35990.0289617067421652 \\
\hline $3065.70253781972951 \mathrm{e}-08$ & 22230.539982545143818 & 5560.744255490380291 & 36390.0244057288016714 \\
\hline $3078.56718763708741 \mathrm{e}-08$ & 22250.604953848523326 & 5610.849725158350464 & 36630.0392570967679895 \\
\hline $3075.99269678325243 \mathrm{e}-08$ & 22300.667247971409584 & 5650.972093727935338 & 36750.0662750534480202 \\
\hline $3084.59227142979302 \mathrm{e}-08$ & 22300.736464654299698 & & \\
\hline $3087.47291720726295 \mathrm{e}-08$ & 22300.699584054191313 & & \\
\hline
\end{tabular}




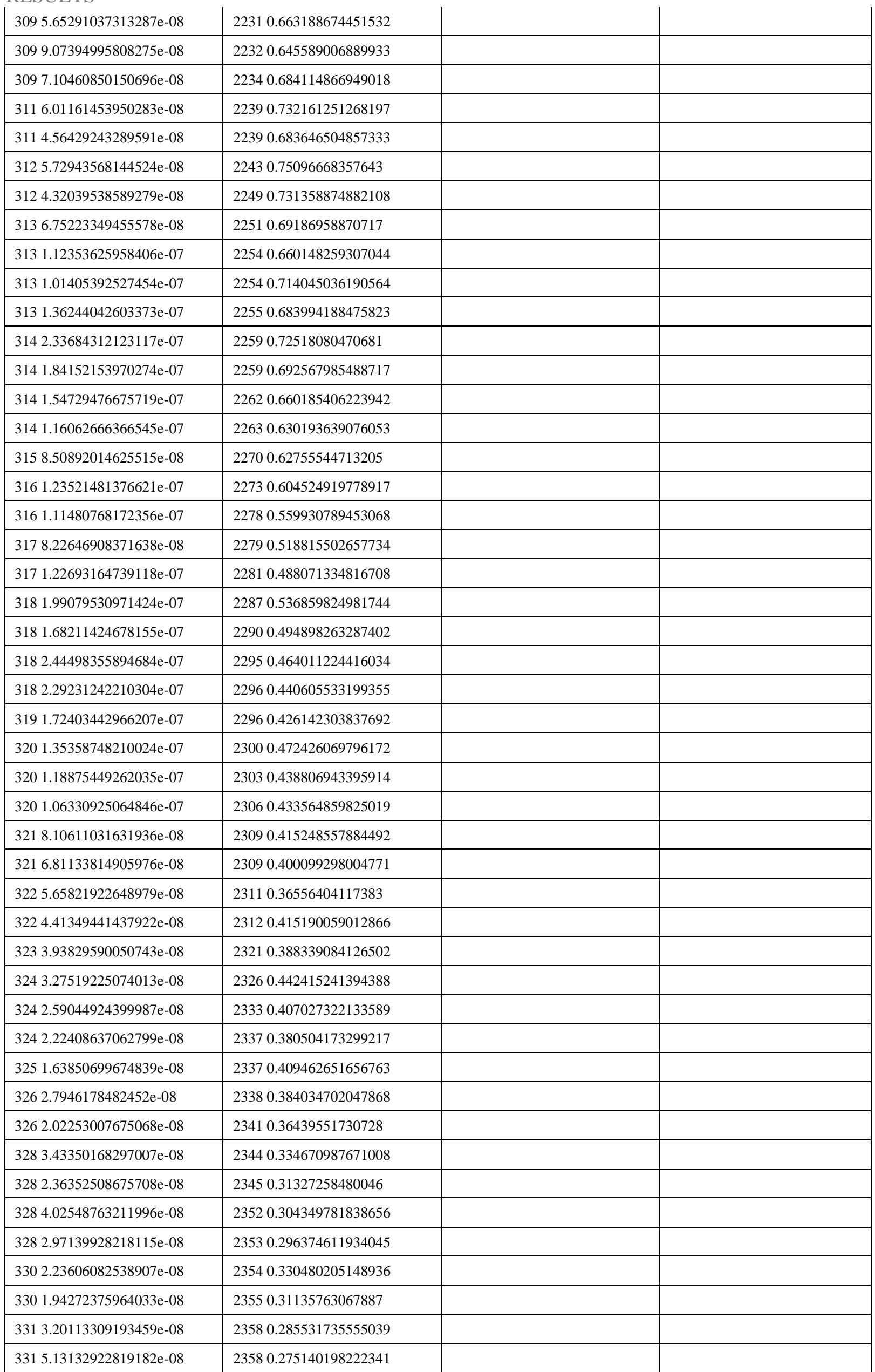


$3313.79362735669631 \mathrm{e}-08$

$3313.09147509813812 \mathrm{e}-08$

$3312.04100456535627 \mathrm{e}-08$

$3321.33721669293152 \mathrm{e}-08$

$3331.0846007980625 \mathrm{e}-08$

$3331.90146637324418 \mathrm{e}-08$

333 3.10021524008164e-08

$3334.86731800419804 \mathrm{e}-08$

$3333.56942257973003 \mathrm{e}-08$

$3342.54956171730214 \mathrm{e}-08$

$3341.90846992653704 \mathrm{e}-08$

$3362.88975652296131 \mathrm{e}-08$

$3362.23459492021405 \mathrm{e}-08$

$3363.64128782681661 \mathrm{e}-08$

$3382.3925822212334 \mathrm{e}-08$

$3383.81719051922857 \mathrm{e}-08$

$3383.09308159085475 \mathrm{e}-08$

$3384.72052519295829 \mathrm{e}-08$

$3393.49388125098216 \mathrm{e}-08$

$3393.01293968663074 \mathrm{e}-08$

$3392.13365038970181 \mathrm{e}-08$

$3391.38700426699501 \mathrm{e}-08$

$3391.84938654390621 \mathrm{e}-08$

$3392.56776936380376 \mathrm{e}-08$

$3403.98218016339769 \mathrm{e}-08$

$3416.52504876796911 \mathrm{e}-08$

$3415.16134306405291 \mathrm{e}-08$

$3417.79366653436142 \mathrm{e}-08$

$3426.40309406607642 \mathrm{e}-08$

$3421.10458597601948 \mathrm{e}-07$

$3428.76807536576152 \mathrm{e}-08$

$3427.15139368834272 \mathrm{e}-08$

$3425.8415000503409 \mathrm{e}-08$

$3431.01744852099017 \mathrm{e}-07$

$3447.03043091521138 \mathrm{e}-08$

$3444.83289859243285 \mathrm{e}-08$

$3443.59914612557688 \mathrm{e}-08$

$3455.5783032526513 \mathrm{e}-08$

347 8.05548171500803e-08

$3491.13800004752918 \mathrm{e}-07$

$3491.77433540082816 \mathrm{e}-07$

$3492.5836314487826 \mathrm{e}-07$

$3493.99356818281404 \mathrm{e}-07$

$3502.68259859437237 \mathrm{e}-07$

$3502.22143570760558 \mathrm{e}-07$

$3523.08259164860658 \mathrm{e}-07$

$3532.3069734178538 \mathrm{e}-07$

\begin{tabular}{|c|c|c|}
\hline \multicolumn{3}{|l|}{23580.307479745222018} \\
\hline 23600.280927089706003 & & \\
\hline 23670.25301681451987 & & \\
\hline 23710.232716410197453 & & \\
\hline 23780.271873747514953 & & \\
\hline 23810.316623056794478 & & \\
\hline 23830.293523461856302 & & \\
\hline 23880.278927647920909 & & \\
\hline 23910.256185006881525 & & \\
\hline 23920.238359290194269 & & \\
\hline 23930.276972743879207 & & \\
\hline 23940.264012632129704 & & \\
\hline 23950.291954118003007 & & \\
\hline 24050.277672001487392 & & \\
\hline 24050.256547099512873 & & \\
\hline 24070.230932296391167 & & \\
\hline 24200.206647846862706 & & \\
\hline 24200.192482585401954 & & \\
\hline 24240.177995324025048 & & \\
\hline 24260.165558714149107 & & \\
\hline 24300.184928473923862 & & \\
\hline 24360.174676161727893 & & \\
\hline 24370.166454066322091 & & \\
\hline 24420.197595488939309 & & \\
\hline 24420.182657615452784 & & \\
\hline 24430.207571928744931 & & \\
\hline 24450.242230548379286 & & \\
\hline 24550.221614733882098 & & \\
\hline 24660.213178900453134 & & \\
\hline 24670.20026651348789 & & \\
\hline 24700.178377094848959 & & \\
\hline 24740.161923306960064 & & \\
\hline 24790.147298206369622 & & \\
\hline 24850.133195775620466 & & \\
\hline 24870.11809515034508 & & \\
\hline 24930.106144369419761 & & \\
\hline 24940.121150106664243 & & \\
\hline 24980.120150753423883 & & \\
\hline 25050.110395571528574 & & \\
\hline 25070.104176140162844 & & \\
\hline 25110.0952456085541571 & & \\
\hline 25120.114239758038072 & & \\
\hline 25140.103440648780117 & & \\
\hline 25150.0906267254202576 & & \\
\hline 25160.089938331762951 & & \\
\hline 25250.0855114670825262 & & \\
\hline 25250.104349957112358 & & \\
\hline
\end{tabular}


RESULTS

$3531.89704727593387 \mathrm{e}-07$

$3532.97430264195597 \mathrm{e}-07$

$3532.52648758580776 \mathrm{e}-07$

$3531.75802860935548 \mathrm{e}-07$

$3541.16216920309498 \mathrm{e}-07$

$3551.77642821674873 \mathrm{e}-07$

$3562.5906512490792 \mathrm{e}-07$

$3562.0370457531893 \mathrm{e}-07$

$3561.87826449393746 \mathrm{e}-07$

$3561.84053501328663 \mathrm{e}-07$

$3562.43992912984936 \mathrm{e}-07$

357 3.48782989600949e-07

$3572.82442746080136 \mathrm{e}-07$

$3584.55670136290109 \mathrm{e}-07$

$3583.18620546835291 \mathrm{e}-07$

$3582.38913614447611 \mathrm{e}-07$

$3593.42340824133203 \mathrm{e}-07$

$3602.58473610736942 \mathrm{e}-07$

$3602.07528594642348 \mathrm{e}-07$

$3601.81247771791071 \mathrm{e}-07$

$3612.97175950292328 \mathrm{e}-07$

$3612.45493689376985 \mathrm{e}-07$

$3623.3418609857172 \mathrm{e}-07$

$3634.16410951054047 \mathrm{e}-07$

$3653.08379391356084 \mathrm{e}-07$

$3655.19411752719634 \mathrm{e}-07$

$3668.18469549246359 \mathrm{e}-07$

$3661.18320187025844 \mathrm{e}-06$

$3671.86077980912636 \mathrm{e}-06$

$3682.48575271910578 \mathrm{e}-06$

$3681.81529677723002 \mathrm{e}-06$

$3691.28769833984688 \mathrm{e}-06$

$3699.08450879633094 \mathrm{e}-07$

$3706.09206813440011 \mathrm{e}-07$

$3714.338419201666 \mathrm{e}-07$

$3713.83080439481098 \mathrm{e}-07$

$3715.93192188147462 \mathrm{e}-07$

$3714.13068204752065 \mathrm{e}-07$

$3723.05688533264181 \mathrm{e}-07$

$3734.52339418699488 \mathrm{e}-07$

$3744.42188237137486 \mathrm{e}-07$

$3743.51985138480337 \mathrm{e}-07$

$3742.65427686496622 \mathrm{e}-07$

375 1.96837363408697e-07

$3762.60846072075438 \mathrm{e}-07$

$3773.60485223005469 \mathrm{e}-07$

$3785.82092544165747 \mathrm{e}-07$

\begin{tabular}{|c|c|c|}
\hline \\
\hline \multicolumn{3}{|l|}{$\begin{array}{|ll|}2545 & 0.127171228625458 \\
2552 & 0.11757695126655\end{array}$} \\
\hline \multicolumn{3}{|l|}{25530.138011150606725} \\
\hline \multicolumn{3}{|l|}{25550.133958142126466} \\
\hline \multicolumn{3}{|l|}{25610.156075612710348} \\
\hline \multicolumn{3}{|l|}{25650.179954411898895} \\
\hline \multicolumn{3}{|l|}{25660.157456814464866} \\
\hline \multicolumn{3}{|l|}{25700.175856502283501} \\
\hline \multicolumn{3}{|l|}{25740.160625683771714} \\
\hline \multicolumn{3}{|l|}{25740.153021834201184} \\
\hline \multicolumn{3}{|l|}{25810.135105007710892} \\
\hline \multicolumn{3}{|l|}{25820.155096921397809} \\
\hline \multicolumn{3}{|l|}{25820.141643681009105} \\
\hline \multicolumn{3}{|l|}{25830.140586217138475} \\
\hline \multicolumn{3}{|l|}{25850.127309971357685} \\
\hline \multicolumn{3}{|l|}{25870.149589367243812} \\
\hline \multicolumn{3}{|l|}{25890.175734747243897} \\
\hline \multicolumn{3}{|l|}{25890.167908958332189} \\
\hline \multicolumn{3}{|l|}{25900.148628871341165} \\
\hline \multicolumn{3}{|l|}{25910.173776376780992} \\
\hline \multicolumn{3}{|l|}{25930.15864242519535} \\
\hline \multicolumn{3}{|l|}{25940.143488998405173} \\
\hline \multicolumn{3}{|l|}{25970.127091608522214} \\
\hline \multicolumn{3}{|l|}{26010.117496398534827} \\
\hline 26020.110430132710181 & & \\
\hline 26090.0997189949606494 & & \\
\hline 26190.120253042483915 & & \\
\hline 26240.117357500740943 & & \\
\hline 26250.139762632952047 & & \\
\hline 26250.130503600419885 & & \\
\hline 26260.11460501993032 & & \\
\hline 26340.135737723442596 & & \\
\hline 26350.130732117013202 & & \\
\hline 26400.11821958461168 & & \\
\hline 26410.130518110914243 & & \\
\hline 26420.156186111200466 & & \\
\hline 26460.14584260326519 & & \\
\hline 26460.137012211079479 & & \\
\hline 26500.120452353401661 & & \\
\hline 26570.146303217841463 & & \\
\hline 26590.130693239183727 & & \\
\hline 26590.116895596835257 & & \\
\hline 26630.106263614741468 & & \\
\hline 26630.123885675415464 & & \\
\hline 26730.144149482775821 & & \\
\hline 26740.132215898368639 & & \\
\hline 26750.131938455670894 & & \\
\hline
\end{tabular}




\begin{tabular}{|c|c|c|c|}
\hline $3794.38855400908267 \mathrm{e}-07$ & 26770.157746404679655 & & \\
\hline $3793.0800121819663 \mathrm{e}-07$ & 26770.170961318980758 & & \\
\hline $3794.48662816565637 \mathrm{e}-07$ & 26780.154783729770627 & & \\
\hline $3806.57538526738222 \mathrm{e}-07$ & 26780.145371429607057 & & \\
\hline $3805.7044755019664 \mathrm{e}-07$ & 26790.175207066227995 & & \\
\hline $3838.51558786929552 \mathrm{e}-07$ & 26900.158961183640501 & & \\
\hline $3831.30396045450176 \mathrm{e}-06$ & 27000.147393054686733 & & \\
\hline $3831.20892472044165 \mathrm{e}-06$ & 27020.171668013673267 & & \\
\hline $3851.89036186026836 \mathrm{e}-06$ & 27040.202987078188986 & & \\
\hline $3852.81477348740289 \mathrm{e}-06$ & 27080.184828569511644 & & \\
\hline $3862.30851696991774 \mathrm{e}-06$ & 27130.171138513951824 & & \\
\hline $3873.72984915952834 \mathrm{e}-06$ & 27150.149152496214251 & & \\
\hline $3875.21664959041157 \mathrm{e}-06$ & 27170.138110056605818 & & \\
\hline $3873.56755015462618 \mathrm{e}-06$ & 27240.121311852569788 & & \\
\hline $3872.58398565833318 \mathrm{e}-06$ & 27250.106997467537576 & & \\
\hline $3874.07830092652439 \mathrm{e}-06$ & 27260.100716739128256 & & \\
\hline $3885.81186833925607 \mathrm{e}-06$ & 27280.0876290092768094 & & \\
\hline $3904.63416563956098 \mathrm{e}-06$ & 27290.081155526706262 & & \\
\hline $3906.56492596606828 \mathrm{e}-06$ & 27340.0769512888192267 & & \\
\hline $3905.11291060756314 \mathrm{e}-06$ & 27360.0737256583132326 & & \\
\hline $3903.90159089513897 \mathrm{e}-06$ & 27370.0697342535592513 & & \\
\hline $3912.93546538376876 \mathrm{e}-06$ & 27370.0600363609887522 & & \\
\hline $3912.54252834253066 \mathrm{e}-06$ & 27490.0540349430200893 & & \\
\hline $3912.27542612563081 \mathrm{e}-06$ & 27510.0516217143236055 & & \\
\hline 391 1.83573647194457e-06 & 27550.0432595874878264 & & \\
\hline $3921.28591070991391 \mathrm{e}-06$ & 27560.0395631318204946 & & \\
\hline $3921.1610491108538 \mathrm{e}-06$ & 27600.0343507162247524 & & \\
\hline $3928.07061853458357 \mathrm{e}-07$ & 27630.0284318453792395 & & \\
\hline $3931.19738626447319 \mathrm{e}-06$ & 27630.0261456782135656 & & \\
\hline $3931.81900462870033 \mathrm{e}-06$ & 27640.0336004499497536 & & \\
\hline $3932.20395898986592 \mathrm{e}-06$ & 27650.0295954901986812 & & \\
\hline $3943.18533569043655 \mathrm{e}-06$ & 27670.0353554767872047 & & \\
\hline $3964.96838458874382 \mathrm{e}-06$ & 27680.0337205937930475 & & \\
\hline $3983.52274038917244 \mathrm{e}-06$ & 27680.0309813635699269 & & \\
\hline $3982.79851489159988 \mathrm{e}-06$ & 27730.0377885160911141 & & \\
\hline $3994.22737456240441 \mathrm{e}-06$ & 27760.0334246635026586 & & \\
\hline $3996.69742075776192 \mathrm{e}-06$ & 27790.0281890346855138 & & \\
\hline $4014.80248439960196 \mathrm{e}-06$ & 27820.0259093662749652 & & \\
\hline $4033.8906256347726 \mathrm{e}-06$ & 27830.0224748243569224 & & \\
\hline $4032.78299586997655 \mathrm{e}-06$ & 27830.0285939163837601 & & \\
\hline $4044.18603279594976 \mathrm{e}-06$ & 27830.0254064997853127 & & \\
\hline $4055.35853219052473 e-06$ & 27920.0237494019751421 & & \\
\hline $4054.81834853149898 \mathrm{e}-06$ & 27930.0305358253854715 & & \\
\hline $4053.89954706803142 \mathrm{e}-06$ & 27930.0371117553250881 & & \\
\hline $4063.23571771321252 \mathrm{e}-06$ & 27970.0439296680537168 & & \\
\hline $4074.13963203604872 \mathrm{e}-06$ & 27980.041743071305032 & & \\
\hline $4083.35359728598217 \mathrm{e}-06$ & 27990.0365043679532935 & & \\
\hline
\end{tabular}




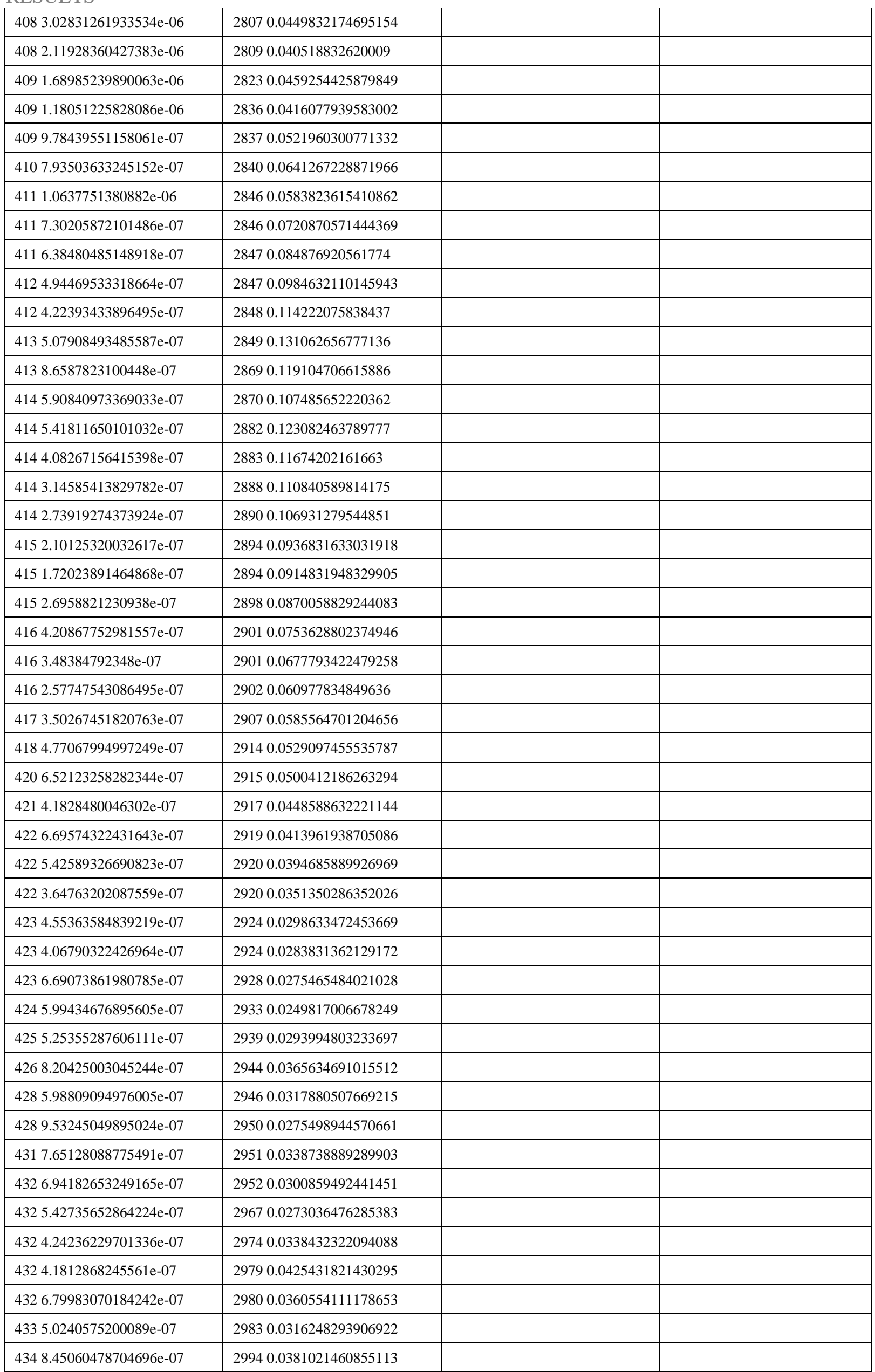


$4371.33628874532388 \mathrm{e}-06$ 29940.0340568294670234

$4372.20554520102834 \mathrm{e}-06$

$4391.50697324108329 \mathrm{e}-06$

$4412.35986364072183 \mathrm{e}-06$

$4411.7676356133256 \mathrm{e}-06$

442 2.57994822283614e-06

442 2.24084846078831e-06

$4442.18020194386881 \mathrm{e}-06$

$4451.89139002138017 \mathrm{e}-06$

$4452.30621395369557 \mathrm{e}-06$

$4461.77746246787791 \mathrm{e}-06$

447 1.40390687830561e-06

447 1.05377018744246e-06

448 7.63781869972391e-07

$4486.79633996081286 \mathrm{e}-07$

$4501.02443503080529 \mathrm{e}-06$

$4501.42401070335474 \mathrm{e}-06$

$4502.38086570669704 \mathrm{e}-06$

$4521.78229586045298 \mathrm{e}-06$

452 2.4151651781823e-06

$4523.85850291328982 \mathrm{e}-06$

$4532.98113086205642 \mathrm{e}-06$

$4532.54446485059567 \mathrm{e}-06$

454 1.91669952442908e-06

$4543.07200818794318 \mathrm{e}-06$

$4552.55572710528007 \mathrm{e}-06$

455 4.20582297055994e-06

$4575.50325520221051 \mathrm{e}-06$

$4574.63689776852849 \mathrm{e}-06$

$4586.44741232447288 \mathrm{e}-06$

$4594.43439808162083 \mathrm{e}-06$

$4593.52750712462324 \mathrm{e}-06$

$4593.01802932101136 \mathrm{e}-06$

462 2.2538142496753e-06

$4621.79454027948722 \mathrm{e}-06$

465 2.30439025017404e-06

$4651.81931132636759 \mathrm{e}-06$

$4651.21801826935553 \mathrm{e}-06$

$4668.54885460865873 \mathrm{e}-07$

$4666.30646759147702 \mathrm{e}-07$

$4679.22904924816059 \mathrm{e}-07$

$4686.51944110141578 \mathrm{e}-07$

$4689.36415973762372 \mathrm{e}-07$

468 1.46452023941368e-06

$4681.10825225818623 \mathrm{e}-06$

$4691.22139535674304 \mathrm{e}-06$

$4701.92905667961707 \mathrm{e}-06$

29970.0297749791962197

30070.0356873437622215

30090.0310659345845803

30150.0278336850306085

30160.0336555514761016

30170.03128092513164

30220.0261488545470606

30230.0243446660261168

30280.0315914033890958

30340.035027754089937

30390.0447254568300698

30450.0385952097016012

30480.0327599083253273

30520.0283645057331173

30530.0338526439384651

30580.0436364520888933

30630.0507513051850758

30770.0443007599709992

30780.0545639814078858

30800.0524733768793391

30810.0448504623044268

30820.0380550981116599

30830.0328295297320348

30840.0280694972539014

30850.034148507068445

30850.0295430871974027

30880.026309446462693

30890.0281258009721693

30890.0266666188029576

30910.0225686205553298

31000.0273832792763703

31070.0249709959688152

31080.0224169837440361

31080.0277655167253323

31090.0240148921647898

31090.0238469621100117

31220.022353117163246

31230.0220992809297211

31240.0204646377927258

31290.0265177968512536

31320.0227441923503642

31320.0210135486648917

31360.0263118690309897

31380.0237402456050828

31390.0209456416976599

31460.0174126011365295

$\mid$ 
RESULTS

$4703.07589339165748 \mathrm{e}-06$

$4712.41848218196505 \mathrm{e}-06$

472 1.77868351403099e-06

$4732.98788538954931 \mathrm{e}-06$

$4732.55373095936484 \mathrm{e}-06$

$4753.90923359239181 \mathrm{e}-06$

$4753.12625525056287 \mathrm{e}-06$

$4774.91246222633634 \mathrm{e}-06$

$4773.99327824263107 \mathrm{e}-06$

$4772.89377626450094 \mathrm{e}-06$

$4772.48573348748948 \mathrm{e}-06$

$4794.02198093329975 \mathrm{e}-06$

$4792.69607035885411 \mathrm{e}-06$

$4813.74616510889769 \mathrm{e}-06$

482 2.94263772138148e-06

482 2.37923849433219e-06

482 3.22223182946946e-06

482 2.47810390674452e-06

$4833.76147279090855 \mathrm{e}-06$

$4832.55063187748483 \mathrm{e}-06$

$4832.03587067171274 \mathrm{e}-06$

$4831.3379205766606 \mathrm{e}-06$

$4849.51595257259186 \mathrm{e}-07$

484 1.53541525660383e-06

$4861.10452282253704 \mathrm{e}-06$

$4871.8441151941051 \mathrm{e}-06$

488 3.10052543761596e-06

$4884.82909582233404 \mathrm{e}-06$

$4904.1748886412396 \mathrm{e}-06$

$4905.93146355931662 \mathrm{e}-06$

$4904.50591551304225 \mathrm{e}-06$

$4907.41542043947163 \mathrm{e}-06$

$4901.25926767852169 \mathrm{e}-05$

$4911.77088219948107 \mathrm{e}-05$

$4931.5681667309253 \mathrm{e}-05$

$4932.56122996248331 \mathrm{e}-05$

$4943.75401112677753 \mathrm{e}-05$

$4965.9260619468926 \mathrm{e}-05$

$4974.13369381165873 \mathrm{e}-05$

$4983.23892200873033 \mathrm{e}-05$

$4982.59573938685698 \mathrm{e}-05$

$4982.22634706525948 \mathrm{e}-05$

$4991.5164013719926 \mathrm{e}-05$

$5011.12517480259644 \mathrm{e}-05$

$5021.67058997547764 \mathrm{e}-05$

502 2.6264583367297e-05

503 3.91425310902749e-05

31480.0162421629812356

31500.0200433633244118

31520.0197203652615867

31580.0178311965405292

31580.0146422812063609

31610.0123115196521252

31660.0111663316519693

31690.014362480219796

31730.0176194436966183

31760.0210014465153892

31790.0183710096760276

31830.0231355167664156

31860.0211613953278679

31880.0248488338679287

31990.0315791613932749

32040.0285316181802018

32070.0368243181233796

32090.0309690266676365

32130.0274374128692462

32180.0238271029915824

32200.0211464842907252

32230.0180578067955731

32240.0240226441329758

32350.02138792386523

32360.0283125690437035

32480.032087070838088

32550.0303562446996953

32620.0273476164917753

32620.0219735389584517

32650.0189127700971208

32760.0232423571430063

32790.0197524516662876

32810.0162258484680616

32840.013759681591574

32860.0115465795246071

32890.00934258489148776

32910.0128325904642822

32960.012192379776463

32980.0121164066180595

33010.0104433445013234

33020.00933384755035493

33030.00894338476901857

33100.00764334957045698

33110.00712768145654885

33110.00884626003382905

33240.00757400036203193

33410.00667723478027027 


\begin{tabular}{|c|c|c|c|}
\hline $5043.01474402267798 \mathrm{e}-05$ & 33670.0055112606928982 & & \\
\hline $5042.55510527249481 \mathrm{e}-05$ & 33800.00457477573101339 & & \\
\hline $5062.29140019107898 \mathrm{e}-05$ & 33880.00567940249481291 & & \\
\hline $5093.63711989486148 \mathrm{e}-05$ & 33890.00510286625340406 & & \\
\hline $5112.51295739103208 \mathrm{e}-05$ & 33920.00430857276404784 & & \\
\hline $5122.07482391663127 \mathrm{e}-05$ & 33980.00581729278311882 & & \\
\hline $5121.803060302219 \mathrm{e}-05$ & 33990.00542447684003655 & & \\
\hline $5131.21312787535466 \mathrm{e}-05$ & 34020.00445658194649412 & & \\
\hline $5138.93546050950711 \mathrm{e}-06$ & 34070.00554439286643127 & & \\
\hline $5156.40075939706275 \mathrm{e}-06$ & 34070.00491889679883606 & & \\
\hline $5161.05396751678422 \mathrm{e}-05$ & 34110.0068700150076918 & & \\
\hline $5171.60022517499137 \mathrm{e}-05$ & 34220.00834661926488389 & & \\
\hline $5192.13254293540688 \mathrm{e}-05$ & 34220.00676435991108115 & & \\
\hline $5202.66584207552212 \mathrm{e}-05$ & 34290.00560571337056226 & & \\
\hline $5203.60407500527016 \mathrm{e}-05$ & 34300.00527255476922495 & & \\
\hline $5212.70550873184838 \mathrm{e}-05$ & 34410.00430523039580788 & & \\
\hline $5221.99550698772866 \mathrm{e}-05$ & 34450.00375343344246593 & & \\
\hline $5231.35714935742826 \mathrm{e}-05$ & 34450.00502395762633323 & & \\
\hline $5231.02529671112128 \mathrm{e}-05$ & 34480.00394695391569322 & & \\
\hline $5231.76662492615831 \mathrm{e}-05$ & 34500.00340647827852902 & & \\
\hline $5242.96331739882971 \mathrm{e}-05$ & 34520.00275114819240196 & & \\
\hline $5254.07232818112613 \mathrm{e}-05$ & 34540.00366745288618542 & & \\
\hline $5256.71281342009555 \mathrm{e}-05$ & 34570.00310923673987218 & & \\
\hline $5265.46262432739031 \mathrm{e}-05$ & 34590.00386694668610088 & & \\
\hline $5264.5419182932549 \mathrm{e}-05$ & 34690.00308202320303874 & & \\
\hline $5283.2149499740175 \mathrm{e}-05$ & 34700.00247890702657549 & & \\
\hline $5282.459735312621 \mathrm{e}-05$ & 34750.00218831881809878 & & \\
\hline $5281.74703023302358 \mathrm{e}-05$ & 34790.00285581454564698 & & \\
\hline $5292.93823590109543 e-05$ & 34800.00399224132836917 & & \\
\hline $5293.61337837074815 \mathrm{e}-05$ & 34900.00329392030980191 & & \\
\hline $5293.07035068973782 \mathrm{e}-05$ & 34950.00295126330397522 & & \\
\hline $5302.77190147841555 \mathrm{e}-05$ & 35010.00234469012535543 & & \\
\hline $5312.10934529629725 \mathrm{e}-05$ & 35080.001910459828949 & & \\
\hline $5312.8878690430445 \mathrm{e}-05$ & 35120.00145542558859091 & & \\
\hline $5321.92034224550941 \mathrm{e}-05$ & 35210.00178884549399505 & & \\
\hline $5321.71638105597172 \mathrm{e}-05$ & 35210.0016646858206798 & & \\
\hline $5342.74951081968844 \mathrm{e}-05$ & 35250.00246544469265153 & & \\
\hline $5354.18276171800791 \mathrm{e}-05$ & 35330.00210652284582258 & & \\
\hline $5366.2955951193433 \mathrm{e}-05$ & 35380.00167279423678346 & & \\
\hline $5376.04540846810275 \mathrm{e}-05$ & 35480.00246757435312339 & & \\
\hline $5379.44288307078711 \mathrm{e}-05$ & 35520.00199139215797062 & & \\
\hline 5370.0001419551258387 & 35580.00281666551468129 & & \\
\hline 5370.000225614593863055 & 35750.0021329800298584 & & \\
\hline 5390.000171363500064858 & 35780.00171660343457436 & & \\
\hline 5410.000137714467283723 & 35810.00160703440560628 & & \\
\hline $5429.44683286101533 \mathrm{e}-05$ & 35850.00119697306081723 & & \\
\hline
\end{tabular}


Table S7. CYR61 and S100A4 are highly expressed in invasive and metastatic Breast cancer patient tissue samples. Expression analysis of CYR61 and S100A4 via fluorescence staining using biomax tissue arrays (BR 20837, BR 248a, and T 087a) with paraffin- embedded patient samples. Table indicate Array type of analyzed samples, patients age, sex, the organic tissue site, pathology diagnosis, classification of M tumors (TNM), grading, stage, type, tissue ID and for most analyzed samples the expression of estrogen (ER), progesterone (PR) and Herceptinreceptor2 (Her2). Expression of CYR61 and S100A4 was assessed as $(-)$ not expressed, $(+)$ low expression, $(++)$ medium expression, $(+++)$ high expression. B, breast; LN, lymph node.

\begin{tabular}{|c|c|c|c|c|c|c|c|c|c|c|c|c|c|c|}
\hline $\begin{array}{l}\text { Array } \\
\text { type }\end{array}$ & Age & Sex & $\begin{array}{c}\text { Organ/ } \\
\text { Anatomic } \\
\text { Site } \\
\end{array}$ & $\begin{array}{c}\text { Pathology } \\
\text { diagnosis }\end{array}$ & TNM & Grade & Stage & Type & Tissue ID. & ER & PR & HER2 & S100A4 & CYR61 \\
\hline BR 20837 & 45 & F & B & IDC & $\begin{array}{l}\text { T1N1 } \\
\text { M0 }\end{array}$ & 1 & IIA & M & Fmg 100017 & - & - & 0 & + & + \\
\hline BR 20837 & 45 & F & $\mathrm{LN}$ & $\begin{array}{l}\text { MET CA } \\
\text { from No.1 }\end{array}$ & - & - & - & MET & Fmg 100017 & - & - & 0 & - & + \\
\hline BR 20837 & 45 & F & B & IDC & $\begin{array}{c}\text { T2N2 } \\
\text { M0 }\end{array}$ & 1 & IIIA & M & Fmg 100096 & + & - & 0 & ++ & + \\
\hline BR 20837 & 45 & F & LN & $\begin{array}{l}\text { MET CA } \\
\text { from No.3 }\end{array}$ & - & - & - & MET & Fmg 100096 & - & + & 0 & + & ++ \\
\hline BR 20837 & 40 & $\mathrm{~F}$ & B & IDC & $\begin{array}{l}\text { T2N1 } \\
\text { M0 }\end{array}$ & 1 & IIB & M & Fmg 100153 & - & - & 0 & + & + \\
\hline BR 20837 & 40 & $\mathrm{~F}$ & $\mathrm{LN}$ & $\begin{array}{c}\text { MET CA } \\
\text { from No.5 } \\
\text { (LN } \\
\text { tissue) } \\
\end{array}$ & - & - & - & MET & Fmg 100153 & - & - & 0 & + & ++ \\
\hline BR 20837 & 50 & $\mathrm{~F}$ & B & IDC & $\begin{array}{c}\text { T2N1 } \\
\text { M0 }\end{array}$ & 1 & IIB & M & Fmg 070169 & - & - & $1+$ & + & ++ \\
\hline BR 20837 & 50 & F & $\mathrm{LN}$ & $\begin{array}{l}\text { MET CA } \\
\text { from No.7 }\end{array}$ & - & - & - & MET & Fmg 070169 & - & - & 0 & + & + \\
\hline BR 20837 & 49 & $\mathrm{~F}$ & B & IDC & $\begin{array}{c}\text { T3N1 } \\
\text { M0 }\end{array}$ & 1 & IIIA & M & Fmg 080061 & $\begin{array}{c}++ \\
+\end{array}$ & - & 0 & + & + \\
\hline BR 20837 & 49 & F & $\mathrm{LN}$ & $\begin{array}{l}\text { MET CA } \\
\text { from No.9 }\end{array}$ & - & - & - & MET & Fmg 080061 & $\begin{array}{c}++ \\
+ \\
\end{array}$ & - & 0 & ++ & ++ \\
\hline BR 20837 & 55 & $\mathrm{~F}$ & B & IDC & $\begin{array}{l}\text { T4N1 } \\
\text { M0 }\end{array}$ & 1 & IIIB & M & Fmg 080090 & + & - & 0 & + & + \\
\hline BR 20837 & 55 & F & LN & $\begin{array}{c}\text { MET CA } \\
\text { from } \\
\text { No.11 } \\
\end{array}$ & - & - & - & MET & Fmg 080090 & $\begin{array}{l}++ \\
+\end{array}$ & + & 0 & + & + \\
\hline BR 20837 & 66 & $\mathrm{~F}$ & B & IDC & $\begin{array}{l}\text { T2N1 } \\
\text { M0 }\end{array}$ & 1 & IIB & M & Fmg 050800 & + & ++ & $3+$ & +++ & +++ \\
\hline BR 20837 & 66 & $\mathrm{~F}$ & $\mathrm{LN}$ & $\begin{array}{l}\text { MET CA } \\
\text { from } \\
\text { No.13 }\end{array}$ & - & - & - & MET & Fmg 050800 & - & - & $3+$ & + & + \\
\hline BR 20837 & 54 & $\mathrm{~F}$ & B & IDC & $\begin{array}{l}\text { T2N1 } \\
\text { M0 }\end{array}$ & 1 & IIB & M & Fmg 060589 & - & - & $3+$ & + & + \\
\hline BR 20837 & 54 & F & $\mathrm{LN}$ & $\begin{array}{l}\text { MET CA } \\
\text { from } \\
\text { No.15 } \\
\end{array}$ & - & - & - & MET & Fmg 060589 & - & - & $3+$ & + & ++ \\
\hline BR 20837 & 46 & $\mathrm{~F}$ & B & IDC & $\begin{array}{l}\text { T2N1 } \\
\text { M0 }\end{array}$ & 2 & IIB & M & Fmg 060130 & - & - & 0 & + & ++ \\
\hline BR 20837 & 46 & F & $\mathrm{LN}$ & $\begin{array}{l}\text { MET CA } \\
\text { from } \\
\text { No.17 } \\
\end{array}$ & - & - & - & MET & Fmg 060130 & - & - & $2+$ & +++ & ++ \\
\hline BR 20837 & 48 & $\mathrm{~F}$ & B & IDC & $\begin{array}{l}\text { T2N1 } \\
\text { M0 }\end{array}$ & 2 & IIB & M & Fmg 100135 & - & - & $3+$ & +++ & +++ \\
\hline BR 20837 & 48 & F & $\mathrm{LN}$ & $\begin{array}{c}\text { MET CA } \\
\text { from } \\
\text { No.19 } \\
\end{array}$ & - & - & - & MET & Fmg 100135 & - & - & $3+$ & + & + \\
\hline BR 20837 & 55 & F & B & IDC & $\begin{array}{c}\text { T2N2 } \\
\text { M0 }\end{array}$ & 2 & IIIA & M & Fmg 100230 & - & - & $3+$ & - & + \\
\hline BR 20837 & 55 & $\mathrm{~F}$ & $\mathrm{LN}$ & $\begin{array}{c}\text { MET CA } \\
\text { from } \\
\text { No. } 21 \\
\end{array}$ & - & - & - & MET & Fmg 100230 & - & - & $3+$ & + & + \\
\hline BR 20837 & 59 & F & B & $\begin{array}{l}\text { IDC (fiBR } \\
\text { fatty } \\
\text { tissue and } \\
\text { blood } \\
\text { vessel) }\end{array}$ & $\begin{array}{l}\text { T2N1 } \\
\text { M0 }\end{array}$ & - & IIB & M & Fmg 060965 & - & - & $*$ & + & + \\
\hline BR 20837 & 59 & F & $\mathrm{LN}$ & $\begin{array}{c}\text { MET CA } \\
\text { from } \\
\text { No. } 23 \\
\end{array}$ & - & - & - & $\begin{array}{c}\text { MET } \\
\cdot \\
\end{array}$ & Fmg 060965 & - & - & $3+$ & + & ++ \\
\hline BR 20837 & 50 & F & B & IDC & $\begin{array}{l}\text { T2N2 } \\
\text { M0 }\end{array}$ & 2 & IIIA & M & Fmg 060049 & ++ & - & $1+$ & + & + \\
\hline BR 20837 & 50 & $\mathrm{~F}$ & LN & MET CA & - & - & - & MET & Fmg 060049 & ++ & - & $1+$ & + & + \\
\hline
\end{tabular}




\begin{tabular}{|c|c|c|c|c|c|c|c|c|c|c|c|c|c|c|}
\hline & & & & $\begin{array}{c}\text { from } \\
\text { No. } 25\end{array}$ & & & & . & & & & & & \\
\hline BR 20837 & 48 & $\mathrm{~F}$ & B & IDC & $\begin{array}{c}\text { T1N1 } \\
\text { M0 }\end{array}$ & 2 & IIA & M & Fmg 100062 & ++ & - & 0 & ++ & ++ \\
\hline BR 20837 & 48 & F & $\mathrm{LN}$ & $\begin{array}{c}\text { MET CA } \\
\text { from } \\
\text { No. } 27 \\
\end{array}$ & - & - & - & $\begin{array}{c}\text { MET } \\
\text {. }\end{array}$ & Fmg 100062 & - & - & 0 & + & + \\
\hline BR 20837 & 45 & $\mathrm{~F}$ & B & IDC & $\begin{array}{c}\text { T2N1 } \\
\text { M0 }\end{array}$ & 2 & IIB & M & Fmg 100181 & - & - & $3+$ & +++ & +++ \\
\hline BR 20837 & 45 & F & LN & $\begin{array}{c}\text { MET CA } \\
\text { from } \\
\text { No. } 29 \\
\end{array}$ & - & - & - & $\begin{array}{c}\text { MET } \\
\cdot\end{array}$ & Fmg 100181 & - & - & $3+$ & + & + \\
\hline BR 20837 & 55 & $\mathrm{~F}$ & B & IDC & $\begin{array}{c}\text { T2N2 } \\
\text { M0 }\end{array}$ & 2 & IIIA & M & Fmg 100167 & - & - & $3+$ & + & + \\
\hline BR 20837 & 55 & $\mathrm{~F}$ & LN & $\begin{array}{c}\text { MET CA } \\
\text { from } \\
\text { No. } 31\end{array}$ & - & - & - & $\begin{array}{c}\text { MET } \\
.\end{array}$ & Fmg 100167 & - & ++ & 0 & + & + \\
\hline BR 20837 & 39 & $\mathrm{~F}$ & B & IDC & $\begin{array}{c}\text { T3N2 } \\
\text { M0 }\end{array}$ & 2 & IIIA & M & Fmg 060256 & - & + & 0 & + & +++ \\
\hline BR 20837 & 39 & F & LN & $\begin{array}{c}\text { MET CA } \\
\text { from } \\
\text { No.33 } \\
\end{array}$ & - & - & - & $\begin{array}{c}\text { MET } \\
.\end{array}$ & Fmg 060256 & + & ++ & 0 & + & + \\
\hline BR 20837 & 54 & F & B & IDC & $\begin{array}{c}\text { T2N2 } \\
\text { M0 }\end{array}$ & 2 & IIIA & M & Fmg 100101 & + & - & 0 & + & + \\
\hline BR 20837 & 54 & $\mathrm{~F}$ & LN & $\begin{array}{c}\text { MET CA } \\
\text { from } \\
\text { No.35 }\end{array}$ & - & - & - & $\begin{array}{c}\text { MET } \\
\text {. }\end{array}$ & Fmg 100101 & - & - & 0 & ++ & ++ \\
\hline BR 20837 & 38 & $\mathrm{~F}$ & B & $\begin{array}{c}\text { IDC } \\
\text { (tumor } \\
\text { necrosis) }\end{array}$ & $\begin{array}{c}\text { T3N1 } \\
\text { M0 }\end{array}$ & - & IIB & M & Fmg 100103 & - & - & $*$ & + & +++ \\
\hline BR 20837 & 38 & F & LN & $\begin{array}{c}\text { MET CA } \\
\text { from } \\
\text { No.37 } \\
\end{array}$ & - & - & - & $\begin{array}{c}\text { MET } \\
\cdot\end{array}$ & Fmg 100103 & - & - & 0 & ++ & +++ \\
\hline BR 20837 & 49 & F & B & IDC & $\begin{array}{c}\text { T2N1 } \\
\text { M0 }\end{array}$ & 2 & IIB & M & Fmg 060127 & + & - & $3+$ & ++ & + \\
\hline BR 20837 & 49 & F & LN & $\begin{array}{c}\text { MET CA } \\
\text { from } \\
\text { No.39 }\end{array}$ & - & - & - & $\begin{array}{c}\text { MET } \\
.\end{array}$ & Fmg 060127 & - & - & $3+$ & +++ & + \\
\hline BR 20837 & 56 & F & B & IDC & $\begin{array}{c}\text { T2N1 } \\
\text { M0 }\end{array}$ & 2 & IIB & M & Fmg 060146 & - & - & $1+$ & ++ & + \\
\hline BR 20837 & 56 & F & $\mathrm{LN}$ & $\begin{array}{c}\text { MET CA } \\
\text { from } \\
\text { No.41 } \\
\end{array}$ & - & - & - & MET & Fmg 060146 & - & - & 0 & + & + \\
\hline BR 20837 & 39 & F & B & IDC & $\begin{array}{c}\text { T4N2 } \\
\text { M0 }\end{array}$ & 2 & IIIB & M & Fmg 060154 & - & - & 0 & + & + \\
\hline BR 20837 & 39 & F & $\mathrm{LN}$ & $\begin{array}{c}\text { MET CA } \\
\text { from } \\
\text { No.43 } \\
\end{array}$ & - & - & - & $\begin{array}{c}\text { MET } \\
\cdot\end{array}$ & Fmg 060154 & - & - & 0 & - & + \\
\hline BR 20837 & 52 & F & B & IDC & $\begin{array}{c}\text { T2N1 } \\
\text { M0 }\end{array}$ & 2 & IIB & M & Fmg 060191 & - & - & 0 & + & + \\
\hline BR 20837 & 52 & F & LN & $\begin{array}{c}\text { MET CA } \\
\text { from } \\
\text { No.45 } \\
\end{array}$ & - & - & - & $\begin{array}{c}\text { MET } \\
\cdot\end{array}$ & Fmg 060191 & - & - & 0 & + & + \\
\hline BR 20837 & 41 & $\mathrm{~F}$ & B & IDC & $\begin{array}{c}\text { T2N2 } \\
\text { M0 }\end{array}$ & 2 & IIIA & M & Fmg 060033 & + & ++ & 0 & + & ++ \\
\hline BR 20837 & 41 & F & LN & $\begin{array}{c}\text { MET CA } \\
\text { from } \\
\text { No.47 }\end{array}$ & - & - & - & $\begin{array}{c}\text { MET } \\
\cdot \\
\end{array}$ & Fmg 060033 & ++ & ++ & 0 & - & ++ \\
\hline BR 20837 & 69 & F & B & IDC & $\begin{array}{c}\text { T4N1 } \\
\text { M0 }\end{array}$ & 2 & IIIB & M & Fmg 050767 & $\begin{array}{c}++ \\
+ \\
\end{array}$ & - & $2+$ & ++ & ++ \\
\hline BR 20837 & 69 & $\mathrm{~F}$ & $\mathrm{LN}$ & $\begin{array}{c}\text { MET CA } \\
\text { from } \\
\text { No.49 } \\
\end{array}$ & - & - & - & $\begin{array}{c}\text { MET } \\
\cdot \\
\end{array}$ & Fmg 050767 & $\begin{array}{c}++ \\
+\end{array}$ & - & $2+$ & ++ & + \\
\hline BR 20837 & 53 & $\mathrm{~F}$ & B & IDC & $\begin{array}{c}\text { T2N2 } \\
\text { M0 }\end{array}$ & 2 & IIIA & M & Fmg 060601 & - & - & $3+$ & + & + \\
\hline BR 20837 & 53 & F & $\mathrm{LN}$ & $\begin{array}{c}\text { MET CA } \\
\text { from } \\
\text { No.51 }\end{array}$ & - & - & - & $\begin{array}{c}\text { MET } \\
\cdot\end{array}$ & Fmg 060601 & - & - & $3+$ & +++ & ++ \\
\hline BR 20837 & 54 & F & B & IDC & $\begin{array}{c}\text { T2N2 } \\
\text { M0 }\end{array}$ & 2 & IIIA & M & Fmg 100105 & - & - & 0 & +++ & + \\
\hline BR 20837 & 54 & F & LN & $\begin{array}{l}\text { MET CA } \\
\text { from } \\
\text { No.53 } \\
\text { (sparse } \\
\text { carcinoma } \\
\text { tissue) } \\
\end{array}$ & - & - & - & $\begin{array}{c}\text { MET } \\
.\end{array}$ & Fmg 100105 & - & - & 0 & + & + \\
\hline BR 20837 & 49 & $\mathrm{~F}$ & $\mathrm{~B}$ & IDC & T2N2 & 2 & IIIA & $\mathrm{M}$ & Fmg 060741 & + & + & $2+$ & + & +++ \\
\hline
\end{tabular}




\begin{tabular}{|c|c|c|c|c|c|c|c|c|c|c|c|c|c|c|}
\hline & & & & & M0 & & & & & & & & & \\
\hline BR 20837 & 49 & F & $\mathrm{LN}$ & $\begin{array}{c}\text { MET CA } \\
\text { from } \\
\text { No.55 }\end{array}$ & - & - & - & $\begin{array}{c}\text { MET } \\
\cdot\end{array}$ & Fmg 060741 & - & - & 0 & +++ & + \\
\hline BR 20837 & 60 & F & B & IDC & $\begin{array}{l}\text { T1N1 } \\
\text { M0 }\end{array}$ & 2 & IIA & M & Fmg 060771 & ++ & + & $1+$ & - & + \\
\hline BR 20837 & 60 & F & $\mathrm{LN}$ & $\begin{array}{l}\text { MET CA } \\
\text { from } \\
\text { No.57 } \\
\end{array}$ & - & - & - & $\begin{array}{c}\text { MET } \\
.\end{array}$ & Fmg 060771 & ++ & ++ & $1+$ & - & - \\
\hline BR 20837 & 50 & F & B & IDC & $\begin{array}{c}\text { T2N1 } \\
\text { M0 }\end{array}$ & 2 & IIB & M & Fmg 100224 & - & - & 0 & + & +++ \\
\hline BR 20837 & 50 & F & $\mathrm{LN}$ & $\begin{array}{c}\text { MET CA } \\
\text { from } \\
\text { No.59 } \\
\end{array}$ & - & - & - & $\begin{array}{c}\text { MET } \\
\text {. }\end{array}$ & Fmg 100224 & - & - & 0 & + & ++ \\
\hline BR 20837 & 54 & $\mathrm{~F}$ & B & IDC & $\begin{array}{c}\text { T2N2 } \\
\text { M0 }\end{array}$ & 2 & IIIA & M & Fmg 100104 & - & - & $3+$ & ++ & ++ \\
\hline BR 20837 & 54 & F & $\mathrm{LN}$ & $\begin{array}{c}\text { MET CA } \\
\text { from } \\
\text { No.61 } \\
\end{array}$ & - & - & - & $\begin{array}{c}\text { MET } \\
\text {. }\end{array}$ & Fmg 100104 & - & - & 0 & + & + \\
\hline BR 20837 & 42 & F & B & IDC & $\begin{array}{c}\text { T2N1 } \\
\text { M0 }\end{array}$ & 2 & IIB & M & Fmg 100279 & $*$ & - & $3+$ & + & + \\
\hline BR 20837 & 42 & F & $\mathrm{LN}$ & $\begin{array}{c}\text { MET CA } \\
\text { from } \\
\text { No.63 } \\
\end{array}$ & - & - & - & $\begin{array}{c}\text { MET } \\
\cdot\end{array}$ & Fmg 100279 & $*$ & - & $3+$ & + & + \\
\hline BR 20837 & 52 & $\mathrm{~F}$ & B & IDC & $\begin{array}{c}\text { T2N1 } \\
\text { M0 }\end{array}$ & 3 & IIB & M & Fmg 060773 & $\begin{array}{c}++ \\
+\end{array}$ & + & $1+$ & ++ & ++ \\
\hline BR 20837 & 52 & $\mathrm{~F}$ & $\mathrm{LN}$ & $\begin{array}{c}\text { MET CA } \\
\text { from } \\
\text { No.65 } \\
\end{array}$ & - & - & - & $\begin{array}{c}\text { MET } \\
\cdot\end{array}$ & Fmg 060773 & $\begin{array}{c}++ \\
+\end{array}$ & + & $1+$ & +++ & + \\
\hline BR 20837 & 39 & $\mathrm{~F}$ & B & IDC & $\begin{array}{c}\text { T2N1 } \\
\text { M0 }\end{array}$ & 3 & IIB & M & Fmg 060781 & - & - & $3+$ & + & + \\
\hline BR 20837 & 39 & F & $\mathrm{LN}$ & $\begin{array}{l}\text { MET CA } \\
\text { from } \\
\text { No.67 }\end{array}$ & - & - & - & $\begin{array}{c}\text { MET } \\
.\end{array}$ & Fmg 060781 & - & - & $3+$ & ++ & + \\
\hline BR 20837 & 35 & F & B & IDC & $\begin{array}{c}\text { T1N1 } \\
\text { M0 }\end{array}$ & 3 & IIA & M & Fmg 060782 & + & - & $3+$ & ++ & ++ \\
\hline BR 20837 & 35 & $\mathrm{~F}$ & $\mathrm{LN}$ & $\begin{array}{c}\text { MET CA } \\
\text { from } \\
\text { No.69 } \\
\end{array}$ & - & - & - & MET & Fmg 060782 & ++ & - & $3+$ & + & + \\
\hline BR 20837 & 51 & $\mathrm{~F}$ & B & IDC & $\begin{array}{c}\text { T2N0 } \\
\text { M0 }\end{array}$ & 3 & IIA & M & Fmg 061010 & + & + & $1+$ & ++ & +++ \\
\hline BR 20837 & 51 & F & $\mathrm{LN}$ & $\begin{array}{l}\text { MET CA } \\
\text { from } \\
\text { No.71 } \\
\end{array}$ & - & - & - & $\begin{array}{c}\text { MET } \\
\cdot \\
\end{array}$ & Fmg 061010 & + & + & $1+$ & +++ & ++ \\
\hline BR 20837 & 50 & F & B & IDC & $\begin{array}{c}\text { T4N1 } \\
\text { M0 }\end{array}$ & 3 & IIIB & M & Fmg 070122 & - & $*$ & $*$ & - & ++ \\
\hline BR 20837 & 50 & F & $\mathrm{LN}$ & $\begin{array}{c}\text { MET CA } \\
\text { from } \\
\text { No. } 73 \\
\end{array}$ & - & - & - & $\begin{array}{c}\text { MET } \\
\cdot \\
\end{array}$ & Fmg 070122 & - & - & $1+$ & - & + \\
\hline BR 20837 & 48 & F & B & IDC & $\begin{array}{c}\text { T2N1 } \\
\text { M0 }\end{array}$ & 3 & IIB & M & Fmg 050797 & + & $\begin{array}{c}++ \\
+\end{array}$ & $2+$ & - & +++ \\
\hline BR 20837 & 48 & F & $\mathrm{LN}$ & $\begin{array}{l}\text { MET CA } \\
\text { from } \\
\text { No.75 } \\
\end{array}$ & - & - & - & MET & Fmg 050797 & + & $\begin{array}{c}++ \\
+\end{array}$ & $2+$ & - & ++ \\
\hline BR 20837 & 55 & F & B & IDC & $\begin{array}{c}\text { T2N1 } \\
\text { M0 }\end{array}$ & 3 & IIB & M & Fmg 060821 & + & + & 0 & ++ & ++ \\
\hline BR 20837 & 55 & F & $\mathrm{LN}$ & $\begin{array}{l}\text { MET CA } \\
\text { from } \\
\text { No.77 }\end{array}$ & - & - & - & $\begin{array}{c}\text { MET } \\
.\end{array}$ & Fmg 060821 & + & + & 0 & - & + \\
\hline BR 20837 & 48 & F & B & IDC & $\begin{array}{c}\text { T2N2 } \\
\text { M0 }\end{array}$ & 3 & IIIA & M & Fmg 060999 & + & ++ & 0 & - & + \\
\hline BR 20837 & 48 & F & $\mathrm{LN}$ & $\begin{array}{c}\text { MET CA } \\
\text { from } \\
\text { No.79 } \\
\end{array}$ & - & - & - & $\begin{array}{c}\text { MET } \\
\text {. }\end{array}$ & Fmg 060999 & + & + & 0 & - & + \\
\hline BR 20837 & 34 & F & B & IDC & $\begin{array}{c}\text { T2N1 } \\
\text { M0 }\end{array}$ & 3 & IIB & M & Fmg 070242 & $\begin{array}{c}++ \\
+ \\
\end{array}$ & - & $1+$ & + & ++ \\
\hline BR 20837 & 34 & F & $\mathrm{LN}$ & $\begin{array}{c}\text { MET CA } \\
\text { from } \\
\text { No. } 81 \\
\end{array}$ & - & - & - & MET & Fmg 070242 & $\begin{array}{c}++ \\
+ \\
\end{array}$ & - & $1+$ & + & + \\
\hline BR 20837 & 50 & F & B & IDC & $\begin{array}{c}\text { T2N1 } \\
\text { M0 }\end{array}$ & 3 & IIB & M & Fmg 080055 & $\begin{array}{c}++ \\
+\end{array}$ & - & 0 & + & ++ \\
\hline BR 20837 & 50 & F & $\mathrm{LN}$ & $\begin{array}{c}\text { MET CA } \\
\text { from } \\
\text { No. } 83 \\
\end{array}$ & - & - & - & MET & Fmg 080055 & $\begin{array}{c}++ \\
+ \\
\end{array}$ & - & 0 & + & ++ \\
\hline BR 20837 & 32 & F & $\mathrm{B}$ & IDC & $\begin{array}{c}\text { T2N1 } \\
\text { M0 }\end{array}$ & 3 & IIB & $\mathrm{M}$ & Fmg 050793 & - & - & 0 & ++ & + \\
\hline BR 20837 & 32 & $F$ & $\mathrm{LN}$ & MET CA & - & - & - & MET & Fmg 050793 & - & - & 0 & + & ++ \\
\hline
\end{tabular}




\begin{tabular}{|c|c|c|c|c|c|c|c|c|c|c|c|c|c|c|}
\hline & & & & $\begin{array}{c}\text { from } \\
\text { No.85 }\end{array}$ & & & & . & & & & & & \\
\hline BR 20837 & 87 & $\mathrm{~F}$ & B & IDC & $\begin{array}{c}\text { T2N1 } \\
\text { M0 }\end{array}$ & 3 & IIB & M & Fmg 050794 & - & - & 0 & - & + \\
\hline BR 20837 & 87 & F & $\mathrm{LN}$ & $\begin{array}{c}\text { MET CA } \\
\text { from } \\
\text { No.87 } \\
\end{array}$ & - & - & - & $\begin{array}{c}\text { MET } \\
\text {. }\end{array}$ & Fmg 050794 & - & - & $1+$ & - & + \\
\hline BR 20837 & 50 & $\mathrm{~F}$ & B & $\begin{array}{c}\text { IDC } \\
\text { (degenerat } \\
\text { ion tissue) }\end{array}$ & $\begin{array}{c}\text { T2N1 } \\
\text { M0 }\end{array}$ & - & IIB & M & Fmg 070167 & - & - & 0 & - & + \\
\hline BR 20837 & 50 & F & LN & $\begin{array}{c}\text { MET CA } \\
\text { from } \\
\text { No. } 89 \\
\text { (degenerat } \\
\text { ion tissue) }\end{array}$ & - & - & - & $\begin{array}{c}\text { MET } \\
\cdot\end{array}$ & Fmg 070167 & - & - & 0 & - & + \\
\hline BR 20837 & 47 & F & B & IDC & $\begin{array}{c}\text { T2N1 } \\
\text { M0 }\end{array}$ & 3 & IIB & M & Fmg 061126 & - & - & $3+$ & + & ++ \\
\hline BR 20837 & 47 & $\mathrm{~F}$ & LN & $\begin{array}{l}\text { MET CA } \\
\text { from } \\
\text { No. } 91 \\
\end{array}$ & - & - & - & $\begin{array}{c}\text { MET } \\
\cdot\end{array}$ & Fmg 061126 & - & - & $3+$ & - & + \\
\hline BR 20837 & 52 & $\mathrm{~F}$ & B & IDC & $\begin{array}{l}\text { T2N1 } \\
\text { M0 }\end{array}$ & 3 & IIB & M & Fmg 070124 & - & - & $2+$ & - & ++ \\
\hline BR 20837 & 52 & F & LN & $\begin{array}{c}\text { MET CA } \\
\text { from } \\
\text { No.93 }\end{array}$ & - & - & - & $\begin{array}{c}\text { MET } \\
\text {. }\end{array}$ & Fmg 070124 & - & - & $2+$ & - & +++ \\
\hline BR 20837 & 68 & $\mathrm{~F}$ & B & IDC & $\begin{array}{c}\text { T2N1 } \\
\text { M0 }\end{array}$ & 3 & IIB & M & Fmg 060779 & - & - & 0 & + & + \\
\hline BR 20837 & 68 & F & LN & $\begin{array}{c}\text { MET CA } \\
\text { from } \\
\text { No.95 } \\
\end{array}$ & - & - & - & $\begin{array}{c}\text { MET } \\
\text {. }\end{array}$ & Fmg 060779 & - & - & 0 & - & ++ \\
\hline BR 20837 & 37 & F & B & IDC & $\begin{array}{c}\text { T3N1 } \\
\text { M0 }\end{array}$ & 3 & IIIA & M & Fmg 050765 & - & - & $3+$ & + & ++ \\
\hline BR 20837 & 37 & F & $\mathrm{LN}$ & $\begin{array}{c}\text { MET CA } \\
\text { from } \\
\text { No. } 97 \\
\end{array}$ & - & - & - & $\begin{array}{c}\text { MET } \\
.\end{array}$ & Fmg 050765 & - & - & $3+$ & ++ & + \\
\hline BR 20837 & 52 & F & B & IDC & $\begin{array}{c}\text { T2N1 } \\
\text { M0 }\end{array}$ & 3 & IIB & M & Fmg 100132 & - & - & $3+$ & + & ++ \\
\hline BR 20837 & 52 & F & LN & $\begin{array}{c}\text { MET CA } \\
\text { from } \\
\text { No.99 } \\
\end{array}$ & - & - & - & $\begin{array}{c}\text { MET } \\
\cdot\end{array}$ & Fmg 100132 & - & - & $3+$ & ++ & +++ \\
\hline BR 20837 & 33 & F & B & IDC & $\begin{array}{c}\text { T3N3 } \\
\text { M0 }\end{array}$ & 3 & IIIC & M & Fmg 060568 & - & - & $1+$ & + & ++ \\
\hline BR 20837 & 33 & $\mathrm{~F}$ & LN & $\begin{array}{l}\text { MET CA } \\
\text { from } \\
\text { No.101 } \\
\end{array}$ & - & - & - & $\begin{array}{c}\text { MET } \\
\cdot \\
\end{array}$ & Fmg 060568 & + & + & $1+$ & + & + \\
\hline BR 20837 & 47 & F & B & IDC & $\begin{array}{c}\text { T2N1 } \\
\text { M0 }\end{array}$ & 3 & IIB & M & Fmg 060588 & - & + & $2+$ & + & + \\
\hline BR 20837 & 47 & F & $\mathrm{LN}$ & $\begin{array}{l}\text { MET CA } \\
\text { from } \\
\text { No.103 } \\
\end{array}$ & - & - & - & MET & Fmg 060588 & ++ & $\begin{array}{c}++ \\
+\end{array}$ & $2+$ & + & + \\
\hline BR 20837 & 56 & F & B & IDC & $\begin{array}{c}\text { T2N1 } \\
\text { M0 }\end{array}$ & 3 & IIB & M & Fmg 110095 & - & - & 0 & + & ++ \\
\hline BR 20837 & 56 & F & $\mathrm{LN}$ & $\begin{array}{l}\text { MET CA } \\
\text { from } \\
\text { No.105 }\end{array}$ & - & - & - & $\begin{array}{c}\text { MET } \\
\text {. }\end{array}$ & Fmg 110095 & - & - & 0 & + & ++ \\
\hline BR 20837 & 42 & F & B & IDC & $\begin{array}{c}\text { T2N1 } \\
\text { M0 }\end{array}$ & 3 & IIB & M & Fmg 120083 & - & - & 0 & + & ++ \\
\hline BR 20837 & 42 & F & LN & $\begin{array}{c}\text { MET CA } \\
\text { from } \\
\text { No.107 } \\
\end{array}$ & - & - & - & $\begin{array}{c}\text { MET } \\
\cdot\end{array}$ & Fmg 120083 & - & - & 0 & + & + \\
\hline BR 20837 & 54 & F & B & IDC & $\begin{array}{c}\text { T2N1 } \\
\text { M0 }\end{array}$ & 3 & IIB & M & Fmg 060784 & - & - & $3+$ & + & ++ \\
\hline BR 20837 & 54 & F & LN & $\begin{array}{l}\text { MET CA } \\
\text { from } \\
\text { No.109 } \\
\end{array}$ & - & - & - & $\begin{array}{c}\text { MET } \\
\cdot\end{array}$ & Fmg 060784 & - & - & $3+$ & + & + \\
\hline BR 20837 & 42 & F & B & IDC & $\begin{array}{c}\text { T2N2 } \\
\text { M0 }\end{array}$ & 3 & IIIA & M & Fmg 060787 & - & - & $3+$ & + & ++ \\
\hline BR 20837 & 42 & $\mathrm{~F}$ & $\mathrm{LN}$ & $\begin{array}{c}\text { MET CA } \\
\text { from } \\
\text { No.111 } \\
\end{array}$ & - & - & - & MET & Fmg 060787 & - & - & $3+$ & + & ++ \\
\hline BR 20837 & 31 & F & B & IDC & $\begin{array}{c}\text { T3N1 } \\
\text { M0 }\end{array}$ & 3 & IIIA & M & Fmg 050134 & ++ & ++ & 0 & ++ & ++ \\
\hline BR 20837 & 31 & F & LN & $\begin{array}{l}\text { MET CA } \\
\text { from } \\
\text { No.113 } \\
\text { (chronic } \\
\text { inflammat }\end{array}$ & - & - & - & $\begin{array}{c}\text { MET } \\
.\end{array}$ & Fmg 050134 & - & - & 0 & + & + \\
\hline
\end{tabular}




\begin{tabular}{|c|c|c|c|c|c|c|c|c|c|c|c|c|c|c|}
\hline & & & & $\begin{array}{c}\text { ion with } \\
\text { fiBR ous } \\
\text { tissue and } \\
\text { blood } \\
\text { vessel) }\end{array}$ & & & & & & & & & & \\
\hline BR 20837 & 40 & F & B & IDC & $\begin{array}{l}\text { T2N1 } \\
\text { M0 }\end{array}$ & 3 & IIB & M & Fmg 060963 & $\begin{array}{c}++ \\
+\end{array}$ & ++ & $2+$ & ++ & ++ \\
\hline BR 20837 & 40 & F & $\mathrm{LN}$ & $\begin{array}{c}\text { MET CA } \\
\text { from } \\
\text { No. } 115 \\
\end{array}$ & - & - & - & $\begin{array}{c}\text { MET } \\
.\end{array}$ & Fmg 060963 & - & - & 0 & + & + \\
\hline BR 20837 & 50 & F & B & IDC & $\begin{array}{l}\text { T2N1 } \\
\text { M0 }\end{array}$ & 3 & IIB & M & Fmg 120115 & ++ & - & 0 & + & + \\
\hline BR 20837 & 50 & F & $\mathrm{LN}$ & $\begin{array}{l}\text { MET CA } \\
\text { from } \\
\text { No.117 } \\
\end{array}$ & - & - & - & $\begin{array}{c}\text { MET } \\
\cdot\end{array}$ & Fmg 120115 & ++ & - & 0 & + & + \\
\hline BR 20837 & 37 & F & B & IDC & $\begin{array}{c}\text { T2N1 } \\
\text { M0 }\end{array}$ & 3 & IIB & M & Fmg 080106 & - & - & $1+$ & - & + \\
\hline BR 20837 & 37 & $\mathrm{~F}$ & $\mathrm{LN}$ & $\begin{array}{c}\text { MET CA } \\
\text { from } \\
\text { No.119 } \\
\end{array}$ & - & - & - & $\begin{array}{c}\text { MET } \\
\cdot\end{array}$ & Fmg 080106 & - & - & $1+$ & - & + \\
\hline BR 20837 & 32 & $\mathrm{~F}$ & B & IDC & $\begin{array}{l}\text { T2N1 } \\
\text { M0 }\end{array}$ & 3 & IIB & M & Fmg 060594 & + & ++ & 0 & +++ & ++ \\
\hline BR 20837 & 32 & F & $\mathrm{LN}$ & $\begin{array}{l}\text { MET CA } \\
\text { from } \\
\text { No. } 121\end{array}$ & - & - & - & $\begin{array}{c}\text { MET } \\
\cdot\end{array}$ & Fmg 060594 & - & ++ & 0 & ++ & + \\
\hline BR 20837 & 51 & $\mathrm{~F}$ & B & IDC & $\begin{array}{c}\text { T2N1 } \\
\text { M0 }\end{array}$ & 3 & IIB & M & Fmg 060597 & - & - & $3+$ & + & ++ \\
\hline BR 20837 & 51 & F & $\mathrm{LN}$ & $\begin{array}{c}\text { MET CA } \\
\text { from } \\
\text { No. } 123 \\
\end{array}$ & - & - & - & $\begin{array}{c}\text { MET } \\
\cdot\end{array}$ & Fmg 060597 & + & - & $3+$ & + & +++ \\
\hline BR 20837 & 52 & F & B & IDC & $\begin{array}{l}\text { T1N1 } \\
\text { M0 }\end{array}$ & 3 & IIA & M & Fmg 100020 & $\begin{array}{c}++ \\
+\end{array}$ & - & 0 & + & + \\
\hline BR 20837 & 52 & F & $\mathrm{LN}$ & $\begin{array}{c}\text { MET CA } \\
\text { from } \\
\text { No.125 } \\
\text { (LN } \\
\text { tissue) } \\
\end{array}$ & - & - & - & $\begin{array}{c}\text { MET } \\
\cdot\end{array}$ & Fmg 100020 & - & - & 0 & ++ & + \\
\hline BR 20837 & 45 & F & B & IDC & $\begin{array}{c}\text { T2N1 } \\
\text { M0 }\end{array}$ & 3 & IIB & M & Fmg 100235 & - & - & $1+$ & - & ++ \\
\hline BR 20837 & 45 & F & $\mathrm{LN}$ & $\begin{array}{l}\text { MET CA } \\
\text { from } \\
\text { No. } 127 \\
\end{array}$ & - & - & - & $\begin{array}{c}\text { MET } \\
\cdot\end{array}$ & Fmg 100235 & - & - & $1+$ & - & + \\
\hline BR 20837 & 49 & F & B & IDC & $\begin{array}{l}\text { T2N2 } \\
\text { M0 }\end{array}$ & 3 & IIIA & M & Fmg 100041 & - & - & 0 & + & + \\
\hline BR 20837 & 49 & $\mathrm{~F}$ & $\mathrm{LN}$ & $\begin{array}{c}\text { MET CA } \\
\text { from } \\
\text { No.129 } \\
\end{array}$ & - & - & - & $\begin{array}{c}\text { MET } \\
\cdot\end{array}$ & Fmg 100041 & - & - & 0 & - & + \\
\hline BR 20837 & 32 & F & B & IDC & $\begin{array}{c}\text { T2N2 } \\
\text { M0 }\end{array}$ & 3 & IIIA & M & Fmg 060426 & - & - & $1+$ & + & + \\
\hline BR 20837 & 32 & F & $\mathrm{LN}$ & $\begin{array}{c}\text { MET CA } \\
\text { from } \\
\text { No.131 } \\
\text { (LN } \\
\text { tissue) } \\
\end{array}$ & - & - & - & $\begin{array}{c}\text { MET } \\
.\end{array}$ & Fmg 060426 & + & - & $1+$ & ++ & ++ \\
\hline BR 20837 & 46 & F & B & $\begin{array}{c}\text { IDC (B } \\
\text { tissue) }\end{array}$ & $\begin{array}{l}\text { T2N1 } \\
\text { M0 }\end{array}$ & - & IIB & M & Fmg 060211 & - & - & $*$ & - & + \\
\hline BR 20837 & 46 & F & $\mathrm{LN}$ & $\begin{array}{c}\text { MET CA } \\
\text { from } \\
\text { No.133 } \\
\end{array}$ & - & - & - & $\begin{array}{c}\text { MET } \\
.\end{array}$ & Fmg 060211 & - & - & $3+$ & + & ++ \\
\hline BR 20837 & 44 & F & B & IDC & $\begin{array}{c}\text { T2N2 } \\
\text { M0 }\end{array}$ & 3 & IIIA & M & Fmg 060391 & - & - & $3+$ & - & + \\
\hline BR 20837 & 44 & F & $\mathrm{LN}$ & $\begin{array}{c}\text { MET CA } \\
\text { from } \\
\text { No.135 } \\
\end{array}$ & - & - & - & $\begin{array}{c}\text { MET } \\
\cdot\end{array}$ & Fmg 060391 & $\begin{array}{c}++ \\
+\end{array}$ & ++ & $2+$ & - & + \\
\hline BR 20837 & 45 & F & B & IDC & $\begin{array}{l}\text { T2N1 } \\
\text { M0 }\end{array}$ & 1 & IIB & M & Fmg 100069 & - & - & $3+$ & + & + \\
\hline BR 20837 & 45 & F & $\mathrm{LN}$ & $\begin{array}{c}\text { MET CA } \\
\text { from } \\
\text { No.137 } \\
\end{array}$ & - & - & - & $\begin{array}{c}\text { MET } \\
\cdot\end{array}$ & Fmg 100069 & - & - & $3+$ & - & + \\
\hline BR 20837 & 45 & F & B & IDC & $\begin{array}{c}\text { T2N2 } \\
\text { M0 }\end{array}$ & 3 & IIIA & M & Fmg 120025 & + & - & 0 & - & + \\
\hline BR 20837 & 45 & F & $\mathrm{LN}$ & $\begin{array}{c}\text { MET CA } \\
\text { from } \\
\text { No.139 } \\
\end{array}$ & - & - & - & $\begin{array}{c}\text { MET } \\
\cdot\end{array}$ & Fmg 120025 & ++ & - & 0 & - & + \\
\hline BR 20837 & 48 & $\mathrm{~F}$ & $\mathrm{~B}$ & IDC & $\begin{array}{l}\text { T2N1 } \\
\text { M0 }\end{array}$ & 3 & IIB & $\mathrm{M}$ & Fmg 110034 & - & - & 0 & +++ & ++ \\
\hline BR 20837 & 48 & $\mathrm{~F}$ & $\mathrm{LN}$ & MET CA & - & - & - & MET & Fmg 110034 & - & - & 0 & ++ & + \\
\hline
\end{tabular}




\begin{tabular}{|c|c|c|c|c|c|c|c|c|c|c|c|c|c|c|}
\hline & & & & $\begin{array}{c}\text { from } \\
\text { No.141 }\end{array}$ & & & & . & & & & & & \\
\hline BR 20837 & 48 & $\mathrm{~F}$ & B & IDC & $\begin{array}{c}\text { T2N1 } \\
\text { M0 }\end{array}$ & 3 & IIB & M & Fmg 100217 & - & - & $3+$ & - & + \\
\hline BR 20837 & 48 & $\mathrm{~F}$ & $\mathrm{LN}$ & $\begin{array}{c}\text { MET CA } \\
\text { from } \\
\text { No.143 } \\
\text { (necrosis } \\
\text { tissue) }\end{array}$ & - & - & - & MET & Fmg 100217 & $*$ & - & $*$ & - & ++ \\
\hline BR 20837 & 35 & $\mathrm{~F}$ & B & IDC & $\begin{array}{l}\text { T2N2 } \\
\text { M0 }\end{array}$ & 3 & IIIA & M & Fmg 090034 & - & - & 0 & ++ & +++ \\
\hline BR 20837 & 35 & $\mathrm{~F}$ & LN & $\begin{array}{l}\text { MET CA } \\
\text { from } \\
\text { No.145 } \\
\end{array}$ & - & - & - & $\begin{array}{c}\text { MET } \\
\text {. }\end{array}$ & Fmg 090034 & - & - & $1+$ & +++ & +++ \\
\hline BR 20837 & 43 & $\mathrm{~F}$ & B & IDC & $\begin{array}{l}\text { T2N1 } \\
\text { M0 }\end{array}$ & 3 & IIB & M & Fmg 080053 & - & - & $1+$ & ++ & +++ \\
\hline BR 20837 & 43 & $\mathrm{~F}$ & $\mathrm{LN}$ & $\begin{array}{c}\text { MET CA } \\
\text { from } \\
\text { No.147 } \\
\end{array}$ & - & - & - & $\begin{array}{c}\text { MET } \\
\cdot\end{array}$ & Fmg 080053 & - & - & $2+$ & ++ & ++ \\
\hline BR 20837 & 51 & $\mathrm{~F}$ & B & IDC & $\begin{array}{c}\text { T3N2 } \\
\text { M0 }\end{array}$ & 3 & IIIA & M & Fmg 070120 & - & $*$ & $*$ & - & - \\
\hline BR 20837 & 51 & $\mathrm{~F}$ & LN & $\begin{array}{c}\text { MET CA } \\
\text { from } \\
\text { No.149 } \\
\end{array}$ & - & - & - & $\begin{array}{c}\text { MET } \\
\cdot\end{array}$ & Fmg 070120 & - & $*$ & $*$ & - & - \\
\hline BR 20837 & 50 & $\mathrm{~F}$ & B & IDC & $\begin{array}{c}\text { T3N1 } \\
\text { M0 }\end{array}$ & 3 & IIIA & M & Fmg 100292 & ++ & + & $1+$ & ++ & ++ \\
\hline BR 20837 & 50 & $\mathrm{~F}$ & $\mathrm{LN}$ & $\begin{array}{l}\text { MET CA } \\
\text { from } \\
\text { No.151 } \\
\end{array}$ & - & - & - & $\begin{array}{c}\text { MET } \\
.\end{array}$ & Fmg 100292 & + & - & $1+$ & +++ & +++ \\
\hline BR 20837 & 42 & $\mathrm{~F}$ & B & IDC & $\begin{array}{c}\text { T2N1 } \\
\text { M0 }\end{array}$ & 3 & IIB & M & Fmg 100148 & - & - & $2+$ & + & + \\
\hline BR 20837 & 42 & $\mathrm{~F}$ & $\mathrm{LN}$ & $\begin{array}{l}\text { MET CA } \\
\text { from } \\
\text { No.153 }\end{array}$ & - & - & - & $\begin{array}{c}\text { MET } \\
.\end{array}$ & Fmg 100148 & - & ++ & 0 & + & + \\
\hline BR 20837 & 72 & $\mathrm{~F}$ & B & $\begin{array}{c}\text { IDC } \\
\text { (sparse) }\end{array}$ & $\begin{array}{l}\text { T2N1 } \\
\text { M0 }\end{array}$ & 3 & IIB & M & Fmg 080070 & - & - & 0 & + & + \\
\hline BR 20837 & 72 & $\mathrm{~F}$ & LN & $\begin{array}{l}\text { MET CA } \\
\text { from } \\
\text { No.155 } \\
\end{array}$ & - & - & - & $\begin{array}{c}\text { MET } \\
\cdot\end{array}$ & Fmg 080070 & - & - & $3+$ & + & + \\
\hline BR 20837 & 79 & $\mathrm{~F}$ & B & IDC & $\begin{array}{c}\text { T2N1 } \\
\text { M0 }\end{array}$ & 3 & IIB & M & Fmg 060580 & - & - & 0 & + & ++ \\
\hline BR 20837 & 79 & $\mathrm{~F}$ & $\mathrm{LN}$ & $\begin{array}{l}\text { MET CA } \\
\text { from } \\
\text { No.157 } \\
\end{array}$ & - & - & - & $\begin{array}{c}\text { MET } \\
\cdot\end{array}$ & Fmg 060580 & - & - & 0 & ++ & + \\
\hline BR 20837 & 50 & $\mathrm{~F}$ & B & IDC & $\begin{array}{c}\text { T2N1 } \\
\text { M0 }\end{array}$ & 3 & IIA & M & Fmg 100164 & - & - & 0 & + & + \\
\hline BR 20837 & 50 & $\mathrm{~F}$ & $\mathrm{LN}$ & $\begin{array}{l}\text { MET CA } \\
\text { from } \\
\text { No.159 } \\
\end{array}$ & - & - & - & MET & Fmg 100164 & - & - & 0 & + & + \\
\hline BR 20837 & 48 & $\mathrm{~F}$ & B & IDC & $\begin{array}{c}\text { T2N1 } \\
\text { M0 }\end{array}$ & 3 & IIB & M & Fmg 100067 & $\begin{array}{c}++ \\
+ \\
\end{array}$ & - & 0 & + & + \\
\hline BR 20837 & 48 & $\mathrm{~F}$ & $\mathrm{LN}$ & $\begin{array}{l}\text { MET CA } \\
\text { from } \\
\text { No.161 } \\
\text { (MET CA } \\
\text { of fiBR } \\
\text { ofatty } \\
\text { tissue) } \\
\end{array}$ & - & - & - & $\begin{array}{c}\text { MET } \\
\cdot\end{array}$ & Fmg 100067 & $\begin{array}{c}++ \\
+\end{array}$ & - & 0 & + & + \\
\hline BR 20837 & 47 & F & B & IDC & $\begin{array}{c}\text { T4N1 } \\
\text { M0 }\end{array}$ & 3 & IIIB & M & Fmg 060077 & ++ & + & 0 & + & ++ \\
\hline BR 20837 & 47 & $\mathrm{~F}$ & $\mathrm{LN}$ & $\begin{array}{l}\text { MET CA } \\
\text { from } \\
\text { No.163 } \\
\end{array}$ & - & - & - & $\begin{array}{c}\text { MET } \\
\cdot\end{array}$ & Fmg 060077 & $\begin{array}{l}++ \\
+\end{array}$ & $\begin{array}{c}++ \\
+\end{array}$ & 0 & + & - \\
\hline BR 20837 & 54 & $\mathrm{~F}$ & B & IDC & $\begin{array}{l}\text { T2N1 } \\
\text { M0 }\end{array}$ & 3 & IIB & M & Fmg 100244 & - & - & $2+$ & +++ & +++ \\
\hline BR 20837 & 54 & $\mathrm{~F}$ & $\mathrm{LN}$ & $\begin{array}{c}\text { MET CA } \\
\text { from } \\
\text { No. } 165 \\
\end{array}$ & - & - & - & $\begin{array}{c}\text { MET } \\
\cdot \\
\end{array}$ & Fmg 100244 & - & - & 0 & - & +++ \\
\hline BR 20837 & 54 & $\mathrm{~F}$ & B & IDC & $\begin{array}{l}\text { T2N2 } \\
\text { M0 }\end{array}$ & 3 & IIIA & M & Fmg 100245 & $\begin{array}{c}++ \\
+ \\
\end{array}$ & + & $1+$ & + & +++ \\
\hline BR 20837 & 54 & $\mathrm{~F}$ & $\mathrm{LN}$ & $\begin{array}{c}\text { MET CA } \\
\text { from } \\
\text { No.167 } \\
\end{array}$ & - & - & - & $\begin{array}{c}\text { MET } \\
\cdot\end{array}$ & Fmg 100245 & $\begin{array}{c}++ \\
+ \\
\end{array}$ & + & $1+$ & + & + \\
\hline BR 20837 & 43 & F & B & IDC & $\begin{array}{l}\text { T1N1 } \\
\text { M0 }\end{array}$ & 3 & IIA & M & Fmg 100066 & $\begin{array}{l}++ \\
+ \\
\end{array}$ & - & 0 & - & - \\
\hline BR 20837 & 43 & $\mathrm{~F}$ & $\mathrm{LN}$ & $\begin{array}{l}\text { MET CA } \\
\text { from }\end{array}$ & - & - & - & MET & Fmg 100066 & $\begin{array}{l}++ \\
+ \\
\end{array}$ & - & 0 & + & + \\
\hline
\end{tabular}


54

\begin{tabular}{|c|c|c|c|c|c|c|c|c|c|c|c|c|c|c|}
\hline & & & & No.169 & & & & & & & & & & \\
\hline BR 20837 & 42 & F & B & IDC & $\begin{array}{c}\text { T2N1 } \\
\text { M0 }\end{array}$ & 3 & IIB & M & Fmg 120054 & - & - & 0 & - & ++ \\
\hline BR 20837 & 42 & $\mathrm{~F}$ & $\mathrm{LN}$ & $\begin{array}{c}\text { MET CA } \\
\text { from } \\
\text { No.171 } \\
\end{array}$ & - & - & - & $\begin{array}{c}\text { MET } \\
.\end{array}$ & Fmg 120054 & - & - & 0 & + & + \\
\hline BR 20837 & 50 & $\mathrm{~F}$ & B & ILC & $\begin{array}{c}\text { T2N1 } \\
\text { M0 }\end{array}$ & - & IIB & M & Fmg 070246 & - & - & 0 & - & + \\
\hline BR 20837 & 50 & F & $\mathrm{LN}$ & $\begin{array}{c}\text { MET CA } \\
\text { from } \\
\text { No.173 } \\
\end{array}$ & - & - & - & $\begin{array}{c}\text { MET } \\
\cdot\end{array}$ & Fmg 070246 & - & - & 0 & - & ++ \\
\hline BR 20837 & 19 & $\mathrm{~F}$ & B & ILC & $\begin{array}{c}\text { T2N1 } \\
\text { M0 }\end{array}$ & - & IIB & M & Fmg 070179 & + & - & $2+$ & - & ++ \\
\hline BR 20837 & 19 & F & $\mathrm{LN}$ & $\begin{array}{l}\text { MET CA } \\
\text { from } \\
\text { No. } 175\end{array}$ & - & - & - & MET & Fmg 070179 & + & - & $2+$ & - & + \\
\hline BR 20837 & 55 & $\mathrm{~F}$ & B & ILC & $\begin{array}{c}\text { T2N2 } \\
\text { M0 }\end{array}$ & - & IIIA & M & Fmg 100027 & - & - & $3+$ & + & ++ \\
\hline BR 20837 & 55 & $\mathrm{~F}$ & $\mathrm{LN}$ & $\begin{array}{l}\text { MET CA } \\
\text { from } \\
\text { No.177 }\end{array}$ & - & - & - & $\begin{array}{c}\text { MET } \\
\cdot\end{array}$ & Fmg 100027 & - & - & $3+$ & + & +++ \\
\hline BR 20837 & 45 & $\mathrm{~F}$ & B & ILC & $\begin{array}{c}\text { T2N1 } \\
\text { M0 }\end{array}$ & - & IIB & M & Fmg 100047 & - & - & 0 & + & ++ \\
\hline BR 20837 & 45 & F & $\mathrm{LN}$ & $\begin{array}{c}\text { MET CA } \\
\text { from } \\
\text { No.179 } \\
\end{array}$ & - & - & - & $\begin{array}{c}\text { MET } \\
\cdot\end{array}$ & Fmg 100047 & - & - & 0 & + & ++ \\
\hline BR 20837 & 55 & $\mathrm{~F}$ & B & ILC & $\begin{array}{c}\text { T2N1 } \\
\text { M0 }\end{array}$ & - & IIB & M & Fmg 110031 & + & - & 0 & + & +++ \\
\hline BR 20837 & 55 & F & $\mathrm{LN}$ & $\begin{array}{l}\text { MET CA } \\
\text { from } \\
\text { No.181 } \\
\end{array}$ & - & - & - & MET & Fmg 110031 & ++ & - & 0 & + & ++ \\
\hline BR 20837 & 54 & F & B & ILC & $\begin{array}{l}\text { T2N1 } \\
\text { M0 }\end{array}$ & - & IIB & M & Fmg 100044 & - & - & 0 & + & + \\
\hline BR 20837 & 54 & F & $\mathrm{LN}$ & $\begin{array}{c}\text { MET CA } \\
\text { from } \\
\text { No.183 } \\
\end{array}$ & - & - & - & $\begin{array}{c}\text { MET } \\
\cdot\end{array}$ & Fmg 100044 & - & - & 0 & - & + \\
\hline BR 20837 & 74 & F & B & ILC & $\begin{array}{c}\text { T2N1 } \\
\text { M0 }\end{array}$ & - & IIB & M & Fmg 060128 & - & - & 0 & + & ++ \\
\hline BR 20837 & 74 & F & $\mathrm{LN}$ & $\begin{array}{c}\text { MET CA } \\
\text { from } \\
\text { No.185 } \\
\end{array}$ & - & - & - & $\begin{array}{c}\text { MET } \\
\cdot\end{array}$ & Fmg 060128 & - & - & 0 & + & + \\
\hline BR 20837 & 51 & F & B & $\begin{array}{l}\text { ILC (fiBR } \\
\text { ofatty } \\
\text { tissue and } \\
\text { blood } \\
\text { vessel) }\end{array}$ & $\begin{array}{l}\text { T2N1 } \\
\text { M0 }\end{array}$ & - & IIB & M & Fmg 100212 & - & - & $*$ & + & + \\
\hline BR 20837 & 51 & F & $\mathrm{LN}$ & $\begin{array}{c}\text { MET CA } \\
\text { from } \\
\text { No.187 } \\
\end{array}$ & - & - & - & MET & Fmg 100212 & - & - & 0 & + & - \\
\hline BR 20837 & 50 & F & B & $\begin{array}{l}\text { Medullary } \\
\text { carcinoma }\end{array}$ & $\begin{array}{c}\text { T3N1 } \\
\text { M0 }\end{array}$ & - & IIIA & M & Fmg 080030 & - & - & 0 & + & + \\
\hline BR 20837 & 50 & F & $\mathrm{LN}$ & $\begin{array}{c}\text { MET CA } \\
\text { from } \\
\text { No.189 } \\
\end{array}$ & - & - & - & $\begin{array}{c}\text { MET } \\
\cdot\end{array}$ & Fmg 080030 & - & - & 0 & + & + \\
\hline BR 20837 & 48 & F & B & $\begin{array}{c}\text { Invasive } \\
\text { micro } \\
\text { papillary } \\
\text { carcinoma }\end{array}$ & $\begin{array}{l}\text { T2N1 } \\
\text { M0 }\end{array}$ & - & IIB & M & Fmg 120067 & ++ & + & $2+$ & + & + \\
\hline BR 20837 & 48 & $\mathrm{~F}$ & $\mathrm{LN}$ & $\begin{array}{l}\text { MET CA } \\
\text { from } \\
\text { No.191 } \\
\end{array}$ & - & - & - & $\begin{array}{c}\text { MET } \\
\text {. }\end{array}$ & Fmg 120067 & ++ & + & $2+$ & - & + \\
\hline BR 20837 & 50 & F & B & $\begin{array}{c}\text { Mixed } \\
\text { carcinoma } \\
\text { (IDC and } \\
\text { ILC) }\end{array}$ & $\begin{array}{c}\text { T3N2 } \\
\text { M0 }\end{array}$ & - & IIIA & M & Fmg 060600 & ++ & - & $2+$ & + & + \\
\hline BR 20837 & 50 & F & $\mathrm{LN}$ & $\begin{array}{c}\text { MET CA } \\
\text { from } \\
\text { No.193 } \\
\end{array}$ & - & - & - & $\begin{array}{c}\text { MET } \\
.\end{array}$ & Fmg 060600 & ++ & - & $2+$ & + & ++ \\
\hline BR 20837 & 65 & $\mathrm{~F}$ & B & $\begin{array}{c}\text { Mixed } \\
\text { carcinoma } \\
\text { (IDC and } \\
\text { ILC ) }\end{array}$ & $\begin{array}{l}\text { T1N1 } \\
\text { M0 }\end{array}$ & - & IIA & M & Fmg 060775 & ++ & $\begin{array}{l}++ \\
+\end{array}$ & $2+$ & +++ & + \\
\hline BR 20837 & 65 & $\mathrm{~F}$ & $\mathrm{LN}$ & $\begin{array}{c}\text { MET CA } \\
\text { from } \\
\text { No.195 } \\
\end{array}$ & - & - & - & $\begin{array}{c}\text { MET } \\
\cdot\end{array}$ & Fmg 060775 & ++ & $\begin{array}{l}++ \\
+\end{array}$ & $2+$ & +++ & + \\
\hline BR 20837 & 54 & $\mathrm{~F}$ & B & $\begin{array}{c}\text { Mixed } \\
\text { carcinoma }\end{array}$ & $\begin{array}{l}\text { T2N1 } \\
\text { M0 }\end{array}$ & - & IIB & M & Fmg 100221 & + & - & $3+$ & + & + \\
\hline
\end{tabular}




\begin{tabular}{|c|c|c|c|c|c|c|c|c|c|c|c|c|c|c|}
\hline & & & & $\begin{array}{l}\text { (IDC and } \\
\text { ILC) }\end{array}$ & & & & & & & & & & \\
\hline BR 20837 & 54 & F & $\mathrm{LN}$ & $\begin{array}{l}\text { MET CA } \\
\text { from } \\
\text { No.197 }\end{array}$ & - & - & - & $\begin{array}{c}\text { MET } \\
\cdot\end{array}$ & Fmg 100221 & - & - & $3+$ & - & + \\
\hline BR 20837 & 43 & F & B & $\begin{array}{c}\text { Mixed } \\
\text { carcinoma } \\
\text { (IDC and } \\
\text { ILC ) }\end{array}$ & $\begin{array}{l}\text { T2N1 } \\
\text { M0 }\end{array}$ & - & IIB & M & Fmg 070244 & ++ & - & $2+$ & + & + \\
\hline BR 20837 & 43 & F & $\mathrm{LN}$ & $\begin{array}{l}\text { MET CA } \\
\text { from } \\
\text { No.199 } \\
\end{array}$ & - & - & - & $\begin{array}{c}\text { MET } \\
\cdot\end{array}$ & Fmg 070244 & ++ & - & $2+$ & + & + \\
\hline BR 20837 & 48 & F & B & $\begin{array}{c}\text { Mixed } \\
\text { carcinoma } \\
\text { (IDC and } \\
\text { ILC ) }\end{array}$ & $\begin{array}{l}\text { T2N2 } \\
\text { M0 }\end{array}$ & - & IIIA & M & Fmg 110129 & - & - & $3+$ & - & + \\
\hline BR 20837 & 48 & F & $\mathrm{LN}$ & $\begin{array}{l}\text { MET CA } \\
\text { from } \\
\text { No.201 }\end{array}$ & - & - & - & $\begin{array}{c}\text { MET } \\
.\end{array}$ & Fmg 110129 & - & - & $3+$ & + & + \\
\hline BR 20837 & 45 & $\mathrm{~F}$ & B & $\begin{array}{c}\text { Mixed } \\
\text { carcinoma } \\
\text { (IDC and } \\
\text { ILC ) }\end{array}$ & $\begin{array}{l}\text { T2N1 } \\
\text { M0 }\end{array}$ & - & IIB & M & Fmg 100054 & - & - & 0 & + & + \\
\hline BR 20837 & 45 & F & $\mathrm{LN}$ & $\begin{array}{l}\text { MET CA } \\
\text { from } \\
\text { No.203 } \\
\end{array}$ & - & - & - & $\begin{array}{c}\text { MET } \\
\cdot\end{array}$ & Fmg 100054 & - & - & 0 & + & + \\
\hline BR 20837 & 43 & F & B & $\begin{array}{c}\text { Mixed } \\
\text { carcinoma } \\
\text { (IDC and } \\
\text { ILC) }\end{array}$ & $\begin{array}{c}\text { T2N2 } \\
\text { M0 }\end{array}$ & - & IIIA & M & Fmg 100273 & ++ & ++ & 0 & + & ++ \\
\hline BR 20837 & 43 & F & $\mathrm{LN}$ & $\begin{array}{l}\text { MET CA } \\
\text { from } \\
\text { No.205 }\end{array}$ & - & - & - & $\begin{array}{c}\text { MET } \\
.\end{array}$ & Fmg 100273 & ++ & ++ & 0 & + & ++ \\
\hline BR 20837 & 49 & F & B & $\begin{array}{c}\text { Mixed } \\
\text { carcinoma } \\
\text { (sparse } \\
\text { IDC and } \\
\text { ILC ) }\end{array}$ & $\begin{array}{l}\text { T2N2 } \\
\text { M0 }\end{array}$ & - & IIIA & M & Fmg 060250 & - & - & $*$ & - & +++ \\
\hline BR 20837 & 49 & $\mathrm{~F}$ & $\mathrm{LN}$ & $\begin{array}{c}\text { MET CA } \\
\text { from } \\
\text { No. } 207 \\
\end{array}$ & - & - & - & $\begin{array}{c}\text { MET } \\
\cdot\end{array}$ & Fmg 060250 & - & - & $3+$ & + & + \\
\hline BR 248a & 34 & F & B & IDC & $\begin{array}{c}\text { T3N0 } \\
\text { M0 }\end{array}$ & $1--2$ & IIB & M & Fmg 040048 & & & & +++ & + \\
\hline BR 248a & 37 & F & B & IDC & $\begin{array}{l}\text { T2N0 } \\
\text { M0 }\end{array}$ & $1--2$ & IIA & M & Fmg 020357 & & & & +++ & ++ \\
\hline BR 248a & 60 & F & B & IDC & $\begin{array}{c}\text { T2N0 } \\
\text { M0 }\end{array}$ & 2 & IIA & M & Fmg 040031 & & & & ++ & - \\
\hline BR 248a & 57 & F & B & IDC & $\begin{array}{c}\text { T2N0 } \\
\text { M0 }\end{array}$ & 2 & IIA & M & Fmg 040001 & & & & + & - \\
\hline BR 248a & 38 & F & B & IDC & $\begin{array}{c}\text { T1N0 } \\
\text { M0 }\end{array}$ & 2 & I & M & Fmg 040052 & & & & +++ & + \\
\hline BR 248a & 55 & F & B & IDC & $\begin{array}{l}\text { T2N0 } \\
\text { M0 }\end{array}$ & 2 & IIA & M & Fmg 040104 & & & & +++ & ++ \\
\hline BR 248a & 45 & F & B & IDC & $\begin{array}{c}\text { T2N0 } \\
\text { M0 }\end{array}$ & 2 & IIA & M & Fmg 040113 & & & & +++ & - \\
\hline BR 248a & 48 & F & B & IDC & $\begin{array}{c}\text { T2N0 } \\
\text { M0 }\end{array}$ & 2 & IIA & M & Fmg 040118 & & & & ++ & - \\
\hline BR 248a & 58 & F & B & IDC & $\begin{array}{c}\text { T2N0 } \\
\text { M0 }\end{array}$ & 2 & IIA & M & Fmg 040120 & & & & ++ & + \\
\hline BR 248a & 34 & F & B & IDC & $\begin{array}{c}\text { T2N0 } \\
\text { M0 }\end{array}$ & 2 & IIA & M & Fmg 040123 & & & & ++ & ++ \\
\hline BR 248a & 49 & F & B & IDC & $\begin{array}{c}\text { T2N0 } \\
\text { M0 }\end{array}$ & 2 & IIA & M & Fmg 040125 & & & & ++ & ++ \\
\hline BR 248a & 58 & F & B & IDC & $\begin{array}{l}\text { T2N0 } \\
\text { M0 }\end{array}$ & 2 & IIA & M & Fmg 040130 & & & & + & ++ \\
\hline BR 248a & 38 & F & B & IDC & $\begin{array}{l}\text { T2N1 } \\
\text { M0 }\end{array}$ & 2 & IIB & M & Fmg 040131 & & & & ++ & +++ \\
\hline BR 248a & 79 & F & B & IDC & $\begin{array}{l}\text { T2N1 } \\
\text { M0 }\end{array}$ & 3 & IIB & M & Fmg 010491 & & & & + & - \\
\hline BR 248a & 43 & F & B & IDC & $\begin{array}{l}\text { T2N0 } \\
\text { M0 }\end{array}$ & 3 & IIA & M & Fmg 040004 & & & & - & - \\
\hline BR 248a & 46 & F & $\mathrm{B}$ & IDC & $\begin{array}{c}\text { T3N0 } \\
\text { M0 }\end{array}$ & 3 & IIB & M & Fmg 040074 & & & & ++ & ++ \\
\hline BR 248a & 76 & F & B & IDC & $\begin{array}{c}\text { T4N0 } \\
\text { M0 }\end{array}$ & 3 & IIIB & M & Fmg 010789 & & & & + & + \\
\hline BR 248a & 47 & F & B & $\begin{array}{l}\text { Medullary } \\
\text { carcinoma }\end{array}$ & $\begin{array}{l}\text { T2N0 } \\
\text { M0 }\end{array}$ & - & IIA & M & Fmg 040016 & & & & ++ & ++ \\
\hline
\end{tabular}


RESULTS

56

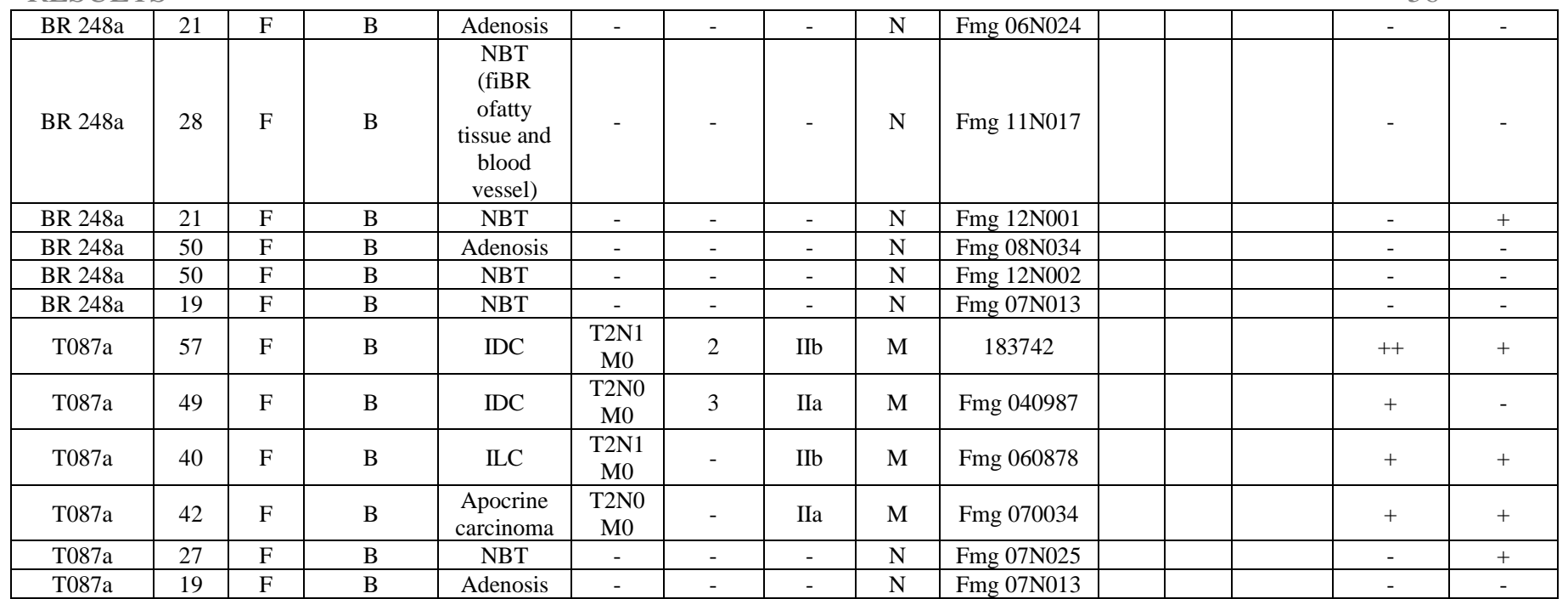




\subsection{MANUSCRIPT B}

Identification of drivers of breast cancer invasion by secretome analysis: insight into

\section{CTGF signaling}

\section{Citation}

Hellinger, J. W., Schömel, F., Lenz, C., Bauerschmitz, G., Emons, G., \& Gründker, C.

Identification of drivers of breast cancer invasion by secretome analysis: insight into CTGF signaling. (under revision at Communications Biology)

Own contribution: Conducted experiments and analyzed data for figures 1- 7 and supplemental material. Shared contribution for experiments presented in figures $6 \mathrm{G}$ and $6 \mathrm{H}$. Contribution to: method design, figure arrangement, manuscript writing, and manuscript revision. 


\section{Abstract}

Altered tumor micro environmental consistency facilitates tumor progression toward metastasis. Here, we combine data from secretome and proteome analysis using mass spectrometry with microarray data from mesenchymal transformed breast cancer cells (MCF7-EMT) to elucidate drivers of epithelial-mesenchymal transition and cell invasion. Suppression of growth factor CTGF reduced invasion in 2D and 3D invasion assays and expression of TGFBI, ZEB1 and LOX, while cell-extracellular matrix (ECM) adhesion is increased in mesenchymal transformed breast cancer cells. Increased expression of CTGF leads to an increased 3D invasion, expression of FN1, SPARC and CD44, and decreased cellECM adhesion. GnRH agonist Triptorelin reduces CTGF expression in a RhoA-dependent manner. Our results suggest, that CTGF drives breast cancer cell invasion and therefore represents an attractive therapeutic target for drug development to prevent breast cancer dissemination.

\section{Introduction}

Metastasis is second leading cause of cancer-related death in the US. Barely $27 \%$ of breast cancer patients diagnosed with distant metastasis survive a period of 5 years (133). Breast cancer mortality will increase by $46.5 \%$ until 2040 to almost 1 million deaths worldwide (134). Single most frequent site for breast cancer metastasis is bone, which accounts for $70 \%$ of all metastatic breast cancer (135). Elucidation of drivers of cancer metastasis is therefore pivotal. The metastatic cascade is initiated by dissemination of cancer cells into surrounding tissue (136). Micro environments of primary tumor and metastatic niche have shared communication networks. Tumor stroma stiffness facilitates deposition and remodeling of extracellular matrix $(\mathrm{ECM})$ in breast cancer $(2,63,64)$. Cancer cells, cancer associated fibroblast, and immune cells modulate ECM by deposition of structural components like collagens or fibronectin (FN1), secretion of growth factors (e.g. Transforming growth factorbeta-induced protein ig-h3, connective tissue growth factor) and ECM-transforming enzymes (e.g. Lysyl oxidase) (2). Gene expression studies identified a bone metastatic signature which includes expression of connective tissue growth factor (CTGF) and is associated with poor patient outcome and metastasis $(58,137)$. Cancer cells can embrace developmental processes like epithelial-mesenchymal transition (EMT) to gain invasive properties and stemness, which could help them to disseminate, intravasate, circulate, extravasate and retain during dormancy but are in need of mesenchymal-epithelial transition (MET) to reactivate upon cues from metastatic niche and outgrow (138). This theory is consistent with observations that clinical 
samples of human metastasis resemble epithelial phenotype of primary tumors (139). There is an urgent need to identify potential drivers of cell invasion, the initial step within metastatic cascade, at the primary site and colonization at distant sites. A better understanding of transient dynamic processes of high cellular plasticity could help to intercept the metastatic cascade, which could in turn lead to identification of targets for new treatment options to prevent cancer cell dissemination and metastatic outgrowth. We aim to identify secreted proteins priming micro environment resulting in increased cancer cell dissemination and driving epithelial-mesenchymal transition.

We combined co-culture model for bone-directed breast cancer cell invasion with mass spectrometry based secretome analysis and identified secreted CTGF is a potential driver for breast cancer cell invasion. In this system, CTGF was found to regulate cell-ECM adhesion, proteolytic activity and expression of EMT inducing genes. Moreover, CTGF expression is dependent on RhoA activity and that treatment of invasive breast cancer cells with gonadotropin releasing hormone $(\mathrm{GnRH})$ agonist Triptorelin could increase RhoA activity. These data indicate, that CTGF is a promising target to inhibit invasion in highly plastic breast cancer cells and aggressive triple negative breast cancer (TNBC) cells.

\section{Results}

\section{Identifying potential drivers of breast cancer cell invasion}

Up to $13.6 \%$ of breast cancer patients (diagnosed in stage I-III) will develop bone metastasis within 15 years of follow-up (140). Previous studies demonstrate that co-culture of breast cancer cells with osteosarcoma cells (MG-63) or osteoblast-like cells increased invasiveness (132). However, mechanisms by which breast cancer cells metastasize to bone remain elusive. To shed light on drivers for bone-directed breast cancer invasion, we decided to investigate if identified potential drivers by analyzing secretome of co-culture media using mass spectrometry. Excluding serum from media and analyzing only secreted proteins, we first tested if non-invasive MCF-7 breast cancer cells gain invasive properties when co-cultured with osteosarcoma cells without adding serum to media (fig.1 A). Indeed, invasiveness of MCF-7 breast cancer cells increased more than 4-fold, when using Matrigel in a transwell coculture invasion assay (fig. $1 \mathrm{~A}$; co-culture matrigel: $413.7 \pm 83.07 \%$ vs. MCF-7 matrigel; $\mathrm{P}=$ $0.0021, \mathrm{n}=12$ ) and a more than 7 -fold increase of invasiveness, when using gelatin (fig. 1A; co-culture gelatin: $737.5 \pm 250.9 \%$ vs. MCF-7 gelatin; $\mathrm{P}=0.0316, \mathrm{n}=6)$. We next co-cultured MCF-7 cells with MG-63 cells and analyzed co-culture media using mass spectrometry 
secretome analysis to identify proteins that drive bone-directed metastasis. We could identify 28 secreted potential drivers for bone-directed breast cancer cell invasion (fig. $1 \mathrm{~B}, \mathrm{C}$, and $\mathrm{S} 1)$. Gene ontology (GO) enrichment analysis elucidated that observed secreted proteins play most prominently roles in extracellular matrix organization (fig. 1 S2, FDR $3.26 \times 10^{-15} ; 50 \%$ of detected proteins), extracellular structure organization (fig. 1 S2, FDR $1.52 \times 10^{-14} ; 50 \%$ of detected proteins) and wound healing (fig. 1 S2, FDR $8.92 \times 10^{-9} ; 39 \%$ of detected proteins). Further classification of observed proteins using Shiny GO indicated that $39 \%$ of detected proteins are categorized within locomotion and cell motility and $36 \%$ within cell adhesion (fig. $1 \mathrm{~S} 3, \mathrm{~S} 4 \mathrm{~A}$ ). Additionally, we could detect that co-culture media in comparison to MG-63 media a decreases MMP2 protein expression and an increased SPARC expression was detected (fig.1 S 4B). To further examine underlying molecular mechanism of breast cancer cell invasion we analyzed lysates of co-cultured MCF-7 cells compared to untreated MCF-7 cells (fig.1 S4 and S5). GO enrichment analysis elucidated that observed regulated proteins play most prominently roles in protein folding (fig.1 S6, FDR $7.55 \times 10^{-6}$; 33\% of detected proteins), programmed cell death (fig. 1 S6, FDR $1.34 \times 10^{-5} ; 61 \%$ of detected proteins) and cellular response to cytokine stimulus (fig. $1 \mathrm{~S} 6$, FDR $1.34 \times 10^{-5} ; 50 \%$ of detected proteins). Interestingly, cell death associated proteins seem to be regulated prominently, including HSPA9 (heat shock protein family A (Hsp70) member 9), HSP90B1 (heat shock protein $90 \beta$ family member 1), HSP90AB1 (heat shock protein $90 \alpha$ family class B member 1), HSPD1 (heat shock protein family D (Hsp60) member), and HSPB1 (heat shock protein family B member 1) (fig. 1 S4D, S5 and S6). While detected findings from proteome analysis are different from detected secretome findings, GO grouping of proteome findings elucidated similar results compared to secretome findings. Proteome analysis findings where categorized (amongst others) in 33\% locomotion, 33\% cell motility and $27 \%$ cell adhesion (fig.1 S7).

Cells undergoing dynamic EMT programs reveal an increased invasive behavior (51). Microarray analysis of MCF-7 breast cancer cells within a dynamic TGF $\beta$-dependent EMT program exhibited an increased expression of CTGF, CD44 molecule (CD44), Sushi, von Willebrand factor type A, EGF and pentraxin domain containing 1 (SVEP1), Transforming growth factor-beta-induced protein ig-h3 (TGFBI), Secreted Protein Acidic And Cysteine Rich (SPARC), Lysyl oxidase (LOX), FN1 and Matrix Metallopeptidase 2 (MMP2) and Follistatin-like 1(FSTL1) (51). Interestingly, we found these proteins are highly secreted in co-culture medium of MCF-7 and MG-63 as elucidated by secretome analysis (fig. $1 \mathrm{D}$, and S1). 


\section{CTGF expression correlates with invasiveness of mesenchymal transformed and TNBC} cells

One of the potential drivers of invasion is CTGF, which is upregulated during wound healing and has an impact on osteolytic breast cancer metastasis $(111,141)$. Using patient data from large public cancer genomic datasets CTGF expression was assessed in bone, lung, liver, and brain where breast cancer spreads most prominently (142). Expression of CTGF in bone and lung appeared to be close to expression in breast tissue, while expression in brain in liver is reduced compared to breast (fig. 2 S8). CTGF mRNA expression is upregulated in mesenchymal transformed (fig. 2A; MCF-7-EMT: $1.995 \pm 0.4356$ vs. MCF-7; $\mathrm{P}=0.0454$; $\mathrm{n}=6$ ) and TNBC cells (fig. 2A; MDA-MB-231: $190.5 \pm 45.81$ fold change vs. MCF-7; $\mathrm{P}=$ $0.0061 ; \mathrm{n}=4$ ). Protein expression analysis gave similar results (fig. 2B; MCF-7-EMT: $321 \pm$ 82.6 \% vs. $\mathrm{M} ; \mathrm{P}=0.0233 ; \mathrm{n}=6$ and MDA-MB-231: $213 \pm 27.17 \% ; \mathrm{P}=0.002 ; \mathrm{n}=6)$. To verify the potential use of CTGF as a therapeutic target for invasive breast cancer we analyzed 24 breast tissue sections. Of these, 18 were invasive ductal carcinomas and $88.9 \%$ exhibit a positive signal (fig. $2 \mathrm{C}, \mathrm{D}$ and S 8 indicated by + or ++ ) for CTGF while $80 \%$ of the 6 analyzed normal breast tissues were negative for CTGF (fig. 2 C, D and S 9 indicated by -).

Detection of mesenchymal transformed and aggressive breast cancer cells is a major requirement to select specific treatment options. Previously, it was demonstrated that cells in transient transitional stages express specific cell receptor markers (143). We found, that highly plastic breast cancer cells and TNBC do not only express more CTGF but co-express CD106 (Vascular cell adhesion molecule 1) and CD51 (Integrin subunit alpha V) in a higher probability than non-invasive MCF-7 cells (fig. $2 \mathrm{E}$ and F; MCF-7-EMT $72.67 \pm 18.21$ counts

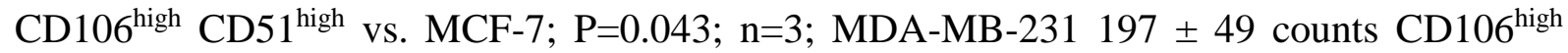
CD51 $1^{\text {high }}$ vs. $\mathrm{MCF}-7 ; \mathrm{P}=0.0217, \mathrm{n}=3$ ).

Findings from secretome and proteome analyses prominently grouped into locomotion and cell motility categories. Therefore, we assessed impact of CTGF expression on invasiveness of mesenchymal transformed and TNBC cells. Using RNA interference CTGF expression was transiently suppressed (fig. 3 S10 A and B). Suppression of CTGF leads to reduced invasion of mesenchymal transformed (fig. $3 \mathrm{~A}$ and B; MCF-7-EMT $61.41 \pm 7.427 \%$ vs control; $\mathrm{P}=0.0034 ; \mathrm{n}=18$ ) and TNBC (fig. 3B; MDA-MB-231 $79.44 \pm 4.64 \%$ vs control; $\mathrm{P}=0.0258$; $\mathrm{n}=17$ ) cells in $2 \mathrm{D}$ transwell invasion co-culture assay. Recent reports suggested that YAPactivation appears differently dependent on dimension model used (144). CTGF is transcriptional expressed upon YAP translocation to nucleus. We therefore tested, if effects 
were reproducible in 3D invasion assay setup (fig. $3 \mathrm{C}$ ). Reducing CTGF expression transiently reduced invaded area in 3D breast cancer spheroids of mesenchymal transformed (fig. 3D and E; MCF-7-EMT 94.25 $\pm 2.535 \%$ vs control; $\mathrm{P}=0.032 ; \mathrm{n}=15$ ) and TNBC cells (fig. $3 \mathrm{D}$ and $\mathrm{E}$; MDA-MB-231 $55.93 \pm 13.3 \%$ vs control; $\mathrm{P}=0.0044 ; \mathrm{n}=9$ ) cells.

Upon co-culturing breast cancer cells with osteosarcoma cells, cells gain invasive potential and exhibit a specific expression profile. It was suggested earlier, that an increased CTGF expression alters expression of matrix metalloproteinases and MMP-2 promotes migration by cleaving fibronectin and CTGF (145-147). It remained unclear though, whether extracellular MMP2, CTGF and FN1 facilitate invasion in breast cancer interdependently. Consequently, we analyzed if spheroid invaded area and proliferation were altered when treated with human MMP2, CTGF and FN1. Furthermore, we analyzed if treatment with an MMP2 inhibitor (BB94, Batimastat) reduces breast cancer invasiveness. We found that 3D spheroid area growth was increased when treated with recombinant human CTGF (rhCTGF; fig. 3F; rhCTGF: $135.5 \pm 35.5 \%$ mean difference vs. untreated; $\mathrm{p}=0.0006 ; \mathrm{F}=21.61 ; \mathrm{n}=6)$, recombinant human MMP2 (rhMMP2, fig. 3F; rhMMP2: $137.8 \pm 37.8 \%$ mean difference vs. untreated; $\mathrm{p}=0.0003 ; \mathrm{F}=21.61 ; \mathrm{n}=6$ ), rhCTGF and human FN1 (hFN1) and recombinant human MMP2 (fig. 3F; rhCTGF+hFN1+rhMMP2: $137 \pm 37 \%$ mean difference vs. untreated; $\mathrm{p}=0.0003 ; \mathrm{F}=$ 21.61; $\mathrm{n}=6$ ), or rhCTGF and rhMMP2 (fig. 3F; rhCTGF+rhMMP2: $137.2 \pm 37.2 \%$ mean difference vs. untreated; $\mathrm{p}=0.0015 ; \mathrm{F}=21.61 ; \mathrm{n}=4)$. Adding hFN1, combination of hFN1 with rhCTGF or rhMMP2 does not alter spheroid area growth (fig 3F). In contrast, combining hFN1 and BB-94 treatment (fig. 3F; hFN1+BB-94: $68.4 \pm 31.6 \%$ mean difference vs. untreated; $\mathrm{p}=0.0028 ; \mathrm{F}=21.61 ; \mathrm{n}=4$ ), or rhMMP2 and BB-94 (fig. 3F; rhMMP2+BB-94: 69.4 $\pm 30.1 \%$ mean difference vs. untreated; $\mathrm{p}=0.0041 ; \mathrm{F}=21.61 ; \mathrm{n}=6)$ or rhCTGF and hFN1 and rhMMP2 and BB-94 (fig. 3F; rhCTGF+hFN1+rhMMP2+BB-94: $75.66 \pm 24.34 \%$ mean difference vs. untreated control; $\mathrm{p}=0.0006 ; \mathrm{F}=21.61 ; \mathrm{n}=6$ ) results in decreased area growth. Combination of rhCTGF with BB-94 did not alter invasive area growth. While none of the settings altered proliferation (S10 D).

\section{CTGF alters cell-ECM adhesion and proteolytic activity of breast cancer cells}

Cell invasion as initial step of metastatic cascade results from suppression of cell-cell adhesion modulated by cadherin's and cell-ECM adhesion promoted through different receptors including integrins (148). Secretome- and proteome analysis elucidated that coculturing non-invasive MCF-7 breast cancer cells with osteosarcoma cells led to an expression alteration of proteins involved in cell adhesion. We tested if cell-ECM adhesion 
was altered in invasive breast cancer cells (MCF-7-EMT, MDA-MB-231) when intracellular CTGF was suppressed by RNA interference, extracellular CTGF was blocked using CTGFspecific antibodies or non-invasive MCF-7 breast cancer cells were treated with rhCTGF. CTGF suppression increased cell-ECM adhesion (fig. 4A, B; MCF-7-EMT: $146.3 \pm 12.1 \%$ vs. control; $\mathrm{p}=0.0185 ; \mathrm{n}=3$; MDA-MB-231: $168.3 \pm 14.3 \%$ vs. control; $\mathrm{p}=0.0083 ; \mathrm{n}=3$ ). Blocking extracellular CTGF increased cell-ECM adhesion (fig. 4C, D; MCF-7-EMT: 120.6 $\pm 5.724 \%$ vs. IgG control; $\mathrm{p}=0.0071 ; \mathrm{n}=5$; MDA-MB-231: $110.5 \pm 3.776 \%$ vs. IgG control; $\mathrm{p}=0.0493 ; \mathrm{n}=3$ ). Adding rhCTGF to non-invasive MCF-7 breast cancer cells resulted in dosedependent decreased cell-ECM adhesion (fig. 4E, F; MCF-7 1 $\mu \mathrm{g} / \mathrm{ml}$ rhCTGF: $94.2 \pm 5.809 \%$ mean difference vs. untreated; $\mathrm{p}=0.0459 ; \mathrm{F}=6.244 ; \mathrm{n}=3$ ).

Matrix metalloproteinases contribute to invadopodia formation and tissue invasion through proteolytic activity alteration of cells (149). We examined, whether suppression of CTGF or treatment with rhCTGF regulates relative proteolytic activity of breast cancer cells. Reduced CTGF expression decreased relative proteolytic activity of mesenchymal transformed breast cancer cells (fig. 4G; MDA-MB-231 CTGF-: $117 \pm 28.92 \%$ vs. control; $\mathrm{p}=0.0205 ; \mathrm{n}=3$ ), while it did not alter relative proteolytic activity of TNBC cells (fig. 4G). Treatment with rhCTGF induced proteolytic activity in non-invasive MCF-7 breast cancer cells (fig. $4 \mathrm{H}$; MCF-7 rhCTGF: $113.7 \pm 4.229 \%$ vs. untreated; $\mathrm{p}=0.0314 ; \mathrm{n}=3$ ).

\section{CTGF differentially regulates potential drivers of invasion and EMT-markers in mesenchymal transformed and triple negative breast cancer cells}

To further analyze underlying mechanisms of CTGF-induced invasion and suppressed adhesion we examined, if reduced CTGF expression alters expression of TGFBI, CD44, SPARC, FN1, LOX and FSTL1 which were all identified potential drivers for invasion by secretome analysis. We could detect, that reduced CTGF in mesenchymal transformed breast cancer cells suppressed expression of TGFBI (fig. 5A; TGFBI CTGF-: $0.6474 \pm 0.1107$ FC vs. TGFBI control; $\mathrm{p}=0.0052 ; \mathrm{n}=6$ ) and LOX (fig. 5A; LOX CTGF: $0.7933 \pm 0.043$ FC vs. LOX control; $\mathrm{p}=0.0088 ; \mathrm{n}=3$ ), and increased expression of CD44 (fig. 5A; CD44 $\mathrm{CTGF}^{-}$ $: 1.21 \pm 0.045$ FC vs. CD44 control; $p=0.0096 ; n=3$ ), SPARC (fig. 5A; SPARC CTGF ${ }^{-}: 2.083$ \pm 0.2749 FC vs. SPARC control; $\mathrm{p}=0.0169 ; \mathrm{n}=3$ ) and FN1 (fig. 5A; FN1 CTGF $: 1.41 \pm$ 0.07234 FC vs. FN1 control; $\mathrm{p}=0.0048 ; \mathrm{n}=3$ ). Suppressed CTGF expression altered FN1 (fig. 5B; FN1 CTGF $: 1.557 \pm 0.1014$ FC vs. FN1 control; $\mathrm{p}=0.0054 ; \mathrm{n}=3$ ) expression in TNBC cells. 
We found that CTGF had in impact on TGFBI-expression, and further wanted to test, whether a reduced CTGF expression can regulate expression of EMT transcription factors. We examined expression of Cadherin 1 (CDH1), Vimentin (Vim), ZEB1 and SNAIl family transcriptional repressor 2 (SNAI2) after transient CTGF suppression in mesenchymal transformed and TNBC cells. We found that downregulation of CTGF led to reduced ZEB1 expression in mesenchymal transformed breast cancer cells (fig. 5C; $0.7767 \pm 0.063 \mathrm{FC}$ vs. control; $\mathrm{p}=0.0138 ; \mathrm{n}=3)$. In contrast, suppressed CTGF resulted in downregulated Vimentin expression in TNBC cells (fig. 5D; $0.65 \pm 0.0985 ; \mathrm{p}=0.0237 ; \mathrm{n}=3$ ).

\section{GnRH agonist regulates CTGF expression through altered RhoA activity in mesenchymal transformed breast cancer cells}

Most luminal breast cancer will metastasize to bone (150). Suppression of ovarian function is part of therapy of endocrine-sensitive premenopausal early and advanced hormone breast cancer. Triptorelin, a GnRH agonist, revealed clinical benefit in high-risk patients by suppressing ovarian steroids and it has been investigated in attempt to preserve ovarian function during chemotherapy in young female patients (151). GnRH receptor is expressed in $50-64 \%$ of all human breast cancers (152-156). Around $15 \%$ of all human breast cancers are stated as TNBC, which is associated with high risk recurrence and metastasis $(157,158)$. Approximately $74 \%$ of all TNBC express GnRH receptor $(7,132,159)$. It was observed that GnRH agonist Triptorelin has in impact on breast cancer invasiveness (51, 132, 160). Accordingly, we wanted to assess whether, Triptorelin treatment suppresses CTGF expression. Mesenchymal transformed breast cancer cells were treated for 48 hours with $10^{-9}$ $\mathrm{M}$ or $10^{-7} \mathrm{M}$ Triptorelin every 24 hours. We found that treatment with $10^{-7} \mathrm{M}$ Triptorelin reduced CTGF expression (fig. 6A; Triptorelin $10^{-7} \mathrm{M}: 0.435 \pm 0.565 \mathrm{FC}$ vs. untreated; $\mathrm{p}=0.0052 ; \mathrm{F}=8.366 ; \mathrm{n}=3$; and fig. $6 \mathrm{~B} ; 83.67 \pm 3.383 \%$ vs. untreated control; $\mathrm{p}=0.0085 ; \mathrm{n}=3$ ) which we could verify in TNBC cell as well (S11 A, B). Furthermore, we analyzed, whether Triptorelin treatment altered cell-ECM adhesion. We found that $10^{-7} \mathrm{M}$ Triptorelin treatment increased cell-ECM adhesion (fig. $6 \mathrm{C}$, D; Triptorelin $10^{-7} \mathrm{M}$ : $114.9 \pm 3.861 \%$ vs untreated; $\mathrm{p}=0.0049 ; \mathrm{n}=5$ ), which we found to be true for TNBC cells as well (fig. $6 \mathrm{~S} 11 \mathrm{C}, \mathrm{D}$ ).

It was suggested earlier that RhoA determines mesenchymal cell fate and regulates CTGF cleavage (161). We wanted to test, if $\mathrm{GnRH}$ agonist Triptorelin facilitates reduced invasiveness and increased adhesion by regulating RhoA activity. We found that Triptorelin regulates RhoA activity in a time-dependent manner. After 4 hours Triptorelin treatment $\left(10^{-7}\right.$ M) no increased RhoA activity could be detected by active RhoA pulldown. After 24 hours a 
clear increased RhoA activity appeared (fig. 6E). Furthermore, we found that mesenchymal transformed breast cancer cells treated with a Rho activator exhibit a decreased invasive capacity (fig. 6F; RhoA activator II: $22.99 \pm 9.922 \%$ vs. untreated; $p=0.0401 ; n=7$ ), which could be verified for TNBC cells as well (fig. 6 S11 E). Besides, non-invasive MCF-7 breast cancer cells with transiently suppressed RhoA expression exhibit an increased invasiveness (fig. 6G; RhoA : $123.1 \pm 7.73 \%$ vs. control; $\mathrm{p}=0.0432 ; \mathrm{n}=18$ ). Furthermore, we tested if this increased invasiveness is due to an increased CTGF expression. We could observe that through reduction of RhoA expression (verification; fig. $6 \mathrm{~S} 12$ A and $6 \mathrm{H}$; RhoA: RhoA: $0.7033 \pm 0.04702 \mathrm{FC}$ vs. control; $\mathrm{p}=0.0032 ; \mathrm{n}=3$ ) $\mathrm{CTGF}$ expression is increased (fig. $6 \mathrm{H}$; CTGF RhoA: $2.88 \pm 0.3143$ FC vs. control; $p=0.0039 ; n=3$ ), while proliferation was not altered (fig. $6 \mathrm{~S} 12 \mathrm{~B}$ ).

\section{Discussion}

Tumor metastasis is highly regulated by micro environmental changes. Drugs are needed to modify breast micro environment were tumor cells gain ability to disseminate and bone micro environment, which is the niche where breast cancer cells preferentially colonize and remain in a state of survival and dormancy. Micro environmental modifications may be lethal for isolated, dormant cancer cells, reducing risk of reactivating dormant cells and growth of distant metastases over time is a high priority in preventing metastasis. Here we suggest potential drivers of initial dissemination of tumor cells with regards to bone-directed metastasis.

An increased CTGF expression in human breast cancer correlates with poor patient outcome and drug resistance (6). While it was suggested previously that downregulation of CTGF inhibits bone metastasis in a BMP9-dependent manner (162). A major question has remained: if targeting CTGF will help to prevent breast cancer cell dissemination into surrounding tissue, and which underlying molecular mechanisms are involved in breast cancer directed bone metastasis.

We found that CTGF is highly upregulated in invasive ductal carcinoma (fig. 2C) and during co-culture of breast cancer cells with osteosarcoma cells (fig. 1 C, D). Furthermore, CTGF expression is comparable in bone and mammary gland tissue (fig. 2 S8).

Consistent with recent findings we could assess that an elevated expression of CTGF led to increased cell invasiveness and correlated with bone-directed metastasis. Reducing CTGF expression resulted in a decreased invasion in 2D and 3D invasion assays. It was suggested 
earlier, that FN1 has a protective function against metastasis when uncleaved (147) and that autocrine FN1 inhibits breast cancer metastasis (163). Additionally, it was proposed that CTGF is cleaved by MMPs to reactivate angiogenesis (145). Expression of MMP2 was upregulated when MCF-7 cells were co-cultured with osteosarcoma cells (fig. 1C, D). We tested if 3D MCF-7 spheroid area growth can be altered when CTGF and/or FN1 and/or MMP2 and /or a MMP inhibitor are added. Interestingly, we found that spheroid area growth was significantly increased when CTGF or MMP2, CTGF and MMP2, and CTGF with FN1 and MMP2 are added (fig. 3F). But there was no increased area growth when FN1 or FN1 with CTGF neither FN1 with MMP2 was added. Therefore we could assess that FN1 does not alter invasive behavior of breast cancer cells in 3D invasion setup. Also, treatment with CTGF and FN1 or MMP2 with FN1 did not alter invasive behavior as well (fig. 1G), which could be an indicator for a protective FN1 feature. Only treatment with CTGF, MMP2 and FN1 led to an increased area growth. This effect could be reversed by an additional treatment with an MMP inhibitor (BB-94). But surprisingly this inhibitor was not effective enough to reverse effect of CTGF treatment, which could be an indicator for a MMP2-independent mechanism.

Loss of intercellular and cell-ECM adhesion allows malignant cells to escape from their site of origin (164). To further analyze, why cancer cells treated with extracellular CTGF are highly invasive, we analyzed their cell-ECM adhesive and proteolytic abilities. We suggest that reduced CTGF increases cell-ECM adhesion (fig. 4-D), while ECM degradation was decreased (fig. 4G). Increased extracellular CTGF expression led to decreased cell-ECM adhesion (fig. 4E) and increased ECM degradation (fig. $4 \mathrm{H}$ ). This is supported by previous findings that CTGF induces expression of ECM degradations genes and fibronectin (165).

MCF-7-EMT cells exhibited increased expression of TGFBI, Twist, Vimentin and Ncadherin, while E-cadherin expression was reduced. Also MCF-7-EMT cells are more invasive (51). We could furthermore identify, that these mesenchymal transformed breast cancer cells revealed a high ITG $\alpha$ V (CD51) and VCAM-1 (CD106) co-expression compared to non- invasive MCF-7 breast cancer cells (fig. 2 E-F). Interestingly it was suggested, that CTGF stimulates osteosarcoma metastasis by upregulating VCAM-1 expression. Additionally, VCAM-1 may have a role in activation of dormant micro metastasis $(58,166$, 167). CTGF enhances cell motility in breast cancer through integrin $\alpha$ V $\beta 3$-ERK1/2 dependent S100A4 upregulation (168). We analyzed impact of CTGF on other secretome analysis detected targets and could detect that reducing CTGF expression represses TGFBI, LOX and ZEB1 expression in mesenchymal transformed breast cancer cells (fig. 5 A, C). LOX was 
demonstrated to be involved in collagen I stabilization leading to chemo resistance (169). It was proposed previously that EMT-TFs SNAI1 and SNAI2 activate TGBFI signaling in breast cancer and that CTGF and SPARC are upregulated as well (170). Reduced CTGF expression led to increased CD44, SPARC, and FN1 expression in mesenchymal transformed breast cancer cells (fig. 5A). CD44 is a stem cell marker and appears to have a dual nature regarding tumor progression and metastasis (171). SPARC has anticancer effects (172), inhibits bone metastasis (173) and was suggested to be involved in same biological pathways than CTGF (174). We could assess earlier in that study that an increased FN1 expression prevents 3D invasion, even when CTGF is added as well. This could indicate that downregulation of CTGF leads to an increased FN1 expression. We found that suppressed CTGF upregulated FN1 in TNBC cells, and downregulated Vimentin (fig. 5 B, D). Except for similar CTGF-dependent FN1 regulation, regulated targets are cell-type specific and could be related to expression of hormone- receptors or to MDA-MB-231 cell line specific mutations. These interesting observations need further evaluation by analyzing CTGF driven mechanism in another TNBC cell line and a hormone receptor positive mesenchymal transformed cell line.

Discovering the prominent role of CTGF during breast cancer invasion by modifying cell adhesion, ECM degradation and FN1 expression, we wanted to test if CTGF can be targeted and elucidated molecular mechanism by which CTGF can be repressed to suppress cell dissemination and colonization at distant sites. We found that GnRH agonist Triptorelin, which is in clinical use for ovarian function suppression of premenopausal breast cancer with high clinical risk of recurrence (151) and was demonstrated to reduce breast cancer invasion (7), reduced CTGF expression in mesenchymal transformed breast cancer in a dose-dependent manner (fig. 6A, B). Furthermore, we found that CTGF was downregulated by Triptorelin treatment in TNBC cells (fig. $6 \mathrm{~S} 11$ A, B). GnRH receptor is expressed in 50-60\% of all human breast cancer and to a further extent in approximately $74 \%$ of all $\operatorname{TNBC}(7,132,159)$. We could demonstrate that treatment with $10^{-7} \mathrm{M}$ Triptorelin led to an increased cell-ECM adhesion in mesenchymal transformed breast cancer cells (fig. $6 \mathrm{C}$ ) and TNBC cells (fig. 6 S11 C) as it was detected by CTGF suppression as well.

It was suggested that RhoA determines lineage fate of mesenchymal stem cells in ECM and that RhoA activity controls CTGF cleavage (161). Beside, Arguilar-Rojas and colleagues found out that Busrelin, a GnRH agonist, regulates RhoA activity in MDA-MB-231 breast cancer cells thereby decreasing invasiveness (175). We wanted to examine, if Triptorelin 
regulates RhoA activity and also if RhoA expression has an impact on CTGF expression. We could observe that Triptorelin induces RhoA activity in a time-dependent manner through in mesenchymal transformed breast cancer cells (fig. 6E). As expected, invasiveness of mesenchymal transformed breast cancer cells was reduced when RhoA was activated. Later we wanted to assess if reducing RhoA expression has an impact on invasiveness of noninvasive MCF-7 breast cancer. We found that transient RhoA suppression led to increased invasion (fig. 6G), which is facilitated through upregulation of CTGF (fig. 6H). This led to the conclusion that CTGF expression is dynamically regulated through RhoA activation and thereby regulates cell-ECM adhesion.

On molecular level it would be interesting to evaluate, if Triptorelin treatment has an impact on cell plasticity by regulating EMT-TF expression. CTGF activates ERK1/2 signaling through ITG $\alpha \mathrm{V}$ cascade (168) and plastic breast cancer cell co-express higher ITG $\alpha \mathrm{V}$ and VCAM-1 receptors and exhibit an increased CTGF expression. ERK1/2 appears to be a new treatment option with promising preclinical phase I trials $(176,177)$. Targeting CTGF when cancer cells gained drug resistance, could help to identify new treatment options. In addition, a new phase III trial study (HOrmonal BOne Effects-2, HOBOE-2) revealed interesting results using zoledronic acid which is approved to treat osteoporosis (178). In this context it may be worthwhile to examine if zoledronic acid reduces extracellular CTGF, which may open up possibilities for preventing bone metastasis.

Using proteome analysis it was detected, that heat shock proteins (HSP) are dysregulated when breast cancer cells are co-cultured with osteosarcoma cells (Supplement 4 C, D and Supplement 5). Nonetheless, further evaluation is necessary due to different basal expression of detected potential drivers within different cell lines. It was suggested previously, that cancer cells are more dependent on heat shock protein chaperonage due to an elevated level of misfolded onco-proteins $(179,180)$. Additionally, inhibiting HSP90 inhibits versatile proinvasive and proangiogenic pathways (181). Inhibiting HSP90 led to LATS1 and LATS2 depletion, which led to reduced YAP phosphorylation and decreased CTGF expression (182). Targeting HSP90 could be of great interest to regulate CTGF expression and HSP90 inhibitors are currently under investigation for metastatic breast cancer (183-185) .

In summary, we identified a novel mechanism by which extracellular CTGF drives cell dissemination by regulating cell adhesion, ECM degradation and regulation of EMT inducing factor TGFBI. Furthermore, we propose that CTGF is a versatile regulator in breast cancer and facilitates SPARC, LOX, ZEB1, VIM and FN1 expression changes. Moreover, it was 
assessed that CTGF expression is regulated by RhoA activity. Performed experiments support value of CTGF as therapeutic target for invasive breast cancer, and GnRH agonist Triptorelin could be of value in clinical applications.

\section{Methods}

\section{Cell culture}

Human breast cancer cell lines MCF-7, MDA-MB-231 were obtained from the American Type Cell Collection (ATCC; Manassas, VA, USA) and cultured in minimum essential medium (MEM; biowest, Nuaillé, France) supplemented with $10 \%$ fetal bovine serum (FBS; biochrom, Berlin, Germany), 1 \% Penicillin/Streptomycin (P/S; Gibco, Carlsbad, CA, USA), 0,1\% Transferrin (Sigma, St. Louis, USA) and 26 IU Insulin (Sanofi, Frankfurt, Germany). Human osteosarcoma cell line MG-63 was purchased from ATCC and cultured Dulbecco's modified eagle medium (DMEM; Gibco) supplemented with 10\% FBS (biochrom) and 1\% Penicillin/Streptomycin (Gibco). To retain identity of cell lines, purchased cells were expanded and aliquots were frozen in liquid nitrogen. A new frozen stock was used every half year and mycoplasma testing of cultured cell lines was performed routinely using PCR Mycoplasma Test Kit I/C (PromoCell GmbH, Heidelberg, Germany). All cells were cultured in a humidified atmosphere with $5 \% \mathrm{CO}_{2}$ at $37^{\circ} \mathrm{C}$.

\section{Generation of mesenchymal transformed MCF-7 cells}

Mesenchymal transformed MCF-7 breast cancer cells (MCF-7-EMT) were generated as described earlier (51). Briefly, $4 \times 10^{4}$ cells $/ \mathrm{ml}$ were cultured in prolonged mammosphere culture (5-6 weeks) in ultralow adherence six well plates (Corning, Lowell, MA, USA) in DMEM/F12 supplemented with $10 \%$ charcoal-stripped fetal calf serum (cs-FCS;PANbiotech, Aidenbach, Germany), 2\% B27 supplement (Invitrogen, Darmstadt, Germany), 1\% penicillin/streptomycin, $0.5 \mathrm{mg} / \mathrm{ml}$ hydrocortisone (Sigma, St. Louis, MO, USA ), $5 \mu \mathrm{g} / \mathrm{ml}$ insulin, $20 \mathrm{ng} / \mathrm{ml}$ epidermal growth factor (EGF; Sigma, St. Louis, MO, USA).

\section{Small interfering RNA transfection}

Breast cancer cell lines MCF-7-EMT (5 x $10^{5}$ cells/ml), MDA-MB-231 (2.5 x $10^{5}$ cells $\left./ \mathrm{ml}\right)$ were seeded in $2 \mathrm{ml}$ of MEM with $10 \%$ FBS (-P/S) in $25 \mathrm{~cm}^{2}$ cell culture flask. Cells were transiently transfected with siRNA specific to CTGF (sc-39329 pool of three specific siRNAs; Santa Cruz Biotechnology (SCBT), Dallas, USA) or RhoA (sc-44209 pool of three specific siRNAs; SCBT) in OPTI-MEM I medium (Gibco, Carlsbad, CA, USA) with siRNA 
transfection reagent (sc-29528; Santa Cruz Biotechnology, Dallas, USA). A non-targeting control was used as control (sc-37007 control-A; Santa Cruz Biotechnology, Dallas, TX, USA). After an incubation period of $6 \mathrm{~h}$, MEM supplemented with $20 \%$ FBS and 20\% penicillin/streptomycin was added.

\section{Transwell co-culture invasion assay}

Using co-culture transwell assay as describes earlier (132), $1 \times 10^{4}$ breast cancer cells were seeded in DMEM w/o phenol red, supplemented with 10\% cs-FCS into a cell cultural insert (upper well) with a polycarbonate membrane $(8 \mu \mathrm{m}$ pore diameter, Merck Millipore, Cork, Ireland) coated with $30 \mu \mathrm{L}$ of a Matrigel ${ }^{\circledR}$ (BD Bioscience, Bedford, MA, USA) solution (1:2 in serum-free DMEM) or gelatin (1mg/ml in PBS, Sigma). Osteosarcoma cells were seeded $\left(2.5 \times 10^{4}\right)$ in DMEM supplemented with or without $10 \%$ cs-FCS into the lower well (24well-plate). After 24 hours cells were co-cultured for 96 hours or 48 hours when treated with RhoA activator II. Invaded cells on lower side of inserts were stained with hematoxylin and number of cells in four randomly selected fields of each insert was counted.

\section{D spheroid assay}

Assessment of 3D cell invasion was pursued as describes earlier with minor changes (186). Briefly $1 \times 10^{3}$ breast cancer cells were seeded in $100 \mu \mathrm{L}$ in a well of an ultra-low-adherence 96-well plate (ULA; Nexcelom, Cenibra GmbH, Bramsche, Germany). After 48 hours spheroid formation was visually confirmed and $50 \mu \mathrm{L}$ of media was removed. Thereafter, 50 $\mu \mathrm{L}$ Matrigel were added to wells with spheroids. Central position of spheroids was checked visually and Matrigel was allowed to solidify for 1 hour at $37^{\circ} \mathrm{C}$ and $5 \% \mathrm{CO}^{2}$. Afterwards 50 $\mu \mathrm{L}$ media were added to each well and a picture was taken marking time point 0 (tOh). When indicated rhCTGF (recombinant human connective tissue growth factor; $1 \mu \mathrm{g} / \mathrm{ml}$; R\&D systems), pdhFN1 (plasma-derived human fibronectin 1; $1 \mu \mathrm{g} / \mathrm{ml}$; R\&D systems), rhMMP2 (recombinant human matrix metalloproteinase 2;0.01 $\mathrm{g} / \mathrm{ml}$; R\&D systems, Minneapolis, MN, USA), Batimastat (BB-94, 4nM; Selleckchem, Munich, Germany) polyclonal rabbit IgG control $(15 \mu \mathrm{g} / \mathrm{ml}$; R\&D systems) or anti-CTGF (15 $\mu \mathrm{g} / \mathrm{ml}$; Novus Biologicals). Spheroid growth area was analyzed using ImageJ polygonal selection and measurement. Mean values were calculated and compared to respective control. 


\section{Adherence Assay}

Cell-ECM adherence was examined by coating 96-well plates with bovine collagen I (30 $\mu \mathrm{L}$; $0.04 \mathrm{mg} / \mathrm{ml}$; BD Bioscience) for 12 hours at $4^{\circ} \mathrm{C}$. Solution was aspirated and plate was left to dry under bench. Cells were washed 3 times with FBS-free DMEM and cultured for 8 hours in DMEM-FBS prior to adhesion assessment. Cells were detached using 10mM EDTA-PBS solution. Cells were pelleted (1300 rpm for 5 minutes) and washed twice with DMEM supplemented with $0.1 \%$ BSA. Cells were seeded $\left(2 \times 10^{4}\right)$ in DMEM supplemented with $0.1 \%$ BSA, when indicated treated with rhCTGF $\left(1 \mu \mathrm{g} / \mathrm{ml}\right.$; R\&D systems), Triptorelin $\left(10^{-7} \mathrm{M}\right)$, polyclonal rabbit IgG control $(15 \mu \mathrm{g} / \mathrm{ml}$; R\&D systems) or anti-CTGF $(15 \mu \mathrm{g} / \mathrm{ml}$; Novus Biologicals), and incubated at $37^{\circ} \mathrm{C}$ with $5 \% \mathrm{CO}_{2}$ for $20 \mathrm{~min}$. Non-adherent cells were washed of by adding $100 \mu \mathrm{L}$ of DMEM four times. Adherent cells were counter-stained with crystal violet solution $(0.5 \%)$ for $20 \mathrm{~min}$ at RT shaking. Wells were washed four times with $\mathrm{ddH}_{2} \mathrm{O}$ and dried for at least 2 hours. Pictures were taken and afterwards $200 \mu \mathrm{L}$ Methanol were added to each well, incubated for 20 min shaking and absorbance was assessed at 570 nm using Synergy (BioTek Instruments, Bad Friedrichshall, Germany). Each experiment was performed in six replicates. Mean values were compared to respective control.

\section{ECM degradation}

Degradation of ECM was examined by depriving cell from FBS 12 hours prior to seeding. Wells of a 96-well plate were coated with $50 \mu \mathrm{L}$ FITC-conjugated gelatin $(2 \mathrm{mg} / \mathrm{ml}$; BioVision Inc, Milpitas, CA,USA) diluted 1:5 with unlabeled gelatin (Sigma) and incubated for 1 hour at $37^{\circ} \mathrm{C}$ and $5 \% \mathrm{CO}_{2}$. Solution was discarded and plate left to dry under bench. FBS deprived cells were seeded $\left(1 \times 10^{4}\right)$ on gelatin coated wells and when indicated treated with rhCTGF ( $1 \mu \mathrm{g} / \mathrm{ml}$; R\&D systems). After 24 hours proteolytic activity was detected by measuring fluorescence (extinction 490nm/emission 520nm) using Synergy (BioTek Instruments, Bad Friedrichshall, Germany). Each experiment was performed in three replicates. Mean values were compared to respective control.

\section{AlamarBlue Assay}

Transiently transfected breast cancer cells were seeded in 96- wells $\left(1.25 \times 10^{3}\right)$ in DMEM w/o phenol-red supplemented with 10\% cs-FBS and relative AlamarBlue reduction (BioRad, Hercules, USA) was assessed at 48 hours and/or 120 hours. 3D spheroids were grown as described above and 48 hours after seeded in Matrigel AlamarBlue was added and incubated for 4 hours. Thereafter, relative AlamarBlue reduction was measured by absorbance reading 
at $540 \mathrm{~nm}$ and $630 \mathrm{~nm}$, using Synergy (BioTek Instruments). Relative AlamarBlue Reduction was calculated as indicated by manufacturer.

\section{Immuno-histochemical staining}

Immuno-histochemical staining of human tissue array slide (BR248a; US Biomax, Derwood, MD, USA) was performed as described earlier (7). Sections were deparaffinized and rehydrated. Thereafter, antigens were retrieved by slide incubation in $0.01 \mathrm{M}$ citrate buffer (pH 6.0) in microwave (700W) for 5 minutes. Using 3\% hydrogen peroxidase solution for 6 min endogenous peroxidase activity was quenched. Sections were incubated over night with primary labeled antibodies against CTGF $(0.02 \mathrm{mg} / \mathrm{ml}$; Novus Biologicals) in fluorescence staining solution $\left(1 \% \mathrm{BSA}+0.4 \%\right.$ TRITON X-100 in PBS) at $4^{\circ} \mathrm{C}$. Labeling with secondary was performed by incubating slide with secondary rabbit antibody Alexa488 (Invitrogen) and DAPI $(1 \mu \mathrm{g} / \mathrm{ml}$; Novus Biologicals) in fluorescence staining solution for 30 minutes at room temperature protected from light. Staining was visualized using a Zeiss Scope A1 Axio microscope (ZEISS, Oberkochen, Germany) with an oil EC PLAN-NEOFLUAR 100x (ZEISS, Oberkochen, Germany) objective and ZEN software (ZEISS, Oberkochen, Germany).

\section{Flow Cytometry}

Cells were detached from culture dish with trypsin for 5 min and washed once with PBS. $1 \times 10^{6}$ were suspended in pre-cooled flow cytometry staining solution (PBS, $10 \%$ FCS, $1 \mathrm{NaN}_{3}$ ) and incubated with conjugated primary antibodies (CD51-FITC; CD-106-APC; eBioscience Inc., ThermoFisher Scientific, Waltham, MN, USA) for 20 minutes at $4{ }^{\circ} \mathrm{C}$. Stained cells were washed twice with flow cytometry staining solution and analyzed immediately by BD CANTOII flow cytometer (BD Biosciences). Untreated cells and UltraComp compensations beads (Invitrogen) incubated with labeled antibodies were used as negative control for determining specificity of signal.

\section{Western Blot analysis}

In Western Blot analysis, cells were lysed in lyse buffer consisting of cell lytic $\mathrm{M}$ buffer (Sigma, St. Louis, USA) supplemented with 0.1\% phosphatase-inhibitor (Sigma, St. Louis, MO, USA) and $0.1 \%$ protease-inhibitor (Sigma, St. Louis, MO, USA ). Isolated proteins $(40 \mu \mathrm{g})$ were fractioned using $12 \%$ SDS gels and electro-transferred to a polyvinylidene difluoride membrane (Merck Millipore, Cork, Ireland). Primary antibodies against CTGF 
1:1000 (\#NB100-724, Novus Biologicals), RhoA 1:500 (\#ARH04, Cytoskeleton, Denver, CO, USA) and GAPDH 1:2000 (\#5174S, Cell Signaling, Danvers, MA, USA) were used. Membrane was washed and incubated in horseradish peroxidase-conjugated secondary antibody (GE Healthcare, Buckinghamshire, UK). Antibody-bond protein bands were assayed using a chemiluminescent luminol enhancer solution (Cyanagen, Bologna, Italy).

\section{RhoA pull-down}

RhoA pulldown assay was examines using Rho activation assay biochem Kit as describes by the manufacturer (BK036-S; Cytoskeleton Inc.). Briefly, $300 \mu \mathrm{g}$ proteins was loaded with 50 $\mu \mathrm{g}$ Rhotekin rho binding domain (RBD) glutathione agarose bound beads which binds/precipitates specifically active GTP-bond Rho proteins. To quantify active RhoA total RhoA protein was determined. A positive cellular control loaded with non-hydrolysable GTP analog $(\mathrm{GTP} \gamma \mathrm{S})$ and a negative control loaded with GDP were determined from each examined sample. To assess functionality of assay one sample was treated with RhoA activator II (CN03, $1 \mu \mathrm{g} / \mathrm{ml}$, Cytoskeleton). As quantitation estimate for endogenous Rho, HisRhoA protein was run on gel together with examined samples.

\section{Mass spectrometric secretome and proteome analysis}

\section{Sample preparation}

Breast cancer cells were seeded $\left(0.75 \times 10^{5}\right)$ in Bio-one ThinCert (Greiner Bio-one, Kremsmünster, Austria) and Osteosarcoma cells were seeded $\left(1,3 \times 10^{5}\right)$ in 6 wells. After 24 hours cells were deprived of FBS and co-cultured for 96 hours. Cell medium was precipitated with acetone. Medium was centrifuged for 10 minutes at $13300 \mathrm{rpm}$ at $4^{\circ} \mathrm{C}$ and five times volume on pre-cooled $\left(-20^{\circ} \mathrm{C}\right)$ was added to samples. Samples were vortexed and protein precipitation performed for 2 hours at $-20^{\circ} \mathrm{C}$. Protein was pelleted by centrifugation for 30 minutes at $13300 \mathrm{rpm}$ at $4^{\circ} \mathrm{C}$. Protein pellets were washed with ethanol $(80 \%$, pre-cooled at $20^{\circ} \mathrm{C}$ ), centrifuged for 30 minutes at $13300 \mathrm{rpm}$ at $4^{\circ} \mathrm{C}$, and protein pellets were air dried.

Cell lysates were generated by cutting membranes from insert and recovering cells with Recovery solution (Corning, New York, NY, USA) for 1 hour at $4{ }^{\circ} \mathrm{C}$ while shaking. Cells were pelleted and resuspended in $30 \mu \mathrm{L}$ lysis buffer.

MS sample processing

For generation of a peptide library, equal amount aliquots from comparable samples were pooled to a total amount of $100 \mu \mathrm{g}$, and separated into eight fractions using a reversed phase 
spin column (Pierce High $\mathrm{pH}$ Reversed-Phase Peptide Fractionation Kit, ThermoFisher Scientific). All samples were spiked with a synthetic peptide standard used for retention time alignment (iRT Standard, Schlieren, Schweiz).

Protein digests were analyzed on a nanoflow chromatography system (Eksigent nanoLC425) hyphenated to a hybrid triple quadrupole-TOF mass spectrometer (TripleTOF 5600+) equipped with a Nanospray III ion source (Ionspray Voltage $2400 \mathrm{~V}$, Interface Heater Temperature $150^{\circ} \mathrm{C}$, Sheath Gas Setting 12) and controlled by Analyst TF 1.7.1 software build 1163 (all AB Sciex). In brief, peptides were dissolved in loading buffer (2\% acetonitrile, $0.1 \%$ formic acid in water) to a concentration of $0.42 \mu \mathrm{g} / \mu 1$. For each analysis $2.1 \mu \mathrm{g}$ of digested protein were enriched on a precolumn $(0.18 \mathrm{~mm}$ ID x $20 \mathrm{~mm}$, Symmetry C18, $5 \mu \mathrm{m}$, Waters, Milford/MA, U.S.A) and separated on an analytical RP-C18 column (0.075 mm ID x $250 \mathrm{~mm}$, HSS T3, $1.8 \mu \mathrm{m}$, Waters) using a 90 min linear gradient of 5-35\% acetonitrile/0.1\%

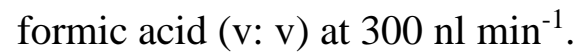

Qualitative LC/MS/MS analysis was performed using a Top25 data-dependent acquisition method with an MS survey scan of $m / z, 350-1250$ accumulated for $350 \mathrm{~ms}$ at a resolution of 30,000 full width at half maximum (FWHM). MS/MS scans of $\mathrm{m} / \mathrm{z}$ 180-1600 were accumulated for $100 \mathrm{~ms}$ at a resolution of 17,500 FWHM and a precursor isolation width of 0.7 FWHM, resulting in a total cycle time of $2.9 \mathrm{~s}$. Precursors above a threshold MS intensity of 125 cps with charge states $2+, 3+$, and 4+ were selected for MS/MS, the dynamic exclusion time was set to $30 \mathrm{~s}$. MS/MS activation was achieved by CID using nitrogen as a collision gas and manufacturer's default rolling collision energy settings. Three technical replicates per reversed phase fraction were analyzed to construct a spectral library.

For quantitative SWATH analysis, MS/MS data were acquired using 65 variable size windows (187) across the $400-1,050 \mathrm{~m} / \mathrm{z}$ range. Fragments were produced using rolling collision energy settings for charge state $2+$, and fragments acquired over an $\mathrm{m} / \mathrm{z}$ range of 350-1400 for $40 \mathrm{~ms}$ per segment. Including a $100 \mathrm{~ms}$ survey scan this resulted in an overall cycle time of $2.75 \mathrm{~s}$. Two replicate injections were acquired for each biological sample.

Protein identification was achieved using ProteinPilot Software version 5.0 build 4769 (AB Sciex) at "thorough" settings. MS/MS spectra from combined qualitative analyses were searched against UniProtKB human reference proteome (revision 04-2018, 93.661 entries) augmented with a set of 52 known common laboratory contaminants to identify 217 proteins at a False Discovery Rate (FDR) of 5\% in the secretome, and 2,033 proteins at an FDR of $1 \%$ 
for whole proteome analysis. We consciously allowed for a larger FDR in the secretome analysis since identified candidate proteins were further validated during SWATH data extraction and by biochemical experimentation.

Spectral library generation and SWATH peak extraction were achieved in PeakView Software version 2.1 build 11041 (AB Sciex) using SWATH quantitation microApp version 2.0 build 2003. Following retention time correction using iRT standard, peak areas were extracted using information from MS/MS library at an FDR of 1\% (188). Resulting peak areas were then summed to peptide and finally protein area values, which were used for further statistical analysis.

\section{Real-time quantitative PCR analysis}

Total RNA was extracted using an RNeasy mini kit (Qiagen, Hilden, Germany) and $2 \mu \mathrm{g}$ were reverse transcribed with high capacity cDNA reverse transcription kit (Qiagen, Hilden, Germany). Real- time qPCR was performed using SYBR green PCR master mix kit (Qiagen, Hilden, Germany) and following Primers: CTGF (forward) 5'CTTGCGAAGCTGACCTGGAA-3', CTGF (reverse) 5'- GTGCAGCCAGAAAGCTCAAA3', TGFBI (forward) 5'- AGGCCTTCGAGAAGATCCCT -3', TGFBI (reverse) 5'GAGATGATCGCCTTCCCGTT-3', CD44 (forward) 5'- CACACCCTCCCCTCATTCAC3', CD44 (reverse) 5'- CAGCTGTCCCTGTTGTCGAA -3', SPARC (forward) 5'GTGCGAGCTGGATGAGAACA-3', SPARC (reverse) 5'TTGCAAGGCCCGATGTAGTC-3', FN1 (forward) 5'- GCTGCACATGTCTTGGGAAC3', FN1 (reverse) 5'- CATGAAGCACTCAATTGGGCA-3', LOX (forward) 5'GGGCGACGACCCTTACAAC-3', LOX (reverse) 5'- GCCCTGTATGCTGTACTGGC-3', FSTL1 (forward) 5'- TCTGCCAGCCCAGTTGTTTG-3', FSTL1 (reverse) 5'GAGTCCAGGCGAGAATCACC-3', CDH1 (forward) 5'-CCTCCTGAAAAGAGAGTGGA -3', CDH1 (reverse) 5'- GTGTCCGGATTAATCTCCAG-3', VIM (forward) 5'GCTGCTAACTACCAAGACAC-3', VIM (reverse) 5'-TCAGGTTCAGGGAGGAAAAG 3', ZEB1 (forward) 5'- AAGACAAACTGCATATTGTGGAAG-3', ZEB1 (reverse) 5'CTGCTTCATCTGCCTGAGCTT-3', SNAI2 (forward) 5'-GCCAAACTACAGCGAACTGG -3', SNAI2 (reverse) 5'-GAGAGAGGCCATTGGGTAGC -3', RhoA (forward) 5'CAAGGACCAGTTCCCAGAGG -3', RhoA (reverse) 5'-TGTCCCACAAAGCCAACTCT 3', and GAPDH (forward) 5'- GAAGGTCGGAGTCAACGGAT -3', GAPDH (reverse) 5'TGGAATTTGCCATGGGTGGA -3' .PCR conditions were: denaturing once at $95^{\circ} \mathrm{C}(2$ minutes), $95^{\circ} \mathrm{C}$ ( 5 seconds), $60^{\circ} \mathrm{C}$ ( 15 seconds) for 40 cycles. 


\section{Data analysis}

Gene ontology enrichment analysis, networks summarizing overlapping terms and hierarchical lustering trees were conducted using Shiny GO v0.60 with a p-value cutoff (FDR) of 0.05 (189).

\section{CTGF expression analysis in human tissues}

Statistical analysis of tissue-specific CTGF expression was conducted using large public cancer genomics datasets (GTEX, TARGET, TCGA) as described previously (190).

\section{Statistical analysis}

All experiments were performed at least in three biological and technical replicates. Data were analyzed by GraphPad Prism Software version 7.03 (GraphPad Software Inc., La Jolla, CA/USA) using unpaired, two-tailed, parametric t-test comparing two groups (treatment to respective control) by assuming both populations have same standard derivation or ANOVA one-way analysis when more than two groups were compared. F-values were recorded and a Dunnett's multiple comparison test with no matching or pairing between groups was calculated. $\mathrm{P}<0.05$ was considered statistically significant.

\section{Availability of data and material}

The datasets used and/or analyzed during current study are available from the corresponding author on reasonable request.

\section{Competing interests}

The authors declare that they have no competing interests. 


\section{Figures and tables}

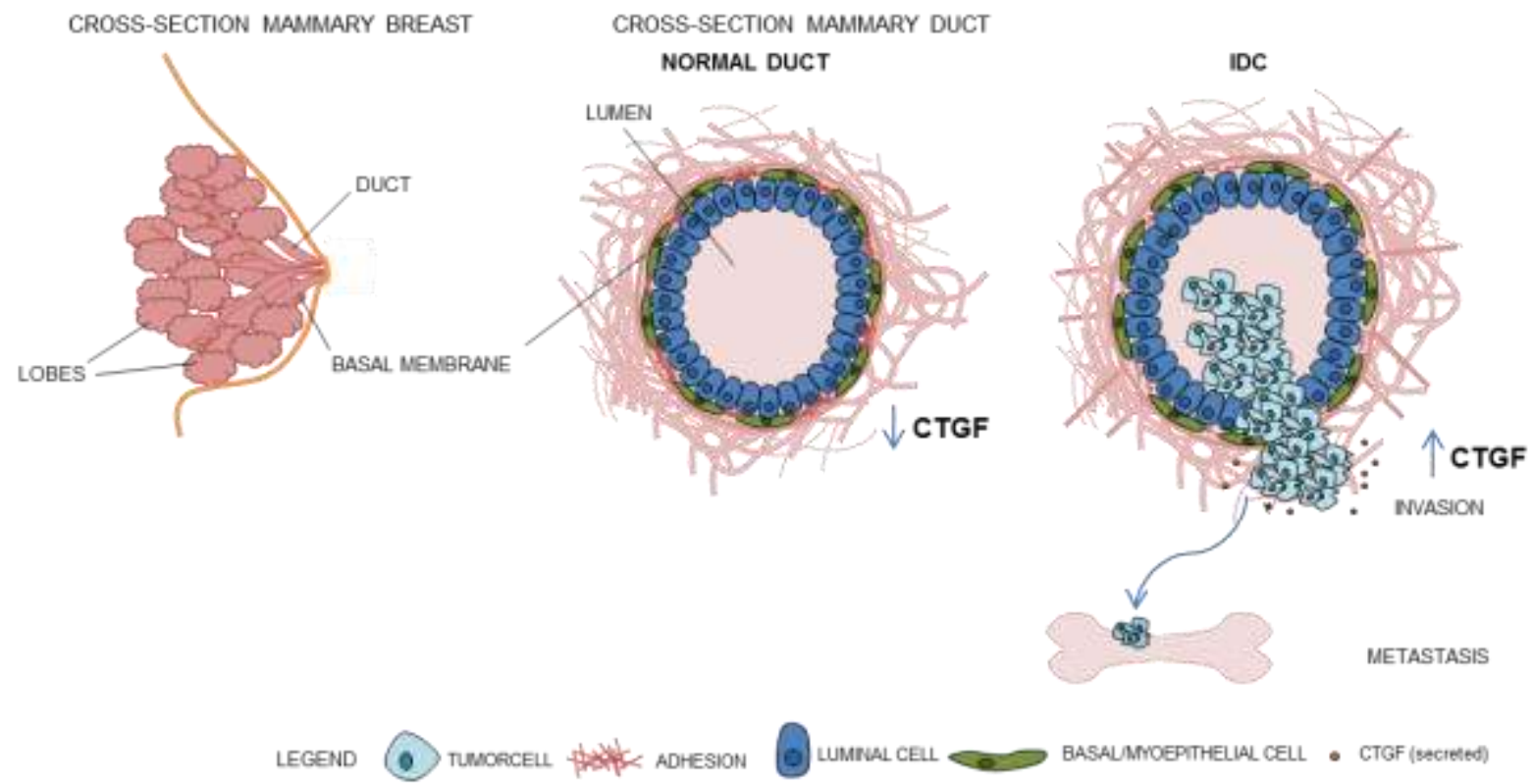

Graphical abstract Anatomy of mammary duct and lobes (cross-section) vs. anatomy of invasive ductal carcinoma (IDC). Connective tissue growth factor (CTGF) expression is downregulated in normal duct. Increased extracellular CTGF expression leads to breast cancer bone-directed invasiveness. 
A

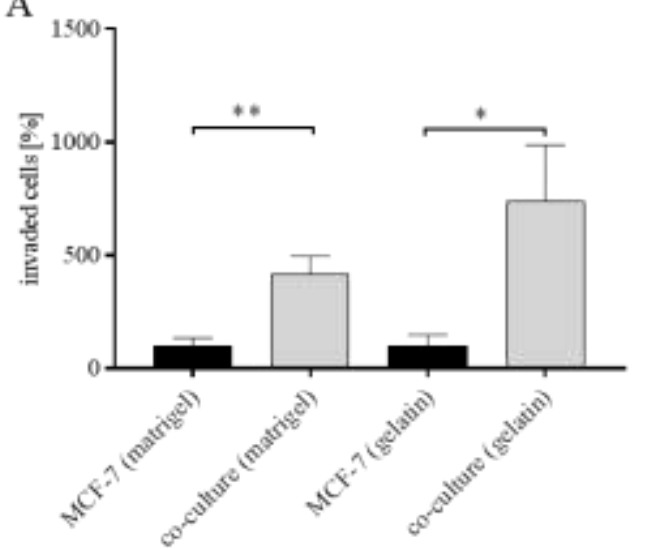

$\mathrm{C}$

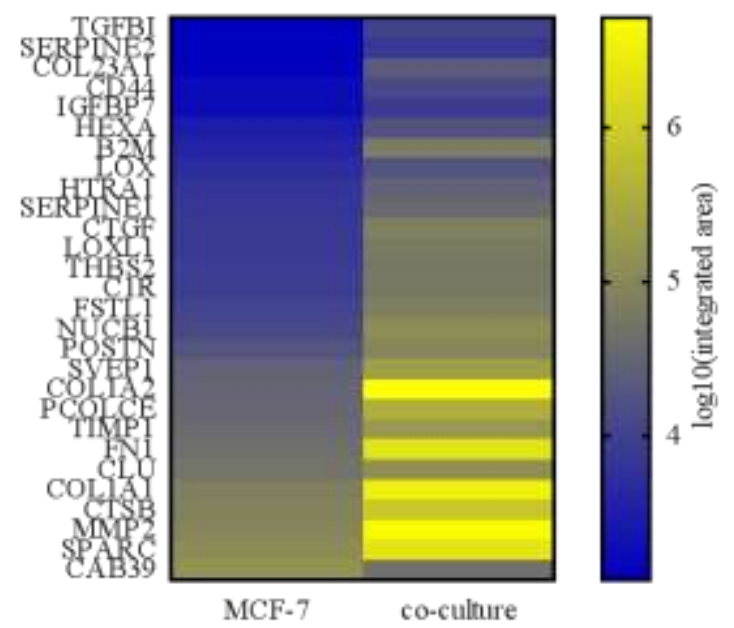

B

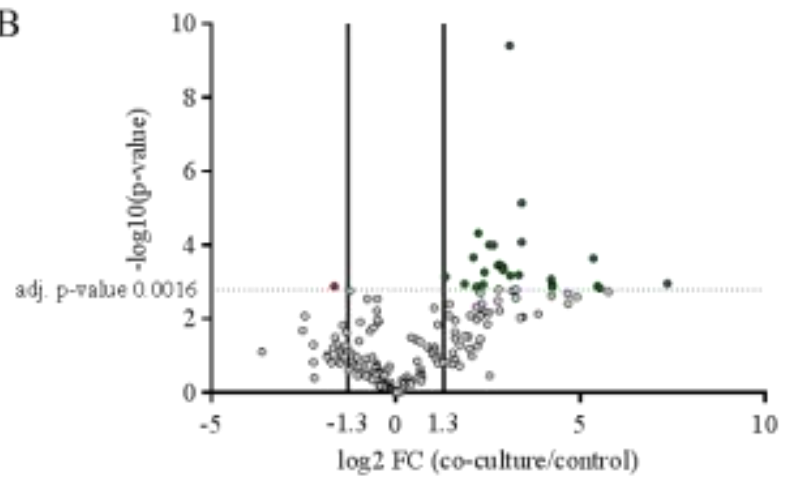

$\mathrm{D}$

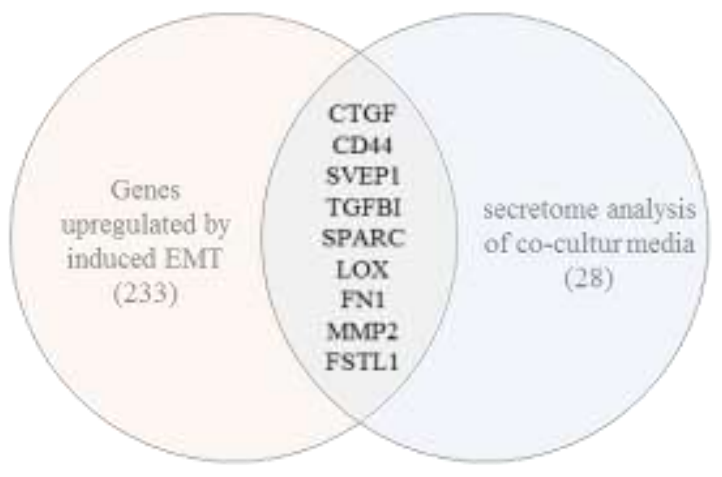

Figure 1 Identifying drivers of breast cancer cell invasion. A Transwell-invasion co-culture assay of MCF-7 breast cancer cells and MG-63 osteosarcoma cells without FBS addition and Matrigel or Collagen I coated insert. Invaded cells under the filter were stained and counted in four randomly selected regions after 96 hours in co-culture. Data represent mean \pm SEM. MCF-7 (Matrigel) n=12, MCF-7 (gelatin) $\mathrm{n}=6$, unpaired, two-sided t-test to respective control. * $P<0.05 ; * * P<0.01 \mathbf{B}$ Volcano plot demonstrating potential bone-directed breast cancer invasiveness related targets using secretome analysis. Detected target proteins were stated as discovery when adjusted p-value (adj. p-value) was below 0.0016 (dotted line) with a false-discovery rate (FDR) of $1 \%$ and a $\log 2$ fold change (FC) higher 1.3 or lower -1.3 . Every dot indicates one target, green dots indicate upregulated discoveries and red dot indicates downregulated discovery. $n=6$, discovery determined using the two-stage linear step-up procedure of Benjamini, Krieger and Yekutieli, with $\mathrm{Q}=1 \%$. Each row was analyzed individually, without assuming a consistent SD. C Heat map visualizing all discoveries with a color gradient of $\log 10$ integrated area of mean values of three biological and two technical replicates corresponding to B. D Scheme of overlapping targets from microarray analysis of MCF-7 cells under dynamic EMT program and secretome analysis of co-cultured MCF-7 cells with a fold change of higher 1.3 or lower -1.3 and FDR 5\% (microarray) and FDR 1\% (secretome analysis). 
A

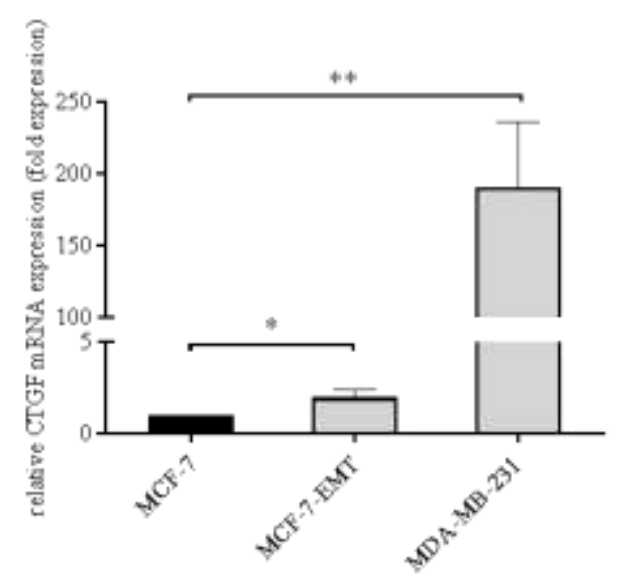

C

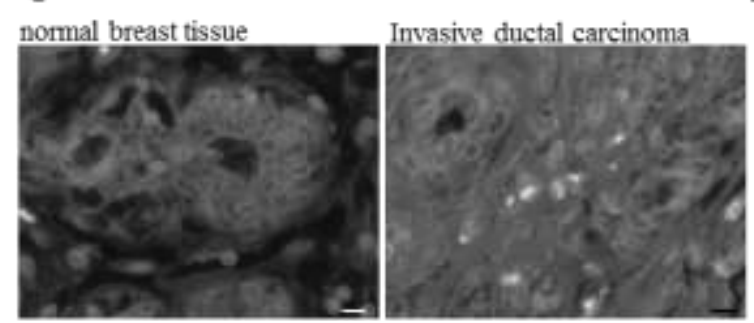

E

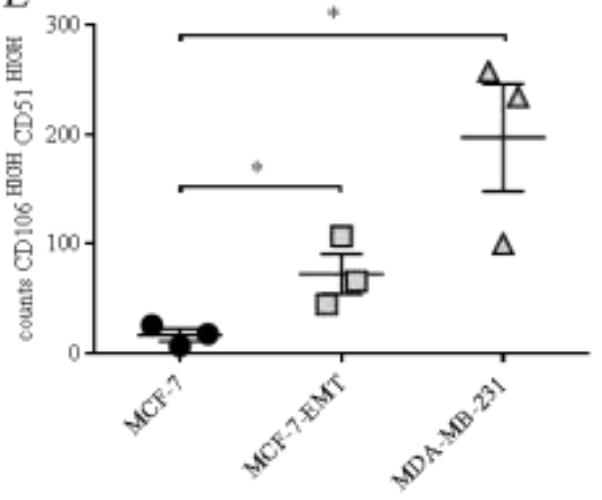

B

CTGF

GAPDH

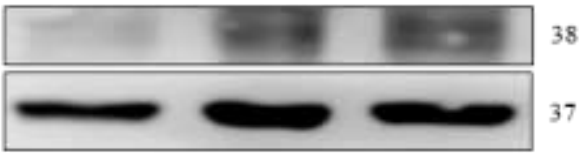

$++$

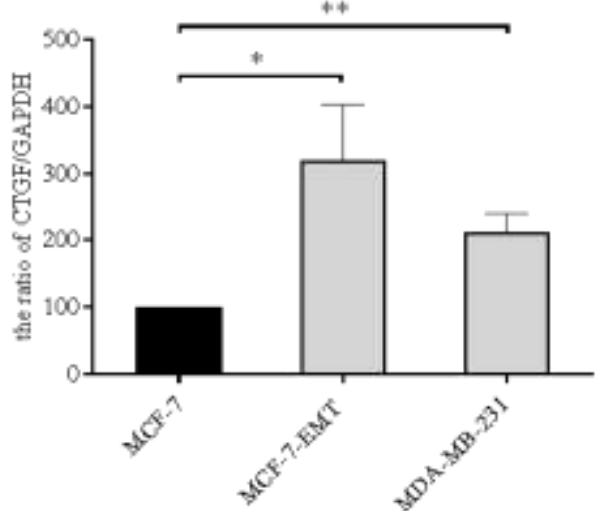

D

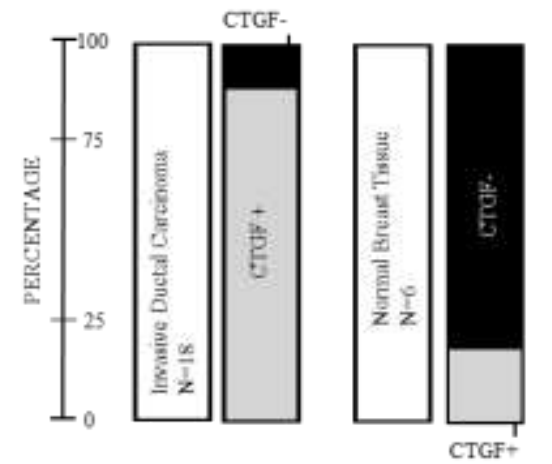

F

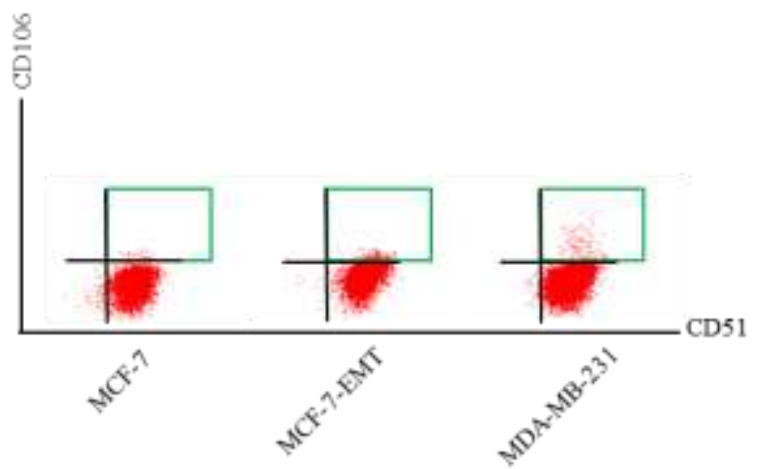

Figure 2 CTGF expression correlates with invasiveness of mesenchymal transformed and TNBC cells. A Assessment of CTGF mRNA expression in different breast cancer cell lines using quantitative real-time PCR. Data represent mean \pm SEM. MCF-7-EMT n=6, MDA-MB-231 n=4 using unpaired, two-tailed t-test analysis to respective control (MCF-7). ${ }^{*} P<0.05$; ** $P<0.01$ B Quantification and representative experiments of CTGF protein expression in different breast cancer cell lines compared to non-invasive MCF-7 breast cancer cell line. CTGF band intensity was quantified by densitometry and normalized to GAPDH. Data represent mean \pm SEM. $n=6$ using unpaired, two-tailed t-test analysis to respective control (MCF-7). $* P<0.05 ; * * P<0.01$ C Patient tissue sections $(\mathrm{n}=24)$ were analyzed for CTGF expression. Representative images of normal breast tissue (right panel) and IDC (invasive ductal carcinoma, left panel) are illustrated. D Graph illustrating distribution of CTGF expression within two different analyzed patient sample categories. E Results of three independent flow cytometry experiments of CD51 and CD106 co-expression in MCF-7 (circle), MCF-7-EMT (square) and MDA-MB-231 (triangle) breast cancer cell lines. Data represent mean \pm SEM. MCF-7-EMT, MDA-MB-231 n=3 using unpaired, two-tailed t-test analysis to respective control (MCF-7). $* P<0.05$ F Proportion of CD51 to CD106 was asses using flow cytometry after staining with fluorescence-labeled antibodies. A representative experiment to $\mathrm{E}$ is illustrated. 


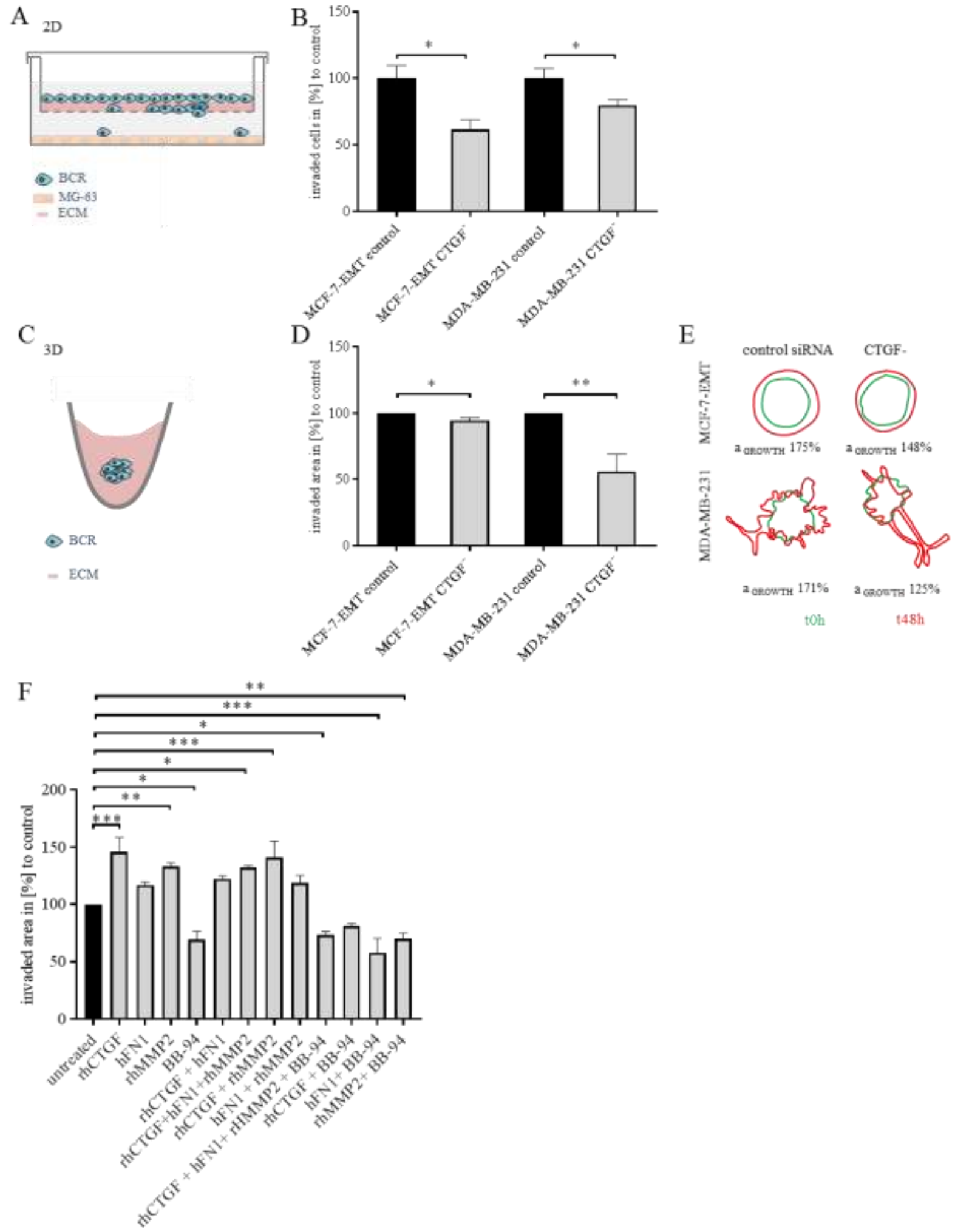

Figure 3 CTGF regulates invasiveness in breast cancer cells. A Scheme illustrating 2D invasion experiment using a coculture transwell invasion assay. BCR = breast cancer cell, ECM = extracellular matrix $\mathbf{B}$ Following CTGF siRNA transfection invaded cells under filter were counted in four randomly selected regions, using a co-culture Matrigel invasion assay for 96 hours. Data represent mean \pm SEM. MCF-7-EMT $n=15$, MDA-MB-231 $n=9$ using unpaired, two-tailed t-test analysis to respective control. $* P<0.05$ C Scheme illustrating 3D spheroid invasion assay. Cells were seeded in ultra-low attachment wells and after initial spheroid formation (48 hours), spheroids were surrounded by Matrigel matrix and further cultivated. D 3 D spheroid assay was performed after transient CTGF siRNA transfection. Invaded area was assessed using ImageJ software and relative area growth was calculated corresponding to respective control. Data represent mean \pm SEM.MCF-7-EMT n=15, MDA-MB-231 n=9 using unpaired, two-tailed t-test analysis to respective control. $* P<0.05 ; * * P$ 
$<0.01 \mathrm{E}$ Representative experiment illustrating area measurement of 3D spheroids. Green shape corresponding to initial spheroid size right after adding Matrigel and red shape corresponding to time point 48 hours after Matrigel adding. F $3 \mathrm{D}$ spheroid assay of MCF-7 cells treated with different combinations of $1 \mu \mathrm{g} / \mathrm{ml} \mathrm{rhCTGF}, 1 \mu \mathrm{g} / \mathrm{ml} \mathrm{hFN} 1,1 \mu \mathrm{g} / \mathrm{ml} \mathrm{rhMMP} 2$, and/or 4nM BB-94 (Batimastat) for 48 hours every 24 hours. Area growth of spheroids was assessed using ImageJ software and relative area growth was calculated corresponding to untreated control. Data represent mean \pm SEM. $n=4-6$ using oneway ANOVA and a Dunnett's multiple comparison test with no matching or pairing between groups was calculated to assess significant differences compared to untreated control. *P<0.05; ** $P<0.01 ; * * * P<0.005$ 

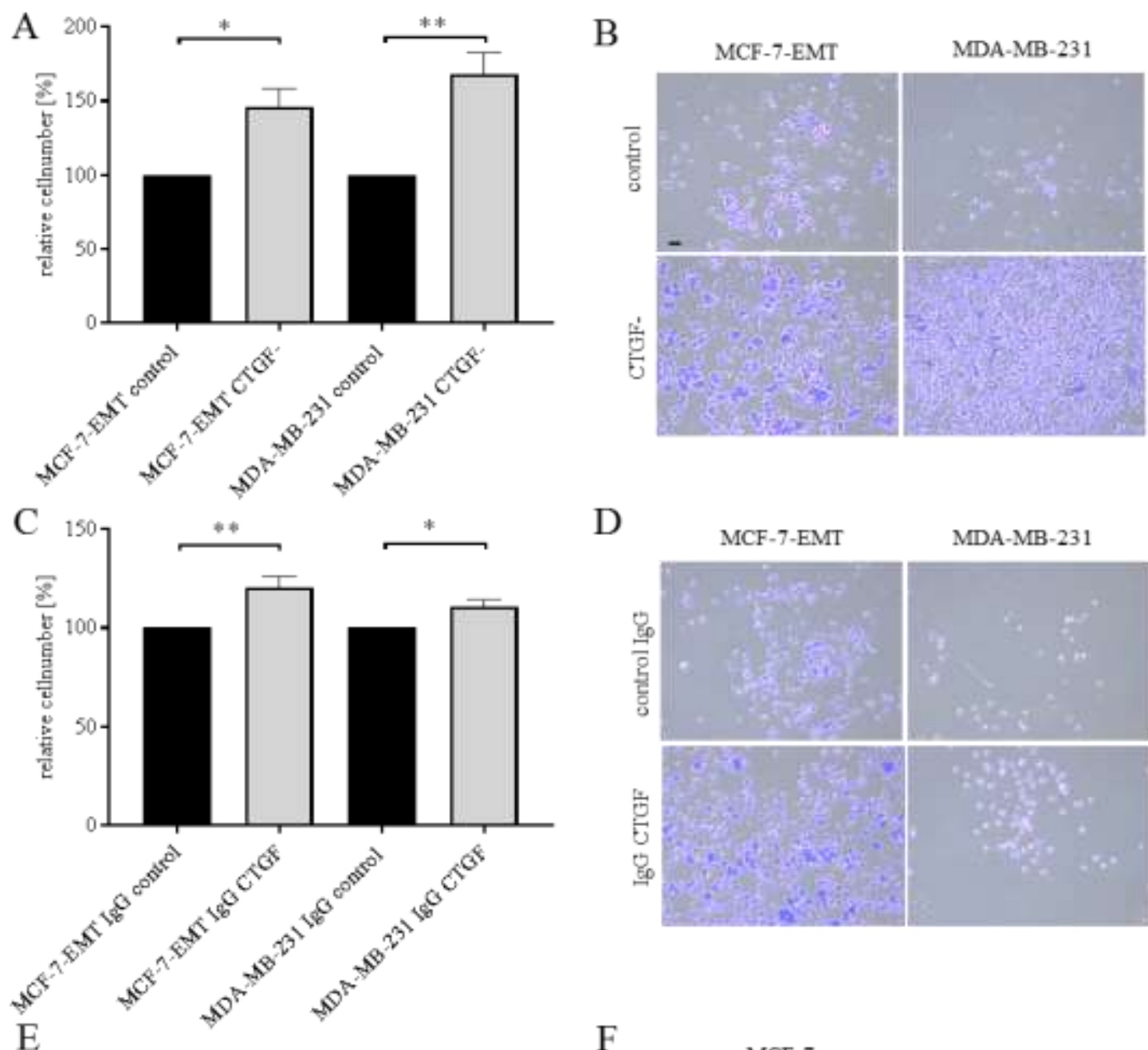

D
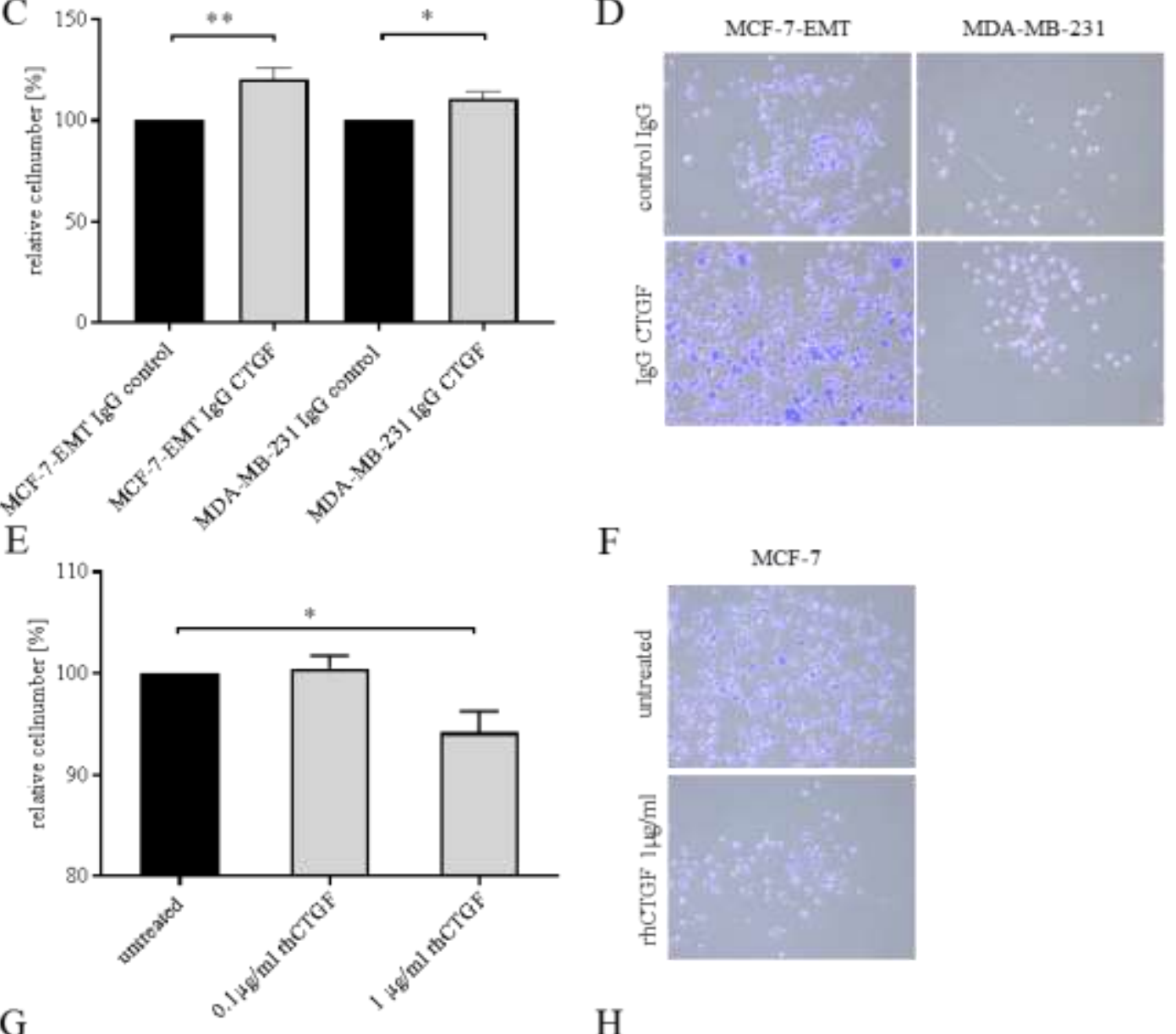

F

MCF-7

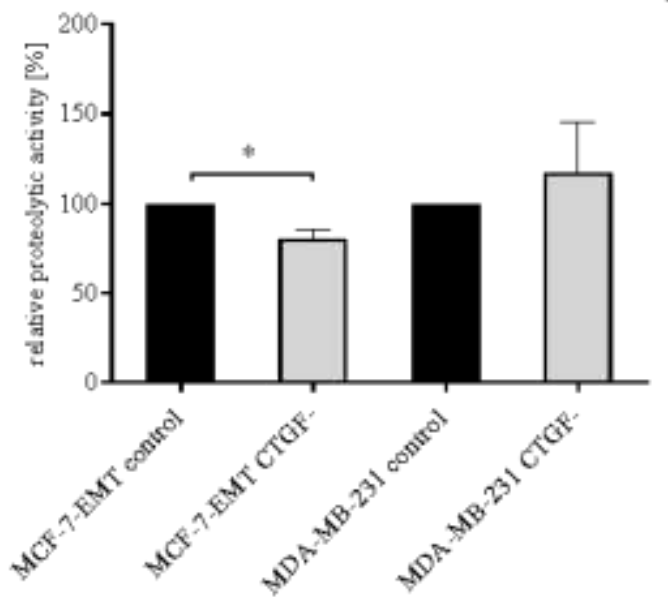

H

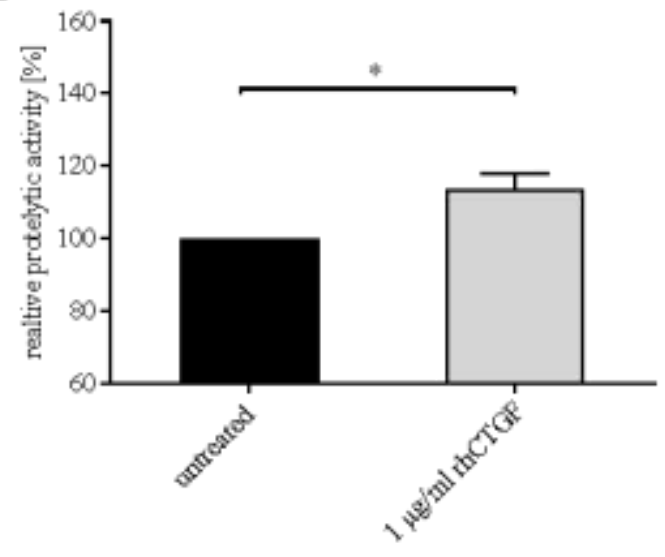


Figure 4 CTGF alters cell-ECM adhesion and proteolytic activity of breast cancer cells. A Adhesion analysis of transiently transfected mesenchymal transformed and triple-negative breast cancer cells. Adhesive cells where counterstained with crystal violet and absorption was measured at 570nm. Data represent mean \pm SEM. MCF-7-EMT n=3, MDAMB-231 n=3 using unpaired, two-tailed t-test analysis to respective control. * $P<0.05 ; * * P<0.01$ B Representative images corresponding to A. C Extracellular CTGF was reduced using a blocking-antibody against CTGF and cell-ECM adhesion was assessed. Data represent mean \pm SEM. MCF-7-EMT $n=6$, MDA-MB-231 $n=3$ using unpaired, two-tailed t-test analysis to respective control (IgG control). $* P<0.05 ; * * P<0.01$ D Representative images corresponding to C. E MCF-7 cells where treated with recombinant human CTGF (rhCTGF) in different concentrations prior to assessing of cell-ECM adhesion. Data represent mean \pm SEM. $n=3$ using one-way ANOVA with $F=6.244$ and a Dunnett's multiple comparison test with no matching or pairing between groups. $* P<0.05$ F Representative images corresponding to E. G Following transient transfection mesenchymal transformed and triple negative breast cancer cells were seeded on FITC-conjugated gelatin $(0.2 \%)$. Degradation of gelatin /proteolytic activity results in an increase of fluorescence. Data represent mean \pm SEM. MCF7-EMT n=3, MDA-MB-231 n=3 using unpaired, two-tailed t-test analysis to respective control. $* P<0.05 \mathbf{H}$ Assessment of proteolytic activity of MCF-7 breast cancer cells after treatment with rhCTGF. Data represent mean \pm SEM. M n=3 using unpaired, two-tailed t-test analysis to respective control (untreated). ${ }^{*} P<0.05$. Scale bar gauges $200 \mu \mathrm{m}$.

A

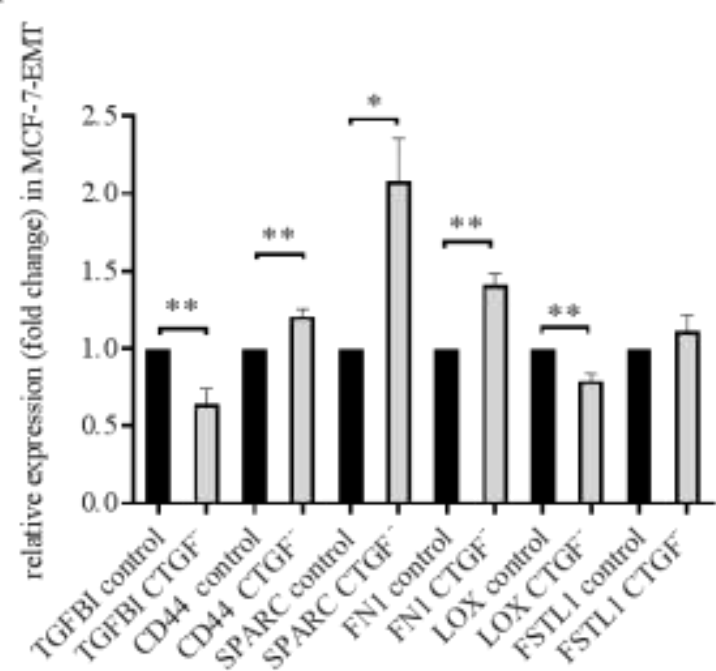

$\mathrm{C}$

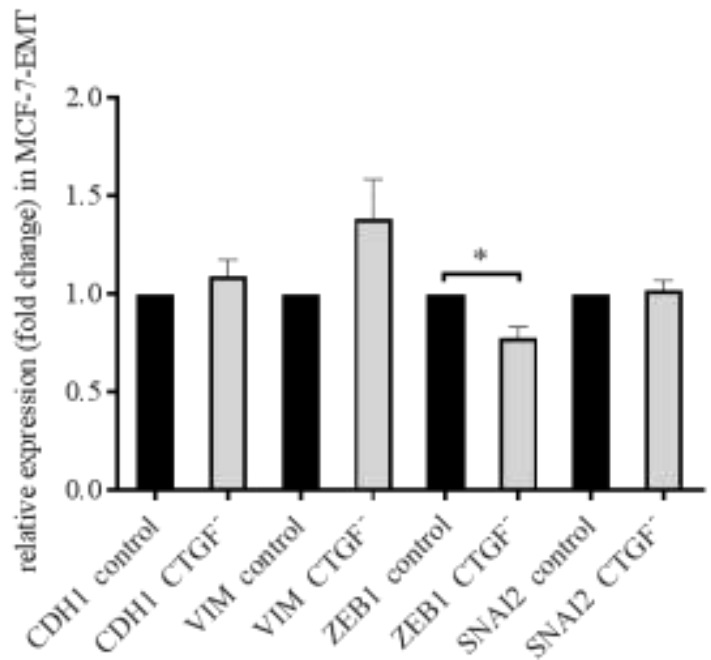

$\mathrm{B}$

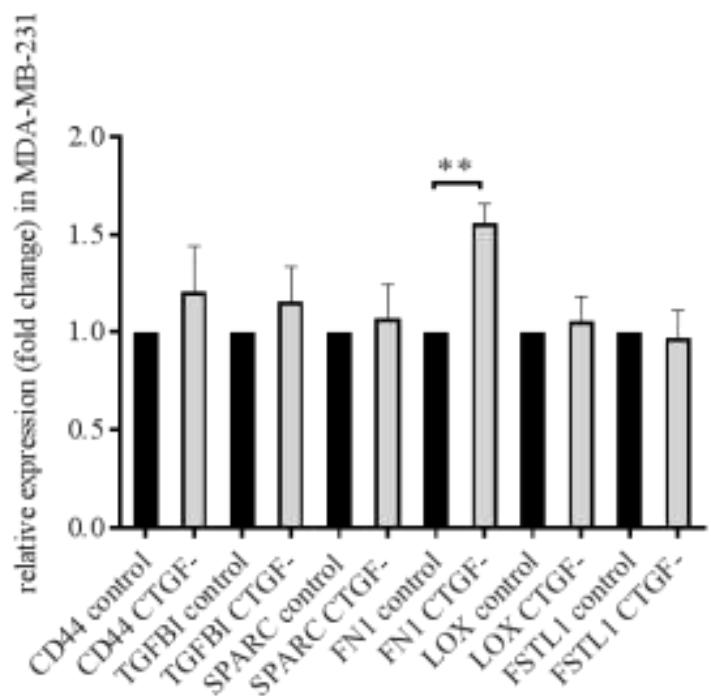

$\mathrm{D}$

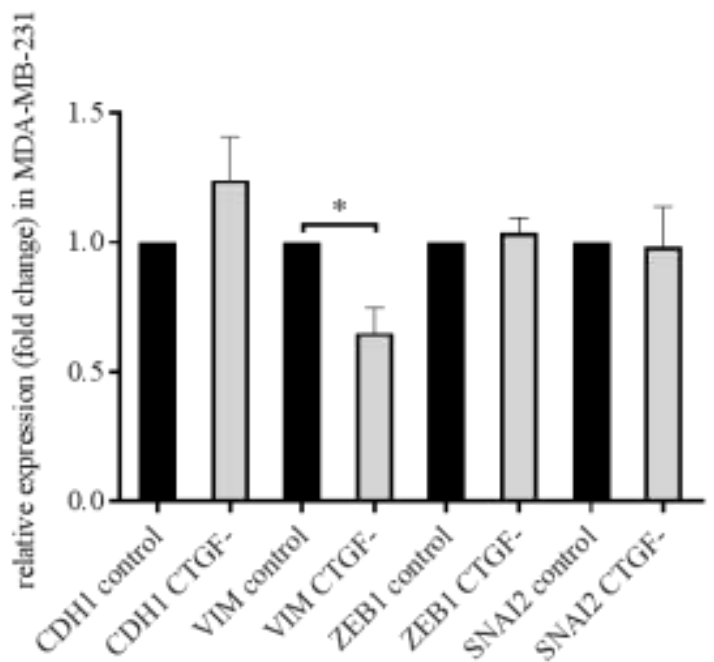

Figure 5 CTGF regulates expression of potential drivers of invasion and EMT-markers. A Relative quantification of TGFBI, CD44, SPARC, FN1, LOX and FSTL1 mRNA expression in mesenchymal transformed breast cancer cells treated transiently with CTGF siRNA for 48 hours. Data represent mean \pm SEM. MCF-7-EMT $n=3$ using unpaired, two-tailed t-test analysis to respective control. * $P<0.05$;** $P<0.01$ B Relative quantification of TGFBI, CD44, SPARC, FN1, LOX and FSTL1 mRNA expression in triple negative breast cancer cells treated transiently with CTGF siRNA for 48 hours. Data represent mean \pm SEM. MDA-MB-231 n=3 using unpaired, two-tailed t-test analysis to respective control. $* P<0.05 \mathbf{C}$ Relative quantification of EMT markers VIM, CDH1, SNAI2 and ZEB1 mRNA expression in mesenchymal transformed breast cancer cells treated transiently with CTGF siRNA for 48 hours. Data represent mean \pm SEM. MCF-7-EMT $n=3$ using 
unpaired, two-tailed t-test analysis to respective control. * $P<0.05$ D Relative quantification of EMT markers VIM, CDH1, SNAI2 and ZEB1 mRNA expression in triple negative breast cancer cells treated transiently with CTGF siRNA for 48 hours. Data represent mean \pm SEM. MDA-MB-231 $\mathrm{n}=3$ using unpaired, two-tailed t-test analysis to respective control. $* P<0.05$

A

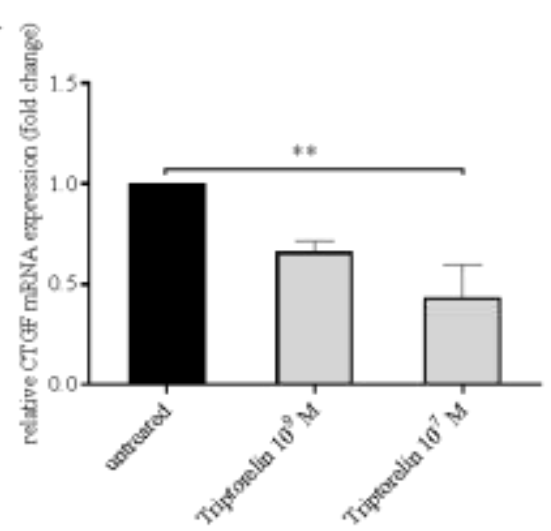

$\mathrm{C}$

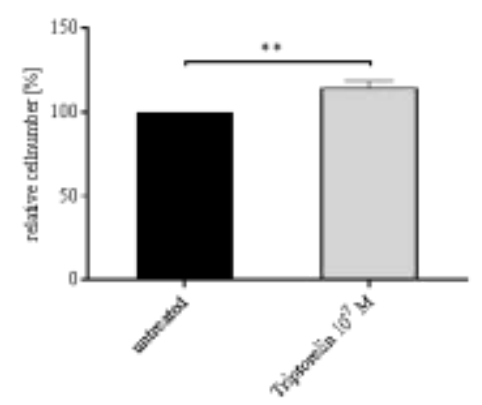

$\mathrm{F}$

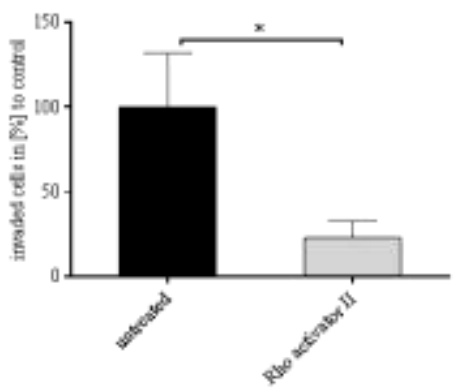

B
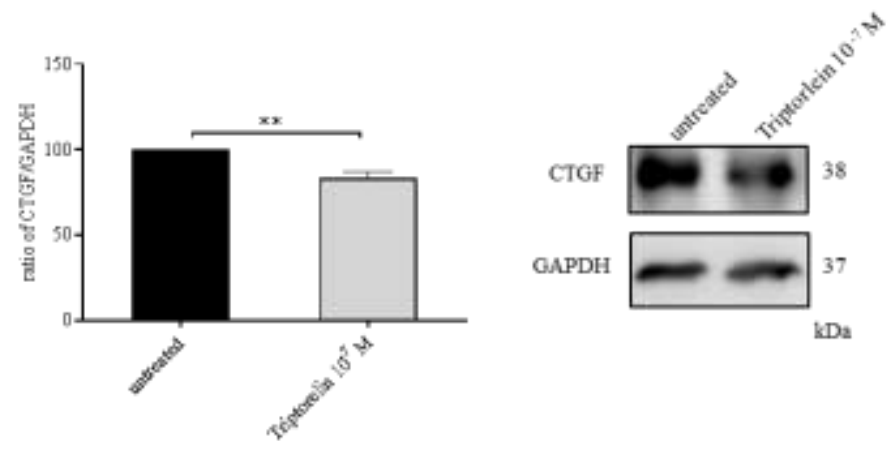

D

MCF-7-EMT

E
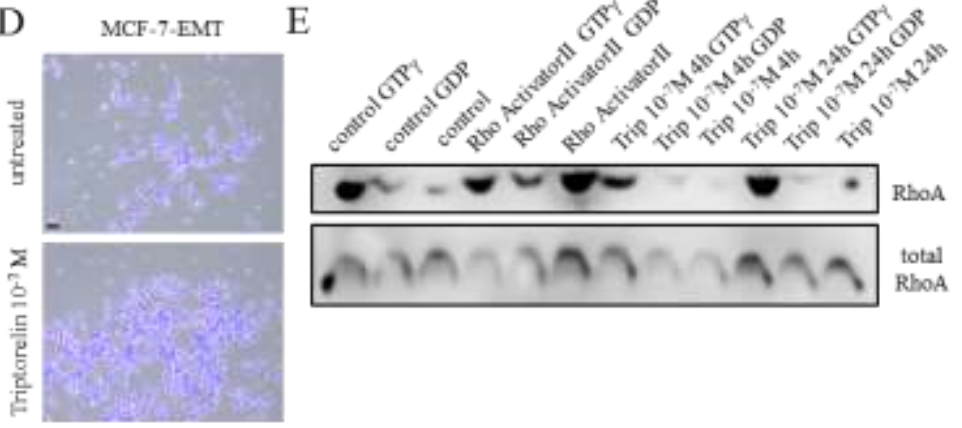

G

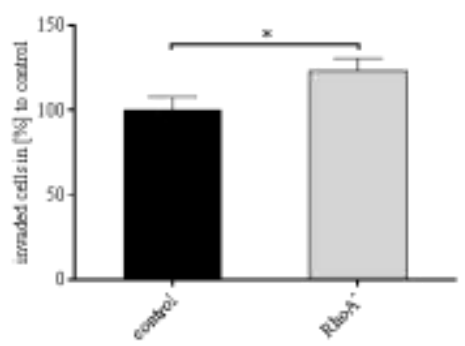

$\mathrm{H}$

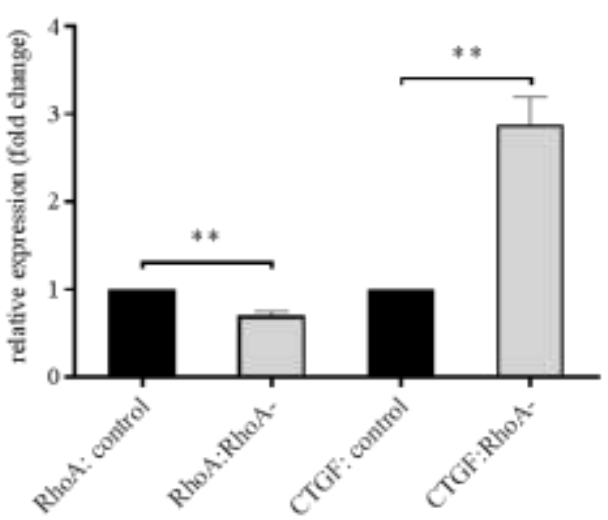

Figure 6 GnRH agonist regulates CTGF through RhoA activity in mesenchymal transformed breast cancer cells. A Relative quantification of CTGF mRNA expression in mesenchymal transformed breast cancer cells (MCF-7-EMT) treated 
for 48 hours with $10^{-9} \mathrm{M}$ or $10^{-7} \mathrm{M}$ Triptorelin. Data represent mean \pm SEM. MCF-7-EMT $\mathrm{n}=3$ using one-way ANOVA with $\mathrm{F}=8.366$ and a Dunnett's multiple comparison test with no matching or pairing between groups. $* * P<0.01$ B Quantification and representative experiment of CTGF protein expression after Triptorelin treatment for 48 hours $\left(10^{-7} \mathrm{M}\right)$. CTGF band intensity was quantified by densitometry and normalized to GAPDH. Data represent mean \pm SEM. MCF-7-EMT $n=3$ using unpaired, two-tailed t-test analysis to respective control (untreated). $* * P<0.01$ (C) Adhesion analysis of mesenchymal transformed breast cancer cells treated with $10^{-7} \mathrm{M}$ Triptorelin. Adhesive cells where counter-stained with crystal violet and absorption was measured at 570nm. Data represent mean \pm SEM. MCF-7-EMT $n=5$ using unpaired, two-tailed t-test analysis to respective control (untreated). $* * P<0.01$ D Representative images corresponding to C. Scale bar gauges $200 \mu \mathrm{m}$. E RhoA activity pull-down of untreated MCF-7-EMT cells, MCF-7-EMT cells treated 3 hours with an specific Rho activator $(1 \mu \mathrm{g} / \mathrm{ml})$ and MCF-7-EMT cells treated with $10^{-7} \mathrm{M}$ Triptorelin for 4 or 24 hours. F $2 \mathrm{D}$ invasion assay. After 48 hours treatment with or without Rho activator II treatment $(1 \mu \mathrm{g} / \mathrm{ml})$ supplement invaded cells under filter were counted in four randomly selected regions. Data represent mean \pm SEM. MCF-7-EMT $n=7$ using unpaired, two-tailed t-test analysis to respective control (untreated). $* P<0.05$ G Following transient RhoA siRNA transfection invaded cells under filter was counted in four randomly selected regions. Data represent mean \pm SEM. M n=18 using unpaired, two-tailed t-test analysis to respective control. * $P<0.05 \mathrm{H}$ Relative quantification of RhoA and CTGF mRNA expression in MCF-7 cells after transient RhoA transfection $(\mathrm{t} O \mathrm{~h})$. Data represent mean \pm SEM. M n=3 using unpaired, two-tailed t-test analysis to respective control. $* * P$ $<0.01$

A

MCF-7-EMT

+GnRH ANALOGA

EXTRACELLULAR SPACE
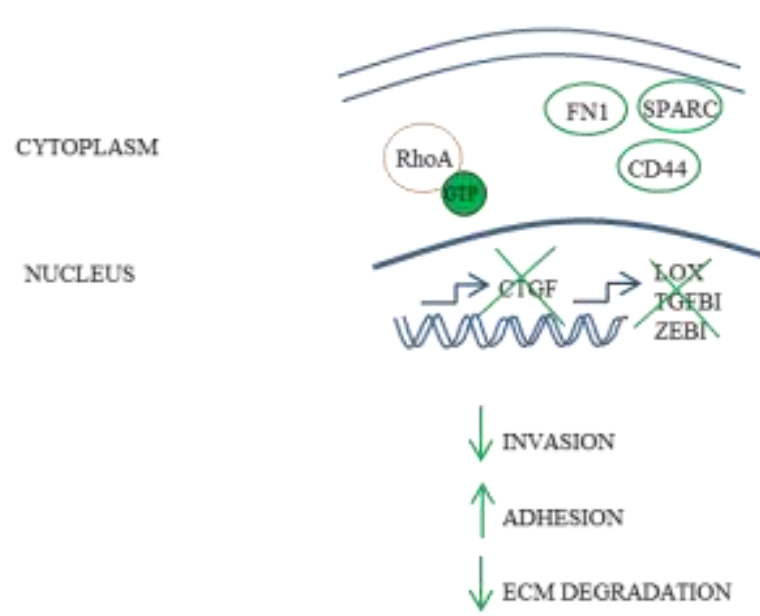

B

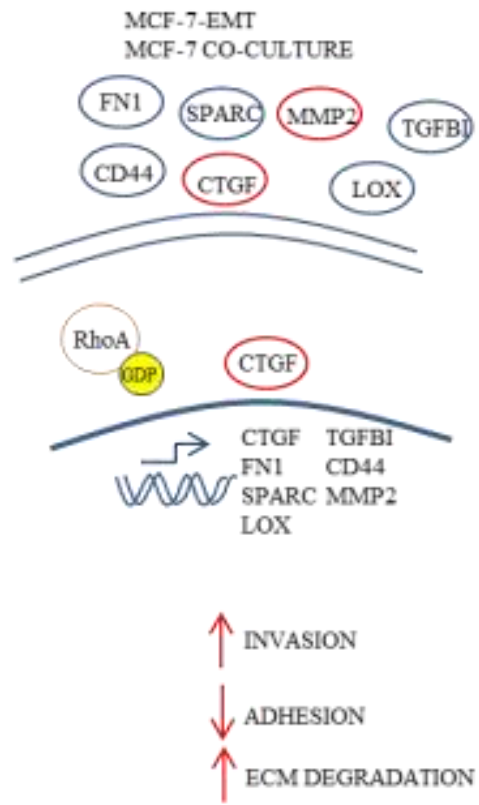

Figure 7 Proposed model of CTGF driven invasion in breast cancer. A Mesenchymal transformed breast cancer cells with Triptorelin treatment, CTGF blocking antibody or transiently suppressed CTGF expression reduces invasiveness, increased cell-ECM adhesion and reduced ECM degradation. On the other hand B co-cultured non-invasive MCF-7 breast cancer cells or mesenchymal transformed breast cancer cells exhibit an increased CTGF expression higher invasion, decreased cell-ECM adhesion and increased ECM degradation. 
Supplementary Information

Identification of breast cancer invasion drivers by secretome analysis: insight into CTGF signaling

Johanna W. Hellinger ${ }^{1}$,Franziska Schömel ${ }^{1}$, Christof Lenz ${ }^{2,3}$, Gerd Bauerschmitz ${ }^{1}$, Günter Emons ${ }^{1}$, Carsten Gründker ${ }^{1}$

\section{Affiliation}

${ }^{1}$ Department of Gynecology and Obstetrics, University Medical Center Göttingen, Göttingen, Germany

${ }^{2}$ Bioanalytical Mass Spectrometry Group, Max Planck Institute for Biophysical Chemistry, Göttingen, Germany

${ }^{3}$ Department of Clinical Chemistry, Bioanalytics, University Medical Center Göttingen, Göttingen, Germany

\section{Includes:}

Supplementary figures: fig. 1 S4; fig. 2 S8; fig. 3 S10, fig. 6 S11, fig. 6 S12

Supplementary tables: fig. 1 S1; fig. 1 S2; fig. 1 S3; fig. 1 S5; fig. 1 S6; fig. 1 S7; fig. 2 S9

Supplement 1: Protein findings from secretome analysis of co-cultured breast cancer cells with osteosarcoma cells. Information is given about gene symbol/User ID, Ensemble Gene ID, p-value and mean values of co-culture media and MCF-7 control media. List was used to further examine Gene Ontology (GO) enrichment using Shiny GO v06.0.

\begin{tabular}{|c|c|c|c|c|c|}
\hline $\mathrm{i}$ & User ID & Ensembl Gene ID & p-value & $\begin{array}{c}\text { mean co- } \\
\text { culture }\end{array}$ & $\begin{array}{c}\text { mean MCF-7 } \\
\text { control }\end{array}$ \\
\hline 1 & HTRA1 & ENSG00000166033 & 0,00021228 & 28234 & 6597 \\
\hline 2 & CD44 & ENSG00000026508 & 0,00037961 & 12615 & 1688 \\
\hline 3 & C1R & ENSG00000159403 & 0,00033183 & 61150 & 8715 \\
\hline 4 & POSTN & ENSG00000133110 & 0,0011454 & 95683 & 18550 \\
\hline 5 & HEXA & ENSG00000213614 & $9,7674 \mathrm{E}-05$ & 16849 & 2926 \\
\hline 6 & B2M & ENSG00000166710 & 0,00135842 & 70650 & 3738 \\
\hline 7 & LOXL1 & ENSG00000129038 & $3,8422 \mathrm{E}-10$ & 65281 & 7724 \\
\hline 8 & MMP2 & ENSG00000087245 & 0,00146649 & 4431667 & 96000 \\
\hline 9 & COL1A1 & ENSG00000108821 & 0,0002255 & 3191667 & 78133 \\
\hline 10 & NUCB1 & ENSG00000104805 & 0,00158982 & 120358 & 12667 \\
\hline 11 & CNN2 & ENSG00000064666 & $7,0889 \mathrm{E}-06$ & 81240 & 7659 \\
\hline 12 & CAB39 & ENSG00000135932 & 0,00129469 & 45224 & 143832 \\
\hline 13 & SERPINE2 & ENSG00000135919 & $9,9725 \mathrm{E}-05$ & 7465 & 1199 \\
\hline 14 & FN1 & ENSG00000115414 & 0,00127185 & 2013667 & 45350 \\
\hline 15 & FSTL1 & ENSG00000163430 & 0,00158654 & 77483 & 11262 \\
\hline
\end{tabular}




\begin{tabular}{|c|c|c|c|c|c|}
16 & IGFBP7 & ENSG00000163453 & $4,6509 \mathrm{E}-05$ & 8350 & 1784 \\
\hline 17 & TGFBI & ENSG00000120708 & 0,00065803 & 10008 & 1168 \\
\hline 18 & SPARC & ENSG00000113140 & 0,00082713 & 2172000 & 116933 \\
\hline 19 & LOX & ENSG00000113083 & 0,00111492 & 18118 & 5004 \\
\hline 20 & COL23A1 & ENSG00000050767 & 0,00116807 & 23983 & 1270 \\
\hline 21 & THBS2 & ENSG00000186340 & 0,00035021 & 59250 & 8683 \\
\hline 22 & COL1A2 & ENSG00000164692 & 0,00108052 & 5150000 & 31383 \\
\hline 23 & SERPINE1 & ENSG00000106366 & 0,00054046 & 37167 & 7040 \\
\hline 24 & PCOLCE & ENSG00000106333 & $8,2456 \mathrm{E}-05$ & 367167 & 34500 \\
\hline 25 & CTSB & ENSG00000164733 & 0,00064317 & 827167 & 82000 \\
\hline 26 & CLU & ENSG00000120885 & 0,00071045 & 130026 & 51465 \\
\hline 27 & SVEP1 & ENSG00000165124 & 0,00046555 & 218000 & 29017 \\
\hline 28 & TIMP1 & ENSG00000102265 & 0,00135049 & 168650 & 37333 \\
\hline
\end{tabular}

Supplement 2 GO enrichment analysis of findings from secretome analysis. Protein discoveries listed in Fig. 1 S1 were examined for GO enrichment using Shiny GO v06.0. Information is given about enrichment FDR, how many genes within the discovery list are enriched within specific functional category, total number of genes within specific functional category, functional category and genes listed from discoveries which are enriched in specific category.

\begin{tabular}{|c|c|c|c|c|}
\hline $\begin{array}{l}\text { Enrichment } \\
\text { FDR }\end{array}$ & $\begin{array}{l}\text { Genes } \\
\text { in list }\end{array}$ & $\begin{array}{l}\text { Total } \\
\text { genes }\end{array}$ & $\begin{array}{l}\text { Functional } \\
\text { Category }\end{array}$ & Genes \\
\hline $3,26 \mathrm{E}-15$ & 14 & 392 & $\begin{array}{l}\text { Extracellular } \\
\text { matrix } \\
\text { organization }\end{array}$ & $\begin{array}{l}\text { COL23A1, MMP2 , COL1A1 , TGFBI , POSTN , } \\
\text { COL1A2, LOX , CD44, TIMP1 , SERPINE1 , } \\
\text { SPARC , FN1 , LOXL1 , HTRA1 }\end{array}$ \\
\hline $1,52 \mathrm{E}-14$ & 14 & 460 & $\begin{array}{l}\text { Extracellular } \\
\text { structure } \\
\text { organization }\end{array}$ & $\begin{array}{l}\text { COL23A1, MMP2, COL1A1, TGFBI, POSTN, } \\
\text { COL1A2, LOX, CD44, TIMP1, SERPINE1, SPARC, } \\
\text { FN1, LOXL1, HTRA1 }\end{array}$ \\
\hline $8,92 \mathrm{E}-09$ & 11 & 585 & Wound healing & $\begin{array}{l}\text { SERPINE1, SERPINE2, CNN2, TIMP1, COL1A1, } \\
\text { LOX, SPARC, FN1, POSTN, CD44, COL1A2 }\end{array}$ \\
\hline $3,22 \mathrm{E}-08$ & 11 & 687 & $\begin{array}{l}\text { Blood vessel } \\
\text { development }\end{array}$ & $\begin{array}{l}\text { COL23A1, COL1A1, THBS2, SPARC, MMP2, LOX, } \\
\text { FN1, LOXL1, SERPINE1, TGFBI, COL1A2 }\end{array}$ \\
\hline $3,22 \mathrm{E}-08$ & 11 & 716 & $\begin{array}{l}\text { Response to } \\
\text { wounding }\end{array}$ & $\begin{array}{l}\text { SERPINE1, SERPINE2, CNN2, TIMP1, COL1A1, } \\
\text { LOX, SPARC, FN1, POSTN, CD44, COL1A2 }\end{array}$ \\
\hline $3,22 \mathrm{E}-08$ & 11 & 715 & $\begin{array}{l}\text { Vasculature } \\
\text { development }\end{array}$ & $\begin{array}{l}\text { COL23A1,COL1A1,THBS2,SPARC,MMP2,LOX, } \\
\text { FN1,LOXL1,SERPINE1,TGFBI,COL1A2 }\end{array}$ \\
\hline $3,22 \mathrm{E}-08$ & 18 & 2983 & $\begin{array}{l}\text { Cellular } \\
\text { response to } \\
\text { organic } \\
\text { substance }\end{array}$ & $\begin{array}{l}\text { CD44, COL1A2, MMP2, PCOLCE, COL1A1, LOX, } \\
\text { SPARC, POSTN, IGFBP7, HTRA1, CTSB, SERPINE1, } \\
\text { CLU, CNN2, TIMP1, FN1, FSTL1, B2M }\end{array}$ \\
\hline $3,22 \mathrm{E}-08$ & 11 & 724 & $\begin{array}{l}\text { Cardiovascular } \\
\text { system } \\
\text { development }\end{array}$ & $\begin{array}{l}\text { COL23A1, COL1A1, THBS2, SPARC, MMP2, LOX, } \\
\text { FN1, LOXL1, SERPINE1, TGFBI, COL1A2 }\end{array}$ \\
\hline $5,11 \mathrm{E}-08$ & 19 & 3547 & $\begin{array}{l}\text { Response to } \\
\text { organic } \\
\text { substance }\end{array}$ & $\begin{array}{l}\text { TIMP1, CD44, CLU, COL1A2, MMP2, PCOLCE, } \\
\text { COL1A1, LOX, SPARC, LOXL1, POSTN, IGFBP7, } \\
\text { HTRA1, B2M, CTSB, SERPINE1, CNN2, FN1, FSTL1 }\end{array}$ \\
\hline $3,11 \mathrm{E}-07$ & 20 & 4507 & $\begin{array}{l}\text { Response to } \\
\text { stress }\end{array}$ & $\begin{array}{l}\text { CD44, MMP2, SERPINE1, SERPINE2, CAB39, CLU, } \\
\text { CNN2, TIMP1, COL1A1, LOX, SPARC, FN1, POSTN, } \\
\text { C1R, FSTL1, IGFBP7, HTRA1, COL1A2, CTSB, B2M }\end{array}$ \\
\hline $4,16 \mathrm{E}-07$ & 18 & 3536 & $\begin{array}{l}\text { Cellular } \\
\text { response to } \\
\text { chemical } \\
\text { stimulus }\end{array}$ & $\begin{array}{l}\text { CD44, POSTN, COL1A2, MMP2, PCOLCE, COL1A1, } \\
\text { LOX, SPARC, IGFBP7, HTRA1, B2M, CTSB, SERPINE1, } \\
\text { CLU, CNN2, TIMP1, FN1, FSTL1 }\end{array}$ \\
\hline $1,31 \mathrm{E}-06$ & 12 & 1372 & $\begin{array}{l}\text { Response to } \\
\text { cytokine }\end{array}$ & $\begin{array}{l}\text { TIMP1, PCOLCE, COL1A1, LOX, SPARC, POSTN, } \\
\text { CD44, CNN2, MMP2, FN1, COL1A2, B2M }\end{array}$ \\
\hline
\end{tabular}




\begin{tabular}{|c|c|c|c|c|}
\hline $1,31 \mathrm{E}-06$ & 11 & 1077 & $\begin{array}{l}\text { Circulatory } \\
\text { system } \\
\text { development }\end{array}$ & $\begin{array}{l}\text { COL23A1, COL1A1, THBS2, SPARC, MMP2, LOX, } \\
\text { FN1, LOXL1, SERPINE1, TGFBI, COL1A2 }\end{array}$ \\
\hline $2,76 \mathrm{E}-06$ & 10 & 901 & $\begin{array}{l}\text { Regulated } \\
\text { exocytosis }\end{array}$ & $\begin{array}{l}\text { CD44, CNN2, TIMP1, SERPINE1, SPARC, FN1, } \\
\text { CLU, CAB39, CTSB, B2M }\end{array}$ \\
\hline $6,12 \mathrm{E}-06$ & 15 & 2785 & $\begin{array}{l}\text { Anatomical } \\
\text { structure } \\
\text { morphogenesis }\end{array}$ & $\begin{array}{l}\text { COL23A1, THBS2, SERPINE1, SPARC, FN1, CLU, } \\
\text { MMP2, COL1A1, LOX, POSTN, SERPINE2, HTRA1, } \\
\text { TGFBI, CD44, COL1A2 }\end{array}$ \\
\hline $6,12 \mathrm{E}-06$ & 11 & 1278 & $\begin{array}{l}\text { Cellular } \\
\text { response to } \\
\text { cytokine } \\
\text { stimulus }\end{array}$ & $\begin{array}{l}\text { PCOLCE, COL1A1, LOX, POSTN, CD44, CNN2, MMP2, } \\
\text { TIMP1, FN1, COL1A2, B2M }\end{array}$ \\
\hline 7,03E-06 & 10 & 1023 & Exocytosis & $\begin{array}{l}\text { CD44, CNN2, TIMP1, SERPINE1, SPARC, FN1, } \\
\text { CLU, CAB39, CTSB, B2M }\end{array}$ \\
\hline $7,03 \mathrm{E}-06$ & 8 & 541 & $\begin{array}{l}\text { Skeletal system } \\
\text { development }\end{array}$ & $\begin{array}{l}\text { COL1A1, MMP2, TIMP1, LOX, SPARC, TGFBI, } \\
\text { CD44, COL1A2 }\end{array}$ \\
\hline $9,69 \mathrm{E}-06$ & 12 & 1704 & $\begin{array}{l}\text { Response to } \\
\text { endogenous } \\
\text { stimulus }\end{array}$ & $\begin{array}{l}\text { TIMP1, CD44, COL1A2, MMP2, COL1A1, LOX, } \\
\text { SPARC, POSTN, IGFBP7, HTRA1, CTSB, FSTL1 }\end{array}$ \\
\hline $9,87 \mathrm{E}-06$ & 12 & 1715 & Secretion by cell & $\begin{array}{l}\text { FN1, POSTN, SERPINE2, CD44, CNN2, TIMP1, } \\
\text { SERPINE1, SPARC, CLU, CAB39, CTSB, B2M }\end{array}$ \\
\hline $1,35 \mathrm{E}-05$ & 8 & 603 & $\begin{array}{l}\text { Blood vessel } \\
\text { morphogenesis }\end{array}$ & $\begin{array}{l}\text { COL23A1, THBS2, SPARC, MMP2, LOX, FN1, } \\
\text { SERPINE1, TGFBI }\end{array}$ \\
\hline $1,39 \mathrm{E}-05$ & 13 & 2168 & $\begin{array}{l}\text { Tissue } \\
\text { development }\end{array}$ & $\begin{array}{l}\text { COL23A1, SERPINE1, COL1A1, FN1, TIMP1, } \\
\text { LOX, TGFBI, POSTN, SERPINE2, COL1A2, CTSB, } \\
\text { CD44, MMP2 }\end{array}$ \\
\hline $1,63 \mathrm{E}-05$ & 5 & 135 & $\begin{array}{l}\text { Platelet } \\
\text { degranulation }\end{array}$ & TIMP1, SERPINE1, SPARC, FN1, CLU \\
\hline $1,94 \mathrm{E}-05$ & 11 & 1506 & Cell migration & $\begin{array}{l}\text { CD44, SERPINE1, COL1A1, SPARC, FN1, CNN2, } \\
\text { LOX, POSTN, TIMP1, SERPINE2, COL1A2 }\end{array}$ \\
\hline $1,94 \mathrm{E}-05$ & 12 & 1861 & Secretion & $\begin{array}{l}\text { FN1, POSTN, SERPINE2, CD44, CNN2, TIMP1, } \\
\text { SERPINE1, SPARC, CLU, CAB39, CTSB, B2M }\end{array}$ \\
\hline $3,13 \mathrm{E}-05$ & 8 & 694 & $\begin{array}{l}\text { Cellular } \\
\text { response to } \\
\text { growth factor } \\
\text { stimulus }\end{array}$ & $\begin{array}{l}\text { CD44, COL1A2, COL1A1, LOX, SPARC, POSTN, } \\
\text { HTRA1, FSTL1 }\end{array}$ \\
\hline $4,09 \mathrm{E}-05$ & 8 & 723 & $\begin{array}{l}\text { Response to } \\
\text { growth factor }\end{array}$ & $\begin{array}{l}\text { CD44, COL1A2, COL1A1, LOX, SPARC, POSTN, } \\
\text { HTRA1, FSTL1 }\end{array}$ \\
\hline $4,53 \mathrm{E}-05$ & 7 & 511 & Angiogenesis & $\begin{array}{l}\text { COL23A1, THBS2, SPARC, MMP2, FN1, SERPINE1, } \\
\text { TGFBI }\end{array}$ \\
\hline $4,53 \mathrm{E}-05$ & 11 & 1670 & Cell motility & $\begin{array}{l}\text { CD44, SERPINE1, COL1A1, SPARC, FN1, CNN2, } \\
\text { LOX, POSTN, TIMP1, SERPINE2, COL1A2 }\end{array}$ \\
\hline $4,53 \mathrm{E}-05$ & 11 & 1670 & $\begin{array}{l}\text { Localization of } \\
\text { cell }\end{array}$ & $\begin{array}{l}\text { CD44, SERPINE1, COL1A1, SPARC, FN1, CNN2, } \\
\text { LOX, POSTN, TIMP1, SERPINE2, COL1A2 }\end{array}$ \\
\hline
\end{tabular}

Supplement 3 GO group enrichment analysis of findings from secretome analysis. Protein discoveries listed in Fig. 1 S1 were examined for GO group enrichment using Shiny GO v06.0.

\begin{tabular}{|c|l|l|}
\hline $\mathrm{N}$ & High level GO category & Genes \\
\hline 20 & Response to stress & $\begin{array}{l}\text { CD44, MMP2, SERPINE1, SERPINE2, CAB39, CLU, CNN2, TIMP1, COL1A1, } \\
\text { LOX, SPARC, FN1, POSTN, C1R, FSTL1, IGFBP7, HTRA1, COL1A2, CTSB, } \\
\text { B2M }\end{array}$ \\
\hline 15 & $\begin{array}{l}\text { Anatomical structure } \\
\text { morphogenesis }\end{array}$ & $\begin{array}{l}\text { COL23A1, THBS2, SERPINE1, SPARC, FN1, CLU, MMP2, COL1A1, LOX, } \\
\text { POSTN, SERPINE2, HTRA1, TGFBI, CD44, COL1A2 }\end{array}$ \\
\hline 14 & $\begin{array}{l}\text { Regulation of response to } \\
\text { stimulus }\end{array}$ & $\begin{array}{l}\text { CD44, SERPINE1, SERPINE2, COL1A1, FN1, B2M, TIMP1, LOX, CLU, POSTN, } \\
\text { C1R, HTRA1, COL1A2, CTSB }\end{array}$ \\
\hline
\end{tabular}




\begin{tabular}{|c|c|c|}
\hline 13 & Immune system process & $\begin{array}{l}\text { CD44, CLU, B2M, CNN2, LOX, C1R, HTRA1, SERPINE1, COL1A1, FN1, } \\
\text { CAB39, COL1A2, CTSB }\end{array}$ \\
\hline 13 & $\begin{array}{l}\text { Response to external } \\
\text { stimulus }\end{array}$ & $\begin{array}{l}\text { COL1A1, SERPINE1, SERPINE2, CNN2, POSTN, LOX, SPARC, LOXL1, } \\
\text { FSTL1, HTRA1, B2M, CLU, C1R }\end{array}$ \\
\hline 12 & $\begin{array}{l}\text { Response to endogenous } \\
\text { stimulus }\end{array}$ & $\begin{array}{l}\text { TIMP1, CD44, COL1A2, MMP2, COL1A1, LOX, SPARC, POSTN, IGFBP7, } \\
\text { HTRA1, CTSB, FSTL1 }\end{array}$ \\
\hline 12 & Regulation of localization & $\begin{array}{l}\text { CAB39, SERPINE1, COL1A1, SPARC, FN1, CNN2, NUCB1, POSTN, } \\
\text { SERPINE2, CLU, B2M, TIMP1 }\end{array}$ \\
\hline 12 & Multi-organism process & $\begin{array}{l}\text { FN1, MMP2, SPARC, LOXL1, SERPINE2, IGFBP7, CTSB, HTRA1, B2M, CLU, } \\
\text { SERPINE1, TIMP1 }\end{array}$ \\
\hline 11 & Locomotion & $\begin{array}{l}\text { CD44, SERPINE1, COL1A1, SPARC, FN1, CNN2, LOX, POSTN, TIMP1, } \\
\text { SERPINE2, COL1A2 }\end{array}$ \\
\hline 11 & Cell motility & $\begin{array}{l}\text { CD44, SERPINE1, COL1A1, SPARC, FN1, CNN2, LOX, POSTN, TIMP1, } \\
\text { SERPINE2, COL1A2 }\end{array}$ \\
\hline 11 & $\begin{array}{l}\text { Regulation of } \\
\text { developmental process }\end{array}$ & $\begin{array}{l}\text { THBS2, SERPINE1, COL1A1, SPARC, SERPINE2, LOX, FN1, POSTN, B2M, } \\
\text { CD44, TIMP1 }\end{array}$ \\
\hline 11 & $\begin{array}{l}\text { Regulation of multicellular } \\
\text { organismal process }\end{array}$ & $\begin{array}{l}\text { THBS2, SERPINE1, SERPINE2, COL1A1, SPARC, FN1, CLU, B2M, LOX, } \\
\text { POSTN, TIMP1 }\end{array}$ \\
\hline 11 & Localization of cell & $\begin{array}{l}\text { CD44, SERPINE1, COL1A1, SPARC, FN1, CNN2, LOX, POSTN, TIMP1, } \\
\text { SERPINE2, COL1A2 }\end{array}$ \\
\hline 11 & $\begin{array}{l}\text { Regulation of biological } \\
\text { quality }\end{array}$ & $\begin{array}{l}\text { B2M, SERPINE1, SERPINE2, CLU, LOX, SPARC, FN1, POSTN, THBS2, } \\
\text { COL1A2, COL1A1 }\end{array}$ \\
\hline 11 & $\begin{array}{l}\text { Regulation of molecular } \\
\text { function }\end{array}$ & $\begin{array}{l}\text { TIMP1, SERPINE1, SERPINE2, CAB39, CD44, B2M, PCOLCE, LOX, FN1, } \\
\text { CTSB, CLU }\end{array}$ \\
\hline 10 & Cell adhesion & $\begin{array}{l}\text { CD44, TGFBI, POSTN, SERPINE1, FN1, IGFBP7, COL1A1, SERPINE2, SVEP1, } \\
\text { THBS2 }\end{array}$ \\
\hline 10 & Cell proliferation & TIMP1, SPARC, FN1, CLU, CNN2, MMP2, TGFBI, SERPINE2, HTRA1, IGFBP7 \\
\hline 10 & Biological adhesion & $\begin{array}{l}\text { CD44, TGFBI, POSTN, SERPINE1, FN1, IGFBP7, COL1A1, SERPINE2, SVEP1, } \\
\text { THBS2 }\end{array}$ \\
\hline 10 & Regulation of signalling & $\begin{array}{l}\text { CD44, SERPINE1, COL1A1, FN1, TIMP1, LOX, POSTN, SERPINE2, HTRA1, } \\
\text { CLU }\end{array}$ \\
\hline 9 & $\begin{array}{l}\text { Regulation of immune } \\
\text { system process }\end{array}$ & B2M, LOX, CLU, C1R, HTRA1, SERPINE1, COL1A1, COL1A2, CTSB \\
\hline 9 & Immune response & B2M, CLU, C1R, CD44, CNN2, COL1A1, CAB39, COL1A2, CTSB \\
\hline 9 & $\begin{array}{l}\text { Anatomical structure } \\
\text { formation involved in } \\
\text { morphogenesis }\end{array}$ & COL23A1, THBS2, SERPINE1, SPARC, FN1, MMP2, COL1A1, HTRA1, TGFBI \\
\hline 8 & Immune effector process & B2M, CLU, C1R, HTRA1, CD44, CNN2, CAB39, CTSB \\
\hline 8 & $\begin{array}{l}\text { Response to abiotic } \\
\text { stimulus }\end{array}$ & MMP2, COL1A1, CAB39, CNN2, SPARC, POSTN, SERPINE2, IGFBP7 \\
\hline 8 & Regulation of locomotion & SERPINE1, COL1A1, SPARC, FN1, CNN2, POSTN, TIMP1, SERPINE2 \\
\hline 7 & Catabolic process & MMP2, TIMP1, CLU, CTSB, CD44, SERPINE2, HEXA \\
\hline 7 & Regulation of cell adhesion & SERPINE1, FN1, COL1A1, POSTN, SERPINE2, CD44, TGFBI \\
\hline 7 & $\begin{array}{l}\text { Cellular component } \\
\text { biogenesis }\end{array}$ & CLU, COL1A1, LOX, FN1, CAB39, COL1A2, THBS2 \\
\hline 6 & Reproduction & MMP2, SERPINE2, IGFBP7, CTSB, HTRA1, TIMP1 \\
\hline 6 & Response to biotic stimulus & SPARC, LOXL1, HTRA1, B2M, CLU, SERPINE1 \\
\hline 6 & Reproductive process & MMP2, SERPINE2, IGFBP7, CTSB, HTRA1, TIMP1 \\
\hline 6 & Leukocyte activation & CD44, CLU, B2M, CNN2, CAB39, CTSB \\
\hline 6 & Response to other organism & SPARC, LOXL1, HTRA1, B2M, CLU, SERPINE1 \\
\hline 5 & System process & TGFBI, POSTN, SERPINE2, COL1A1, COL1A2 \\
\hline 5 & Macromolecule localization & CLU, COL1A1, FN1, NUCB1, POSTN \\
\hline 5 & $\begin{array}{l}\text { Multi-organism } \\
\text { reproductive process }\end{array}$ & MMP2, SERPINE2, IGFBP7, CTSB, TIMP1 \\
\hline 5 & $\begin{array}{l}\text { Multi-multicellular } \\
\text { organism process }\end{array}$ & MMP2, SERPINE2, IGFBP7, CTSB, TIMP1 \\
\hline 5 & Leukocyte migration & SERPINE1, CD44, COL1A1, FN1, COL1A2 \\
\hline 4 & Cell growth & FN1, POSTN, SERPINE2, IGFBP7 \\
\hline 4 & Growth & FN1, POSTN, SERPINE2, IGFBP7 \\
\hline
\end{tabular}




\begin{tabular}{|r|l|l|}
\hline 3 & $\begin{array}{l}\text { Activation of immune } \\
\text { response }\end{array}$ & CLU, C1R, CTSB \\
\hline 3 & $\begin{array}{l}\text { Immune system } \\
\text { development }\end{array}$ & CNN2, LOX, B2M \\
\hline 3 & $\begin{array}{l}\text { Developmental process } \\
\text { involved in reproduction }\end{array}$ & SERPINE2, CTSB, HTRA1 \\
\hline 3 & Regulation of growth & FN1, SERPINE2, IGFBP7 \\
\hline 3 & $\begin{array}{l}\text { Interspecies interaction } \\
\text { between organisms }\end{array}$ & FN1, CTSB, B2M \\
\hline 3 & $\begin{array}{l}\text { Cellular localization } \\
\text { ",CLU COL1A1 NUCB1" }\end{array}$ & CLU, COL1A1, NUCB1 \\
\hline 2 & Protein folding & CLU, B2M \\
\hline 2 & $\begin{array}{l}\text { Multicellular organism } \\
\text { reproduction }\end{array}$ & SERPINE2, CTSB \\
\hline 2 & Taxis & LOX, SERPINE1 \\
\hline 2 & $\begin{array}{l}\text { Regulation of multi- } \\
\text { organism process }\end{array}$ & HTRA1, TIMP1 \\
\hline 2 & $\begin{array}{l}\text { Regulation of cellular } \\
\text { component biogenesis }\end{array}$ & CLU, THBS2 \\
\hline 2 & Developmental growth & FN1, POSTN \\
\hline 2 & $\begin{array}{l}\text { Multicellular organismal } \\
\text { reproductive process }\end{array}$ & SERPINE2, CTSB \\
\hline 2 & Protein activation cascade & CLU, C1R \\
\hline 2 & Regulation of homeostasis & SERPINE1, SERPINE2 \\
\hline
\end{tabular}


A 6.10 -08 Celluar response 10 cryokine stimulus

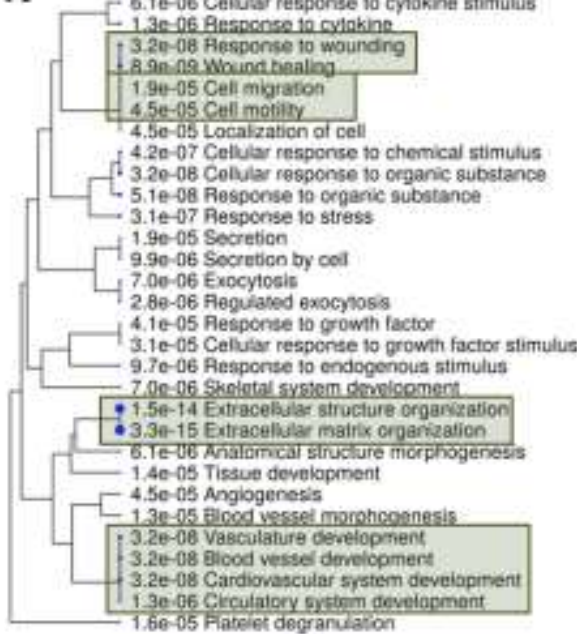

$\mathrm{C}$

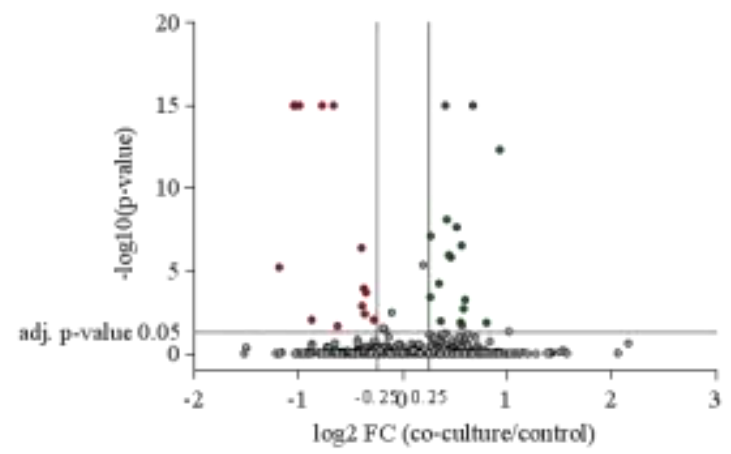

B

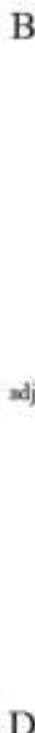

D

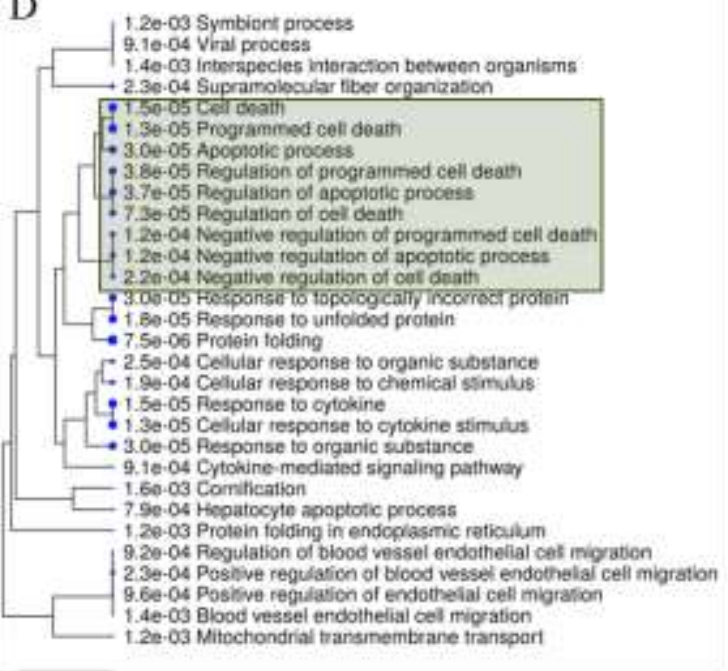

Supplement 4 Functional analysis of detected discoveries from secretome and proteome analysis of co-cultured breast cancer cells. A Hierarchical clustering tree using shiny GO v06.0 Gene ontology enrichment of discoveries from co-culture media with corresponding p-values. B Volcano plot demonstrating potential bone-directed breast cancer invasiveness related targets using proteome analysis of media from co-cultures MCF-7 cells vs MG-63 control. Detected target proteins were stated as discovery when adjusted p-value was below 0.03 (dotted line) with a false-discovery rate (FDR) of $5 \%$ and a log 2 fold change (FC) higher 0.25 or lower -0.25 . Every dot indicates one target, green dots indicate upregulated discoveries and red dot indicates downregulated discoveries. $\mathrm{n}=6$, discovery determined using two-stage linear step-up procedure of Benjamini, Krieger and Yekutieli, with $\mathrm{Q}=5 \%$. Each row was analyzed individually, without assuming a consistent SD. C Volcano plot demonstrating potential bone-directed breast cancer invasiveness related targets using proteome analysis of lysates from co-cultures MCF-7 cells vs MCF-7 control. Detected target proteins were stated as discovery when adjusted pvalue was below 0.05 (dotted line) with a false-discovery rate (FDR) of $1 \%$ and a log 2 fold change (FC) higher 0.25 or lower -0.25. Every dot indicates one target, green dots indicate upregulated discoveries and red dot indicates downregulated discoveries. $\mathrm{n}=6$, discovery determined using two-stage linear step-up procedure of Benjamini, Krieger and Yekutieli, with Q $=1 \%$. Each row was analyzed individually, without assuming a consistent SD. D Hierarchical clustering tree using shiny GO v06.0 Gene ontology enrichment of discoveries from co-culture lysates with corresponding p-values.

Supplement 5 Protein findings from proteome analysis of cell lysates from co-cultured breast cancer cells with osteosarcoma cells (MG-63) compared to MCF-7 monoculture. Information about gene symbol/User ID, Ensemble Gene ID, Gene Type, Chromosome location (Chr) and genomic position is given. List was used to further examine Gene Ontology (GO) enrichment using Shiny GO v06.0.

\begin{tabular}{|c|c|c|c|c|c|}
\hline $\mathrm{i}$ & User ID & Ensembl Gene ID & p-value & $\begin{array}{c}\text { mean co- } \\
\text { culture }\end{array}$ & $\begin{array}{c}\text { mean MCF-7 } \\
\text { control }\end{array}$ \\
\hline 1 & HIST2H3PS2 & ENSG00000203818 & $<0,000000000000001$ & 711875 & 1418125 \\
\hline 2 & CFL1 & ENSG00000172757 & $3,995 \mathrm{E}-07$ & 1362500 & 1800000 \\
\hline
\end{tabular}




\begin{tabular}{|c|c|c|c|c|c|}
3 & SLC3A2 & ENSG00000168003 & $4,69 \mathrm{E}-13$ & 1318625 & 694125 \\
\hline 4 & KRT8 & ENSG00000170421 & $<0,000000000000001$ & 2528750 & 5233750 \\
\hline 5 & HSP90B1 & ENSG00000166598 & $<0,000000000000001$ & 3183750 & 2406250 \\
\hline 6 & KRT18 & ENSG00000111057 & $<0,000000000000001$ & 1963750 & 4050125 \\
\hline 7 & ATP5F1B & ENSG00000110955 & $1,11105 \mathrm{E}-06$ & 1610000 & 1189625 \\
\hline 8 & PDIA3 & ENSG00000167004 & $1,48704 \mathrm{E}-06$ & 1531250 & 1115875 \\
\hline 9 & KRT19 & ENSG00000171345 & $<0,000000000000001$ & 1441250 & 2472250 \\
\hline 10 & FASN & ENSG00000169710 & $<0,000000000000001$ & 3546250 & 2232500 \\
\hline 11 & ATP5F1A & ENSG00000152234 & $5,68907 \mathrm{E}-05$ & 1645000 & 1297625 \\
\hline 12 & HSPD1 & ENSG00000144381 & $7,80485 \mathrm{E}-09$ & 1988750 & 1490500 \\
\hline 13 & PREX1 & ENSG00000124126 & $6,12649 \mathrm{E}-06$ & 304250 & 694500 \\
\hline 14 & HSPA9 & ENSG00000113013 & $2,96513 \mathrm{E}-07$ & 1378750 & 936375 \\
\hline 15 & HSP90AB1 & ENSG00000096384 & $2,19282 \mathrm{E}-08$ & 1622500 & 1139500 \\
\hline 16 & MDH2 & ENSG00000146701 & $7,73663 \mathrm{E}-08$ & 2807500 & 2343750 \\
\hline 17 & HSPB1 & ENSG00000106211 & $<0,000000000000001$ & 4387500 & 6976250 \\
\hline
\end{tabular}

Supplement 6 GO enrichment analysis of findings from proteome analysis. Protein discoveries from co-cultured breast cancer cell lysates listed in S5 were examined for GO enrichment using Shiny GO v06.0. Information is given about the enrichment FDR, how many genes with the discovery list are enriched within specific functional category, total number of genes within specific functional category, functional category and genes listed from the discoveries which are enriched in specific category.

\begin{tabular}{|c|c|c|c|c|}
\hline $\begin{array}{l}\text { Enrichment } \\
\text { FDR }\end{array}$ & $\begin{array}{l}\text { Genes } \\
\text { in list }\end{array}$ & $\begin{array}{l}\text { Total } \\
\text { genes }\end{array}$ & Functional Category & Genes \\
\hline $7,55 \mathrm{E}-06$ & 6 & 245 & Protein folding & HSPA9, HSPD1, PDIA3, HSP90AB1, HSP90B1, HSPB1 \\
\hline $1,34 \mathrm{E}-05$ & 11 & 2257 & Programmed cell death & $\begin{array}{l}\text { HSPD1, KRT18, HSP90AB1, HSPB1, PDIA3, KRT8, } \\
\text { HSP90B1, HSPA9, PREX1, KRT19, CFL1 }\end{array}$ \\
\hline $1,34 \mathrm{E}-05$ & 9 & 1278 & $\begin{array}{l}\text { Cellular response to } \\
\text { cytokine stimulus }\end{array}$ & $\begin{array}{l}\text { HSP90AB1, ATP5F1B, KRT18, PDIA3, FASN, KRT8, } \\
\text { HSPA9, HSP90B1, CFL1 }\end{array}$ \\
\hline $1,46 \mathrm{E}-05$ & 11 & 2415 & Cell death & $\begin{array}{l}\text { HSPD1, KRT18, HSP90AB1, HSPB1, PDIA3, KRT8, } \\
\text { HSP90B1, HSPA9, PREX1, KRT19, CFL1 }\end{array}$ \\
\hline $1,48 \mathrm{E}-05$ & 9 & 1372 & Response to cytokine & $\begin{array}{l}\text { HSP90AB1, ATP5F1B, KRT18, PDIA3, FASN, KRT8, } \\
\text { HSPA9, HSP90B1, CFL1 }\end{array}$ \\
\hline $1,82 \mathrm{E}-05$ & 5 & 193 & $\begin{array}{l}\text { Response to unfolded } \\
\text { protein }\end{array}$ & HSPA9, HSPD1, HSP90AB1, HSPB1, HSP90B1 \\
\hline $2,97 \mathrm{E}-05$ & 10 & 2106 & Apoptotic process & $\begin{array}{l}\text { HSPD1, KRT18, HSP90AB1, HSPB1, PDIA3, KRT8, } \\
\text { HSP90B1, HSPA9, PREX1, CFL1 }\end{array}$ \\
\hline $2,97 \mathrm{E}-05$ & 12 & 3547 & $\begin{array}{l}\text { Response to organic } \\
\text { substance }\end{array}$ & $\begin{array}{l}\text { HSPA9, HSP90AB1, HSPD1, HSP90B1, ATP5F1B, } \\
\text { KRT18, PDIA3, FASN, KRT8, CFL1, HSPB1, SLC3A2 }\end{array}$ \\
\hline $2,97 \mathrm{E}-05$ & 5 & 227 & $\begin{array}{l}\text { Response to } \\
\text { topologically incorrect } \\
\text { protein }\end{array}$ & HSPA9, HSPD1, HSP90AB1, HSPB1, HSP90B1 \\
\hline $3,69 \mathrm{E}-05$ & 9 & 1657 & $\begin{array}{l}\text { Regulation of apoptotic } \\
\text { process }\end{array}$ & $\begin{array}{l}\text { KRT18, HSPD1, HSP90AB1, HSPB1, PDIA3, HSP90B1, } \\
\text { HSPA9, PREX1, CFL1 }\end{array}$ \\
\hline 3,79E-05 & 9 & 1681 & $\begin{array}{l}\text { Regulation of } \\
\text { programmed cell death }\end{array}$ & $\begin{array}{l}\text { KRT18, HSPD1, HSP90AB1, HSPB1, PDIA3, HSP90B1, } \\
\text { HSPA9, PREX1, CFL1 }\end{array}$ \\
\hline $7,27 \mathrm{E}-05$ & 9 & 1835 & Regulation of cell death & $\begin{array}{l}\text { KRT18, HSPD1, HSP90AB1, HSPB1, PDIA3, HSP90B1, } \\
\text { HSPA9, PREX1, CFL1 }\end{array}$ \\
\hline 0,000115066 & 7 & 966 & $\begin{array}{l}\text { Negative regulation of } \\
\text { apoptotic process }\end{array}$ & $\begin{array}{l}\text { KRT18, HSP90AB1, HSPB1, HSPD1, HSP90B1, HSPA9, } \\
\text { CFL1 }\end{array}$ \\
\hline 0,00012323 & 7 & 987 & $\begin{array}{l}\text { Negative regulation of } \\
\text { programmed cell death }\end{array}$ & $\begin{array}{l}\text { KRT18, HSP90AB1, HSPB1, HSPD1, HSP90B1, HSPA9, } \\
\text { CFL1 }\end{array}$ \\
\hline 0,000191624 & 11 & 3536 & $\begin{array}{l}\text { Cellular response to } \\
\text { chemical stimulus }\end{array}$ & $\begin{array}{l}\text { HSPA9, HSP90AB1, HSP90B1, HSPB1, ATP5F1B, } \\
\text { KRT18, PREX1, PDIA3, FASN, KRT8, CFL1 }\end{array}$ \\
\hline 0,000219305 & 7 & 1099 & $\begin{array}{l}\text { Negative regulation of } \\
\text { cell death }\end{array}$ & $\begin{array}{l}\text { KRT18, HSP90AB1, HSPB1, HSPD1, HSP90B1, HSPA9, } \\
\text { CFL1 }\end{array}$ \\
\hline 0,000225829 & 6 & 712 & $\begin{array}{l}\text { Supramolecular fiber } \\
\text { organization }\end{array}$ & HSP90B1, KRT19, CFL1, PREX1, KRT8, HSP90AB1 \\
\hline
\end{tabular}




\begin{tabular}{|r|r|r|l|l|}
\hline 0,000225829 & 3 & 55 & $\begin{array}{l}\text { Positive regulation of } \\
\text { blood vessel endothelial } \\
\text { ell migration }\end{array}$ & ATP5F1B, ATP5F1A, HSPB1 \\
\hline 0,000251526 & 10 & 2938 & $\begin{array}{l}\text { Cellular response to } \\
\text { organic substance }\end{array}$ & $\begin{array}{l}\text { HSPA9, HSP90AB1, HSP90B1, ATP5F1B, KRT18, PDIA3, } \\
\text { FASN, KRT8, HSPB1, CFL1 }\end{array}$ \\
\hline 0,000790234 & 2 & 12 & $\begin{array}{l}\text { Hepatocyte apoptotic } \\
\text { process }\end{array}$ & KRT18, KRT8 \\
\hline 0,000911637 & 6 & 951 & Viral process & KRT18, HSPD1, KRT8, KRT19, HSP90AB1, CFL1 \\
\hline 0,000911637 & 6 & 950 & $\begin{array}{l}\text { Cytokine-mediated } \\
\text { signalling pathway }\end{array}$ & KRT18, KRT8, HSP90AB1, HSPA9, HSP90B1, CFL1 \\
\hline 0,000915372 & 3 & 95 & $\begin{array}{l}\text { Regulation of blood } \\
\text { vessel endothelial cell } \\
\text { migration }\end{array}$ & ATP5F1B, ATP5F1A, HSPB1 \\
\hline 0,000962601 & 3 & 98 & $\begin{array}{l}\text { Positive regulation of } \\
\text { endothelial cell } \\
\text { migration }\end{array}$ & ATP5F1B, ATP5F1A, HSPB1 \\
\hline 0,001203543 & 3 & 109 & $\begin{array}{l}\text { Mitochondrial } \\
\text { transmembrane } \\
\text { transport }\end{array}$ & HSPD1, ATP5F1B, ATP5F1A \\
\hline 0,001203543 & 2 & 17 & $\begin{array}{l}\text { Protein folding in } \\
\text { endoplasmic reticulum }\end{array}$ & HSP90B1, PDIA3 \\
\hline 0,001203543 & 6 & 1024 & $\begin{array}{l}\text { Symbiont process } \\
\text { KRT18, HSPD1, KRT8, KRT19, HSP90AB1, CFL1 }\end{array}$ \\
\hline 0,001435777 & 3 & 119 & $\begin{array}{l}\text { Blood vessel } \\
\text { endothelial cell } \\
\text { migration }\end{array}$ & ATP5F1B, ATP5F1A, HSPB1 \\
\hline 0,001435777 & 6 & 1084 & $\begin{array}{l}\text { Interspecies interaction } \\
\text { between organisms }\end{array}$ & KRT18, HSPD1, KRT8, KRT19, HSP90AB1, CFL1 \\
\hline 0,001588854 & 3 & 125 & $\begin{array}{l}\text { Cornification } \\
\text { KRT18, KRT8, KRT19 }\end{array}$ \\
\hline
\end{tabular}

Supplement 7: GO group enrichment analysis of findings from proteome analysis. Protein discoveries listed in S5 were examined for GO group enrichment using Shiny GO v06.0.

\begin{tabular}{|c|c|c|}
\hline $\mathrm{N}$ & High level GO category & Genes \\
\hline 9 & Regulation of biological quality & $\begin{array}{l}\text { HSPB1, HSP90AB1, PREX1, PDIA3, CFL1, ATP5F1B, HSPA9, HSPD1, } \\
\text { HSP90B1 }\end{array}$ \\
\hline 8 & Immune system process & $\begin{array}{l}\text { HSPD1, HSPA9, PREX1, FASN, HSP90AB1, HSP90B1, PDIA3, } \\
\text { SLC3A2 }\end{array}$ \\
\hline 8 & Response to stress & $\begin{array}{l}\text { HSPB1, HSPA9, ATP5F1A, HSP90B1, PDIA3, HSPD1, HSP90AB1, } \\
\text { KRT8 }\end{array}$ \\
\hline 8 & Anatomical structure morphogenesis & KRT19, HSP90AB1, PREX1, KRT8, CFL1, HSPB1, ATP5F1B, KRT18 \\
\hline 8 & $\begin{array}{l}\text { Regulation of multicellular organismal } \\
\text { process }\end{array}$ & $\begin{array}{l}\text { HSP90AB1, HSPD1, HSPB1, HSPA9, PREX1, ATP5F1B, ATP5F1A, } \\
\text { CFL1 }\end{array}$ \\
\hline 8 & Cellular localization & $\begin{array}{l}\text { HSP90AB1, HSPD1, ATP5F1B, ATP5F1A, KRT18, HSPA9, HSPB1, } \\
\text { HSP90B1 }\end{array}$ \\
\hline 7 & Cellular component biogenesis & HSP90AB1, HSP90B1, KRT19, HSPA9, PREX1, KRT8, HSPD1 \\
\hline 7 & Multi-organism process & KRT18, HSPD1, KRT8, KRT19, HSPB1, CFL1, HSP90AB1 \\
\hline 6 & Protein folding & HSPA9, HSPD1, PDIA3, HSP90AB1, HSP90B1, HSPB1 \\
\hline 6 & Biological adhesion & HSPB1, HSPD1, ATP5F1B, KRT18, PREX1, HSP90AB1 \\
\hline 6 & Macromolecule localization & HSP90AB1, HSPD1, KRT18, HSPA9, HSPB1, HSP90B1 \\
\hline 6 & Locomotion & ATP5F1B, PREX1, CFL1, ATP5F1A, HSPB1, SLC3A2 \\
\hline 6 & Interspecies interaction between organisms & KRT18, HSPD1, KRT8, KRT19, HSP90AB1, CFL1 \\
\hline 6 & Regulation of response to stimulus & HSP90AB1, HSPD1, HSPB1, PREX1, PDIA3, HSP90B1 \\
\hline 6 & Cell motility & ATP5F1B, PREX1, CFL1, ATP5F1A, HSPB1, SLC3A2 \\
\hline 6 & Localization of cell & ATP5F1B, PREX1, CFL1, ATP5F1A, HSPB1, SLC3A2 \\
\hline 5 & Cell adhesion & HSPB1, HSPD1, ATP5F1B, KRT18, PREX1 \\
\hline 5 & Response to external stimulus & HSP90B1, PREX1, KRT8, HSPB1, CFL1 \\
\hline
\end{tabular}




\begin{tabular}{|r|l|l|}
\hline 5 & Response to abiotic stimulus & HSPA9, HSP90B1, HSP90AB1, KRT8, HSPD1 \\
\hline 5 & Regulation of localization & HSP90AB1, PREX1, ATP5F1B, ATP5F1A, HSPB1 \\
\hline 5 & $\begin{array}{l}\text { Anatomical structure formation involved in } \\
\text { morphogenesis }\end{array}$ & KRT19, KRT8, CFL1, HSPB1, ATP5F1B \\
\hline 5 & Regulation of developmental process & HSPA9, PREX1, HSP90AB1, HSPB1, CFL1 \\
\hline 5 & Regulation of molecular function & HSP90AB1, HSPD1, HSP90B1, HSPB1, PREX1 \\
\hline 4 & Immune system development & HSPD1, HSPA9, PREX1, FASN \\
\hline 4 & Regulation of immune system process & HSPD1, HSPA9, HSP90AB1, HSP90B1 \\
\hline 4 & Response to biotic stimulus & HSPD1, KRT8, HSPB1, CFL1 \\
\hline 4 & Regulation of signalling & HSP90AB1, HSPB1, PREX1, PDIA3 \\
\hline 4 & Regulation of locomotion & PREX1, ATP5F1B, ATP5F1A, HSPB1 \\
\hline 3 & Reproduction & HSP90AB1, KRT8, KRT19 \\
\hline 3 & Activation of immune response & HSPD1, HSP90AB1, HSP90B1 \\
\hline 3 & $\begin{array}{l}\text { Developmental process involved in } \\
\text { reproduction }\end{array}$ & HSP90AB1, KRT8, KRT19 \\
\hline 3 & Immune response & HSPD1, HSP90AB1, HSP90B1 \\
\hline 3 & Catabolic process & HSP90AB1, HSP90B1, HSPB1 \\
\hline 3 & Reproductive process & HSP90AB1, KRT8, KRT19 \\
\hline 3 & Regulation of cell adhesion & HSPD1, ATP5F1B, PREX1 \\
\hline 3 & Leukocyte activation & HSPD1, PREX1, HSP90AB1 \\
\hline 3 & Response to other organism & KRT8, HSPB1, CFL1 \\
\hline 2 & Immune effector process & HSPD1, HSP90AB1 \\
\hline 2 & Cell proliferation & HSPD1, ATP5F1A \\
\hline 2 & Response to endogenous stimulus & HSP90AB1, HSP90B1 \\
\hline 2 & Cell cycle process & CFL1, HSP90AB1 \\
\hline 2 & Taxis & PREX1, HSPB1 \\
\hline 2 & Leukocyte migration & \\
\hline & & \\
\hline
\end{tabular}

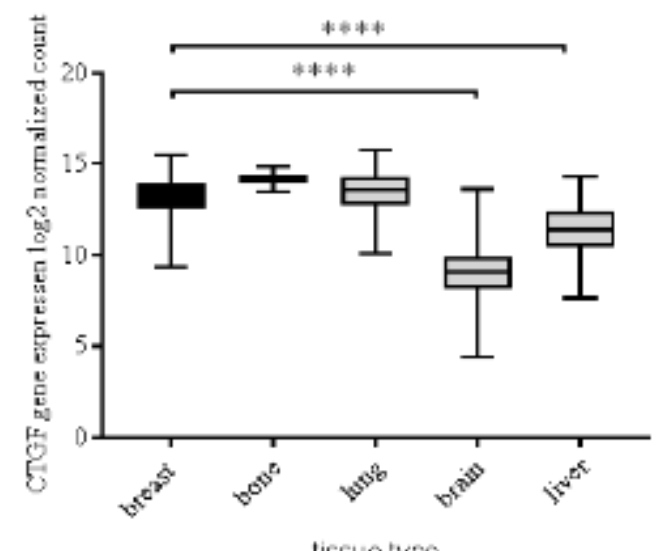

Supplement 8 Tissue expression analysis of CTGF. CTGF expression in human bone ( $n=2)$, breast ( $n=179)$, lung ( $n=287)$ and brain $(\mathrm{n}=1136)$ tissue was assessed using xenabrowse with datasets from GTEX, TARGET, and TCGA. One-way ANOVA and a Dunnett's multiple comparison test with no matching or pairing between groups was calculated to assess significant differences compared to the untreated control. **** $P<0.0001$ 
Supplement 9: CTGF expression in invasive ductal carcinoma and normal breast tissue. CTGF expression was assessed in 24 patient samples from biomax tissue array (BR248a). Following information are given: Sex/Age, pathology diagnosis, TNM (Tumor, Node, and Metastasis), Tumor Grading, Stage, Type, Tissue-ID and corresponding detected CTGF expression.

\begin{tabular}{|c|c|c|c|c|c|c|c|}
\hline $\begin{array}{l}\text { Sex/ } \\
\text { Age }\end{array}$ & Pathology diagnosis & TNM & Grade & Stage & Type & Tissue ID. & $\begin{array}{l}\text { CTGF } \\
\text { expression }\end{array}$ \\
\hline $\mathrm{F} / 34$ & Invasive ductal carcinoma & T3N0M0 & $1--2$ & IIB & malignant & Fmg040048 & + \\
\hline $\mathrm{F} / 37$ & Invasive ductal carcinoma & T2N0M0 & $1--2$ & IIA & malignant & Fmg020357 & + \\
\hline $\mathrm{F} / 60$ & Invasive ductal carcinoma & T2N0M0 & 2 & IIA & malignant & Fmg040031 & + \\
\hline $\mathrm{F} / 57$ & Invasive ductal carcinoma & T2N0M0 & 2 & IIA & malignant & Fmg040001 & + \\
\hline $\mathrm{F} / 38$ & Invasive ductal carcinoma & T1N0M0 & 2 & I & malignant & Fmg040052 & ++ \\
\hline $\mathrm{F} / 55$ & Invasive ductal carcinoma & T2N0M0 & 2 & IIA & malignant & Fmg040104 & - \\
\hline $\mathrm{F} / 45$ & Invasive ductal carcinoma & T2N0M0 & 2 & IIA & malignant & Fmg040113 & ++ \\
\hline $\mathrm{F} / 48$ & Invasive ductal carcinoma & T2N0M0 & 2 & IIA & malignant & Fmg040118 & $+/++$ \\
\hline $\mathrm{F} / 58$ & Invasive ductal carcinoma & T2N0M0 & 2 & IIA & malignant & Fmg040120 & ++ \\
\hline $\mathrm{F} / 34$ & Invasive ductal carcinoma & T2N0M0 & 2 & IIA & malignant & Fmg040123 & ++ \\
\hline $\mathrm{F} / 49$ & Invasive ductal carcinoma & T2N0M0 & 2 & IIA & malignant & Fmg040125 & + \\
\hline $\mathrm{F} / 58$ & Invasive ductal carcinoma & T2N0M0 & 2 & IIA & malignant & Fmg040130 & ++ \\
\hline $\mathrm{F} / 38$ & Invasive ductal carcinoma & T2N1M0 & 2 & IIB & malignant & Fmg040131 & + \\
\hline $\mathrm{F} / 79$ & Invasive ductal carcinoma & T2N1M0 & 3 & IIB & malignant & Fmg010491 & + \\
\hline $\mathrm{F} / 43$ & Invasive ductal carcinoma & T2N0M0 & 3 & IIA & malignant & Fmg040004 & - \\
\hline $\mathrm{F} / 46$ & Invasive ductal carcinoma & T3N0M0 & 3 & IIB & malignant & Fmg040074 & + \\
\hline F/76 & Invasive ductal carcinoma & T4N0M0 & 3 & IIIB & malignant & Fmg010789 & + \\
\hline $\mathrm{F} / 47$ & Medullary carcinoma & T2N0M0 & - & IIA & malignant & Fmg040016 & + \\
\hline $\mathrm{F} / 21$ & Adenosis & - & - & - & normal & Fmg06N024 & - \\
\hline $\mathrm{F} / 28$ & $\begin{array}{l}\text { Normal breast tissue (fibro } \\
\text { fatty tissue and blood vessel) }\end{array}$ & - & - & - & normal & Fmg11N017 & - \\
\hline $\mathrm{F} / 21$ & Normal breast tissue & - & - & - & normal & Fmg12N001 & + \\
\hline $\mathrm{F} / 50$ & Adenosis & - & - & - & normal & Fmg08N034 & - \\
\hline $\mathrm{F} / 50$ & Normal breast tissue & - & - & - & normal & Fmg12N002 & - \\
\hline $\mathrm{F} / 19$ & Normal breast tissue & - & - & - & normal & Fmg07N013 & - \\
\hline
\end{tabular}


A

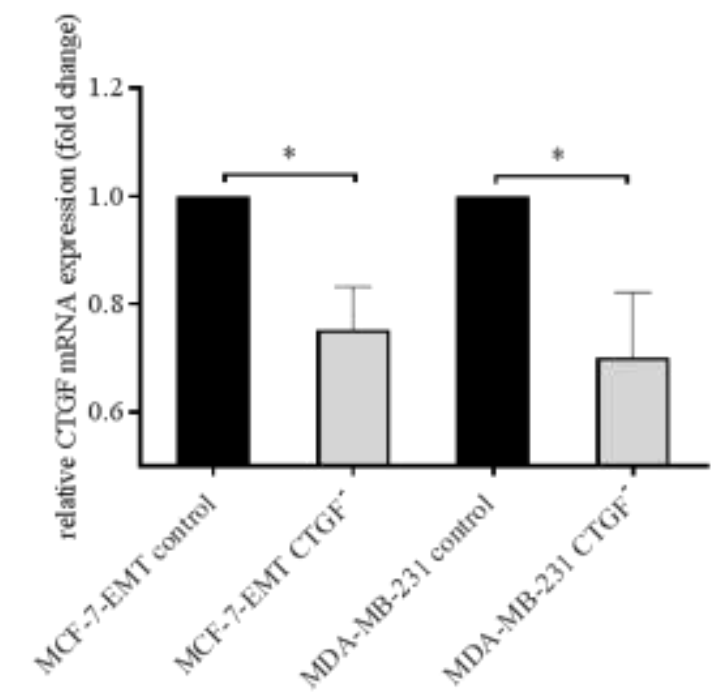

$\mathrm{C}$

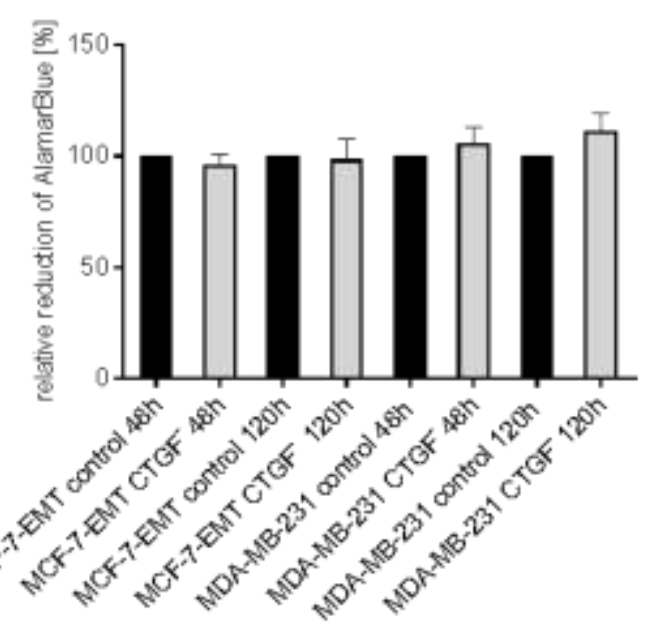

B

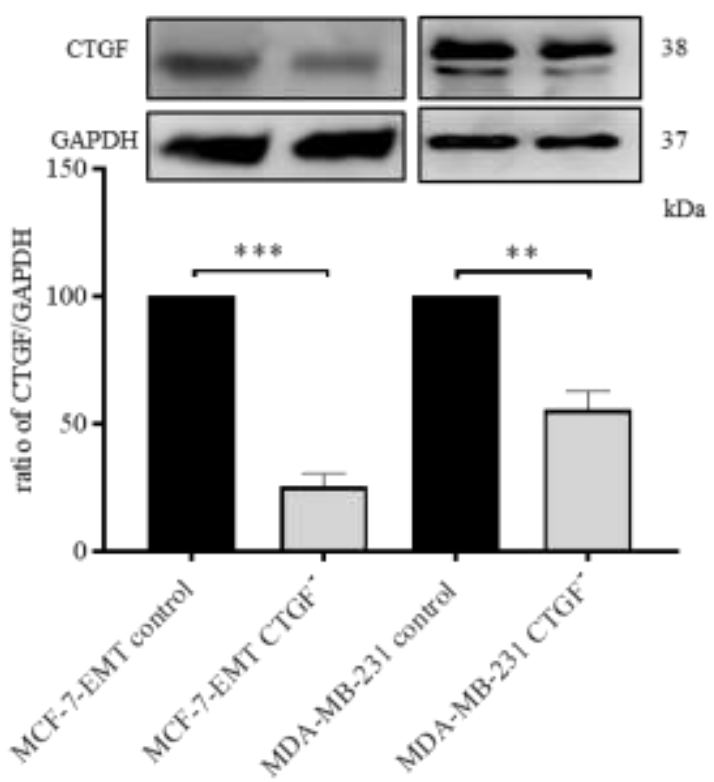

$\mathrm{D}$

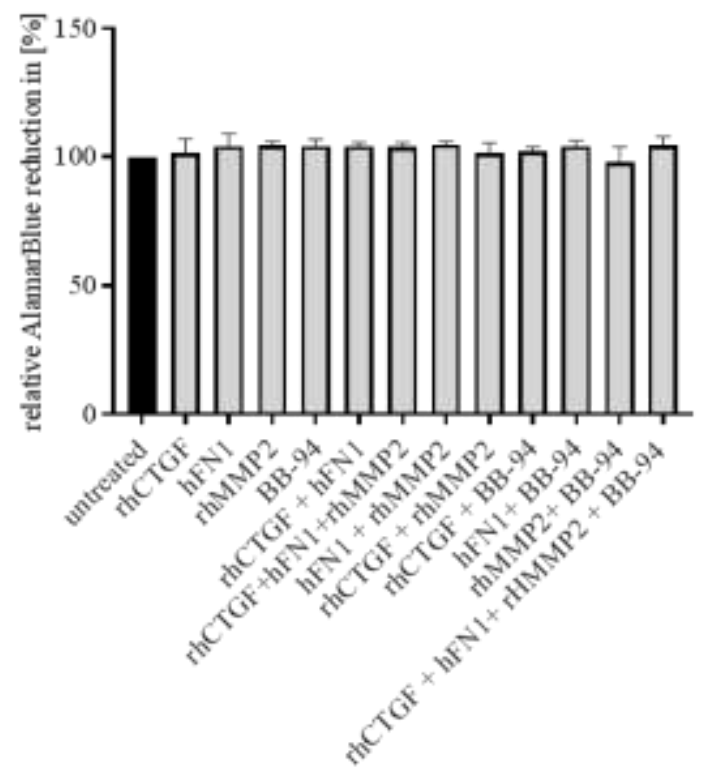

Supplement 10: CTGF expression does not alter proliferation in vitro. A CTGF mRNA expression in different breast cancer cell lines 120 hours after siRNA transfection was detected by real-time quantitative PCR. Data represent the mean \pm SEM. MCF-7-EMT n=4, MDA-MB-231 n=5 using unpaired, two-tailed t-test analysis compared to respective control. * $P<0.05$ B CTGF protein expression of different breast cancer cells 48 hours after CTGF siRNA transfection was detected by western blotting. The CTGF band intensity was quantified by densitometry and normalized to GAPDH. Data represent the mean \pm SEM. $\mathrm{n}=3$ using unpaired, two-tailed t-test analysis compared to respective control. $* * P<0.01 ; * * * P<0.005 \mathbf{C}$ Relative AlamarBlue reduction in different breast cancer cell lines 48 and 120 hours after CTGF siRNA transfection at 4 hours AlamarBlue incubation. Data represent the mean \pm SEM. MCF-7-EMT t48h $n=3$, MCF-7-EMT t120h $n=4$ and MDAMB-231 n=3 using unpaired, two-tailed t-test analysis compared to respective control. D 3D spheroid invasion assay with different compounds supplemented. Spheroids were embedded in Matrigel, after 48 hours AlamarBlue was added and absorption was measured after 4hours incubation. $\mathrm{n}=3$ 
$\mathrm{A}$
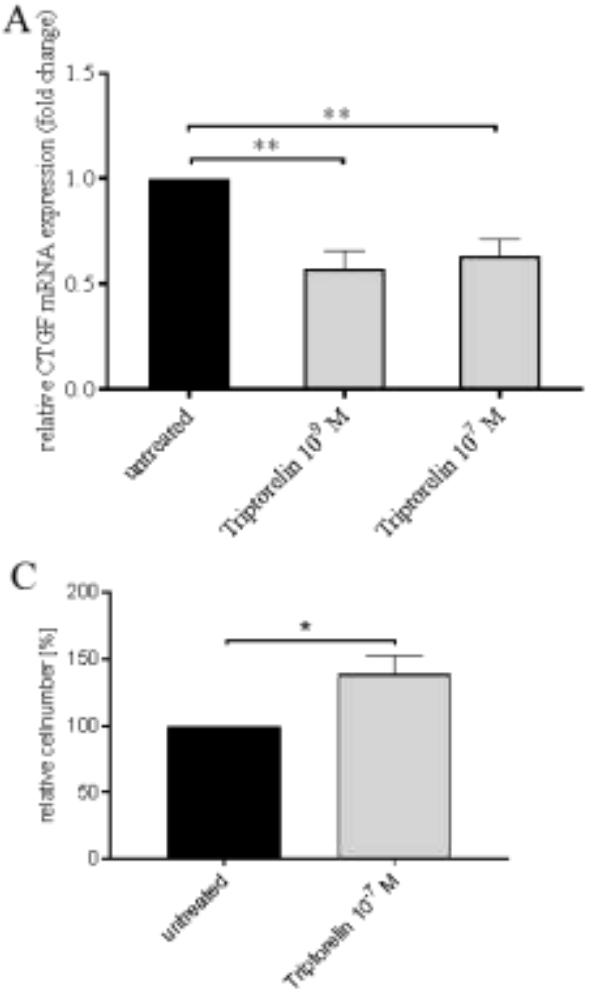

B
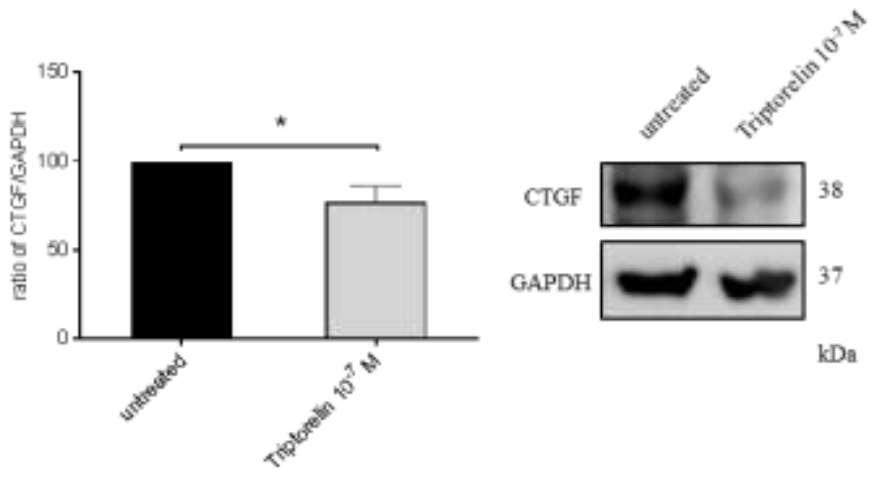

$\mathrm{D}$

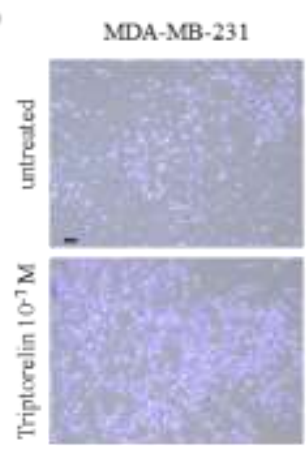

$\mathrm{F}$

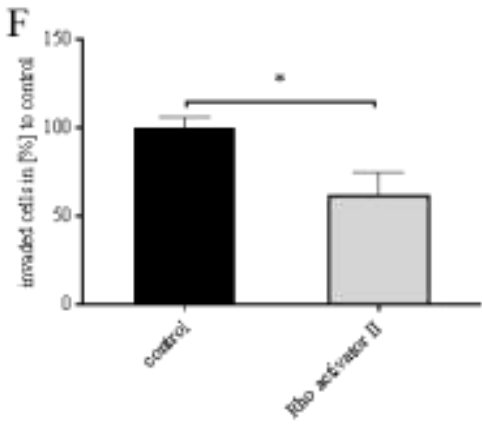

Supplement 11: GnRH agonist regulates CTGF expression in TNBC cells. A Relative quantification of CTGF mRNA expression in TNBC cells (MDA-MB-231) treated for 48 hours with $10^{-9} \mathrm{M}$ or $10^{-7} \mathrm{M}$ Triptorelin. Data represent the mean \pm SEM. MDA-MB-231 $\mathrm{n}=4$ using one-way ANOVA with $\mathrm{F}=12.29$ and a Dunnett's multiple comparison test with no matching or pairing between groups. ${ }^{*} P<0.01$ B Quantification and representative experiment of CTGF protein expression after Triptorelin treatment for 48 hours $\left(10^{-7} \mathrm{M}\right)$. The CTGF band intensity was quantified by densitometry and normalized to GAPDH. Data represent the mean \pm SEM. MDA-MB-231 $n=7$ using unpaired, two-tailed t-test analysis to respective control (untreated). $* P<0.05 \mathrm{C}$ Cell-ECM adhesion analysis of TNBC cells treated with $10^{-7} \mathrm{M}$ Triptorelin. Adhesive cells where counter-stained with crystal violet and absorption was measured at 570nm. Data represent the mean \pm SEM. MDA-MB-231 $\mathrm{n}=3$ using unpaired, two-tailed t-test analysis to respective control (untreated). $* P<0.05$ D Representative images corresponding to $C$. F Following RhoA activator II treatment $(1 \mu \mathrm{g} / \mathrm{ml})$ invaded MDA-MB-231 cells under the filter were counted in four randomly selected regions, using a co-culture Matrigel invasion assay for 48 hours. Data represent the mean \pm SEM. $\mathrm{n}=9$ Using unpaired, two-tailed t-test analysis to respective control. $* P<0.05$ 

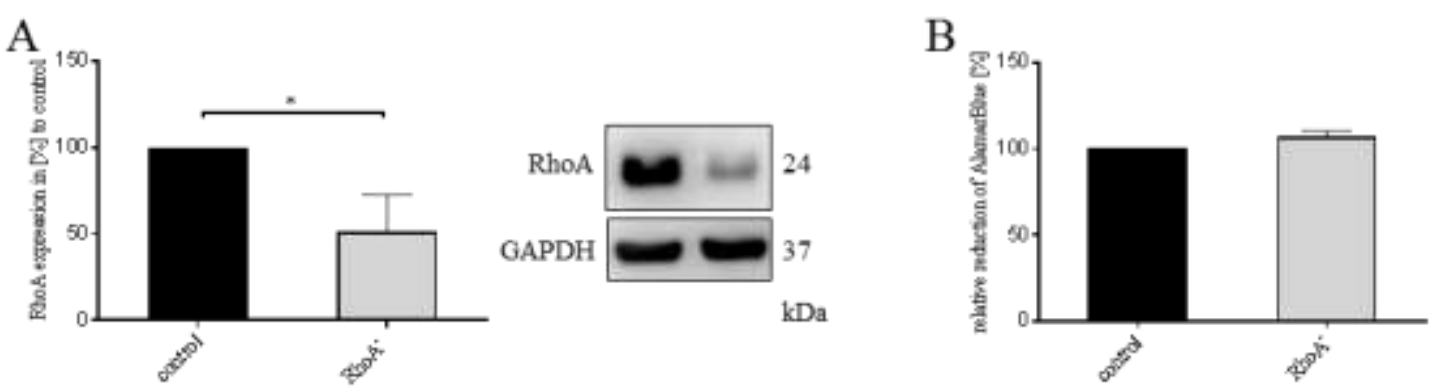

Supplement 12: Reducing RhoA expression does not alter proliferation in vitro. (A) RhoA protein expression in MCF-7 breast cancer cells 48 hours after RhoA siRNA transfection was detected by western blotting. The RhoA band intensity was quantified by densitometry and normalized to GAPDH. Data represent the mean \pm SEM. $n=3$ using unpaired, two-tailed t-test analysis compared to respective control. $* P<0.05$ (B) Relative AlamarBlue reduction in MCF-7 breast cancer cells 48 hours after RhoA siRNA transfection at 4 hours AlamarBlue incubation. Data represent the mean \pm SEM. $n=3$ using unpaired, twotailed t-test analysis compared to respective control.

References for this Manuscript are included along with introduction and discussion references at the end of the thesis. 


\section{DISCUSSION}

In this study, we aimed to identify the molecular mechanisms of reduced breast cancer invasion when CYR61 expression was diminished. Additionally, the extracellular drivers of breast cancer bone-directed invasion were identified. Furthermore, the molecular mechanism of reduced breast cancer invasion during reduced CTGF expression was identified. Main findings were as follows:

1) CYR61 expression correlates with invasiveness of TNBC cells (MDA-MB-231, HCC1806) and mesenchymal-transformed breast cancer cells (MCF-7-EMT, T47D-EMT). Reduced CYR61 expression led to diminished ERK1/2 phosphorylation, thereby reducing S100A4 expression. This signaling cascade could be assured by reduced YAP expression, which led to reduced CYR61 expression, reduced ERK1/2 phosphorylation, and reduced S100A4 expression (Figure 4).

2) CYR61 and S100A4 can be of value as a prognostic marker and therapeutic target for advanced and metastatic breast cancer.

3) We successfully identified 28 drivers of breast cancer bone-directed invasion by combining co-culturing techniques with secretome analysis using mass spectrometry. Additionally, nine identified drivers overlapped with genes upregulated during mesenchymal transition.

4) CTGF is one driver of breast cancer bone-directed invasion and is upregulated during mesenchymal transition. Reduced CTGF expression increased cell-ECM adhesion and decreased proteolytic activity of breast cancer cells. Additionally, CTGF regulates Zeb1, vimentin, LOX, SPARC, CD44, and transforming growth factor beta induced (TGFBI) expression in a cell-specific manner.

5) CTGF can be of value as a therapeutic target for advanced and metastatic breast cancer. Additionally, breast cancer cells treated with gonadotropin- releasing hormone $(\mathrm{GnRH})$ agonist exhibited reduced CTGF expression by induced RhoA activity. These results indicate this agonist may be a possible treatment option. 


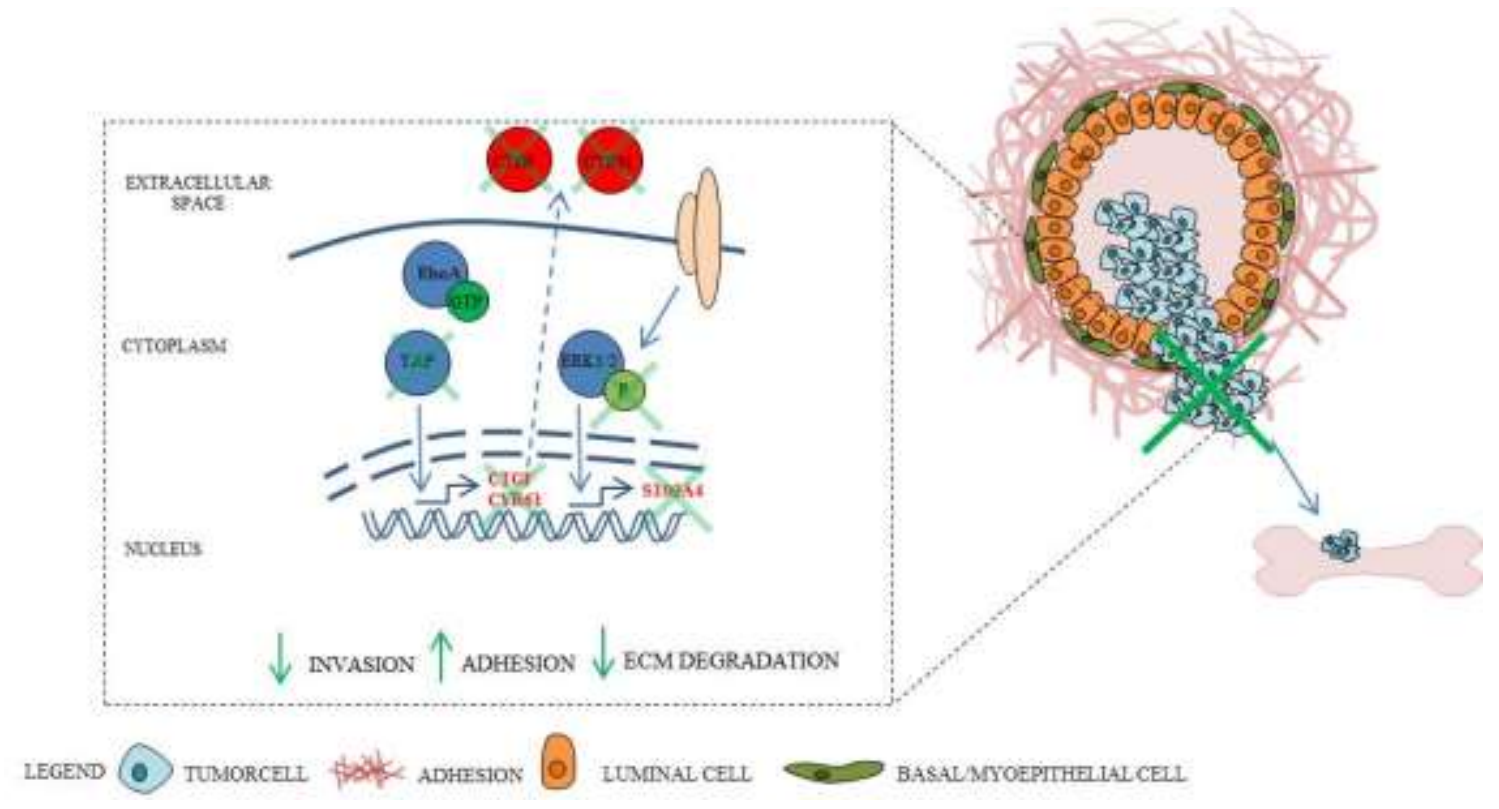

Figure 4 Scheme of signaling, that impedes invasion in highly invasive breast cancer cells. Illustration indicates how reduction of CYR61 or CTGF reduced breast cancer cell invasion.

\subsection{IDENTIFICATION OF MOLECULAR MECHANISMS UNDERLYING REDUCED BREAST CANCER INVASIVENESS DUE TO REDUCED CYR61 EXPRESSION}

As a matricellular protein, CYR61 acts as link between the ECM and cells within the TME (79). It binds to versatile receptors, thereby influencing manifold cellular processes such as invasion, migration, proliferation, survival, and wound healing (77, 80, 92, 93). Additionally, CYR61 has oncogenic function in several tumor entities including the breast $(97,114,191$, 192). Invasion is the initial step of the invasion-metastatic cascade. Cells unable to invade will not intravasate into the vascular system, extravasate into the distant parenchyma, or form metastases at distant sites (19-22). Bone metastasis is the prominent site for metastases in cancer, accounting for $70 \%$ and more of all metastases primarily located in the breast, prostate, and brain $(8,193)$. Despite having harsh physical environmental circumstances, disseminated tumor cells are able to colonize within the bone microenvironment with features different from the primary site of tumor growth (60). Identifying targets to stage tumor progression and impede invasion of primary breast cancer cells may help to cure currently incurable metastatic breast cancer. Our data suggest higher CYR61 expression in invasive TNBC cells (MDA-MB-231/basal b-like, HCC1806/ basal a-like) and mesenchymaltransformed breast cancer cells (MCF-7-EMT, T47D-EMT), which were generated from noninvasive breast cancer cells from luminal A subtype (MCF-7, T47D) (Manuscript A Figure 1 A). These mesenchymal-transformed breast cancer cells showed increased expression of 
TGFBI, vimentin, zinc finger E-box-binding homeobox 1 (Zeb1), Snail family transcriptional repressor 2 (SNAI2), and E-cadherin (Manuscript A Figure S1 A-F). It was previously demonstrated that targeting extracellular CYR61 through specific antibodies led to reduced 2D transwell invasion in co-culture with osteosarcoma cells (7). In our study, transient reduced intracellular CYR61 expression led to reduced 2D transwell invasion in co-culture with osteosarcoma cells and reduced 3D spheroid invaded area growth, which was not due to altered proliferation (Manuscript A Figure 1 C-D + Figure S2 B).

To shed light on the underlying molecular mechanisms of CYR61 related breast cancer invasion, we found S100A4 to be a potential target. S100A4, which was already reported to affect breast cancer invasion, is regulated through integrin $\alpha v \beta_{3}$ and ERK1/2 (7, 168). Additionally, a previous study demonstrated that CYR61 promotes EMT through $\alpha v \beta_{3}$ and ERK signaling in osteosarcoma cells (191). In accordance with these findings, we report that reduced CYR61 led to decreased S100A4 expression. Reduced S100A4 expression led to reduced 2D transwell invasion and 3D spheroid invaded area growth, while additional treatment with recombinant CYR61 reversed this effect (Manuscript A Figure 2 D - F). Moreover, reduced CYR61 expression led to reduced ERK1/2 phosphorylation. The blocking of ERK1/2 phosphorylation with U0126 (inhibitor of MEK1/2 kinase) treatment led to reduced S100A4 expression and reduced invasiveness (Manuscript A Figure 3 D, E). In accordance with these results, previous studies have reported that S100A4 induces TGF $\beta$ signaling and the EMT and that targeting S100A4 could help to prevent bone metastasis (194196).

Additionally, we wanted to verify these findings by regulating an upstream target of CYR61: YAP. YAP is a key regulator within Hippo signaling that facilitates organ development and angiogenesis (197-199). Increased YAP expression was reported to increase EMT marker expression (200). In our study, reduced YAP expression led to decreased 3D spheroid invaded area growth of invasive breast cancer cells, decreased CYR61 and S100A4 expression, and reduced ERK1/2 phosphorylation. Additional treatment with recombinant human CYR61 neutralized the effect on 3D spheroid invaded area growth. Interestingly, it was reported that the inhibition of ERK1/2 led to reduced YAP expression, which suggests a feedback loop mechanism (201). Regarding the use of CYR61 as a predictive marker for cancer, it was suggested that increased CYR61 expression correlates with poor prognosis in patients with esophageal squamous cell carcinoma (202). Moreover, CYR61 was proposed to be of clinical relevance regarding hormone receptor-positive early-stage breast cancer (203). Our 
observations indicate that CYR61, and to a further extent S100A4, may be of value as a predictive marker and therapeutic target for advanced and metastatic breast cancer (Manuscript A Figure 5, 6). Apart from this, an ongoing prospective trial is aiming to validate expression of different mRNA biomarkers in lung cancer including CCN1/CYR61 (NCT02294578). Another phase I clinical trial indicated a clinical benefit for patients with advanced solid tumors treated with cytostatic drug paclitaxel and cilengitide (antagonist of integrin $\alpha v \beta_{3}$ and $\alpha v \beta_{5}$ ) (204). Regarding S100A4, FDA has already approved niclodamide, which targets S100A4/NFkB/MMP9 signaling. A phase II clinical trial is aiming to test niclodamide for colorectal cancer (NCT02519582), and further applications are suggested for NSCLC (205).

\subsection{IDENTIFICATION OF EXTRACELLULAR DRIVERS OF INVASION}

Secreted proteins of different cell types prime and alter the constitution of the TME and ECM and drive tumor progression (2). We aimed to identify drivers of breast cancer bone-directed invasion by combining a co-culture model of breast cancer cells with osteosarcoma cells and secretome analysis using mass spectrometry. Identifying key regulators of the TME including the ECM could help to stage tumor progression and impede cancer cell invasion. We successfully detected 28 secreted proteins that are upregulated during the co-culture of noninvasive MCF-7 breast cancer cells and MG-63 osteosarcoma cells, compared with media from MCF-7 cells (Manuscript B figure 3 B-D). Additionally, we analyzed the effect of fibronectin (FN1), MMP2, and CTGF on invaded area growth due to gene ontology enrichment of detected potential drivers of breast cancer bone-directed invasion clustered in, but not restricted to, cell motility and cell migration (Manuscript B Supplement 4 A). Treating MCF-7 spheroids with human recombinant CTGF or MMP2 resulted in increased invaded area growth, whereas treatment with human fibronectin had no effect on the invaded area growth (Manuscript B Figure 5 F). Using BB-94, a MMP inhibitor, invaded area growth was diminished. Treatment of MCF-7 spheroids with FN1 and CTGF or FN1 with MMP2 had no effect on the invaded area growth. Regarding FN1 function in cell invasion and tumor progression, it was proposed that FN1 induced EMT through calpain in MCF-7 cells (206). Apart from this, it was demonstrated that only cleaved FN1 induced metastasis in human melanoma and that autocrine FN1 inhibited breast cancer metastasis (147, 163). Comparing the secretome of co-culture media with the media from osteosarcoma cells identified an upregulation of SPARC and a downregulation of MMP2 (Manuscript B Supplement 4 B). The downregulation of MMP2 may be due to MCF-7 breast cancer cells not expressing MMP2 or MMP9 (207). Furthermore, we analyzed the changed proteome by comparing the 
monoculture of MCF-7 and the co-culture of MCF-7 with osteosarcoma cells (MG-63). We found that heat shock proteins are highly dysregulated. Heat shock proteins are upregulated in tumor cells due to higher mutational load, resulting in misfolded proteins. Additionally, there is a great interest in and ongoing clinical trials on the involvement of heat shock proteins in tumor progression (183-185). However, further evaluation is needed to understand how these proteins are regulated with regards to the basal expression of different cell lines. Taken together, we identified potential drivers of breast cancer bone-directed invasion; however, the value of each identified driver needs to be further evaluated. The system we used was a simplified 2 D setup without accounting for fibroblasts, immune cells, or the ECM. Signaling within the TME and at a metastatic niche is very complex, and cell culture techniques have their limitations.

\subsection{IDENTIFICATION OF MOLECULAR MECHANISM UNDERLYING REDRUCED BREAST CANCER INVASIVENESS DUE TO REDUCED CTGF EXPRESSION}

Mesenchymal transformed breast cancer cells (MCF-7-EMT) exhibit an elevated expression of CTGF (51). In addition, secretome analysis of MCF-7 co-cultured with osteosarcoma cells revealed that CTGF is upregulated. CTGF increased the invaded area growth and proteolytic activity and decreased cell-ECM adhesion (Manuscript B Figure $5 \mathrm{~F}$ and Figure $6 \mathrm{E}, \mathrm{H}$ ). In accordance with these observations, reduced CTGF expression decreased the invaded area growth and increased cell-ECM adhesion (Manuscript B Figure 5 A, B and Figure 6 A-D). The effect of neutralizing CTGF antibodies on cell-ECM adhesion was reported previously, indicating comparable results (116). However, the reduction of CTGF was not sufficient to reduce the proteolytic activity in TNBC cell line MDA-MB-231 (Manuscript B Figure 6 G). This could be due to cell line-specific molecular alterations and would need further evaluation using additional TNBC cell lines. Additionally, it could be a cell line-specific result regarding reduced proteolytic activity in mesenchymal-transformed breast cancer cells after reduced CTGF expression. Therefore, additional experiments should be conducted using at least one more mesenchymal transformed luminal A breast cancer cell line. Nonetheless, Wang et al. reported that CTGF induced the expression of ECM-degrading genes (165). Growing evidence exists that increased expression of one or multiple members of the CCN family correlates with poor prognosis in different tumor entities including the breast, prostate, bone, and pancreas $(192,208-211)$. In accordance with these results, our data demonstrated that increased CTGF expression correlates with breast cancer invasiveness (Manuscript B Figure 4 C, D). Apart from this, our data suggests that mesenchymal-transformed breast 
cancer cells express a combination of integrin $\alpha$ v receptor (CD51) and vascular cell adhesion molecule 1 (VCAM-1/CD106) to a higher extent (Manuscript B Figure 4 E, F). This receptor expression combination may be a possible marker for targeting cells with higher plasticity. Furthermore, several studies found that VCAM-1 activates indolent micrometastases and induces survival signaling in breast cancer cells (58, 167, 212). Previously, Hou et al. demonstrated that due to upregulated VCAM-1 expression, CTGF facilitates osteosarcoma migration and metastasis (166). Nonetheless, further research is indispensable to detect the roles of different integrin $\beta$ subunits because integrin $\alpha v$ has versatile possible binding $\beta$ subunits determining the binding of extracellular components (213).

The contribution of EMT to invasiveness and metastasis is still highly debated (24, 43, 214). Therefore, we investigated the effect of CTGF expression on the expression of EMT-TFs and EMT markers. Our results demonstrated a cell line-specific effect, wherein reduced CTGF led to reduced Zeb1 expression in mesenchymal-transformed breast cancer cells. However, in TNBC, reduced CTGF expression led to reduced vimentin expression (Manuscript B Figure 7 C, D). Although SNAI2 did not seem to be regulated through CTGF, a previous study found that SNAI1 and SNAI2 induce the EMT in breast cancer through TGF $\beta$ signaling, thereby regulating CTGF and SPARC (170). In mesenchymal-transformed breast cancer cells, we demonstrated that CTFG regulates versatile targets (TGFBI, CD44, SPARC, FN1 and LOX), which we identified previously as secreted potential drivers of breast cancer bone-directed invasion (Manuscript B Figure 7 A). Lysyl oxidase (LOX) facilitates collagen I stabilization, thereby inducing chemo resistance (169). SPARC binds to collagen in a calcium-dependent manner and regulates ECM assembly (215). Moreover, SPARC is associated with anti-cancer effects, inhibits bone metastasis $(172,173)$. Decreased CTGF expression, led to reduced SPARC expression in mesenchymal-transformed breast cancer cells. Reduced CTGF expression led to increased FN1 expression, which was cell line independent (Manuscript B Figure 7 A, B). After evaluating, which targets are regulated by CTGF, we wanted to shed light on targets regulating CTGF. Moreover, we wanted to investigate a possible treatment option targeting CTGF. Li et al. reported that the activity of GTPase RhoA controls CTGF cleavage and the fate of mesenchymal stem cells (161). Furthermore, Arguilar-Rojas et al. suggested that the treatment with GnRH agonist Busrelin induces RhoA activity in TNBC cells, thereby reducing invasiveness (175). Our data suggest that treatment with a GnRH agonist reduced CTGF expression and increases cell-ECM adhesion in TNBC cells and mesenchymal-transformed breast cancer cells (Manuscript B Figure 8 A-D and Supplement 11). Additionally, treatment with GnRH agonist Triptorelin induced RhoA activity in 
mesenchymal-transformed breast cancer cells (Manuscript B Figure 8 E). Induction of RhoA activity led to reduced invasiveness, while reduced RhoA expression led to increased invasion and expression of CTGF (Manuscript B Figure 8 F-H). Previously reported treatment options targeting CTGF include sinomenine, curcumin, caffeine, simvastatin, and DN9693 (216-220). Additionally, monoclonal antibodies targeting CTGF are in use for the treatment of fibrosis and have been proposed to inhibit the migration of human melanoma cells $(221,222)$. Taken together, CTGF is a promising target regarding invasive breast cancer and metastasis and can be used as a prognostic marker.

\subsection{POSSIBLE THERAPEUTIC IMPLEMENTATIONS}

Our results suggest that matricellular proteins CYR61 and CTGF regulate the invasiveness of breast cancer cells and can be used as predictive markers and therapeutic targets. As previously indicated, different signaling cascades are involved in CYR61- and CTGFdependent breast cancer invasion signaling. Different treatment options can be taken into account when targeting CYR61 and CTGF, including GnRH agonist, targeting the ERK1/2 signaling cascade, and targeting the Hippo pathway with key regulators YAP and TAZ.

\subsubsection{Treatment with GnRH agonist may help prevent EMT induction and invasiveness of breast cancer cells}

Gonadotropin-releasing hormone receptor (GnRH-R) is expressed in different tumor entities dependent or independent of the reproduction system (223). Approximately 50-60\% of all human breast cancers and to a further extent $74 \%$ of breast cancers diagnosed as TNBC expressing GnRH-R $(7,132,159)$. Breast cancer treatment with GnRH agonist resulted in a time- and dose- dependent reduction of in vitro invasion and in vivo metastasis $(132,160)$. Binding to GnRH-R resulted in the activation of phosphotyrosine phosphatases, which inhibited G-protein coupled estrogen receptor 1 (GPER)(152). Schubert et al. demonstrated that even the binding of antagonists to GnRH-R induced apoptosis in endometrial, ovarian, and breast cancer (160). Moreover, Gründker et al. reported that GnRH agonist treatment reduced S100A4 and CYR61 expression in mesenchymal-transformed and TNBC cells (7). GnRH agonist Triptorelin was reported to regulate RhoA activity in mesenchymaltransformed breast cancer cells, which was also found for agonist Busrelin in TNBC cells (175). In our study, we demonstrated that a GnRH agonist increases cell-ECM adhesion and reduced CTGF expression. These mechanisms indicate an advantage of patients with GnRH$\mathrm{R}$ expression. We were able to demonstrate a correlation of increased invasion, increased cellular plasticity, and increased expression of matricellular proteins CYR61 and CTGF. In clinical practice, GnRH agonists are used for the suppression of ovarian function of 
premenopausal breast cancers of a high grade (151). Clinical trials have identified a benefit of adjuvant chemotherapy ovarian suppression, which reduced distant metastasis free survival and overall survival $(8,224)$. It would be of high interest to evaluate the effect of GnRH-R agonist on EMT markers and EMT-TFs.

\subsubsection{ERK1/2 cascade}

In recent years, targeted therapy improved patient survival in different cancer entities and led the way to personalized medicine (225). Molecular alterations of tumors are screened to find treatment options that most benefit patients. Monoclonal antibodies are small molecule inhibitors designed to interfere with known tumorigenic signaling pathways and aim to target tumor cells with special molecular alterations. However, as clonal evolution processes, tumor cells gain resistance that makes them harder to target. Preclinical studies revealed manifold targetable signaling pathways including the MAPK pathway. Versatile clinical trials have aimed to target the kinase Mitogen Activated Protein Kinase Kinase (MEK), which is an upstream regulator of ERK1/2, with inhibitors for different cancer entities including breast cancer, colorectal cancer, and NSCLC (226). Additionally, MEK kinase inhibitors are reported to target cancer with gained resistance to B-Raf proto-oncogene serine/threonine kinase (BRAF). In this study, we demonstrated that treatment of breast cancer spheroid with U0126, which is an inhibitor of MEK1/2, resulted in decreased invaded area growth, reduced S100A4 expression, and decreased proliferation (Manuscript A Figure 3 D-F). ERK1/2 inhibitors appear to be a new treatment option for cancers with gained resistance to MEK kinase inhibitors given its unique position in versatile signaling pathways (176, 177). Furthermore, ERK1/2 phosphorylation is increased in mesenchymal-transformed breast cancer cells and TNBC cells (Manuscript A Figure 3 B). Hou et al. reported that CYR61 targets the MEK-ERK pathway in osteosarcoma cells (191). Breast cancer patients with detected CYR61 or CTGF overexpression may benefit from ERK1/2 targeted therapy. In this study, we demonstrated that reduced CYR61 regulates S100A4 expression through dephosphorylation of ERK1/2. It would be of great interest to evaluate whether targeting CYR61 or CTGF could be used to treat ERK1/2 resistant cancers.

\subsubsection{Hippo pathway}

The Hippo pathway is evolutionary conserved and regulates key events of development such as organ size and angiogenesis. YAP is negatively regulated through the phosphorylation of Large Tumor Suppressor Kinase 1/2 (LATS1/2), which results in degradation of protein. Dephosphorylation of YAP results in translocation to the nucleus, where it transcriptionally activates different target genes including CYR61 and CTGF (197-199). Regarding breast 
cancer, YAP was reported as an oncogene, as well as tumor suppressor (227). Warren et al. reported that increased YAP expression correlates with increased expression of EMT markers (200). We demonstrated that reduced YAP expression led to decreased 3D invaded area growth by suppression of CYR61, p-ERK1/2, and S100A4. In our study, the effect of reduced YAP expression on 3D invasion was restored by extracellular CYR61 addition (Manuscript A Figure 4). Mi et al. observed that breast cancer Hippo signaling induces GGylation-dependent cell proliferation and migration (228). Additionally, breast cancer subtypes that do not express estrogen receptor were more sensitive to the inhibition of GGylation. Moreover, it was reported that taxol resistance is mediated through the Hippo pathway (119). Therefore, it was proposed to target YAP in TNBC with taxol resistance (229). Currently, there is an ongoing clinical trial treating TNBC neoadjuvant with zoledronate and atorvastatin (NCT03358017). Zoledronate, a bisphosphate, was observed to interfere with YAP/TAZ signaling and mevalonate signaling (230). Part of standard treatment regarding early breast cancer is longterm endocrine therapy, leading to decreased estrogen level. Estrogen has a prominent role in skeletal homeostasis (231). To prevent bone damage bisphosphates are added to treatment (232). Different treatment options are necessary to provide patients with different subtypes of breast cancer with appropriate treatment, helping to prolong survival and impede progression. In our study, we demonstrated that CYR61 and CTGF have versatile effects on breast cancer progression and are valuable targets and predictive markers for advanced breast cancer. 


\section{CONCLUSION}

The purpose of this thesis was to target the signaling of invasion to impede breast cancer metastasis. We identified molecular mechanisms through which the reduction of CYR61 led to reduced invasiveness. Additionally, we examined which unique interactions of breast cancer cells with osteosarcoma cells led to increased invasiveness. Furthermore, we evaluated the molecular mechanisms of CTGF, thereby identifying possible treatment strategies to impede breast cancer invasion.

We observed that CYR61 is a key regulator of breast cancer invasion. Reduced CYR61 led to dephosphorylated ERK1/2 and reduced S100A4 expression, thereby reducing 3D spheroid invaded area growth. CYR61 and S100A4 may be utilized as predictive markers and therapeutic target for advanced breast cancer. Moreover, signaling of CYR61 may be impeded by using MEK1/2 inhibitor U0126 or inhibitors of YAP currently under investigation.

Furthermore, we identified versatile potential drivers of breast cancer bone-directed invasion due to secretome analysis of co-culture media from breast cancer cells and osteosarcoma cells. Identification of regulators within TME and ECM, which facilitate tumor initiation, invasion, and tumor progression, would be of benefit for future therapy designs. The TME is crucial for tumor progression, drug delivery, therapy outcome, and drug efficacy. Designing experimental models to better understand the complex interactions appearing in TME would be of great benefit.

Targeting CTGF led to reduced proteolytic activity, decreased 2D transwell invasion and 3D spheroid invaded area growth, and increased cell-ECM invasion. Apart from this, CTGF is regulated by RhoA activity, which can be regulated with $\mathrm{GnRH}$ agonist treatment. 


\section{REFERENCES}

1. Bray F, Ferlay J, Soerjomataram I, Siegel RL, Torre LA, Jemal A. Global cancer statistics 2018: GLOBOCAN estimates of incidence and mortality worldwide for 36 cancers in 185 countries. CA: A Cancer Journal for Clinicians. 2018;68(6):394-424.

2. Emon B, Bauer J, Jain Y, Jung B, Saif T. Biophysics of Tumor Microenvironment and Cancer Metastasis - A Mini Review. Computational and Structural Biotechnology Journal. 2018;16:279-87.

3. Bornstein P. Diversity of function is inherent in matricellular proteins: an appraisal of thrombospondin 1. The Journal of Cell Biology. 1995;130(3):503-6.

4. Sage EH, Bornstein P. Extracellular proteins that modulate cell-matrix interactions. SPARC, tenascin, and thrombospondin. The Journal of Biological Chemistry. 1991;266(23):14831-4.

5. Dhar A, Ray A. Dhar A, Ray AThe $\mathrm{CCN}$ family proteins in carcinogenesis. Experimental Oncology. 2010;32:2-9.

6. Wells JE, Howlett M, Cole CH, Kees UR. Deregulated expression of connective tissue growth factor (CTGF/CCN2) is linked to poor outcome in human cancer. International Journal of Cancer. 2015;137(3):504-11.

7. Grundker C, Bauerschmitz G, Schubert A, Emons G. Invasion and increased expression of S100A4 and CYR61 in mesenchymal transformed breast cancer cells is downregulated by GnRH. International Journal of Oncology. 2016;48(6):2713-21.

8. Harbeck N, Penault-Llorca F, Cortes J, Gnant M, Houssami N, Poortmans P, et al. Breast cancer. Nature Reviews Disease Primers. 2019;5(1):66.

9. Perou CM, Sørlie T, Eisen MB, van de Rijn M, Jeffrey SS, Rees CA, et al. Molecular portraits of human breast tumours. Nature. 2000;406(6797):747-52.

10. Prat A, Ellis MJ, Perou CM. Practical implications of gene-expression-based assays for breast oncologists. Nature Reviews Clinical Oncology. 2012;9(1):48-57.

11. Prat A, Perou CM. Deconstructing the molecular portraits of breast cancer. Molecular Oncology. 2011;5(1):5-23.

12. Parker JS, Mullins M, Cheang MCU, Leung S, Voduc D, Vickery T, et al. Supervised Risk Predictor of Breast Cancer Based on Intrinsic Subtypes. Journal of Clinical Oncology. 2009;27(8):1160-7.

13. Lehmann BD, Bauer JA, Chen X, Sanders ME, Chakravarthy AB, Shyr Y, et al. Identification of human triple-negative breast cancer subtypes and preclinical models for selection of targeted therapies. The Journal of Clinical Investigation. 2011;121(7):2750-67.

14. Burstein MD, Tsimelzon A, Poage GM, Covington KR, Contreras A, Fuqua SAW, et al. Comprehensive Genomic Analysis Identifies Novel Subtypes and Targets of TripleNegative Breast Cancer. Clinical Cancer Research. 2015;21(7):1688-98.

15. Cheang MCU, Martin M, Nielsen TO, Prat A, Voduc D, Rodriguez-Lescure A, et al. Defining Breast Cancer Intrinsic Subtypes by Quantitative Receptor Expression. The Oncologist. 2015;20(5):474-82.

16. Bareche Y, Venet D, Ignatiadis M, Aftimos P, Piccart M, Rothe F, et al. Unravelling triple-negative breast cancer molecular heterogeneity using an integrative multiomic analysis. Annals of Oncology. 2018;29(4):895-902.

17. Kim HK, Park KH, Kim Y, Park SE, Lee HS, Lim SW, et al. Discordance of the PAM50 Intrinsic Subtypes Compared with Immunohistochemistry-Based Surrogate in Breast Cancer Patients: Potential Implication of Genomic Alterations of Discordance. Cancer Research and Treatment : Official Journal of Korean Cancer Association. 2019;51(2):737-47. 18. Lehmann BD, Jovanović B, Chen X, Estrada MV, Johnson KN, Shyr Y, et al. Refinement of Triple-Negative Breast Cancer Molecular Subtypes: Implications for Neoadjuvant Chemotherapy Selection. PLoS One. 2016;11(6):e0157368. 
19. Lambert AW, Pattabiraman DR, Weinberg RA. Emerging Biological Principles of Metastasis. Cell. 2017;168(4):670-91.

20. Fidler IJ. The pathogenesis of cancer metastasis: the 'seed and soil' hypothesis revisited. Nature Reviews Cancer. 2003;3(6):453-8.

21. Gupta GP, Massague J. Cancer metastasis: building a framework. Cell. 2006;127(4):679-95.

22. Talmadge JE, Fidler IJ. AACR Centennial Series: The Biology of Cancer Metastasis: Historical Perspective. Cancer Research. 2010;70(14):5649-69.

23. Craene BD, Berx G. Regulatory networks defining EMT during cancer initiation and progression. Nature Reviews Cancer. 2013;13(2):97-110.

24. Nieto MA. Context-specific roles of EMT programmes in cancer cell dissemination. Nature Cell Biology. 2017;19(5):416-8.

25. Friedl P, Locker J, Sahai E, Segall JE. Classifying collective cancer cell invasion. Nature Cell Biology. 2012;14(8):777-83.

26. Chambers AF, Groom AC, MacDonald IC. Dissemination and growth of cancer cells in metastatic sites. Nature Reviews Cancer. 2002;2(8):563-72.

27. Hanahan D, Weinberg RA. Hallmarks of cancer: the next generation. Cell. 2011;144(5):646-74.

28. Tahmasebi Birgani M, Carloni V. Tumor Microenvironment, a Paradigm in Hepatocellular Carcinoma Progression and Therapy. International Journal of Molecular Sciences. 2017;18(2).

29. De Pascalis C, Etienne-Manneville S. Single and collective cell migration: the mechanics of adhesions. Molecular Biology of the Cell. 2017;28(14):1833-46.

30. Roma-Rodrigues C, Mendes R, Baptista PV, Fernandes AR. Targeting Tumor Microenvironment for Cancer Therapy. International Journal of Molecular Sciences. 2019;20(4).

31. Hui L, Chen Y. Tumor microenvironment: Sanctuary of the devil. Cancer Letters. 2015;368(1):7-13.

32. Willumsen N, Thomsen LB, Bager CL, Jensen C, Karsdal MA. Quantification of altered tissue turnover in a liquid biopsy: a proposed precision medicine tool to assess chronic inflammation and desmoplasia associated with a pro-cancerous niche and response to immuno-therapeutic anti-tumor modalities. Cancer Immunology, Immunotherapy. 2018;67(1):1-12.

33. Pickup MW, Mouw JK, Weaver VM. The extracellular matrix modulates the hallmarks of cancer. EMBO Reports. 2014;15(12):1243-53.

34. Otranto M, Sarrazy V, Bonté F, Hinz B, Gabbiani G, Desmouliere A. The role of the myofibroblast in tumor stroma remodeling. Cell Adhesion \& Migration. 2012;6(3):203-19.

35. Sormendi S, Wielockx B. Hypoxia Pathway Proteins As Central Mediators of Metabolism in the Tumor Cells and Their Microenvironment. Frontiers in Immunology. 2018;9(40).

36. Coulson R, Liew SH, Connelly AA, Yee NS, Deb S, Kumar B, et al. The angiotensin receptor blocker, Losartan, inhibits mammary tumor development and progression to invasive carcinoma. Oncotarget. 2017;8(12).

37. De Pascalis C, Etienne-Manneville S. Single and collective cell migration: the mechanics of adhesions. Molecular Biology of the Cell. 2017;28(14):1833-46.

38. Sanz-Moreno V, Gadea G, Ahn J, Paterson H, Marra P, Pinner S, et al. Rac Activation and Inactivation Control Plasticity of Tumor Cell Movement. Cell. 2008;135(3):510-23.

39. Giampieri S, Pinner S, Sahai E. Intravital Imaging Illuminates Transforming Growth Factor $\beta$ Signaling Switches during Metastasis. Cancer Research. 2010;70(9):3435-9.

40. Wolf K, Friedl P. Molecular mechanisms of cancer cell invasion and plasticity. British Journal of Dermatology. 2006;154(s1):11-5. 
41. Kedrin D, Wyckoff J, Sahai E, Condeelis J, Segall JE. Imaging Tumor Cell Movement In Vivo. Current Protocols in Cell Biology. 2007;35(1):19.7.1-.7.7.

42. Lamouille S, Xu J, Derynck R. Molecular mechanisms of epithelial-mesenchymal transition. Nature Reviews Molecular Cell Biology. 2014;15(3):178-96.

43. Brabletz T, Kalluri R, Nieto MA, Weinberg RA. EMT in cancer. Nature Reviews Cancer. 2018;18(2):128-34.

44. Thiery JP. Epithelial-mesenchymal transitions in tumour progression. Nature Reviews Cancer. 2002;2(6):442-54.

45. Kurrey NK, Jalgaonkar SP, Joglekar AV, Ghanate AD, Chaskar PD, Doiphode RY, et al. Snail and Slug Mediate Radioresistance and Chemoresistance by Antagonizing p53Mediated Apoptosis and Acquiring a Stem-Like Phenotype in Ovarian Cancer Cells. STEM CELLS. 2009;27(9):2059-68.

46. Gupta PB, Onder TT, Jiang G, Tao K, Kuperwasser C, Weinberg RA, et al. Identification of Selective Inhibitors of Cancer Stem Cells by High-Throughput Screening. Cell. 2009;138(4):645-59.

47. Singh A, Settleman J. EMT, cancer stem cells and drug resistance: an emerging axis of evil in the war on cancer. Oncogene. 2010;29(34):4741-51.

48. Tsai Jeff H, Donaher Joana L, Murphy Danielle A, Chau S, Yang J. Spatiotemporal Regulation of Epithelial-Mesenchymal Transition Is Essential for Squamous Cell Carcinoma Metastasis. Cancer Cell. 2012;22(6):725-36.

49. Ocaña Oscar H, Córcoles R, Fabra Á, Moreno-Bueno G, Acloque H, Vega S, et al. Metastatic Colonization Requires the Repression of the Epithelial-Mesenchymal Transition Inducer Prrx1. Cancer Cell. 2012;22(6):709-24.

50. Gaggioli C, Hooper S, Hidalgo-Carcedo C, Grosse R, Marshall JF, Harrington K, et al. Fibroblast-led collective invasion of carcinoma cells with differing roles for RhoGTPases in leading and following cells. Nature Cell Biology. 2007;9(12):1392-400.

51. Ziegler E, Hansen MT, Haase M, Emons G, Grundker C. Generation of MCF-7 cells with aggressive metastatic potential in vitro and in vivo. Breast Cancer Research and Treatment. 2014;148(2):269-77.

52. Bombonati A, Sgroi DC. The molecular pathology of breast cancer progression. The Journal of Pathology. 2011;223(2):308-18.

53. Cheung KJ, Padmanaban V, Silvestri V, Schipper K, Cohen JD, Fairchild AN, et al. Polyclonal breast cancer metastases arise from collective dissemination of keratin 14expressing tumor cell clusters. Proceedings of the National Academy of Sciences. 2016;113(7):E854-E63.

54. Cardoso F, Senkus E, Costa A, Papadopoulos E, Aapro M, André F, et al. 4th ESOESMO International Consensus Guidelines for Advanced Breast Cancer (ABC 4) $\dagger$. Annals of Oncology. 2018;29(8):1634-57.

55. Mariotto AB, Etzioni R, Hurlbert M, Penberthy L, Mayer M. Estimation of the Number of Women Living with Metastatic Breast Cancer in the United States. Cancer Epidemiology Biomarkers \& Prevention. 2017;26(6):809-15.

56. Gobbini E, Ezzalfani M, Dieras V, Bachelot T, Brain E, Debled M, et al. Time trends of overall survival among metastatic breast cancer patients in the real-life ESME cohort. European Journal of Cancer. 2018;96:17-24.

57. Buonomo OC, Caredda E, Portarena I, Vanni G, Orlandi A, Bagni C, et al. New insights into the metastatic behavior after breast cancer surgery, according to well-established clinicopathological variables and molecular subtypes. PLoS One. 2017;12(9):e0184680.

58. Croucher PI, McDonald MM, Martin TJ. Bone metastasis: the importance of the neighbourhood. Nature Reviews Cancer. 2016;16(6):373-86.

59. Fidler IJ, Kripke ML. The challenge of targeting metastasis. Cancer and Metastasis Reviews. 2015;34(4):635-41. 
60. Fortunato L, Mascaro A, Baldi A, Farina M, Cortese G, Ventrone M, et al. Positive Bone Marrow Biopsy Is Associated with a Decreased Disease-Free Survival in Patients with Operable Breast Cancer. Annals of Surgical Oncology. 2009;16:3010-9.

61. Tjensvoll K, Oltedal S, Heikkilä R, Kvaløy JT, Gilje B, Reuben JM, et al. Persistent tumor cells in bone marrow of non-metastatic breast cancer patients after primary surgery are associated with inferior outcome. BMC Cancer. 2012;12(1):190.

62. Domschke C, Diel IJ, Englert S, Kalteisen S, Mayer L, Rom J, et al. Prognostic Value of Disseminated Tumor Cells in the Bone Marrow of Patients with Operable Primary Breast Cancer: A Long-term Follow-up Study. Annals of Surgical Oncology. 2013;20(6):1865-71.

63. Butcher DT, Alliston T, Weaver VM. A tense situation: forcing tumour progression. Nature Reviews Cancer. 2009;9:108.

64. Paszek MJ, Zahir N, Johnson KR, Lakins JN, Rozenberg GI, Gefen A, et al. Tensional homeostasis and the malignant phenotype. Cancer Cell. 2005;8(3):241-54.

65. Ruppender NS, Merkel AR, Martin TJ, Mundy GR, Sterling JA, Guelcher SA. Matrix Rigidity Induces Osteolytic Gene Expression of Metastatic Breast Cancer Cells. PLoS One. 2010;5(11):e15451.

66. Johnson RW, Nguyen MP, Padalecki SS, Grubbs BG, Merkel AR, Oyajobi BO, et al. TGF- $\beta$ Promotion of Gli2-Induced Expression of Parathyroid Hormone-Related Protein, an Important Osteolytic Factor in Bone Metastasis, Is Independent of Canonical Hedgehog Signaling. Cancer Research. 2011;71(3):822-31.

67. Müller A, Homey B, Soto H, Ge N, Catron D, Buchanan ME, et al. Involvement of chemokine receptors in breast cancer metastasis. Nature. 2001;410(6824):50-6.

68. Taichman RS, Cooper C, Keller ET, Pienta KJ, Taichman NS, McCauley LK. Use of the Stromal Cell-derived Factor-1/CXCR4 Pathway in Prostate Cancer Metastasis to Bone. Cancer Research. 2002;62(6):1832-7.

69. Corcoran KE, Trzaska KA, Fernandes H, Bryan M, Taborga M, Srinivas V, et al. Mesenchymal Stem Cells in Early Entry of Breast Cancer into Bone Marrow. PLoS One. 2008;3(6):e2563.

70. Gründker C, Bauerschmitz G, Knapp J, Schmidt E, Olbrich T, Emons G. Inhibition of SDF-1/CXCR4-induced epithelial-mesenchymal transition by kisspeptin-10. Breast Cancer Research and Treatment. 2015;152(1):41-50.

71. Correa D, Somoza RA, Lin P, Schiemann WP, Caplan AI. Mesenchymal stem cells regulate melanoma cancer cells extravasation to bone and liver at their perivascular niche. International Journal of Cancer. 2016;138(2):417-27.

72. Loibl M, Binder A, Herrmann M, Duttenhoefer F, Richards RG, Nerlich M, et al. Direct Cell-Cell Contact between Mesenchymal Stem Cells and Endothelial Progenitor Cells Induces a Pericyte-Like Phenotype In Vitro. BioMed Research International. 2014;2014:10.

73. Wong GS, Rustgi AK. Matricellular proteins: priming the tumour microenvironment for cancer development and metastasis. British Journal of Cancer. 2013;108(4):755-61.

74. Lu P, Weaver VM, Werb Z. The extracellular matrix: A dynamic niche in cancer progression. The Journal of Cell Biology. 2012;196(4):395-406.

75. Christofori G. New signals from the invasive front. Nature. 2006;441(7092):444-50.

76. Joyce JA, Pollard JW. Microenvironmental regulation of metastasis. Nature Reviews Cancer. 2009;9(4):239-52.

77. Lau LF. CCN1/CYR61: the very model of a modern matricellular protein. Cellular and Molecular Life Sciences : CMLS. 2011;68(19):3149-63.

78. Roberts DD. Emerging functions of matricellular proteins. Cellular and Molecular Life Sciences : CMLS. 2011;68(19):3133-6.

79. Chiodoni C, Colombo MP, Sangaletti S. Matricellular proteins: from homeostasis to inflammation, cancer, and metastasis. Cancer and Metastasis Reviews. 2010;29(2):295-307. 
80. Murphy-Ullrich JE, Sage EH. Revisiting the matricellular concept. Matrix biology : Journal of the International Society for Matrix Biology. 2014;37:1-14.

81. Sawyer AJ, Kyriakides TR. Matricellular proteins in drug delivery: Therapeutic targets, active agents, and therapeutic localization. Adv Drug Deliv Rev. 2016;97:56-68.

82. Brellier F, Martina E, Degen M, Heuzé-Vourc'h N, Petit A, Kryza T, et al. Tenascin$\mathrm{W}$ is a better cancer biomarker than tenascin-C for most human solid tumors. BMC Clinical Pathology. 2012;12(1):14.

83. Cao D-X, Li Z-J, Jiang X-O, Lum YL, Khin E, Lee NP, et al. Osteopontin as potential biomarker and therapeutic target in gastric and liver cancers. World Journal of Gastroenterology. 2012;18(30):3923-30.

84. Bork P. The modular architecture of a new family of growth regulators related to connective tissue growth factor. FEBS Letters. 1993;327(2):125-30.

85. Jones JI, Gockerman A, Busby WH, Camacho-Hubner C, Clemmons DR. Extracellular matrix contains insulin-like growth factor binding protein-5: potentiation of the effects of IGF-I. The Journal of Cell Biology. 1993;121(3):679-87.

86. Lau LF. Cell surface receptors for CCN proteins. Journal of Cell Communication and Signaling. 2016;10(2):121-7.

87. Kular L, Pakradouni J, Kitabgi P, Laurent M, Martinerie C. The CCN family: A new class of inflammation modulators? Biochimie. 2011;93(3):377-88.

88. Zarogoulidis P, Tsakiridis K, Karapantzou C, Lampaki S, Kioumis I, Pitsiou G, et al. Use of Proteins as Biomarkers and Their Role in Carcinogenesis. Journal of Cancer. 2015;6(1):9-18.

89. Lin C-C, Chen P-C, Lein M-Y, Tsao C-W, Huang C-C, Wang S-W, et al. WISP-1 promotes VEGF-C-dependent lymphangiogenesis by inhibiting miR-300 in human oral squamous cell carcinoma cells. Oncotarget. 2016;7(9):9993-10005.

90. Mo F-E, Muntean AG, Chen C-C, Stolz DB, Watkins SC, Lau LF. CYR61 (CCN1) Is Essential for Placental Development and Vascular Integrity. Molecular and Cellular Biology. 2002;22(24):8709-20.

91. Chen C-C, Mo F-E, Lau LF. The Angiogenic Factor Cyr61 Activates a Genetic Program for Wound Healing in Human Skin Fibroblasts. Journal of Biological Chemistry. 2001;276(50):47329-37.

92. Todorovic V, Chen CC, Hay N, Lau LF. The matrix protein CCN1 (CYR61) induces apoptosis in fibroblasts. The Journal of Cell Biology. 2005;171(3):559-68.

93. Yang G, Lau L. Cyr61, product of a growth factor-inducible immediate early gene, is associated with the extracellular matrix and the cell surface. Cell Growth Differ. 1991;2(7):351-7.

94. Barreto S, Ray A, Edgar P. Biological characteristics of $\mathrm{CCN}$ proteins in tumor development. Journal of BUON: Official Journal of the Balkan Union of Oncology. 2016;21:1359-67.

95. Feng P, Wang B, Ren EC. Cyr61/CCN1 is a tumor suppressor in human hepatocellular carcinoma and involved in DNA damage response. The International Journal of Biochemistry \& Cell Biology. 2008;40(1):98-109.

96. Tong X, Xie D, O'Kelly J, Miller CW, Muller-Tidow C, Koeffler HP. Cyr61, a member of CCN family, is a tumor suppressor in non-small cell lung cancer. The Journal of Biological Chemistry. 2001;276(50):47709-14.

97. Tsai M-S, Bogart DF, Castañeda JM, Li P, Lupu R. Cyr61 promotes breast tumorigenesis and cancer progression. Oncogene. 2002;21:8178.

98. Lin M-T, Zuon C-Y, Chang C-C, Chen S-T, Chen C-P, Lin B-R, et al. Cyr61 Induces Gastric Cancer Cell Motility/Invasion via Activation of the Integrin/Nuclear Factor«B/Cyclooxygenase-2 Signaling Pathway. Clinical Cancer Research. 2005;11(16):5809-20. 
99. Gery S, Xie D, Yin D, Gabra H, Miller C, Wang H, et al. Ovarian carcinomas: CCN genes are aberrantly expressed and $\mathrm{CCN} 1$ promotes proliferation of these cells. Clinical Cancer Research : an Official Journal of the American Association for Cancer Research. 2005;11(20):7243-54.

100. Xie D, Yin D, Tong X, O'Kelly J, Mori A, Miller C, et al. Cyr61 Is Overexpressed in Gliomas and Involved in Integrin-Linked Kinase-Mediated Akt and $\beta$-Catenin-TCF/Lef Signaling Pathways. Cancer Research. 2004;64(6):1987-96.

101. Huang Y-T, Lan Q, Lorusso G, Duffey N, Rüegg C. The matricellular protein CYR61 promotes breast cancer lung metastasis by facilitating tumor cell extravasation and suppressing anoikis. Oncotarget. 2016;8(6).

102. Vellon L, Menendez JA, Lupu R. $\alpha \mathrm{V} \beta 3$ integrin regulates heregulin (HRG)-induced cell proliferation and survival in breast cancer. Oncogene. 2005;24(23):3759-73.

103. Kim S-M, Park J-H, Chung S-K, Kim J-Y, Hwang H-Y, Chung K-C, et al. Coxsackievirus B3 infection induces cyr61 activation via JNK to mediate cell death. $J$ Virol. 2004;78(24):13479-88.

104. Wiedmaier N, Müller S, Köberle M, Manncke B, Krejci J, Autenrieth IB, et al. Bacteria induce CTGF and CYR61 expression in epithelial cells in a lysophosphatidic acid receptor-dependent manner. International Journal of Medical Microbiology. 2008;298(3):23143.

105. Kurozumi K, Hardcastle J, Thakur R, Shroll J, Nowicki M, Otsuki A, et al. Oncolytic HSV-1 infection of tumors induces angiogenesis and upregulates CYR61. Molecular Therapy : the Journal of the American Society of Gene Therapy. 2008;16(8):1382-91.

106. Rivera-Gonzalez R, Petersen DN, Tkalcevic G, Thompson DD, Brown TA. Estrogeninduced genes in the uterus of ovariectomized rats and their regulation by droloxifene and tamoxifen. The Journal of Steroid Biochemistry and Molecular Biology. 1998;64(1):13-24.

107. Kim YN, Choe SR, Cho KH, Cho DY, Kang J, Park CG, et al. Resveratrol suppresses breast cancer cell invasion by inactivating a RhoA/YAP signaling axis. Experimental \& Molecular Medicine. 2017;49(2):e296.

108. Sampath D, Winneker RC, Zhang Z. Cyr61, a Member of the CCN Family, Is Required for MCF-7 Cell Proliferation: Regulation by 17 $\beta$-Estradiol and Overexpression in Human Breast Cancer. Endocrinology. 2001;142(6):2540-8.

109. Xie D, Miller CW, O'Kelly J, Nakachi K, Sakashita A, Said JW, et al. Breast Cancer: Cyr61 is overexpressed, estrogen-inducible, and associated with more advanced disease. Journal of Biological Chemistry. 2001;276(17):14187-94.

110. Jiang WG, Watkins G, Fodstad O, Douglas-Jones A, Mokbel K, Mansel RE. Differential expression of the CCN family members Cyr61, CTGF and Nov in human breast cancer. Endocrine-related Cancer. 2004;11(4):781-91.

111. Dong Xie KN, Heming Wang, Robert Elashoff, and H. Phillip Koeffler. Elevated Levels of Connective Tissue Growth Factor, WISP-1, and CYR61 in Primary Breast Cancers Associated with More Advanced Features. Cancer Research. 2001;61:6.

112. Kleer CG. Dual roles of CCN proteins in breast cancer progression. Journal of Cell Communication and Signaling. 2016;10(3):217-22.

113. Sánchez-Bailón MP, Calcabrini A, Mayoral-Varo V, Molinari A, Wagner K-U, Losada JP, et al. Cyr61 as mediator of Src signaling in triple negative breast cancer cells. Oncotarget. 2015;6(15).

114. Yu-Ting Huang QL, Girieca Lorusso, Nathalie Duffey, and Curzio Rüegg. The matricellular protein CYR61 promotes breast cancer lung metastasis by facilitating tumor cell extravasation and suppressing anoikis. Oncotarget. 2017;8(6):16.

115. Lin B-R, Chang C-C, Chen L-R, Wu M-H, Wang M-Y, Kuo I-H, et al. Cysteine-Rich 61 (CCN1) Enhances Chemotactic Migration, Transendothelial Cell Migration, and 
Intravasation by Concomitantly Up-Regulating Chemokine Receptor 1 and 2. Molecular Cancer Research. 2007;5(11):1111-23.

116. Ramazani Y, Knops N, Elmonem MA, Nguyen TQ, Arcolino FO, van den Heuvel L, et al. Connective tissue growth factor (CTGF) from basics to clinics. Matrix Biology. 2018;68-69:44-66.

117. Chang C-C, Lin B-R, Wu T-S, Jeng Y-M, Kuo M-L. Input of microenvironmental regulation on colorectal cancer: role of the CCN family. World Journal of Gastroenterology. 2014;20(22):6826-31.

118. Jia Q, Dong Q, Qin L. CCN: core regulatory proteins in the microenvironment that affect the metastasis of hepatocellular carcinoma? Oncotarget. 2016;7(2):1203-14.

119. Lai D, Ho KC, Hao Y, Yang X. Taxol Resistance in Breast Cancer Cells Is Mediated by the Hippo Pathway Component TAZ and Its Downstream Transcriptional Targets Cyr61 and CTGF. Cancer Research. 2011;71(7):2728-38.

120. Bartucci M, Dattilo R, Moriconi C, Pagliuca A, Mottolese M, Federici G, et al. TAZ is required for metastatic activity and chemoresistance of breast cancer stem cells. Oncogene. 2015;34(6):681-90.

121. Chen Y, Abraham DJ, Shi-Wen X, Pearson JD, Black CM, Lyons KM, et al. CCN2 (connective tissue growth factor) promotes fibroblast adhesion to fibronectin. Molecular Biology of the Cell. 2004;15(12):5635-46.

122. Wahab NA, Weston BS, Mason RM. Connective Tissue Growth Factor CCN2 Interacts with and Activates the Tyrosine Kinase Receptor TrkA. Journal of the American Society of Nephrology. 2005;16(2):340-51.

123. Segarini PR, Nesbitt JE, Li D, Hays LG, Yates JR, Carmichael DF. The Low Density Lipoprotein Receptor-related Protein/ 2 2-Macroglobulin Receptor Is a Receptor for Connective Tissue Growth Factor. Journal of Biological Chemistry. 2001;276(44):40659-67.

124. Mercurio S, Latinkic B, Itasaki N, Krumlauf R, Smith JC. Connective-tissue growth factor modulates WNT signalling and interacts with the WNT receptor complex. Development. 2004;131(9):2137-47.

125. Babic AM, Chen C-C, Lau LF. Fisp12/Mouse Connective Tissue Growth Factor Mediates Endothelial Cell Adhesion and Migration through Integrin $\alpha v \beta 3$, Promotes Endothelial Cell Survival, and Induces Angiogenesis In Vivo. Molecular and Cellular Biology. 1999;19(4):2958-66.

126. Jun JI, Lau LF. Taking aim at the extracellular matrix: CCN proteins as emerging therapeutic targets. Nature Reviews Drug Discovery. 2011;10(12):945-63.

127. Kubota S, Takigawa M. Cellular and molecular actions of CCN2/CTGF and its role under physiological and pathological conditions. Clinical Science. 2014;128(3):181-96.

128. Van Beek JP, Kennedy L, Rockel JS, Bernier SM, Leask A. The induction of CCN2 by TGF $\beta 1$ involves Ets-1. Arthritis Research \& Therapy. 2006;8(2):R36.

129. Zhu X, Zhong J, Zhao Z, Sheng J, Wang J, Liu J, et al. Epithelial derived CTGF promotes breast tumor progression via inducing EMT and collagen I fibers deposition. Oncotarget. 2015;6(28):25320-38.

130. Aguiar DP, de Farias GC, de Sousa EB, de Mattos Coelho-Aguiar J, Lobo JC, Casado PL, et al. New strategy to control cell migration and metastasis regulated by CCN2/CTGF. Cancer Cell International. 2014;14:61-.

131. Yeger H, Perbal B. CCN family of proteins: critical modulators of the tumor cell microenvironment. Journal of Cell Communication and Signaling. 2016;10(3):229-40.

132. von Alten J, Fister S, Schulz H, Viereck V, Frosch KH, Emons G, et al. GnRH analogs reduce invasiveness of human breast cancer cells. Breast Cancer Research and Treatment. 2006;100(1):13-21. 
133. Howlader N NA, Krapcho M, Miller D, Bishop K, Kosary CL, Yu M, Ruhl J, Tatalovich Z, Mariotto A, Lewis DR, Chen HS, Feuer EJ, Cronin KA (eds). SEER Cancer Statistics Review. National Cancer Institute Bethesda, MD. 1975-2014.

134. Ferlay J, Colombet M, Soerjomataram I, Mathers C, Parkin DM, Pineros M, et al. Estimating the global cancer incidence and mortality in 2018: GLOBOCAN sources and methods. Int J Cancer. 2019;144(8):1941-53.

135. Pulido C, Vendrell I, Ferreira AR, Casimiro S, Mansinho A, Alho I, et al. Bone metastasis risk factors in breast cancer. Ecancermedicalscience. 2017;11:715-.

136. van Zijl F, Krupitza G, Mikulits W. Initial steps of metastasis: cell invasion and endothelial transmigration. Mutat Res. 2011;728(1-2):23-34.

137. Kang Y, Siegel PM, Shu W, Drobnjak M, Kakonen SM, Cordón-Cardo C, et al. A multigenic program mediating breast cancer metastasis to bone. Cancer Cell. 2003;3(6):53749.

138. Weidenfeld K, Barkan D. EMT and Stemness in Tumor Dormancy and Outgrowth: Are They Intertwined Processes? Frontiers in Oncology. 2018;8:381-.

139. Reya T, Morrison SJ, Clarke MF, Weissman IL. Stem cells, cancer, and cancer stem cells. Nature. 2001;414(6859):105-11.

140. Liede A, Jerzak KJ, Hernandez RK, Wade SW, Sun P, Narod SA. The incidence of bone metastasis after early-stage breast cancer in Canada. Breast Cancer Research and Treatment. 2016;156(3):587-95.

141. Moussad EE-DA, Brigstock DR. Connective Tissue Growth Factor: What's in a Name? Molecular Genetics and Metabolism. 2000;71(1):276-92.

142. Chen M-T, Sun H-F, Zhao Y, Fu W-Y, Yang L-P, Gao S-P, et al. Comparison of patterns and prognosis among distant metastatic breast cancer patients by age groups: a SEER population-based analysis. Scientific Reports. 2017;7(1):9254-.

143. Thompson EW, Nagaraj SH. Transition states that allow cancer to spread. Nature. 2018;536:442-4.

144. Lee JY, Chang JK, Dominguez AA, Lee H-p, Nam S, Chang J, et al. YAPindependent mechanotransduction drives breast cancer progression. Nature Communications. 2019;10(1):1848.

145. Hashimoto G, Inoki I, Fujii Y, Aoki T, Ikeda E, Okada Y. Matrix Metalloproteinases Cleave Connective Tissue Growth Factor and Reactivate Angiogenic Activity of Vascular Endothelial Growth Factor 165. Journal of Biological Chemistry. 2002;277(39):36288-95.

146. Tsai H-C, Su H-L, Huang C-Y, Fong Y-C, Hsu C-J, Tang C-H. CTGF increases matrix metalloproteinases expression and subsequently promotes tumor metastasis in human osteosarcoma through down-regulating miR-519d. Oncotarget. 2014;5(11):3800-12.

147. Jiao Y, Feng X, Zhan Y, Wang R, Zheng S, Liu W, et al. Matrix metalloproteinase-2 Promotes $\alpha v \beta 3$ Integrin-Mediated Adhesion and Migration of Human Melanoma Cells by Cleaving Fibronectin. PLoS One. 2012;7(7):e41591.

148. Danen EHJ. Integrin Signaling as a Cancer Drug Target. ISRN Cell Biology. 2013;2013:14.

149. Jacob A, Prekeris R. The regulation of MMP targeting to invadopodia during cancer metastasis. Front Cell Dev Biol. 2015;3:4-.

150. Marc L. Significance, detection and markers of disseminated breast cancer cells. Endocrine-Related Cancer Endocr Relat Cancer. 2006;13(4):1033-67.

151. Venturelli M, Guaitoli G, Omarini C, Moscetti L. Spotlight on triptorelin in the treatment of premenopausal women with early-stage breast cancer. Breast Cancer (Dove Med Press). 2018;10:39-49.

152. Gründker C, Emons G. The Role of Gonadotropin-Releasing Hormone in Cancer Cell Proliferation and Metastasis. Frontiers in Endocrinology. 2017;8(187). 
153. Fekete M, Wittliff JL, Schally AV. Characteristics and distribution of receptors for [dtrp6]- luteinizing hormone-releasing hormone, somatostatin, epidermal growth factor, and sex steroids in 500 biopsy samples of human breast cancer. Journal of Clinical Laboratory Analysis. 1989;3(3):137-47.

154. Baumann KH, Kiesel L, Kaufmann M, Bastert G, Runnebaum B. Characterization of binding sites for a GnRH-agonist (buserelin) in human breast cancer biopsies and their distribution in relation to tumor parameters. Breast Cancer Research and Treatment. 1993;25(1):37-46.

155. Moriya T, Suzuki T, Pilichowska M, Ariga N, Kimura N, Ouchi N, et al. Immunohistochemical expression of gonadotropin releasing hormone receptor in human breast carcinoma. Pathology International. 2001;51(5):333-7.

156. Mangia A, Tommasi S, Reshkin S, Simone G, Stea B, Schittulli F, et al. Gonadotropin releasing hormone receptor expression in primary breast cancer: Comparison of immunohistochemical, radioligand and Western blot analyses. Oncology Reports. 2002;9:1127-32.

157. Schneeweiss A, Denkert C, Fasching PA, Fremd C, Gluz O, Kolberg-Liedtke C, et al. Diagnosis and Therapy of Triple-Negative Breast Cancer (TNBC) - Recommendations for Daily Routine Practice. Geburtshilfe und Frauenheilkunde. 2019;79(6):605-17.

158. Du Bois A, Schmalfeldt B, Meier W, Sehouli J, Pfisterer J. Arbeitsgemeinschaft Gynäkologische Onkologie (AGO); Kommission OVAR; AGO Study Group Ovarian Cancer (AGO-OVAR); Norddeutsche Gesellschaft für Gynäkologische Onkologie (NOGGO)(2006) Ovarian cancer-can intraperitoneal therapy be regarded as new standard in Germany. International Journal of Gynecological Cancer : Official Journal of the International Gynecological Cancer Society. 2006;6(5):1756-60.

159. Fost C, Duwe F, Hellriegel M, Schweyer S, Emons G, Grundker C. Targeted chemotherapy for triple-negative breast cancers via LHRH receptor. Oncology Reports. 2011;25(5):1481-7.

160. Schubert A, Hawighorst T, Emons G, Grundker C. Agonists and antagonists of GnRH-I and -II reduce metastasis formation by triple-negative human breast cancer cells in vivo. Breast Cancer Research and Treatment. 2011;130(3):783-90.

161. Li C, Zhen G, Chai Y, Xie L, Crane JL, Farber E, et al. RhoA determines lineage fate of mesenchymal stem cells by modulating CTGF-VEGF complex in extracellular matrix. Nature Communications. 2016;7:11455.

162. Ren W, Sun X, Wang K, Feng H, Liu Y, Fei C, et al. BMP9 inhibits the bone metastasis of breast cancer cells by downregulating CCN2 (connective tissue growth factor, CTGF) expression. Molecular Biology Reports. 2014;41(3):1373-83.

163. Shinde A, Libring S, Alpsoy A, Abdullah A, Schaber JA, Solorio L, et al. Autocrine Fibronectin Inhibits Breast Cancer Metastasis. Molecular Cancer Research. 2018;16(10):1579.

164. Abduljauwad SN, Ahmed H-u-R. Enhancing cancer cell adhesion with clay nanoparticles for countering metastasis. Scientific Reports. 2019;9(1):5935.

165. Wang X, McLennan SV, Allen TJ, Twigg SM. Regulation of pro-inflammatory and pro-fibrotic factors by CCN2/CTGF in H9c2 cardiomyocytes. Journal of Cell Communication and Signaling. 2010;4(1):15-23.

166. Hou C-H, Yang R-s, Tsao Y-T. Connective tissue growth factor stimulates osteosarcoma cell migration and induces osteosarcoma metastasis by upregulating VCAM-1 expression. Biochemical Pharmacology. 2018;155:71-81.

167. Lu X, Mu E, Wei Y, Riethdorf S, Yang Q, Yuan M, et al. VCAM-1 Promotes Osteolytic Expansion of Indolent Bone Micrometastasis of Breast Cancer by Engaging $\alpha 4 \beta 1$ Positive Osteoclast Progenitors. Cancer Cell. 2011;20(6):701-14. 
168. Chen P-S, Wang M-Y, Wu S-N, Su J-L, Hong C-C, Chuang S-E, et al. CTGF enhances the motility of breast cancer cells via an integrin- $\alpha$ v $\beta 3$-ERK1/2-dependent S100A4upregulated pathway. Journal of Cell Science. 2007;120(12):2053-65.

169. Rossow L, Veitl S, Vorlová S, Wax JK, Kuhn AE, Maltzahn V, et al. LOX-catalyzed collagen stabilization is a proximal cause for intrinsic resistance to chemotherapy. Oncogene. 2018;37(36):4921-40.

170. Dhasarathy A, Phadke D, Mav D, Shah RR, Wade PA. The Transcription Factors Snail and Slug Activate the Transforming Growth Factor-Beta Signaling Pathway in Breast Cancer. PLoS One. 2011;6(10):e26514.

171. Louderbough JMV, Schroeder JA. Understanding the Dual Nature of CD44 in Breast Cancer Progression. Molecular Cancer Research. 2011;9(12):1573.

172. Chlenski A, Guerrero LJ, Yang Q, Tian Y, Peddinti R, Salwen HR, et al. SPARC enhances tumor stroma formation and prevents fibroblast activation. Oncogene. 2007;26:4513.

173. Ma J, Lu W, Chen D, Xu B, Li Y. Role of Wnt Co-receptor LRP6 in Triple Negative Breast Cancer Cell Migration and Invasion. Journal of Cellular Biochemistry. 2017.

174. Wang JC, Sonnylal S, Arnett FC, De Crombrugghe B, Zhou X. Attenuation of expression of extracellular matrix genes with siRNAs to Sparc and Ctgf in skin fibroblasts of CTGF transgenic mice. Int J Immunopathol Pharmacol. 2011;24(3):595-601.

175. Aguilar-Rojas A, Huerta-Reyes M, Maya-Nunez G, Arechavaleta-Velasco F, Conn PM, Ulloa-Aguirre A, et al. Gonadotropin-releasing hormone receptor activates GTPase RhoA and inhibits cell invasion in the breast cancer cell line MDA-MB-231. BMC Cancer. 2012;12:550.

176. Sullivan RJ, Infante JR, Janku F, Wong DJL, Sosman JA, Keedy V, et al. First-inClass ERK1/2 Inhibitor Ulixertinib (BVD-523) in Patients with MAPK Mutant Advanced Solid Tumors: Results of a Phase I Dose-Escalation and Expansion Study. Cancer Discovery. 2018;8(2):184.

177. Liu F, Yang X, Geng M, Huang M. Targeting ERK, an Achilles' Heel of the MAPK pathway, in cancer therapy. Acta Pharmaceutica Sinica B. 2018;8(4):552-62.

178. Perrone F, De Laurentiis M, de Placido S, Orditura M, Cinieri S, Riccardi F, et al. The HOBOE-2 multicenter randomized phase III trial in premenopausal patients with hormonereceptor positive early breast cancer comparing triptorelin plus either tamoxifen or letrozole or letrozole + zoledronic acid. Annals of Oncology. 2018;29.

179. Chatterjee S, Burns TF. Targeting Heat Shock Proteins in Cancer: A Promising Therapeutic Approach. International Journal of Molecular Sciences. 2017;18(9):1978.

180. Neckers L, Workman P. Hsp90 molecular chaperone inhibitors: are we there yet? Clinical Cancer Research : an Official Journal of the American Association for Cancer Research. 2012;18(1):64-76.

181. KOGA F, KIHARA K, NECKERS L. Inhibition of Cancer Invasion and Metastasis by Targeting the Molecular Chaperone Heat-shock Protein 90. Anticancer Research. 2009;29(3):797-807.

182. Huntoon CJ, Nye MD, Geng L, Peterson KL, Flatten KS, Haluska P, et al. Heat Shock Protein 90 Inhibition Depletes LATS1 and LATS2, Two Regulators of the Mammalian Hippo Tumor Suppressor Pathway. Cancer Research. 2010;70(21):8642-50.

183. Wang H, Lu M, Yao M, Zhu W. Effects of treatment with an Hsp90 inhibitor in tumors based on 15 phase II clinical trials. Mol Clin Oncol. 2016;5(3):326-34.

184. Jhaveri K, Chandarlapaty S, Lake D, Gilewski T, Robson M, Goldfarb S, et al. A Phase II Open-Label Study of Ganetespib, a Novel Heat Shock Protein 90 Inhibitor for Patients With Metastatic Breast Cancer. Clinical Breast Cancer. 2014;14(3):154-60.

185. Modi S, Stopeck A, Linden H, Solit D, Chandarlapaty S, Rosen N, et al. HSP90 Inhibition Is Effective in Breast Cancer: A Phase II Trial of Tanespimycin (17-AAG) Plus 
Trastuzumab in Patients with HER2-Positive Metastatic Breast Cancer Progressing on Trastuzumab. Clinical Cancer Research. 2011;17(15):5132-9.

186. Vinci M, Box C, Eccles SA. Three-dimensional (3D) tumor spheroid invasion assay. Journal of Visualized Experiments : JoVE. 2015(99):e52686.

187. Zhang Y, Bilbao A, Bruderer T, Luban J, Strambio-De-Castillia C, Lisacek F, et al. The Use of Variable Q1 Isolation Windows Improves Selectivity in LC-SWATH-MS Acquisition. Journal of Proteome Research. 2015;14(10):4359-71.

188. Lambert J-P, Ivosev G, Couzens AL, Larsen B, Taipale M, Lin Z-Y, et al. Mapping differential interactomes by affinity purification coupled with data-independent mass spectrometry acquisition. Nature Methods. 2013;10:1239.

189. Ge SX, Jung D. ShinyGO: a graphical enrichment tool for ani-mals and plants. bioRxiv. 2018:315150.

190. Goldman M, Craft B, Hastie M, Repečka K, Kamath A, McDade F, et al. The UCSC Xena platform for public and private cancer genomics data visualization and interpretation. bioRxiv. 2019:326470.

191. Chun-Han Hou F-LL, Sheng-Mon Hou and Ju-Fang Liu. Cyr61 promotes epithelialmesenchymal transitionand tumor metastasis of osteosarcoma byRaf-1/MEK/ERK/Elk1/TWIST-1 signaling pathway. Molecular Cancer. 2014;13(1):13.

192. Haque I, Mehta S, Majumder M, Dhar K, De A, McGregor D, et al. Cyr61/CCN1 signaling is critical for epithelial-mesenchymal transition and stemness and promotes pancreatic carcinogenesis. Molecular Cancer. 2011;10:8.

193. Coleman RE. Metastatic bone disease: clinical features, pathophysiology and treatment strategies. Cancer Treatment Reviews. 2001;27(3):165-76.

194. Chen A, Wang L, Li BY, Sherman J, Ryu JE, Hamamura K, et al. Reduction in Migratory Phenotype in a Metastasized Breast Cancer Cell Line via Downregulation of S100A4 and GRM3. Scientific Reports. 2017;7(1):3459.

195. Ning Q, Li F, Wang L, Li H, Yao Y, Hu T, et al. S100A4 amplifies TGF- $\beta$-induced epithelial-mesenchymal transition in a pleural mesothelial cell line. Journal of Investigative Medicine. 2018;66(2):334-9.

196. Li F, Shi J, Xu Z, Yao X, Mou T, Yu J, et al. S100A4-MYH9 Axis Promote Migration and Invasion of Gastric Cancer Cells by Inducing TGF-beta-Mediated EpithelialMesenchymal Transition. Journal of Cancer. 2018;9(21):3839-49.

197. Boopathy GTK, Hong W. Role of Hippo Pathway-YAP/TAZ Signaling in Angiogenesis. Front Cell Dev Biol. 2019;7(49).

198. Halder G, Johnson RL. Hippo signaling: growth control and beyond. Development. 2011;138(1):9-22.

199. Pan D. The Hippo Signaling Pathway in Development and Cancer. Developmental Cell. 2010;19(4):491-505.

200. Warren JSA, Xiao Y, Lamar JM. YAP/TAZ Activation as a Target for Treating Metastatic Cancer. Cancers. 2018;10(4).

201. You B, Yang Y-L, Xu Z, Dai Y, Liu S, Mao J-H, et al. Inhibition of ERK1/2 downregulates the Hippo/YAP signaling pathway in human NSCLC cells. Oncotarget. 2015;6(6).

202. Xie JJ, Xu LY, Wu ZY, Li LY, Xu XE, Wu JY, et al. Expression of cysteine-rich 61 is correlated with poor prognosis in patients with esophageal squamous cell carcinoma. European Journal of Surgical Oncology (EJSO). 2011;37(8):669-74.

203. Mayer S, Gabriel B, Erbes T, Timme-Bronsert S, Jager M, Rucker G, et al. Cyr61 Expression Pattern and Association with Clinicopathological Factors in Patients with Cervical Cancer. Anticancer Research. 2017;37(5):2451-6.

204. Haddad T, Qin R, Lupu R, Satele D, Eadens M, Goetz MP, et al. A phase I study of cilengitide and paclitaxel in patients with advanced solid tumors. Cancer Chemotherapy and Pharmacology. 2017;79(6):1221-7. 
205. Stewart RL, Carpenter BL, West DS, Knifley T, Liu L, Wang C, et al. S100A4 drives non-small cell lung cancer invasion, associates with poor prognosis, and is effectively targeted by the FDA-approved anti-helminthic agent niclosamide. Oncotarget. 2016;7(23).

206. Li C-L, Yang D, Cao X, Wang F, Hong D-Y, Wang J, et al. Fibronectin induces epithelial-mesenchymal transition in human breast cancer MCF-7 cells via activation of calpain. Oncology Letters. 2017;13(5):3889-95.

207. Singer CF, Kronsteiner N, Marton E, Kubista M, Cullen KJ, Hirtenlehner K, et al. MMP-2 and MMP-9 Expression in Breast Cancer-Derived Human Fibroblasts is Differentially Regulated by Stromal-Epithelial Interactions. Breast Cancer Research and Treatment. 2002;72(1):69-77.

208. Bleau A-M, Planque N, Perbal B. CCN proteins and cancer: two to tango. Frontiers in Bioscience : a Journal and Virtual Library. 2005;10:998-1009.

209. Menendez JA, Vellon L, Mehmi I, Teng PK, Griggs DW, Lupu R. A novel CYR61triggered 'CYR61- $\alpha \mathrm{v} \beta 3$ integrin loop' regulates breast cancer cell survival and chemosensitivity through activation of ERK1/ERK2 MAPK signaling pathway. Oncogene. 2005;24(5):761-79.

210. Menendez JA, Mehmi I, Griggs DW, Lupu R. The angiogenic factor CYR61 in breast cancer: molecular pathology and therapeutic perspectives. Endocrine-related Cancer. 2003;10(2):141-52.

211. Kok SH, Chang HH, Tsai JY, Hung HC, Lin CY, Chiang CP, et al. Expression of Cyr61 (CCN1) in human oral squamous cell carcinoma: An independent marker for poor prognosis. Head \& Neck. 2010;32(12):1665-73.

212. Chen Q, Zhang Xiang HF, Massagué J. Macrophage Binding to Receptor VCAM-1 Transmits Survival Signals in Breast Cancer Cells that Invade the Lungs. Cancer Cell. 2011;20(4):538-49.

213. Schneider JG, Amend SR, Weilbaecher KN. Integrins and bone metastasis: integrating tumor cell and stromal cell interactions. Bone. 2011;48(1):54-65.

214. Ye X, Brabletz T, Kang Y, Longmore GD, Nieto MA, Stanger BZ, et al. Upholding a role for EMT in breast cancer metastasis. Nature. 2017;547(7661):E1-E3.

215. Bradshaw AD. The role of SPARC in extracellular matrix assembly. Journal of Cell Communication and Signaling. 2009;3(3-4):239-46.

216. Bao H-R, Liu X-J, Li Y-L, Men X, Zeng X-L. Sinomenine attenuates airway inflammation and remodeling in a mouse model of asthma. Molecular Medicine Reports. 2016;13(3):2415-22.

217. Yang WH, Kuo MYP, Liu CM, Deng YT, Chang HH, Chang JZC. Curcumin Inhibits TGF $\beta 1$-induced CCN2 via Src, JNK, and Smad3 in Gingiva. Journal of Dental Research. 2013;92(7):629-34.

218. Fehrholz M, Glaser K, Speer CP, Seidenspinner S, Ottensmeier B, Kunzmann S. Caffeine modulates glucocorticoid-induced expression of CTGF in lung epithelial cells and fibroblasts. Respiratory Research. 2017;18(1):51.

219. Mun J-H, Kim Y-M, Kim B-S, Kim J-H, Kim M-B, Ko H-C. Simvastatin inhibits transforming growth factor- $\beta 1$-induced expression of type I collagen, CTGF, and $\alpha$-SMA in keloid fibroblasts. Wound Repair and Regeneration. 2014;22(1):125-33.

220. Kondo S, Tanaka N, Kubota S, Mukudai Y, Yosimichi G, Sugahara T, et al. Novel angiogenic inhibitor DN-9693 that inhibits post-transcriptional induction of connective tissue growth factor (CTGF/CCN2) by vascular endothelial growth factor in human endothelial cells. Molecular Cancer Therapeutics. 2006;5(1):129.

221. Canalis E, Zanotti S, Beamer WG, Economides AN, Smerdel-Ramoya A. Connective Tissue Growth Factor Is Required for Skeletal Development and Postnatal Skeletal Homeostasis in Male Mice. Endocrinology. 2010;151(8):3490-501. 
222. Finger EC, Cheng CF, Williams TR, Rankin EB, Bedogni B, Tachiki L, et al. CTGF is a therapeutic target for metastatic melanoma. Oncogene. 2014;33(9):1093-100.

223. Limonta P, Montagnani Marelli M, Mai S, Motta M, Martini L, Moretti RM. GnRH receptors in cancer: from cell biology to novel targeted therapeutic strategies. Endocrine Reviews. 2012;33(5):784-811.

224. Francis PA, Pagani O, Fleming GF, Walley BA, Colleoni M, Láng I, et al. Tailoring Adjuvant Endocrine Therapy for Premenopausal Breast Cancer. New England Journal of Medicine. 2018;379(2):122-37.

225. Troy AB. Targeted Cancer Therapy: The Next Generation of Cancer Treatment. Current Drug Discovery Technologies. 2015;12(1):3-20.

226. Cheng Y, Tian H. Current Development Status of MEK Inhibitors. Molecules. 2017;22(10).

227. Cao L, Sun PL, Yao M, Jia M, Gao H. Expression of YES-associated protein (YAP) and its clinical significance in breast cancer tissues. Human Pathology. 2017;68:166-74.

228. Mi W, Lin Q, Childress C, Sudol M, Robishaw J, Berlot CH, et al. Geranylgeranylation signals to the Hippo pathway for breast cancer cell proliferation and migration. Oncogene. 2015;34(24):3095-106.

229. Li Y, Wang S, Wei X, Zhang S, Song Z, Chen X, et al. Role of inhibitor of yesassociated protein 1 in triple-negative breast cancer with taxol-based chemoresistance. Cancer Science. 2019;110(2):561-7.

230. Di Agostino S, Sorrentino G, Ingallina E, Valenti F, Ferraiuolo M, Bicciato S, et al. YAP enhances the pro-proliferative transcriptional activity of mutant p53 proteins. EMBO Reports. 2016;17(2):188-201.

231. Streicher C, Heyny A, Andrukhova O, Haigl B, Slavic S, Schüler C, et al. Estrogen Regulates Bone Turnover by Targeting RANKL Expression in Bone Lining Cells. Scientific Reports. 2017;7(1):6460.

232. Gnant M, Mlineritsch B, Stoeger H, Luschin-Ebengreuth G, Knauer M, Moik M, et al. Zoledronic acid combined with adjuvant endocrine therapy of tamoxifen versus anastrozol plus ovarian function suppression in premenopausal early breast cancer: final analysis of the Austrian Breast and Colorectal Cancer Study Group Trial 12. Annals of Oncology. 2014;26(2):313-20. 


\section{APPENDIX}

\begin{tabular}{|c|c|}
\hline \multicolumn{2}{|c|}{ 7.1. LIST OF ABBREVIATIONS } \\
\hline$\%$ & percentage \\
\hline$\mu \mathrm{g}$ & microgram \\
\hline$\mu \mathrm{L}$ & microliter \\
\hline$\mu \mathrm{M}$ & micro molar \\
\hline BRAF & B-Raf Proto-Oncogene, Serine/Threonine Kinase \\
\hline BRCA & Breast Cancer 1 , early onset \\
\hline $\mathrm{CCN}$ & CYR61, $\underline{\text { CTGF, }}$ NOV protein family \\
\hline CD44 & CD44 molecule (Indian Blood Group) \\
\hline CTGF & Connective Tissue Growth Factor \\
\hline CXCL12 & C-X-C Motif Chemokine Ligand 12 \\
\hline CXCR4 & C-X-C Motif Chemokine Receptor 4 \\
\hline CYR61 & Cysteine- Rich Angiogenic Inducer 61 \\
\hline DCIS & ductal carcinoma in situ \\
\hline DFS & distant-metastasis free survival \\
\hline ECM & extracellular matrix \\
\hline EMT & epithelial-mesenchymal transition \\
\hline ER & estrogen receptor \\
\hline
\end{tabular}

ErbB2 Erb-B2 Receptors Tyrosine Kinase 2

ErbB3 Erb-B2 Receptors Tyrosine Kinase 3

ERK1/2 Extracellular Signaling Related Kinase $1 / 2$

ESR1 Estrogen Receptor 1 


\begin{tabular}{|c|c|}
\hline ETS1 & ETS proto-oncogene 1 \\
\hline FN1 & Fibronectin 1 \\
\hline GnRH & Gonadotropin Releasing Hormone \\
\hline GnRH-R & Gonadotropin Releasing Hormone Receptor \\
\hline GPER & G-protein coupled estrogen receptor 1 \\
\hline GRB7 & Growth Factor Receptor Bound Protein 7 \\
\hline HER2 & Erb-B2 Receptors Tyrosine Kinase 2 \\
\hline HSPGs & Heparan Sulfate Proteoglycans \\
\hline IDC & invasive ductal carcinoma \\
\hline IHC & immunohistochemistry \\
\hline ILC & invasive lobular carcinoma \\
\hline IM & immunomodulatory \\
\hline Ki-67 & proliferation marker in clinical practice \\
\hline LAR & Luminal Androgen Receptor \\
\hline LATS $1 / 2$ & Large Tumor Suppressor Kinase 1/2 \\
\hline LOX & Lysyl Oxidase \\
\hline LRPs & Low-Density Receptor Related Protein \\
\hline M & mesenchymal \\
\hline MAP3K1 & Mitogen-Activated Protein Kinase Kinase Kinase 1 \\
\hline MEK & Mitogen-Activated Protein Kinase Kinase 1 \\
\hline MET & mesenchymal-epithelial transition \\
\hline MMP2 & Matrix Metallopeptidase 2 \\
\hline MSL & mesenchymal/stem-like \\
\hline
\end{tabular}


MYC MYC Proto-Oncogene

NOV Nephroblastoma Overexpressed

PI3KCA Phosphatidylinositol-4, 5-Bisphosphate-3 Kinase Catalytic Subunit $\alpha$

PR progesterone receptor

RFS remission-free survival

SDC4 Syndecan 4

SNAI1 Snail Family Transcriptional Repressor 1

SNAI2 Snail family transcriptional repressor 2

SPARC Secreted protein acidic and cysteine rich

TAZ Transcriptional Coactivator with PDZ-Binding Motif

TEAD Transcriptional Enhancer Factor TEF-1

TGF $\beta \quad$ Transforming growth factor $\beta$

TGFBI Transforming Growth Factor Beta Induced

TME tumor micro environment

TNBC triple negative breast cancer

TN-C Tenascin C

TOP2A DNA Topoisomerase II $\alpha$

TP53 Tumor-Suppressor P53

TSP-1 Thrombospondine 1

VCAM-1 Vascular Cell Adhesion Molecule 1

VEGF Vascular Endothelial Growth Factor

VWC Von Willebrand Factor Type C

WISP WNT1-Inducible-Signaling Pathway Protein 
YAP Yes Associated Protein

Zeb1 Zinc finger E box binding home box 1 


\subsection{LIST OF FIGURES}

Figure 1 Characteristics and classification of breast cancer subtypes.

Figure 2 The Invasion-metastatic cascade. 5

Figure 3 Metastatic sites of breast cancer. 8

Figure 4 Scheme of signaling, that impedes invasion in highly invasive breast cancer cells. 


\section{PUBLICATIONS}

Hellinger, J.W., Schömel, F., Lenz, C., Bauerschmitz, G., Emons, G. \& Gründker, C.

Identification of invasion drivers by secretome analysis: Insight into CTGF signaling. (under revision in Communication Biology)

Hellinger, J.W., Hüchel, S.,Goetz, L., Bauerschmitz, G., Emons, G. \& Gründker, C. (2019) Inhibition of CYR61-S100A4 axis Limitis Breast Cancer Invasion. Front Oncol 9, (1074). doi: 10.3389/fonc.2019.01074

Gründker, C., Läsche M., Hellinger, J.W., Emons, G. (2019).

Mechanisms of metastais and cell Mobility- The Role of Metabolism. Geburtshilfe und Frauenheilkd, 79 (2), 184-188. doi: 10.1055/a-0805-9113

Hellinger, J.W., Bauerschmitz, G., Emons, G. \& Gründker, C. (2018a)

CTGF knock-out reduziert Invasivität von mesenchymal transformierten Mammakarzinomzellen. Geburtshilfe und Frauenheilkd, 78 (10), P126. doi: $10.1055 / \mathrm{s}-0038-1671037$

Hellinger, J.W., Bauerschmitz, G., Emons, G. \& Gründker, C. (2018b)

Reduzierte RhoC Expression in mesenchymal tranformierten Mammakarzinomzellen durch Behandlung mit GnRH Agonist Triptorelin beeinflusst Tumorinvasivität. Geburtshilfe und Frauenheilkd, 78 (10), P127. doi: 10.1055/s-0038-1671038 


\section{ACKNOWLEDEMENT}

I thank Prof. Dr. Carsten Gründker and Prof. Dr. Günter Emons for the opportunity to pursue my doctoral thesis at the Laboratory of Molecular Gynecology, and Prof. Dr. Hubertus Jarry for being my supervisor.

I am grateful for the chance to be enrolled at the Göttinger Graduate Scholl of Neuroscience, Biophysics and Molecular Bioscience (GGNB) and the manifold opportunities for personal and professional continuing education offered here. I would like to thank the Deutsche Krebshilfe- Dr. Mildred Scheel Stiftung for funding this interesting and promising project, I was allowed to work on.

I would like to thank my thesis advisory committee members Prof. Dr. Heidi Hahn and Prof. Dr. Dieter Kube for the valuable discussions.

I am grateful for the support and company of the working group of Prof. Dr. Gründker. A special thanks to Prof. Carsten Gründker for his supervision and the confidence to implement my own ideas. And I thank Sonja Blume for her excellent technical assistance. I learned a lot from and enjoyed the supervision of different medical thesis projects.

I am thankful, that I had the possibility to join the lab meetings of the working group of Dr. Florian Wegwitz and for the help, support and feedback I received here.

I am grateful for the support and appreciation of my family and friends, especially from my inspiring sister and caring mom.

My heartfelt gratitude to my boyfriend Marc, who supported me, encouraged me and believed in my strength of purpose and power of endurance throughout this whole journey. 